\title{
«Qui ne risque rien, n'a rien »: Conflict, Distributional Outcomes, and Property Rights in the Copper- and Cobalt-Mining Sector of the DRC
}

\author{
By \\ Sarah Katz-Lavigne \\ A thesis submitted to the \\ Faculty of Graduate and Postdoctoral Affairs \\ Carleton University \\ Ottawa, Ontario, Canada \\ and \\ the Faculty of Arts Graduate School \\ University of Groningen \\ Broerstraat 5, \\ 9712 CP Groningen
}

in partial fulfillment of the requirements for the degree of
Doctor of Philosophy
in
International Affairs

C) Copyright

2020, Sarah Katz-Lavigne

January 23, 2020 


\section{Abstract}

The Democratic Republic of Congo is rich in the copper and cobalt for which there is high demand on the world market. In southeastern DRC, large-scale mining (LSM) has a long history, with a recent resurgence following the end of the second civil war in 2003. This revival of LSM investment resulted in the displacement of artisanal and small-scale mining (ASM) by companies. These conflicts, which have received significant attention in academic literature and policymaking, are sometimes conceptualised as pitting LSM companies against artisanal miners in continuous conflict. Yet structural factors are necessary, but not sufficient to explain the variability of conflict at and around LSM sites. Here, I link conflict incidence to the interactions between three key facets of the property rights (PR) regime at and around LSM sites: corporate enforcement, authorised clandestine extraction, and unauthorised clandestine extraction. I contend that the property rights regime is characterised by overlapping claims that reflect the persistence of clandestine mining within LSM concessions, linked to the fact that outside actors push into the not-quite-hermetic space of the mine. Conflict often erupts in a context of strategic (c)overtness when the cost of providing PR and enforcing informal agreements becomes prohibitive for reasons indirectly linked to resource access, including security guards' need to protect their employment, and companies' reputational concerns. The different security forces that govern authorised clandestine mining also use a range of forceful and non-forceful tactics to "close" LSM sites to unpaid access by artisanal miners, but do not always succeed. The interactions of the different facets also have consequences in terms of the distribution of resources among a range of actors and groups including women, different categories of traders, and ethnic communities. This research highlights that corporate PR are in fact negotiated and contested: the public security forces and other government actors define and enforce other PR, not just companies' property rights, in contexts of "illegality". These findings provide a more fine-grained explanation for LSMASM conflict and why artisanal miners frequently operate peacefully at LSM sites, including through local conflict resolution mechanisms that reduce transaction costs hindering agreement. My findings have relevance for many other areas in resource-rich African countries where artisanal miners operate "illegally". 


\section{Acknowledgements}

This dissertation is the culmination of a very long journey. The fact that this journey has been successful is a testament to the support that I have received from so many friends, family members, and colleagues.

First and foremost, this dissertation belongs to the people that I met in the provinces of HautKatanga and Lualaba and who participated in this research, generously giving their time, knowledge, and assistance to help this $\mathrm{PhD}$ researcher who was setting foot in the region for the first time with just a place to stay. I owe particular thanks to Jerry Kalonji, Christian Bwenda, and Vicky Mukwekwa for their invaluable and patient support, assistance, and friendship. Without two research colleagues in Lubumbashi and in the province of Lualaba, I would not have been able to gather much of the data that I collected and this research would have been far more daunting.

On the list of people without whom this $\mathrm{PhD}$ would not exist I include Professor Jean Daudelin and Prof. Dr. Jana Hönke, my co-supervisors, who have provided support, encouragement, patience, and endless insight during this long and challenging process. I am also grateful to the other members of my committee for accepting to read this dissertation, and travel to Groningen to participate in the defense: Jaap de Wilde, Benjamin Rubbers, Koen Vlassenroot, Dane Rowlands, and Frank Vanclay. Sara Geenen and Jose Diemel provided invaluable advice for doing research in the DRC and Lubumbashi.

Doris Buss and Blair Rutherford at Carleton University were a delight to work with as a research assistant during my $\mathrm{PhD}$. I consider them not only precious mentors but also, and more importantly than that, friends. Patricia Lacroix at Carleton University is another such colleague and friend who provided a much-needed ear and shoulder to cry on when things were tough! I will always be grateful. I have received feedback, advice, and guidance from countless colleagues at conferences and through the journal review process. While there are too many to name here, I have learned so much from so many and I hope to pass this support on in the future. I have greatly enjoyed working with the Canadian Association of African Studies (CAAS) over the years, and my CAAS and Canadian Journal of African Studies (CJAS) colleagues have similarly taught me a great deal about how academic associations work. 
Finally, my friends and family have seen me through this process. Without them, there would be no $\mathrm{PhD}$ ! Amy, we have been friends for $20+$ years and I know we will still be friends in 20 years. You are with me always, no matter where you are in the world. I am grateful to Barbara, my best Groningen friend, for all the office chats, and of course to Annabelle too! Sandra, I enjoyed our times at the gym in Groningen and they really kept me going. Raphaëlle, my holidays in London have been some of my best times and I look forward to the next one. Finally, my family has been there in the toughest times and I love them: Linda, Jean-François, Mikaël, Mollie, Benjamin, Sophie (and Tilly), George, Denise, and of course dearest Poppy! 


\section{Table of Contents}

Abstract

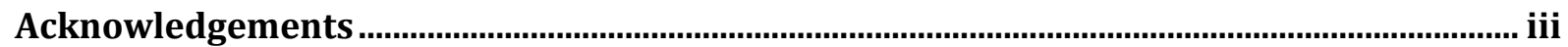

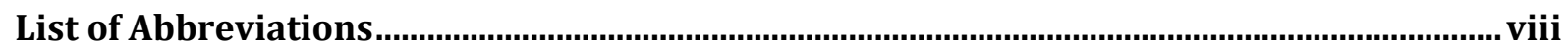

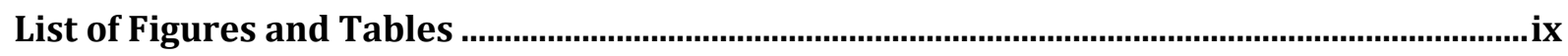

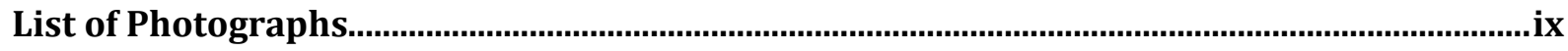

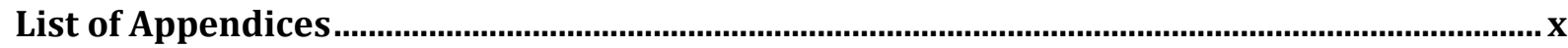

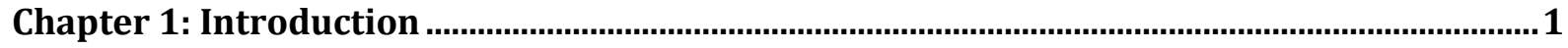

1.1 Dissertation Overview and Discussion of Statehood ..................................................................... 1

1.2 Country Selection and Generalisability ............................................................................................ 4

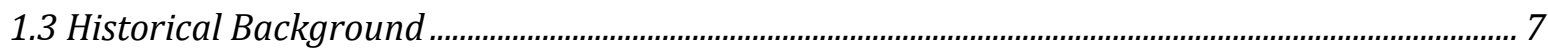

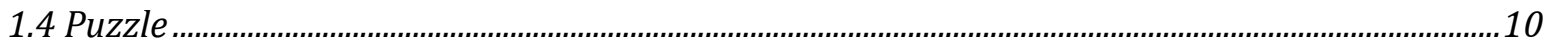

1.5 Research Questions and Main Argument.................................................................................11

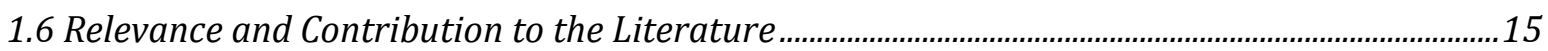

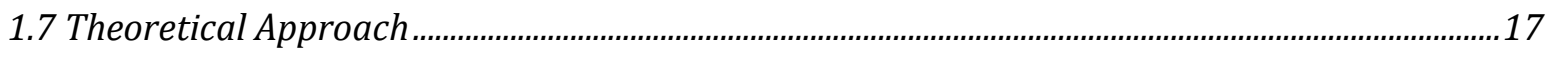

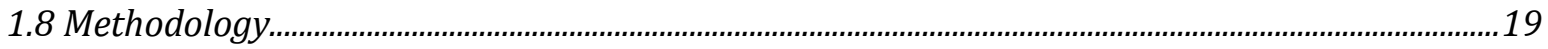

1.8.1 Case Study Selection and Company Characteristics .............................................................19

1.8.2 Methodology and Data Collection Approach............................................................................ 23

1.9 Structure

Chapter 2: Review of the Literature on Conflict between Large-Scale Mining and Artisanal

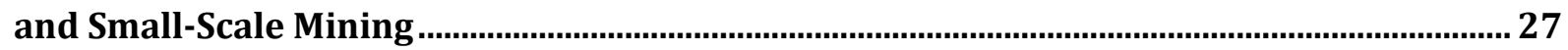

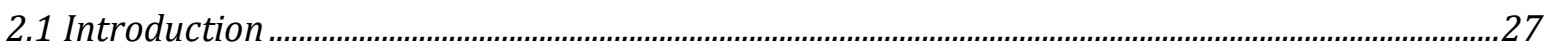

2.2 Company-ASM Conflict in Africa and the Democratic Republic of Congo......................................28

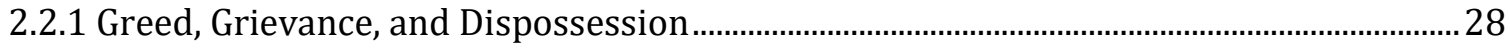

2.2.2 Policy Solutions to Grievance in the Corporate Social Responsibility Literature............ 31

2.2.3 Artisanal Miners' Claims Vis-à-Vis Corporate Enforcement................................................. 34

2.3 Other Corporate Practices and Conflict: Securing Large-Scale Mining Sites ..................................35

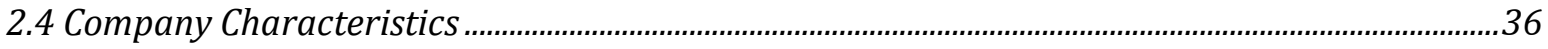

2.5 New Modes of Governance and Elite Involvement …....................................................................38

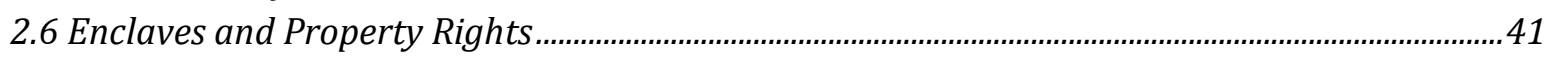

2.9 Conclusion

Chapter 3: Theoretical Framework

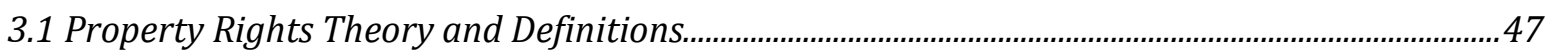

3.2 Critique of Property Rights Theory ……….........................................................................................51

3.2.1 Part One: Enforcement and Conflict ........................................................................................ 53

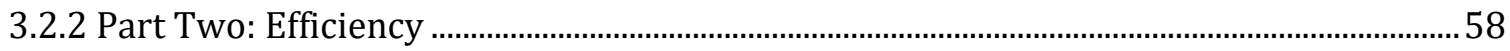

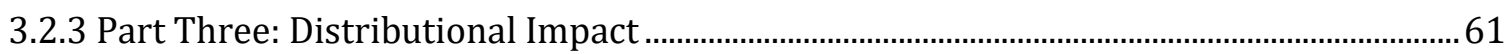

3.3 Applied Property Rights Framework: The Property Rights Regime ................................................65

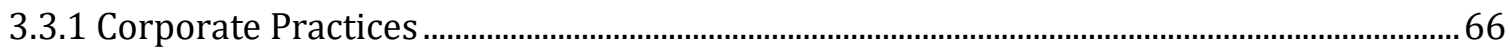

3.3.2 Artisanal Mining in LSM Concessions and the Role of Local Elites...................................... 70

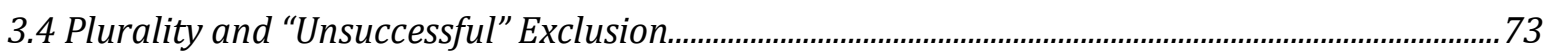

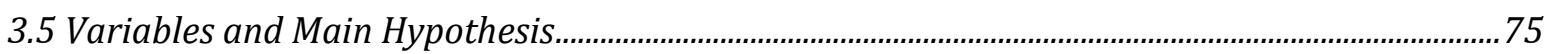

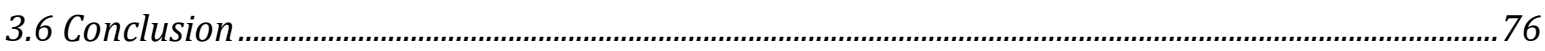


Chapter 4: The Research Puzzle: Similarities in Conflict Dynamics Across Different Sites 79

4.1 Introduction

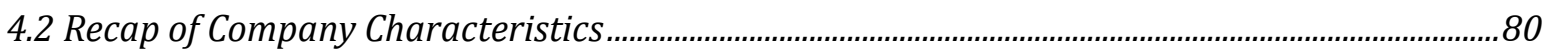

4.3 Conflict Expectations from Company Characteristics and CSR Profiles..............................................86

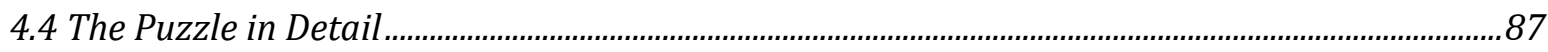

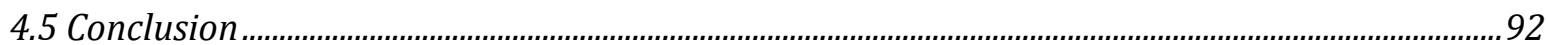

Chapter 5: Research Methodology, Ethics, and Researcher and Participant Safety in a

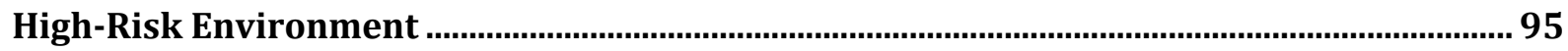

5.1 Introduction

5.2 Case Selection

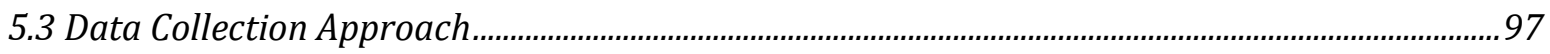

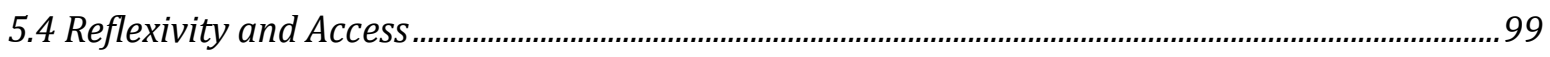

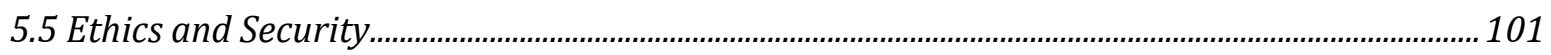

5.5.1 The Question of Remuneration for Research Participants................................................ 106

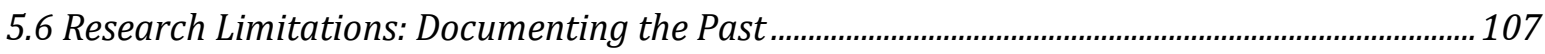

5.6.1 Snowball Sampling........................................................................................................... 111

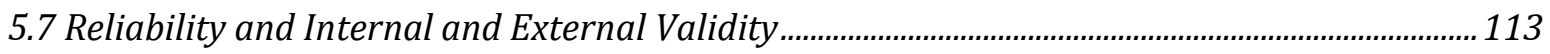

5.8 Conclusion

Chapter 6: The Property Rights Regime: Laying the Groundwork for Understanding

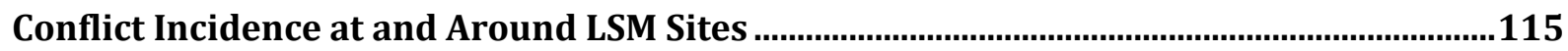

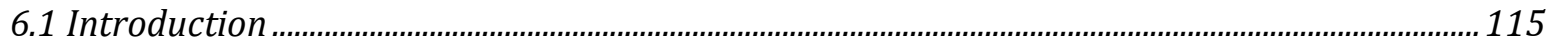

6.2 Description of the Property Rights Regime and Its Components ...............................................116

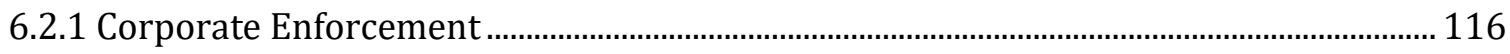

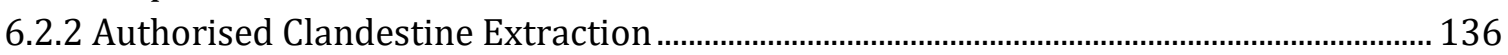

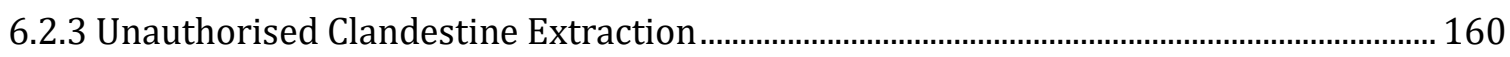

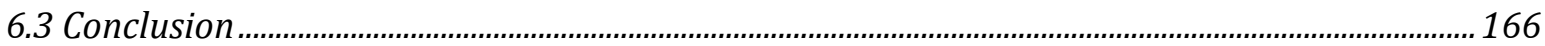

Chapter 7: Conflict Dynamics between Corporate Enforcement, Authorised Clandestine, and Unauthorised Clandestine Mining.............................................................................169

7.1 Conflict between Corporate Enforcement and (Un)Authorised Clandestine Mining................ 171

7.1.1 Overview, Historical Background, and Conflict between Corporate Enforcement and

Unauthorised Clandestine Mining ............................................................................................ 171

7.1.2 When the Covert becomes Overt: Conflict between Corporate Enforcement and

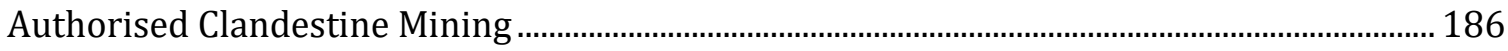

7.1.3 Ethnic Relationships and Conflict....................................................................................... 200

7.2 Summary and Interactions between Facets....................................................................................... 203

7.3 Conflict between Authorised and Unauthorised Clandestine Extraction ...................................... 210

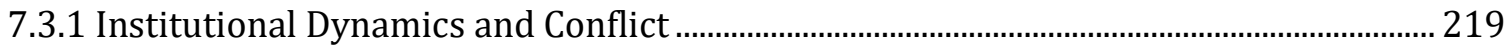

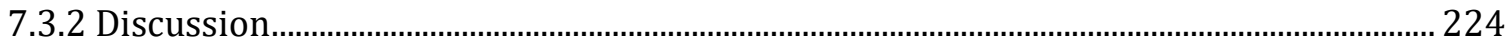

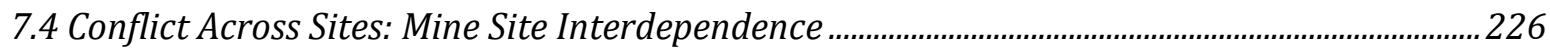

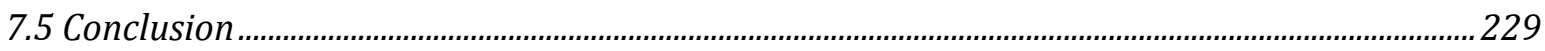

Chapter 8: Distributional Impacts of Property Rights Regime Dynamics at and Around

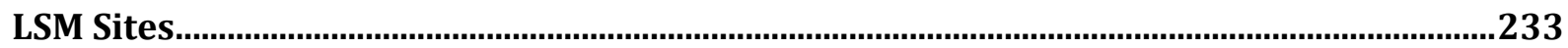

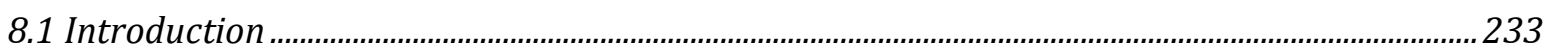

8.2 Distributional Impact of Corporate Enforcement .........................................................................2 236 
8.2.1 Dispossession of Communities by Companies: Initial Clearing by Mining Companies

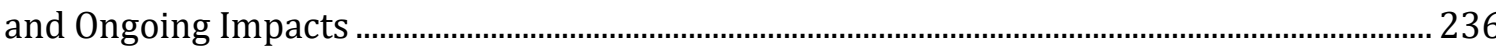

8.2.2 Dispossession of Actors in the Artisanal-Mining Supply Chain........................................ 241

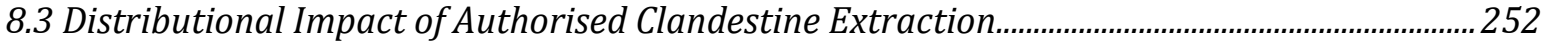

8.3.1 The Clandestine Mining Supply Chain and Payments for Entry ………............................ 252

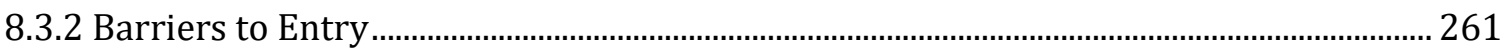

8.4 Distributional Impact of Unauthorised Clandestine Extraction ......................................................2. 264

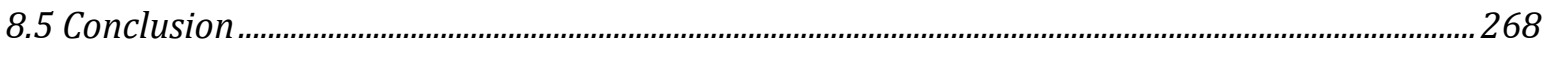

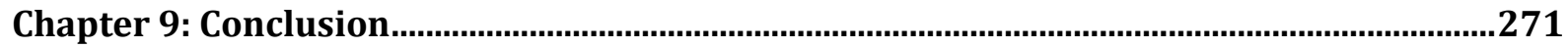

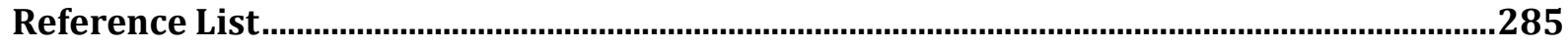

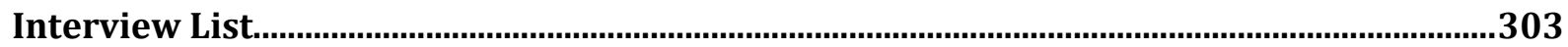

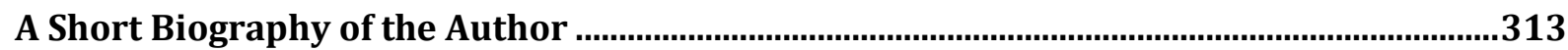




\section{List of Abbreviations}

$\begin{array}{ll}\text { ANR } & \text { Agence nationale de renseignement } \\ \text { ASM } & \text { Artisanal and Small-Scale Mining } \\ \text { CSR } & \text { Corporate Social Responsibility } \\ \text { CUREB } & \text { Carleton University's Research Ethics Board } \\ \text { DRC } & \text { Democratic Republic of Congo } \\ \text { DRLU } & \text { Direction des recettes du Lualaba } \\ \text { DV } & \text { Dependent Variable } \\ \text { EMAK } & \text { Exploitants Miniers Artisanaux du Katanga } \\ \text { Gécamines } & \text { Générale des Carrières et des Mines } \\ \text { GI } & \text { Industrial Guard } \\ \text { GMI } & \text { Groupe mobile d'intervention } \\ \text { FARDC } & \text { Forces armées de la République démocratique du Congo } \\ \text { IAD } & \text { Institutional Analysis and Development } \\ \text { ICMM } & \text { The International Council on Mining \& Metals } \\ \text { IDAK } & \text { Investissements Durables au Katanga } \\ \text { IFC } & \text { International Finance Corporation } \\ \text { IV } & \text { Independent Variable } \\ \text { LNI } & \text { Légion nationale d'intervention } \\ \text { LSM } & \text { Large-scale Mining } \\ \text { MNC } & \text { Multinational Corporation } \\ \text { NGO } & \text { Non-Governmental Organisation } \\ \text { OECD } & \text { Organisation for Economic Co-operation and Development } \\ \text { OPJ } & \text { Officers of the Judicial Police } \\ \text { PMH } & \text { Police des mines et hydrocarbures } \\ \text { PNC } & \text { Police nationale congolaise } \\ \text { PR } & \text { Property Rights } \\ \text { PRR } & \text { Property Rights Regime } \\ \text { PSC } & \text { Private Security Company } \\ \text { SAESSCAM } & \text { Service d'Assistance et d'Encadrement du Small Scale Mining } \\ \text { UN } & \text { United Nations } \\ \text { USD } & \text { US Dollars } \\ \text { ZÉA } & \text { Zones d'exploitation artisanales } \\ & \end{array}$




\section{List of Figures and Tables}

Fig. 1 Run Chart of Diggers Entries - 2014

Fig. 2 Run Chart of Diggers Entries - 2015

Fig. 3 Run Chart of Diggers Entries 2016

Fig. $4 \quad 1$ Year Copper Spot

\section{List of Photographs}

Image 1: Hole in company A's wall, Sarah Katz-Lavigne, November 2016.

Image 2: A trench separating company B from the local community, Sarah Katz-Lavigne, February 2017.

Image 3: Miners at company C's extraction site, Sarah Katz-Lavigne, March 4, 2017. Image 4: Miners at company C's extraction site, Sarah Katz-Lavigne, March 4, 2017. Image 5: Miner at company C's extraction site, Sarah Katz-Lavigne, March 4, 2017. Image 6: Company C's damaged and abandoned community liaison office, Sarah KatzLavigne, March 4, 2017.

Image 7: Damaged window at company C's community liaison office, Sarah Katz-Lavigne, March 4, 2017.

Image 8: Damaged generator at company C's community liaison office, Sarah Katz-Lavigne, March 4, 2017.

Image 9: Community school near hill, Sarah Katz-Lavigne, March 4, 2017.

Image 10: Damaged school window, Sarah Katz-Lavigne, March 4, 2017.

Image 11: Damaged school windows, Sarah Katz-Lavigne, March 4, 2017. 


\section{List of Appendices}

Interview List

A Short Biography of the Author 


\section{Chapter 1: Introduction}

\subsection{Dissertation Overview and Discussion of Statehood}

This dissertation centres on artisanal miners' access to large-scale copper- and cobaltmining sites in southeastern Democratic Republic of Congo (DRC), more specifically those systems and mechanisms through which miners' access is granted or denied, including through "clandestine" means. I examine the conditions under which these processes lead to conflict, as well as the local distributional outcomes of different actors' measures to exclude miners from, or to allow them conditional access to, large-scale mining (LSM) sites. The time period covered by this study begins with private companies' takeover of LSM sites and their clearing of artisanal miners in the DRC in the mid-2000s through to the end of in-country research in May 2017. My main contribution to the scholarly literature is an examination of conflict dynamics within the mining "enclave" that results from the enclosure of LSM sites and the outlawing of artisanal and small-scale mining (ASM) at these sites. Specifically, this contribution addresses the less examined component that encapsulates the multiple actors who grant artisanal miners access to LSM sites in exchange for rents, as well as how artisanal miners circumvent demands for these rents.

My main argument is that the functioning of the property rights regime at and around selected large-scale mining sites - specifically, the extent to which property rights are well defined and enforced - is a crucial factor in determining conflict incidence and distributional outcomes at the local level. The "property rights regime" refers specifically to a) the interplay of corporate enforcement practices; b) "clandestine" mineral extraction not "authorised" by mining firms but participated in by a range of actors at the local level; and c) artisanal miners' "unauthorised clandestine" strategies for gaining access to LSM sites, which include avoiding security and aggressive behaviour.

Particular governance dynamics are said to characterise so-called "weak states" like the DRC, a term - albeit a contentious one - "generally used to define a state that is weak in its core functions of providing security to its citizens (security gap), providing basic services to its citizens (capacity gap), and having legitimacy among its people (legitimacy gap)" (Tyagi, 2012). Risse (2011) refers to these types of settings - which include much of subSaharan Africa - as areas of limited statehood, while Bayart and Ellis (2000) speak about the "rhizome state". Recent theoretical debates have led to a need to contextualise the term "area of limited statehood", which describes a context in which "effective territorial sovereignty, a 
state monopoly on the use of force and authoritative decision-making competence on the side of the state are either non-existent or only partially existent" (Risse \& Lehmkuhl, 2006, p. 4). Risse (2011) cautions against the assumption that the state is not present at all in areas of limited statehood, noting that state governance and $100 \%$ privatisation can be considered two opposite ends of what is actually a continuum of provision of services of governance. Like Risse, Schuppert (2011) emphasizes that state and private regulation exist along a continuum. Hoffman and Kirk (2013) critique the "fragile states" paradigm and refer instead to "conflictaffected and transitioning regions" (p. 2). Coumans (2019), meanwhile, makes the important argument that the "strategic focus on weak governance of host countries in the Global South by the industry and some home states serves to counter social movement efforts to promote home state accountability measures that the industry has argued may constrain profit maximization" (p. 2). Börzel \& Hönke (2011), similarly, argue that even in areas of limited statehood, governments often play the role of principal gatekeeper between the international and domestic realms. Despite their lack of capacity overall, governments continue to allocate mining rights. Several scholars have observed that countries like the DRC exhibit limited statehood (Risse, 2011; Börzel \& Hönke, 2011; Hönke \& Börzel, 2013). The concept of limited statehood is useful, but other terms and concepts offer more helpful insight. This study does not aim to advance the theoretical debate on the nature of the state in the Global South or what has been termed "the majority" (Nguyen, 2019), but rather to acknowledge that statehood in countries like the DRC has specific characteristics and challenges similar to those faced by states elsewhere in the region and in Africa more broadly. For instance, Bayart and Ellis's (2000) concept of the "rhizome state" or Hönke's use of "rhizomatic statehood" is more analytically useful in the context of the DRC, given the government's strategic blend of violent repression and utter neglect. Drawing on Bayart and Ellis's work, Hönke (2010) discusses the

non-territorial strategies governments use to consolidate the central state's despotic power in such a context of multiple authorities and legal pluralism within a territory. The resulting "rhizomatic statehood" is built on personalised, asymmetric networks, delegating the rule of sub-national territories to intermediaries [...] The detailed administrative control of bounded space [...] is replaced by a sporadic, preventive demonstration of despotic, coercive power for stabilizing regimes. (p. 107-108)

I do not, however, claim that the term "rhizomatic" is less problematic than the term "limited", or that the debate on the nature of statehood in Africa is over. Nor do I aim to contribute to an already extensive debate. Jean-Pierre Olivier de Sardan (2008) in fact argued 
that it doesn't make sense, in the African context, to refer to only one variety of real governance. My point is that given the necessity of choosing a term and a concept, "rhizomatic statehood" is a better fit for the specific circumstances of the DRC and the provinces of Haut-Katanga and Lualaba in particular. I use an inevitably imperfect concept as a tool to help analyse governance at and around LSM sites in the DRC. ${ }^{1}$ I approach the three LSM sites in the DRC considered in this study as case studies of a wider phenomenon likely to be found, at least in some form, in the many African countries where large- and small-scale mining are prevalent. Assemblages of hybrid governance are therefore instrumental in corporate engagement in areas of limited statehood (Börzel \& Hönke, 2011). The complexities of hybrid governance arrangements often lead to conflict, but that is not always the case. There is scope for further research on conflict dynamics at the micro level, including when it comes to LSM-ASM relations.

The International Council on Mining \& Metals (ICMM) (2015) finds that the number of conflict incidents, defined as "disputes between companies and communities which involved protests and/or the use of force, as well as legal proceedings against companies related to environmental or social issues" (p. 2) rose worldwide between 2002 and 2012 (with a slight decline from 2012 to 2013). Yet according to ICMM's empirical evidence, incidents in the DRC are relatively rare: in 2013 ICMM documented only 2-3 reported incidents of conflict. This figure is astonishingly low for a country characterised by rhizomatic statehood and predatory governance; extremely low human development, at $176^{\text {th }}$ out of 189 entries in 2018 (United Nations Development Programme, n.d.a); high levels of inequality (United Nations Development Programme, n.d.b); and recurring conflict in different parts of the country, especially eastern DRC. As an April 2016 report by one international and three local non-governmental organisations (NGOs) (SOMO, Afrewatch, ACIDH, and Premicongo) described in the case of southeastern DRC, "[v]iolence has occured [sic] between the police or military and illegal miners trespassing on the mine sites. As the illegal miners flee, police open fire indiscriminately and have reportedly hit innocent civilians.” (p. 5) Hönke (2009) described a "serious conflict" that "developed between industrial and artisanal miners. Interviewees speak of a "guerre civile sociale" in South Katanga during 2005-07 that rapidly developed into a regional problem" (p. 15).

The unexpected ICMM data suggests that at least one of two things holds true: first, that incidents are underreported for reasons that could include lack of data and/or of in-depth

\footnotetext{
${ }^{1}$ When considering literature that explicitly refers to "areas of limited statehood", additionally, I use the same term as that employed by the author or authors.
} 
research at the local level, including on lower-level, less visible conflict. As an industry body, ICMM has an incentive to argue that conflict in the LSM sector is a rare occurrence. Second, the evidence indicates that local contestation over resources is often managed and/or controlled to ensure that some incidents are contained or at least not reported. Persistent, lower-level conflict will not be fully captured if the focus is on incidents on the more extreme end of the scale. ICCM's low numbers for occurrences of conflict at and around LSM sites in the DRC show a need for in-depth analysis and data collection. That is particularly the case given that - as in the two quotes in the previous paragraph - conflicts and/or violence across mine sites are often described in broad terms, rather than delving into the fine-grained details. In interviews with civil society representatives, university professors, and researchers based in Lubumbashi, the capital of the province of Haut-Katanga, some respondents similarly described confrontations between companies and artisanal miners in general terms, either as latent conflict (university researcher, interview, August 13,2016) or as a state of frequent open confrontation (civil society representative, interview, August 10, 2016). Therefore, this study examines a range of conflictual and non-conflictual encounters to assess the conflict phenomenon and put together a framework and explanation for conflict incidence.

\subsection{Country Selection and Generalisability}

There are several reasons for the choice of the Democratic Republic of Congo as the country where the case-study sites are located. The mining sector's economic and political importance for the DRC is a key reason to study mining governance in that country. The DRC is the sixth biggest copper producer worldwide (and the biggest in Africa) (SOMO, Afrewatch, ACIDH, and Premicongo, 2016). In 2014 the mining sector was the principal source of revenue for the Congolese state, making a contribution of \$761.2 million US, which represents $66.7 \%$ of the total for the Congolese extractive industries (EITI, 2015a). In 2015, the extractive industries were estimated to make a contribution of $24.71 \%$ to government revenue (EITI, 2017).

The current nature of statehood in the DRC, particularly the combination of delegation practices and despotic action that fit with the concept of rhizomatic statehood, makes the country an appropriate choice for studying conflict at and around LSM sites in areas where the government, or some other actor, does not step in to resolve the issues underpinning conflict in a manner satisfactory to all parties. Much of the DRC is characterised by multiple overlapping property rights and/or claims to resources, and the government does not fully address or resolve conflict(s) resulting from the existence of these intersecting claims, or 
enforce verbal contracts whose breaking lead to conflict. As noted, however, statehood in the DRC is therefore at times very present and even, overbearingly so. The two provinces where this research was carried out (Haut-Katanga and Lualaba), additionally, are characterised by relatively present and institutionalised statehood, which Diemel and Cuvelier (2015) also contend in their piece on the former province of Katanga. Within the DRC, I therefore focus on the southeastern provinces of Haut-Katanga and Lualaba, the heart of the country's largescale mining economy. Finally, my knowledge of and previous experience working in the DRC, albeit in a different region of the country, meant that this country was also a methodologically sound choice.

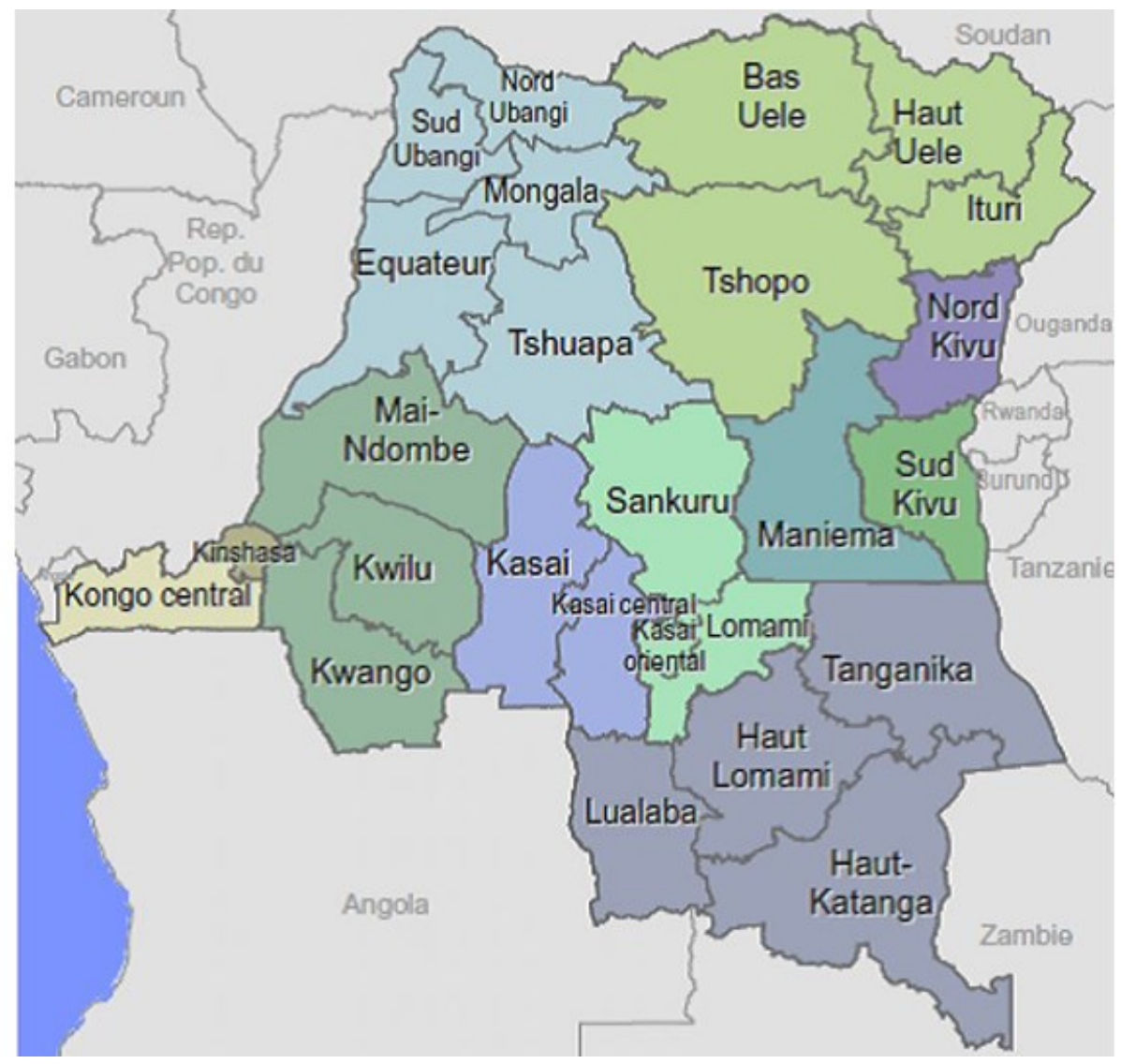

Source: DR Congo National Investment Promotion Agency (2019) 


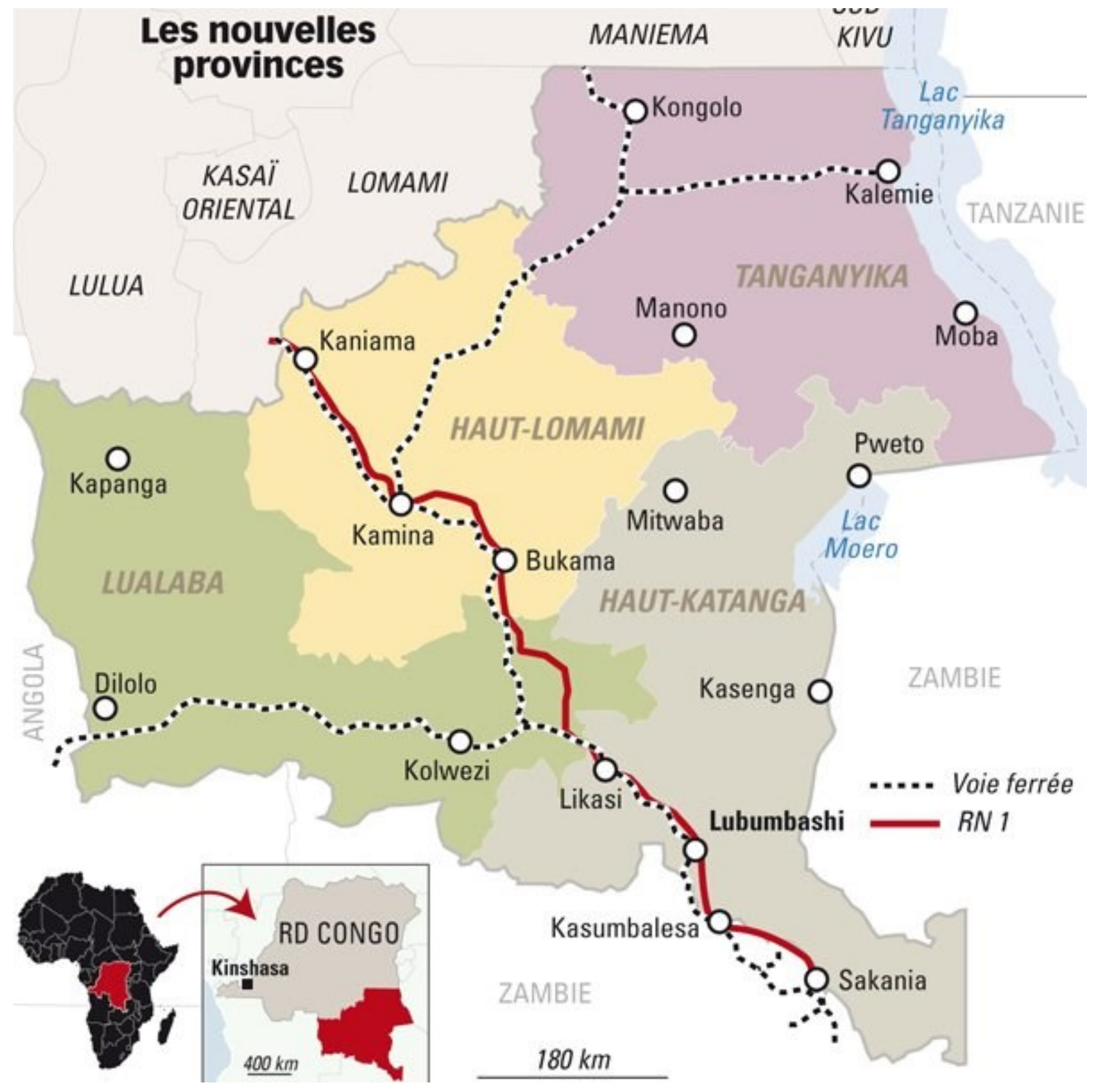

Source: Jeune Afrique

As noted, the choice of the southeastern provinces of Haut-Katanga and Lualaba was also strategic. Unlike the somewhat saturated landscape of conflict and mining research by Congolese and international scholars working in the Kivu provinces in eastern DRC, the south-east has received comparatively little attention from international academics and researchers, and mining-related conflict even less. In eastern DRC, large-scale mining is a relatively new phenomenon, while LSM has long been built into the fabric of the southeastern region. The DRC's copper- and cobalt-producing province of Katanga has historically been the country's principal LSM area, including during the colonial period. While industrial mining is still in its early stages in conflict-affected South Kivu in eastern DRC, relatively 
stable Katanga experienced renewed interest in the post-conflict period in the DRC (Geenen \& Hönke, 2014), a time period that overlapped with the global commodity price boom. In 2015 the Katanga region was subdivided into four provinces (Haut-Katanga, Lualaba, HautLomami, and Tanganyika). The provinces of Haut-Katanga and particularly Lualaba (the two provinces in which the three study sites are found) continue to play a significant role for the country when it comes to indicators like government revenue - of which the former Katanga province provides significantly more than half - though without a correspondingly significant contribution to formal employment. Most of those who mine in the former province of Katanga do so artisanally (International Crisis Group, 2016).

Finally, this analysis is expected to make it possible to generate insights beyond the DRC. As I demonstrate in detail in the literature review, the themes outlined above, including limited and/or rhizomatic statehood; persistent conflict between ASM and LSM; and the large-scale mining sector's significant contribution to the national economy all have echoes in a number of countries elsewhere in Africa. In such contexts, many ordinary people rely on ASM for their livelihoods but are increasingly squeezed by LSM and repressed by the security forces. Therefore, the findings in this dissertation, including the persistence of "clandestine" mining and the link with conflict, are likely to go quite a long way in other settings.

\subsection{Historical Background}

From the mid-1970s onwards, the DRC was, for a range of internal and external reasons, in a state of growing economic crisis (Geenen \& Hönke, 2014), which included the economic downfall of the state-owned copper and cobalt-mining enterprise, the Générale des Carrières et des Mines (Gécamines) (Trefon, 2014). Gécamines's Katangese concessions added up to more than $30,000 \mathrm{~km}^{2}$ across the province, concentrated around the towns of Kolwezi, Likasi, and Lubumbashi (Global Witness, 2006). While Mobutu was in power from 1965-1997, Gécamines was a vital source of funds for the president to maintain his extensive patronage complex. For decades, there was overproduction coupled with underinvestment in Gécamines' mines and factories, and in the early 1990s Gécamines began to suffer a collapse in production. The associated revenue decline was, in the long run, a factor in the end of Mobutu's reign. Yet Gécamines still had control of the DRC's most coveted mining licenses (Carter Center, 2017). By the mid-1990s, with a number of state-owned large-scale mining companies now insolvent, the state had to sell off some of its concessions to private buyers. The wars that took place from 1996-1997 and 1998-2003 brought industrial mining to a halt. 
As the second Congolese war came to an end, the Kabila government introduced a new Mining Code in 2002 with the aim of attracting foreign direct investment in the sector (Geenen \& Hönke, 2014). Large-scale mining re-emerged in the southern part of the province of Katanga (the part that in 2015 became the two new provinces of Haut-Katanga and Lualaba) from 2005 to 2008, a period in which there was increasing stability and the country began to prepare for the 2006 presidential elections (Hönke, 2009; 2010). From 2010 to 2012, further dubious asset sales of key Congolese mining concessions to international mining firms took place, which further highlighted the pattern of corrupt sell-offs that benefit key members of the Congolese elite to the detriment of the Congolese state (Global Witness, 2014).

Alongside these developments, the artisanal extraction of minerals by the population grew in importance as they sought viable livelihood options in a context of economic crisis. By the time renewed industrial investment came to Katanga province in the post-war period, the copper- and cobalt- mining sites around Lubumbashi and elsewhere in the region had become the workplace for tens of thousands of artisanal miners. With the decline of the diamond industry in the nearby Kasai region, many Kasaians also came to Katanga to mine artisanally (civil society representative, interview, August 9, 2016). Lualaba in particular has a significant amount of artisanal mining. Yet companies almost immediately began to clear their newly acquired concessions of these miners so they could begin industrial extraction. Tens of thousands of artisanal miners have been displaced, sometimes multiple times. A dynamic process of property rights $(\mathrm{PR})$ reconfiguration therefore continues to take place across mine sites in southeastern DRC, but there is a marked and ongoing trend towards greater restrictions and less access for ordinary people who depend on the extraction and sale of mineral resources for survival. The signing of contracts and the granting of mining concessions to LSM companies takes place in Kinshasa - about $2000 \mathrm{~km}$ from Lubumbashi as the crow flies (community activist, interview, October 15, 2016), but the effects are felt at the community level around the mine sites, and impact the local population in a myriad of both negative and positive ways.

Due to miners' lack of other viable livelihood options, particularly of livelihoods that allow them to earn as much as they do through ASM, many have resorted to entering LSM concessions to dig for or collect minerals. The multiple conflicts between industrial and artisanal mining in Haut-Katanga and Lualaba, the two provinces in which the three casestudy sites are found, represent a significant social and economic fault line. Entering an LSM site is a violation of Congolese law and puts these miners at risk of imprisonment and human rights abuses. Multiple terms are used to describe individuals and groups who mine using 
artisanal techniques, depending on where they operate. Some use the term "artisanal miners", but specify that artisanal miners are those who operate in designated artisanal mining concessions only, not company-owned mines. Others refer to the miners entering LSM sites as creuseurs (French for "diggers" or "miners") ("Environ 40 morts", 2019), creuseurs clandestins ("clandestine diggers" or "clandestine miners") or simply clandestins (journalist, interview, February 7, 2017) - miners who enter mine sites without permission. The term "clandestine" highlights the ambiguous, covert nature of their activities. Still others use "illegal miners" (SOMO, Afrewatch, ACIDH, and Premicongo, 2016), highlighting that in their view, these miners have no place digging for, or collecting, minerals in industrial mining concessions.

It is necessary to provide context regarding "illegal" activities in places where statehood is rhizomatic. The activities of artisanal miners who operate in LSM sites are illegal according to national law in the DRC and elsewhere in Africa; state agencies and security forces are formally mandated to stop these miners from entering LSM sites. Yet the concept of (il)legality is of limited usefulness given that many LSM contracts were signed in highly irregular conditions and under secretive or unequal conditions (Marysse \& Geenen, 2009; Carter Center, 2007). Additionally, Congolese state institutions and security forces are systematically involved in, and even organise, the extraction of minerals from the concessions of LSM companies whose property rights these agencies are mandated to enforce (Ngoie Mwenze, 2009; Peyer, Feeney, \& Mercier, 2014).

The term used in this dissertation is artisanal miners (after the technique these miners employ) rather than " creuseurs clandestins » or "clandestine" miners - a term that, while often employed by respondents in the DRC, has a pejorative connotation. The relationship between state law and artisanal miners' work in LSM concessions has a significant impact on how these miners' activities are viewed and dealt with. Miners only become "clandestine" once they no longer have sites at which they can "legally" operate, and there is therefore a significant element of constraint and lack of choice in terms of their status.

Despite the importance of the terms used and how they are applied, my aim in this dissertation is not to grapple with questions of (il)legality and (in)formality as they pertain to large-scale and artisanal mining in southeastern DRC, but to understand the mechanisms and networks - including "clandestine" ones - through which mine site access is, at different times, either given or refused. Therefore, I do not engage in depth with questions of legality and illegality as such. Despite the problems with the term "clandestine", I do situate my analysis in the realm of the clandestine, an imperfect but still useful term when applied to a 
given governance realm and set of practices rather than to a group of people. The term is also frequently used in Haut-Katanga and Lualaba, and helpfully encapsulates the ambiguity of artisanal mining within LSM concessions. Other terms, as I have shown, are even more problematic.

In what follows, therefore, I argue that much of copper and cobalt mining takes place in the realm of the "clandestine" that includes, arguably, much if not all of supposedly "formal" and "legal" large-scale mining. While the legality and legitimacy of LSM companies' property rights to mining concessions is frequently unquestioningly accepted by policymakers, including government officials, and by other actors in southeastern DRC, many individuals and groups cast doubt on the legitimacy and/or legality of the contracts that underpin these holdings. From the point of view of some Congolese people, including at the local level where this research was conducted, "corporate enforcement" itself is arguably clandestine, while the "authorised" and "unauthorised" modes of extraction that I discuss in this dissertation are not "clandestine" at all. Legality may not be a matter of fact but rather a matter of definition or, as MiningWatch Canada described it on Twitter in July of 2019: "what is "illegal" depends on who writes the laws." Despite these complexities and in keeping with the example of Meagher (2014) on African clandestine economies, as well as for ease of reading, I do not use quotation marks hereafter when discussing "clandestine" extraction.

\subsection{Puzzle}

Despite the multiplicity of conflict dynamics at and around industrial mining sites, including over land, jobs, and environmental pollution and damage, my research in this region of the DRC demonstrated that it is the relationship between companies and artisanal miners that is the most visibly and enduringly conflictual. Hilson and Yakovleva (2007) echoed these findings in the case of Prestea, Ghana, noting that: "[s]ome of the more serious miningcommunity disputes have involved indigenous artisanal mining groups and large-scale miners" (p. 99). The puzzle that motivated this study is the fact that conflict at mine sites in southeastern DRC is not a constant occurrence, but rather occurs periodically and often involves some form of physical coercion or violence, like when the police fire on fleeing "illegal" miners and accidentally hit innocent bystanders (SOMO, Afrewatch, ACIDH, and Premicongo, 2016). At the three mine sites included in this study, which all have different characteristics, respondents described periods of relative calm punctuated by incidents of physical confrontation between security forces and artisanal miners, sometimes large numbers of miners. Even relative calm or "peace", it should be noted, does not signify the absence of 
conflict. Different sites also have different conflict dynamics that reflect their specific property rights regimes. I therefore view conflict in its different manifestations not as constant or indiscriminate, but as an outcome linked to specific and identifiable property rights regime dynamics at and around mine sites in the region. Therefore, it is necessary to understand the specific manner in which access to mine sites is regulated: whether this access is granted or denied, how - which includes clandestine means - and at what times.

\subsection{Research Questions and Main Argument}

This study addresses two related research questions. First, why do some cases of largescale mining, in contexts of contested access to resources where statehood is rhizomatic, at times result in conflict? I argue that the functioning of the property rights regime is more important than company characteristics when it comes to explaining conflict. For instance, a number of interviewees argued that company $\mathrm{C}$ - which owns mine site $\mathrm{C}$ (several hours by road from Lubumbashi) in the province of Lualaba - respects human rights, a claim that respondents did not make about the two mine sites in the Lubumbashi region. Yet the data gathered, including the company's own reporting, suggest that the functioning of the property rights regime plays a bigger role when it comes to conflict incidence at and around LSM sites.

The second research question pertains to distributional outcomes. What are the distributional outcomes of successful - or unsuccessful - governance at different mine sites? This research question examines the impact of the interactions of the different facets of the property rights regime on different parties' resource access, which includes artisanal miners' access to LSM sites and the minerals found there. Access to LSM sites is a necessary precondition to extracting minerals, but is only one part of the picture. As I show, the fact that an artisanal miner has gained access to an LSM site does not mean he can extract minerals without limits or even at all. There are significant restrictions on a miner's ability to find and collect minerals, not least the fact that he can only take away what he can carry: unprocessed copper ore in bigger amounts ${ }^{2}$ is bulky and heavy. Clandestine extraction, I demonstrate, is heavily policed and regulated. Therefore, what I refer to as the distributional outcome includes not only access to mine sites and minerals, but also volumes of minerals collected and particularly the relative share captured by LSM companies, artisanal miners, and other actors.

\footnotetext{
${ }^{2}$ At the time of the research the cobalt price rise and the demand "boom" had only just begun. Therefore, when I researched clandestine mining, it was often copper ore that was talked about.
} 
I argue that assessing the extent to which different actors' property rights - which includes companies' "formal" and supposedly exclusive property rights - are actually enforced is a necessary step for understanding distributional outcomes. In a context in which the property rights allocation is still highly contested, there is a need to assess outcomes in terms not just of conflict but also of the distribution of resource access. Conflict is important due to its human and other costs, but does not tell the whole story about fairness and economic justice.

This study's main, overarching argument is that conflict, and distributional outcomes in terms of access to minerals and other resources by different groups, are the outcome of the interaction of at least three key facets: 1) mining companies' property rights enforcement practices; 2) the functioning of well-established networks and systems for the clandestine extraction of mineral resources from mine sites and 3) artisanal miners" "unauthorised" attempts to circumvent these processes of "authorised" clandestine extraction. Conflict cannot be fully understood without considering not only the more commonly studied elements of how companies and artisanal miners try to enforce their rights and claims, but also the existence of clandestine systems and networks. The presence and interaction of all these elements makes conflict more likely to happen than in the absence of one or more of these components. The political economy of the DRC and of the provinces of Haut-Katanga and Lualaba includes a set of broader structural realities that represent potential for conflict: high unemployment; limited or nonexistent social welfare provisions; poor governance and financial mismanagement; entrenched and visible inequality; high-profile foreign investment; and more. These structural conditions are important, but not sufficient for understanding the causes of specific outbreaks of conflict at and around LSM sites - i.e. the incidence of conflict. I draw a causal linkage between how companies' mix of practices interact with clandestine networks and systems - networks that exist on a continuum from "authorised" to "unauthorised" - and the form that conflict takes as well as the extent of artisanal miners' exclusion from mine sites and, ultimately, distributional outcomes.

I argue that there are at least three at times competing, at times mutually reinforcing, components of a plural PR regime: a "corporate enforcement" element; an "authorised" clandestine system for the extraction of mineral resources; and an "unauthorised" clandestine component, i.e. miners' attempts to circumvent the rules of clandestine extraction. "Corporate enforcement" refers to the institutional arrangements through which companies define and enforce their claims over minerals, with more or less success. With respect to "authorised" clandestine extraction, a range of actors, including company employees, security contractors, 
state security forces, and others, collaborate to facilitate, organise, and tax, the clandestine (i.e. without company permission) removal of minerals from LSM sites. This frequently systematic and well-organised set of practices is commonly referred to as la frappe or frapper (a French term that I translate as the noun "the strike" or the verb "to strike"). This activity is therefore perceived by some, including by those who engage in it, as rapid and in contravention of Congolese law and corporate property rights, though these activities are also broadly accepted and engaged in by many actors, bodies, and institutions. Miners' "unauthorised" clandestine activities refer to their efforts to circumvent the rules and regulations of the clandestine, yet, I argue, "authorised" - not "officially" and certainly not by companies, but by a range of other actors who possess power and authority - component of the property rights regime. My interest in this third component was sparked by the fact that some traders and artisanal miners themselves referred to these activities as "fraud" and to the miners who engage in it as people who commit "fraud". One trader even referred to miners who do not pay as "clandestine" (trader, interview, May 10, 2017). I avoid the term "fraud" due to its pejorative nature and given the fact that in a context in which the Congolese government and companies like Glencore have been involved in large-scale bribery scandals (Wild, Silver, \& Clowes, 2018; Zhdannikov \& Payne, 2018; RAID, 2019), the question of what constitutes "fraud", and who makes that assessment, is very much up for debate.

Miners do not only utilise subterfuge in their "unauthorised" clandestine efforts. At times, aggressive behaviour, particularly when miners are in groups, is used as a tactic, for example if they are denied access to a mine site or ordered to leave before they are finished working or have been able to collect minerals. While the terms "authorised" and "unauthorised", like the label clandestine, are imperfect and inevitably ambiguous, they do describe key characteristics of the different extraction processes at LSM sites. Clandestine extraction may be "authorised" - at certain times and at certain places - by local authorities and security forces, but is not, and never will be, officially "authorised" by companies. Therefore, the extent to which certain practices are authorised is contested and these terms are not exact. Nonetheless, the terms "authorised" and "unauthorised" are analytically useful for building the theoretical framework, so I do not put them in quotation marks from now on.

The "corporate enforcement" component of the property rights regime, aimed at deterring security risks like unwanted incursions by artisanal miners into concessions, varies from site to site but generally includes a combination of state security (the police), private security companies (PSCs), LSM company security guards, and/or guard dogs. The unofficial, but highly organised, system for the illicit extraction of resources from LSM sites is, I argue, 
another side or facet of "corporate enforcement", and shares many of the same actors. The same private and state security agencies contracted for the enforcement of LSM companies' property rights are often involved in organising the clandestine removal of the minerals they are mandated to protect, though there is room for individual variation, and some agencies, like the Mine Police, are said to be more systematically involved than others. I therefore problematise the term "corporate enforcement" because companies and other agencies, like PSCs, are not unitary, rational actors as they are often assumed to be. Nonetheless, I refer to corporate enforcement without quotation marks from now on because there is a clearly identifiable set of security and other practices associated with LSM investment in southeastern DRC, with marked similarities across sites.

The functioning and objectives of the corporate enforcement and authorised clandestine components at times work together. At other times, the objectives of the two components are in conflict. Yet I contend that even when corporate interests and authorised clandestine arrangements are seemingly in opposition, authorised clandestine extraction at times actually contributes to the achievement of company goals. This occurs, however, in a way that a mining company would view as less than optimal compared to an ideal-world scenario in which all miners were successfully excluded from the concession.

As I argue in the conflict chapter, the clandestine nature of the system for clandestine extraction results is an inherent instability in the overall property rights regime. Unexpected security patrols or the sudden arrival of a company supervisor - i.e. circumstances that disrupt the functioning of a previously "covert" market (Daudelin \& Ratton, 2018) - regularly result in the expulsion of artisanal miners even when they have paid for entry. In turn, miners who refuse the order to leave the site immediately are likely to get chased away, sometimes with coercive means including warning shots and tear gas; have their minerals taken away; and be subject to arrest or even physical violence. Within the population of miners, risk and punishment are not evenly distributed. Miners with fewer connections and/or financial means are more vulnerable, as they frequently attempt to circumvent the systems of clandestine extraction run by the different security forces. Miners who tend to resist the orders given to them by security forces, or who fight back when ordered to leave a mine site, are also at greater risk than those who are compliant. As shown in the chapter on distributional outcomes, despite shouldering the greatest burden of physical risk, miners are at the bottom of the pyramid when it comes to the distribution of benefits from clandestine resource extraction. The security forces use coercion and forceful tactics to "close" the security market to miners who do not accept to pay for LSM-site access. Other groups for which resource access has 
become restricted as a result of LSM investment include lower-level traders, including women; members of autochtonous groups and/or local communities; less powerful customary authorities; and people, including women, involved in a variety of ways in the artisanalmining supply chain.

Company security practices are part of and co-constitute the property rights regime, the functioning of which affects the volume of clandestine traffic entering mining concessions, as even the authorised clandestine mechanisms that govern miners' access to LSM sites have been tightened up over time, particularly at the sites around Lubumbashi. Sites with less clandestine miner traffic reflect more exclusionary distributional dynamics, which leads to a decrease in miners' welfare if they stop mining as a result, or obliges them to move elsewhere in search of a mine site that is still accessible. I therefore highlight the link between access - and its converse, exclusion - and the distribution of resources. I examine the relationship between mine site accessibility/exclusion and conflict. Greater accessibility is desirable in order to reduce or avoid conflict, particularly when, like in southeastern DRC, local claimants like artisanal miners are, at least at times, powerful and well organised.

Mine sites, while frequently treated in the literature as separate and distinct entities, are interdependent in at least two key ways. First, sites are geographically interdependent: a tightening up at one site redirects miner traffic to other sites where property rights enforcement is less effective. Reinforcing security at one site without giving miners alternatives only serves to shift the issue elsewhere. Policy efforts to address conflict at and around large-scale mine sites in Africa should take this interdependence into account. Second, LSM companies speak to and learn from each other when it comes to their security practices.

While authorised clandestine structures and mechanisms for resource extraction are highly exploitative, they nonetheless rest on reciprocity practices and ensure access to mineral resources for artisanal miners with few other livelihood options. The disruption of these mechanisms has significant consequences for miners' livelihoods. While much research and policy work has focused on resolving conflict at and around LSM sites in Africa, there is a need for care to ensure that the resolution of conflict doesn't involve greater exclusion and increased coercion rather than a truly equitable settlement, as when it comes to policy approaches that centre on the removal of artisanal miners from LSM concessions.

\subsection{Relevance and Contribution to the Literature}

The principal contribution this study makes is an empirical one in the form of an adaptation and application of recent advances in property rights theory - particularly 
contributed by scholars who write on land management and conflict in countries of the Global South and Africa - to the often conflictual relationship between LSM and ASM in countries in Africa where statehood is rhizomatic. Using three LSM sites in the Democratic Republic of Congo as case studies, I contribute extensive, detailed analysis and discussion of a facet of the conflicts between LSM and ASM miners that has received less attention in the literature: the clandestine extraction of minerals organised and participated in by a range of actors both within, and outside of, LSM companies.

As discussed, the DRC is for several reasons an appropriate case study for a systematic demonstration of the impact of the functioning of a multifaceted property rights regime, at and around LSM sites, in settings where statehood is rhizomatic. Yet my research findings have much broader implications and lessons. The DRC therefore presents a test case and example, rather than a single and sole case needing to be explained. As I show in the literature review, artisanal mining is an important source of income for a significant segment of the population in multiple countries across different regions of sub-Saharan Africa that also fall into the category of rhizomatic statehood. Similar issues surrounding persistent conflict between LSM and ASM are present in many of these countries, with the government and other actors unable or unwilling to find or provide durable solutions to resolve conflict and ensure a distributional arrangement satisfactory for all parties. Rent-seeking behaviours among different security forces and other actors are also relevant for other country contexts where the public security forces earn low salaries. This dissertation therefore uses the DRC as an empirical illustration, but contains insights likely to be relevant for other African countries and contexts. These insights share similarities with scholarship on other issue areas and types of natural resources, including arrests and forceful repression of community members who trespass into Virunga National Park in eastern DRC (Verweijen \& Kubuya Batundi, 2019) and "official" and "non-official" "taxation" on the DRC's Congo River (Eriksson Baaz, Olsson, \& Verweijen, 2018).

As I show in the literature review, my research echoes several researchers' call for a more embedded understanding of mining companies' practices, including security measures, in contexts where statehood is rhizomatic. My research fills a gap by focusing on conflict within the "enclave" of LSM sites: I systematically examine the variation over time in the incidence of conflict between artisanal miners and companies. I also assess dynamics of exclusion across the three case-study sites, which affect resource access at and around these sites. In keeping with the overarching argument in the dissertation, I link these dynamics to the functioning of the property rights regime at each of the sites. Finally, I shed light on the 
less examined "unauthorised clandestine" element: how artisanal miners use a variety of tactics, from avoidance to aggression, to avoid the often-strict rules and regulations that govern "authorised clandestine" access to LSM sites.

\subsection{Theoretical Approach}

This study adopts a systematic approach based on an adaptation and application of property rights theory in regions where statehood is rhizomatic, to make a contribution to the literature by focusing on: what companies actually do; the complex interactions between company practices and other dimensions of the property rights regime - and broader political economy - at and around mine sites; and the impact of these dynamics on conflict and distributional outcomes. Initially this dissertation, and the theoretical framework, was more centred on the concept of company strategies. Yet given the "messiness" of dynamics surrounding LSM investment, and in line with Geenen and Verweijen's (2017) critique of the concept of "company strategies", I use the term "practices" to better encapsulate what actually takes place on the ground. Company practices is a more appropriate term because strategies and policies suggest a level of intentionality that often does not play out when it comes to onthe-ground dynamics and outcomes. The concept of practices refers to the culmination of company policies and strategies as they interact with, and co-constitute, the PR regime. I argue that practices, as the outcomes on the ground, encompass both strategies and policies. Company practices are therefore a key focus of much literature on LSM-ASM conflict as well as the starting point for this dissertation. Still, company practices form only one part of the overall governance arrangements that result from the interaction of the different facets of the property rights regime.

Based on the work of Daniel Fitzpatrick, Esther Mwangi, and others who have adapted property rights theory to realities in countries of the Global South, I apply a modified property rights framework, which recognises the persistence of a plural, overlapping, and contested property rights regime, to the LSM sector in the DRC. Despite the limitations I outline in the theoretical framework chapter, PR theory is a useful tool for understanding how overlapping and unresolved claims in the mining sector can lead to persistent conflict - though conflict is not inevitable. Conventional property rights theory developed for Europe and North America predicts that as resource values rise, the benefits to private ownership will eventually be greater than the associated costs, and private property rights will emerge. Yet in much of the Global South, the state can't, or will not enforce most rights to private property, even when enshrined in law, in the manner associated with the Weberian state (Fitzpatrick, 2006). 
Property rights may be granted, but will not mean much in practice if they cannot be enforced (Katz-Lavigne, 2016). There are several practices through which companies and other parties try to enforce their rights to property (Fitzpatrick, 2006). I make no assumption about the desirability or greater efficiency of private property, but acknowledge that a struggle is taking place in which companies have sought to enforce their legal rights vis-à-vis other actors for whom corporate de jure rights undermine their de facto, often longstanding, claims to resources.

In the DRC, uneven state presence and limited government enforcement of legal, formal property rights means that companies engage in private governance because public governance is limited or unavailable. In Katanga, all the major international companies drew on coercive enforcement at one time or another (Hönke, 2010). There is no single institutional recipe: each company has a different approach. Given that the proposed framework must offer a more satisfactory explanation for the variation in conflict levels than explanations centred on company characteristics, this study considers and engages with those types of approaches, particularly those that emphasize factors including national origin and where companies are listed. I also demonstrate that in addition to providing a convincing explanation for conflict incidence, property rights theory can help make sense of company characteristics-related elements. Project-related factors like concession size, proximity to the population, and current stage in the life of the project affect the costs of security - i.e. of PR enforcement - in the concession. I also take into account the life of the project as a factor potentially affecting the demand for minerals. While each of the three projects in the study are currently in the extraction phase, one of the three has a far longer projected life, while the other two are already experiencing the mining out of easily accessible minerals. I therefore contend that corporate practices can't necessarily be inferred from company characteristics - particularly given the evolution in company approaches over time - but require in-depth empirical analysis. Understanding how industrial mining companies form an integral part of, and engage with, the property rights regime at and around mine sites makes it possible to move beyond a "good company"/"bad company" dichotomy and to problematise corporate engagement and its effects in places where statehood is rhizomatic. 


\subsection{Methodology}

\subsubsection{Case Study Selection and Company Characteristics}

As I explain in the methodology chapter, the case selection was partly a reflection of practical matters like access and partly an analytical choice. In terms of each company's corporate social responsibility profile and measures, the three companies can be roughly classified according to the categorised of high, medium, and low corporate social responsibility: I elaborate on the reasons for this characterisation later on. Therefore, studying conflict and distributional outcomes across the three sites was a good opportunity, from a methodological perspective, to study the impact of company characteristics and corporate social responsibility measures on conflict and distributional outcomes, while keeping in mind that site $\mathrm{C}$ in particularly has distinctive features including a very large concession and a large population of artisanal miners.

This section provides a descriptive introduction of the three mining companies selected for the case-study analysis. This study systematically examines, compares, and contrasts the situation at three mine sites, which for confidentiality and interviewee protection purposes - given the high sensitivity of the mining sector in the DRC - I refer to as Mine Sites A, B, and C. ${ }^{3}$ Sites A and B were, like many of the DRC's now privately-owned mines, previously owned by the Congolese state-owned copper- and cobalt-mining company la Générale des Carrières et des Mines (Gécamines) (company A manager, interview, September 22, 2016; company B officer, interview, February 6, 2017). Site $C$ was a greenfield investment created as a joint venture, by convention, between Gécamines and a previous owner based in the Global North (Custers \& Nordbrand, 2008). Mine sites A and B are located in the environs of Lubumbashi, the capital of the province of Haut-Katanga: there are several sites in the Lubumbashi area, but only two were chosen for study for reasons explained in the methodology chapter. Sites A and B are in close proximity to one another and historically made up one mine site.

Mine Site $\mathrm{C}$, in the neighbouring province of Lualaba, is several hours by road from Lubumbashi. Site $\mathrm{C}$ is a concession many times larger than $\mathrm{A}$ and $\mathrm{B}$ put together (DRC Cadastre Minier \& Trimble Land Administration, 2017). For a more fine-grained analysis, I distinguish between company C's concession as a whole and different sites within the broader

\footnotetext{
${ }^{3}$ The fact that the activities of artisanal miners who operate in LSM concessions are illegal according to Congolese law makes this a sensitive issue. Given a number of interviewees' concerns that the information they provided could jeopardise their employment or personal safety, it is necessary to protect them by not naming the specific companies and by avoiding providing too many identifying details on each company.
} 
case study corresponding to site C. I consider different sites within the concession as separate cases. Site $\mathrm{C} 1$ is the biggest town in company C's concession, with an estimated population of 200,000. Site C2, about 10 minutes from C1 by road, is a village and bustling market site in which many artisanal miners live, having rented or built temporary homes. Site C3, about half an hour from $\mathrm{C} 1$ by road, is a sprawling town (albeit smaller than $\mathrm{C} 1$ ), with an estimated 20,000 inhabitants, that is also the home of many artisanal miners (two company $\mathrm{C}$ officers, interview, September 27, 2016). Following the argument outlined in this dissertation, I contend that the fact that multiple conflict incidents of a certain intensity - including property damage - have taken place at site $\mathrm{C}$ in the last several years can be linked to site $\mathrm{C}$ 's distinct property rights regime as well as to the specific characteristics of individual sites within the broader case study.

Companies A and B in the Lubumbashi region are both headquartered in the Global South. The owner of site A, company A, is a subsidiary of a firm that belongs to a larger investment group that engages in business activities other than mining, namely pharmaceuticals (Redacted, 2015). The head of company A indeed invested in the region for another purpose originally, but with the new Mining Code in place, decided to pursue mining (company A manager, interview, September 22, 2016). The firm of which company A is a subsidiary "was the first of the new investment companies to start producing pure metals in the DRC", with copper- and cobalt producing as early as 2002 (Redacted, 2015; company A manager, interview, September 22, 2016). Company A is of Global South origin and based in the Global South but with significant links to the Global North: the head of the company is of Indian origin but has important connections to the UK (Global Witness, 2006) and has been referred to as "an Indian based in Canada" (World Bank, 2007, also community activist, interview, October 21,2016). The larger investment group is registered in the United Arab Emirates (Mthembu-Salter, 2011). These different connections make the company more challenging to categorise in terms of origin. Despite this complexity, I nonetheless classify the company as one from the Global South given the head of the company's origin, where the company is listed, and the fact that the company is perceived, in the region, as Indian (community activist, interview, October 21,2016 ). Company A purchased mine site A in 2003 (company A manager, interview, September 22, 2016).

Company B used to be owned by a different company from South Africa, and changed hands several years ago to a Chinese investor, which bought the majority share in 2012 . The company is now majority owned by that Chinese company, and managed by its former owner, the South African company. Site B, run by company B, was registered in the DRC in 2005. 
From that point on, the investment conglomerate involved started to run the firm that used to own company B. In July 2011, that firm announced that a Chinese company intended to offer to buy all of the firm's issued share capital; in January 2012, the firm became a fully-owned subsidiary of a Chinese investment group. After the 2012 purchase, shares belonging to the firm that used to own company B were no longer traded on the Johannesburg Stock Exchange. In November 2013 the purchasing company merged that firm into its subsidiary, which is listed on the Hong Kong Stock Exchange. The subsidiary that purchased company B is a Chinese state-owned enterprise, but the former owner (from South Africa) still manages the company. The managing company's activities are now carried out "in accordance to the rules and regulations of the Hong Kong Stock Exchange: Regulatory Framework of Hong Kong Exchanges and Clearing Limited (HKEx) and the Hong Kong Securities and Futures Commission (SFO)" (Redacted, 2013).

Until late 2016, an American company headquartered in the United States was the majority owner of company $\mathrm{C}$, with the next largest share held by a Canadian firm and $20 \%$ by Gécamines. Investment in the mineral deposits at site $\mathrm{C}$ has a relatively long history: company C was created in 1996 (Redacted, 2016). In May 2016 the U.S.-based company announced that it had formally agreed the sale, to a Chinese company, of its interests in the company that owned $80 \%$ of mine C (Redacted, 2016). This study focuses principally on the period prior to the American sale, which was implemented gradually over the closing months of 2016 and into 2017 (company C officer, informal discussion, September 28, 2016), a period that overlapped with my in-country research.

In addition to national origin, a significant difference between the three companies is the size of their concessions. Company C's concession, at over $1500 \mathrm{~km}^{2}$, is much larger than both company A and B's concessions combined (company A exploration staffer, interview, October 19, 2016). Site A's permit to extract minerals adds up to an area no bigger than 20 square kilometres, while the permits for site B cover even less than that (slightly more than half the area of site A) (DRC Cadastre Minier \& Trimble Land Administration, 2017). There are over 300 hills in the company $\mathrm{C}$ concession - most of which have not yet been tapped for minerals by the company - while company B has only three bassins (open pits) (extrader/former miner, interview, February 17, 2017; Légion nationale d'intervention (LNI) representative and Mine Police representative, interview, March 20, 2017; company B employee, interview, January 27, 2017). In addition to being of different sizes, companies A and $\mathrm{B}$ are in an urban area on the outskirts of a big city (Lubumbashi) (company A exploration staffer, interview, October 19, 2016). Different ethnic communities (Gobbers, 
2016) are mixed together and customary chiefs have less influence, though the part in which company B is located, for instance, is in a chief's territory (company B social department employee, interview, November 16, 2016). Site C, on the other hand, is perhaps better characterised as semi-urban and in parts, rural, though there are several towns in the company's concession.

The three companies also exhibit differences in the volume of copper and cobalt produced - also linked to concession size. The production of the firm of which company $\mathrm{A}$ is a subsidiary, in 2013, was over 19,000 tonnes of copper cathodes and almost 1,200 tonnes of cobalt metal as cobalt hydroxide, which meant that it was one of the DRC's biggest producers (Redacted, 2015). As of 2013 company B was producing 38,000 tonnes of copper per year, and 4,400 tonnes of cobalt (Redacted, 2013). By contrast, in 2014, the much bigger output from company C (with its much larger concession)'s mine sites added up to 202,648 metric tonnes of refined copper, while 13,334 tonnes of contained cobalt in hydroxide was produced. In the previous year, 2013, the numbers for company $C$ were 209,774 tonnes and 12,751 tonnes, respectively (U.S. Department of the Interior \& U.S. Geological Survey, 2017).

In the years prior to the sale, company $\mathrm{C}$ adhered to the Voluntary Principles on Security and Human Rights and submitted yearly reports to the Voluntary Principles reporting mechanism, at least until November 15, 2016, at which point legal responsibility for the operations at site $\mathrm{C}$ was transferred to the new owner (Redacted, 2017). Reporting to the Voluntary Principles appears to have ceased after that. ${ }^{4}$ According to a company B employee, since its inception the corporation has received funding from Standard Bank South Africa. Every two years, there is an environmental audit, based on the Equator Principles and the International Finance Corporation (IFC) guidelines, carried out by an independent firm for reporting to the bank (company B employee, email, August 15, 2018). Company A, like company B, does not follow the Voluntary Principles (former company A employee, email, August 15, 2018). ${ }^{5}$

\footnotetext{
${ }^{4}$ Voluntary Principles reporting for mine site $\mathrm{C}$ appears to have come to an end due to the sale of the majority share in project $\mathrm{C}$ to a Chinese company. Although the new owner's website mentions that the company is aligned with the Voluntary Principles on Security and Human Rights, I was not able to find a 2018 report covering 2017 (REDACTED, n.d.), though I did find a 2017 sustainability report filed by the purchasing company as well as a 2017 environmental, social, and governance report. Neither report mentioned injuries or fatalities sustained by artisanal miners or any other security personnel. As of 1 May 2019, I could not find 2018 reports online.

${ }^{5}$ However, a representative from the PSC responsible for most of the security tasks at site B told me that they adhere to the Voluntary Principles and have been trained in mass crowd control, including the use of tear gas (three PSC managers, interview, March 20, 2017). A representative from the PSC that is responsible for most of the security tasks at site B told me that company B adheres to the Voluntary Principles (three PSC managers, interview, March 20, 2017) but, as mentioned, a company representative said that this is not the case.
} 
Finally, the three companies have different ownership structures. Until the sale, three different companies (with varying shares) owned firm $\mathrm{C}$ while only two companies each owned A and B. Company A, unlike company C, only granted a 5\% share to the Congolese government (i.e. the state-owned copper- and cobalt-mining company Gécamines), noting that "[Company A] has given an undertaking to transfer $5 \%$ of its share capital to the DRC Government." (REDACTED, 2015) Before the Chinese purchase, company B, too, was 80\% owned by the previous owner (the company mentioned above) and $20 \%$ owned by Gécamines ("Factbox-mining in the Democratic Republic of Congo", 2008), with the previous owner then holding a 75\% share of company B ("Democratic Republic of Congo: Mineral industry overview", 2011). Company B is now 75\% owned by the Chinese purchaser (U.S. Department of the Interior \& U.S. Geological Survey, 2017). The government had a 20\% share in firm $\mathrm{C}$ while the American company owned 56\% and a Canadian company, 24 percent. By January 2019, the Chinese buyer had increased its share of site C from $56 \%$ to 80\% (Jamasmie, 2019).

\subsubsection{Methodology and Data Collection Approach}

I use George and Bennett (2005)'s methodology of structured, focused comparison, which involves posing the same question across case studies in a systematic manner. I gathered most of the empirical data for this dissertation through research in southeastern DRC over a period of 7.5 months from August-December 2016 and January-May 2017. I spent nearly a month, over the course of several trips, doing research at sites within company C's concession. The rest of the time I was based in Lubumbashi, with frequent visits to mine sites and adjacent communities on the outskirts of the city. I conducted semi-structured interviews with individuals and groups, as well as mine site visits and observation, at all three sites, in addition to analysing primary and secondary documentation gathered online and in the DRC. I used snowball sampling as a methodological tool to identify respondents in a sensitive research context in which I had few previous contacts. I conducted interviews in both French and Swahili, but was reliant on interpreters for the Swahili-language interviews. Data collection in this complex, insecure, and unfamiliar environment presented a myriad of challenges and limitations, which I discuss in the methodology chapter. 


\subsection{Structure}

The order of chapters is as follows. In Chapter 2, the literature review, I present the multiple strands of literature on which my research draws. Some literature on the causes of conflict between companies and artisanal miners in Africa and the DRC has focused on grievance, dispossession and resistance. A related and sometimes overlapping branch of literature deals with the local impact of the security practices of multinational corporations (MNCs). I also engage with authors who argue that corporate social responsibility can mitigate company-community conflict and conflict between companies and artisanal miners. After situating my research at the intersection of these bodies of literature I argue that there is room for further contributions when it comes to fine-grained analysis of conflict dynamics within the mine site - in a context of incomplete enforcement of multiple and overlapping rights/claims - which property rights theory can help address. Using traditional PR theory as a starting point, chapter 3 engages with a critique of both earlier formulations and more recent adaptations of the theory. Despite these critiques, recent applications of PR theory provide useful insights and tools for studying conflict around land and other resources in the Global South, which is why I draw on specific authors' work from this body of theory to constitute the theoretical framework for this dissertation.

Chapter 3 presents the theoretical framework and main hypothesis. I explain how I approach the research questions, highlight the factors that play a role, and present the dependent variable - conflict along a continuum from non-violent to violent conflict - and independent variable: property-rights regime variables linked to the PR regime at and around mine sites. I develop a modified PR approach by drawing on the PR literature, particularly how it has been applied to land and other conflict in the "Global South". I emphasize the persistence of multiple facets of a property rights regime and lay out the tentative arguments and expectations from this theoretical approach.

In Chapter 4, the research puzzle chapter, I present the primary puzzle that motivated this study, derived from existing publications on conflict at mine sites in southeastern DRC: conflict is not a constant at mine sites, but exhibits variation across time. Despite different corporate practices and approaches, similar conflict dynamics were reported across all sites. These findings suggest that examining corporate characteristics alone is not sufficient for understanding and explaining conflict at mine sites; company practices are just one component of a multi-faceted governance regime. I test this overarching hypothesis in the conflict chapter. 
Chapter 5, the methodology chapter, includes the rationale for the case selection. I discuss the data collection approach, including how I gathered data on the property rights regime at and around mine sites. I then discuss participant recruitment using snowball sampling, and the interview process. I include a discussion of ethics, access, and security working on sensitive subject matter in the challenging DRC context, and describe the significant limitations I encountered. I also address issues of reflexivity: my identity as a white, Western, female, and middle-class researcher, and the impact of my identity and positionality on interactions with interviewees, as well as the impact these factors are likely to have had on the data. I conclude with an assessment of reliability and internal/external validity.

In Chapter 6, I systematically lay out the specific facets of the property rights regime at and around the case study sites, as sketched out in the theoretical chapter. I explain the functioning of each of these components and and examine how they interact. In Chapter 7, the chapter focused on explaining conflict, I apply the theoretical framework in assessing the empirical evidence on conflict over time, and specifically the microdynamics around encounters over time. Through this assessment, I make the case that the common thread between conflict across time and across sites is the impact of dynamics linked to the overall property rights regime - which includes but is not limited to companies' property rights enforcement practices - rather than company characteristics, or even practices, alone. The fact that focusing on companies' security practices alone is insufficient to fully explain the empirical findings reveals the importance of analysing the property rights regime (PRR). Finally, I note that due to the interdependence of mine sites in the region, efforts to better secure any one mine site, in the absence of other measures, will not provide a durable solution to conflict.

Chapter 8 deals with the second research question on the distributional outcomes of the regime constituted by the interactions between the three systems to regulate access to mine sites: corporate enforcement, authorised clandestine, and unauthorised clandestine extraction. This chapter assesses the impact, on outcomes in terms of resource access at the local level, of the interaction between the different facets of the property rights regime. This chapter concludes with a discussion of the distributional implications of mine sites' interdependence: greater exclusion at one site frequently leads miners to move elsewhere rather than to abandon their activities, which allows miners to access resources elsewhere. Chapter 9, the conclusion, summarises the discussion, discusses the policy implications of my research findings, and provides suggestions for further research. 


\section{Chapter 2: Review of the Literature on Conflict between Large-Scale Mining and Artisanal and Small-Scale Mining}

\subsection{Introduction}

In this chapter, I review the relevant components of the extensive literature on the relationship between large-scale mining and artisanal and small-scale mining in Africa, specifically on conflict. Some of this literature links conflict primarily to the fact that LSM has displaced ASM and led to growing impoverishment of people at the local level in artisanal-mining countries in Africa, including the DRC. I identify a need to build on this literature not by further describing these processes of displacement, but by assessing the conflict dynamics within the corporate "enclave". In this chapter, I therefore lay the groundwork for an application of recent property rights theory scholarship to analyse how different parties, like LSM companies, enforce their rights and claims at LSM sites in the region, and the effect on conflict and the distribution of resource access.

While, as I discuss in this chapter, previous and emerging research examines the locallevel economic impacts of LSM compared to ASM, including in the DRC, there is scope for further assessment of the distributional dynamics linked to the interaction of the different elements of the property rights regime at and around LSM sites. Elements whose distributional impacts merit further attention include the clandestine extraction governed to a significant extent by mid-level elites and members of the security forces, and miners' attempts to circumvent the rules and regulations of these clandestine processes.

In this chapter, I first review the literature on LSM-ASM conflict in Africa and the DRC. I see what the literature has to say regarding the claims that artisanal miners make visà-vis corporate enforcement. I argue that although multiple scholars have highlighted artisanal miners' dispossession, and their grievances over being deprived of their livelihoods, as key factors in LSM-ASM conflict, grievance alone is not a sufficient factor to fully explain LSMASM conflict. I next turn to an assessment of the literature on policy efforts to address conflict, including corporate social responsibility measures. Then, I move to a discussion of what the literature has to say other corporate practices beyond CSR: how mining firms secure their sites and enforce their property rights. In the next section I assess what the literature has to say on the importance of company characteristics in determining how mining MNCs behave at the local level. I then review the literature on new modes of governance and elite involvement, particularly in LSM and ASM, before transitioning into a discussion of the 
"enclave" thesis and how it relates to property rights. Finally, I discuss my research contribution, including my analysis of conflict dynamics within the "enclave".

\subsection{Company-ASM Conflict in Africa and the Democratic Republic of Congo}

Contestation between local communities and multinational mining firms is prevalent in much of the global South (Bolay, 2014). Given the abundance of literature on this topic, I focus on dynamics in African countries. Multiple authors from different disciplines have examined conflict between LSM companies and (local) communities across the African continent, including in countries characterised by rhizomatic statehood, in a context of what has been termed a "new scramble" for Africa's resources (Geenen \& Hönke, 2014; Knierzinger, 2014). With respect to the relationship between large-scale mining and artisanal and small-scale mining specifically, conflict, at times violent, over mineral resources in Africa has frequently occurred between artisanal miners and LSM companies. A growing group of scholars in IR, political economy, political ecology, development studies, anthropology and/or the mining sector itself has engaged in in-depth analysis of the conflict dynamics between LSM companies and practitioners of ASM, in areas as diverse as Ghana (Hilson \& Yakovleva, 2007; Aubynn, 2009; Teschner, 2013; Okoh, 2014; Nyame \& Grant, 2014), Tanzania (Hönke and Börzel, 2013; Thomas, 2014; Hönke, 2018), the DRC (Hönke, 2009; Hönke, 2010; Hönke, 2014; Geenen \& Claessens, 2013, 2016; Geenen \& Hönke, 2014; Geenen, 2014; Hönke, 2018), Guinea (Bolay, 2014; Hönke, 2018), and more. Several authors have cited unresolved conflict between LSM and ASM as one of the local impacts of investment by large, Western multinational corporations.

\subsubsection{Greed, Grievance, and Dispossession}

When it comes to LSM-ASM conflict, multiple scholars, including Geenen (2014); Carstens and Hilson (2009); Bolay (2014); and to some extent Okoh (2014), have highlighted artisanal miners' grievances and concerns about being deprived of their livelihoods by companies. The much-criticised (e.g. by Berdal, 2005; Keen, 2012; Hönke, 2014; and to a degree Okoh, 2014) "greed and grievance" framework developed by Paul Collier and Anke Hoeffler (2004) has to some extent found its way into the literature on LSM-ASM conflict. I argue that greed-focused approaches, and even those that focus on grievance, are not sufficient to explain the variation in conflict incidence over time. My approach recognises but 
moves beyond structural explanations for conflict and builds on scholarship that examines the proximate causes of conflict.

Okoh's (2014) piece applies the greed and grievance literature to conflict between artisanal miners and multinational mining companies in the gold-mining sector in Obuasi, Ghana. He contends that LSM-ASM conflict in Obuasi is not linked to grievance, and instead espouses a "greed" approach. According to Okoh, conflict between ASM and the company is “a result of flagrant encroachment of illegal miners on to a company's concession. Most of these encroachers are migrants who do not hold any ancestral ownership of the land - the expropriation of which should cause them to be aggrieved." (p. 56) Yet Okoh acknowledges that many of the migrants who do ASM in the region descend from people from northern Ghana who previously worked in the Obuasi mines and have gained native status in the town. Despite Okoh's recognition that many miners do have a historical - if not ancestral connection to the mining concession, he contends that a record spike in the gold price is the main reason for the recent intensification of so-called "illegal mining" in the AngloGold Ashanti concession - in other words, "greed" - but doesn't provide a satisfactory explanation for why this factor is more convincing than others. Nor does he explain why it is a mark of "greed" when local people understandably take advantage of a price increase for a product mined locally.

In keeping with the focus on ASM miners' supposed "greed", the emphasis in the media or academic literature when discussing artisanal miners is often negative (Nyame \& Grant, 2014), as Hilson and Yakovleva (2007) describe for the case of Prestea, Ghana. Governments and the press at times point to ASM miners' perceived unpredictability, violent behaviour, and supposedly criminal nature (Hilson \& Potter, 2005; Siegel \& Veiga, 2009), despite the fact that artisanal miners are "a group of marginalized people of varying skill, education, and levels of training." (Hilson \& Potter, p. 115) Emphasis is often placed on their “illegal" status or activities (Hilson \& Potter, 2005; Banchirigah, 2006; Hilson \& Yakovleva, 2007; Banchirigah, 2008; Okoh, 2014; Bolay, 2014; SOMO, Afrewatch, ACIDH, \& Premicongo, 2016; Owusu-Nimo, Mantey, Nyarko, Appiah-Effah, \& Aubynn, 2018; Schwartz Taylor \& Taylor, 2018) while large-scale mining companies are often portrayed as "legal owners" (Bolay, 2014). Some scholars have positioned so-called "illegal" ASM as a problem for African governments on the grounds that it has resulted in negative impacts in a range of areas (Banchirigah, 2006; Siegel \& Veiga, 2009). Banchirigah (2006), for instance, argues that "illegal” ASM (i.e. unregistered) "operations cause significant degradation of land 
[...], flourish 'in environments where the rule of law has collapsed' [...] and are generally associated with numerous social ills, including prostitution and HIV/AIDS" (p. 166).

Negative viewpoints on artisanal miners tend to overlook their legitimate grievances, which multiple scholars have drawn attention to. Okoh (2014) himself points to the lack of livelihood options in Obuasi: land is not available for farming and there are few viable alternatives to ASM. Bolay (2014) notes that urban unemployment is an important cause of involvement in ASM. Carstens and Hilson (2009), in their analysis of conflict between foreign large-scale mining companies and indigenous parties involved in ASM, focus on the grievances of artisanal miners whose livelihoods have been jeopardised. They explore the systemic causes of this conflict, like the fact that the country's new legislation privileged LSM actors from outside over ASM miners indigenous to the area. Geenen (2014) describes the dispossession of miners operating in concessions granted to an LSM mining company in South Kivu, DRC. Hönke (2014) argues that rather than promoting peace, MNCs produce new dynamics of insecurity and conflict, particularly for displaced artisanal miners and their dependents.

The key point, for my purposes, from this body of literature is that in a number of African countries artisanal mining provides much-needed livelihood and poverty-alleviation opportunities for a very large and diverse - and possibly increasing - population of miners, both born in the mining area and from elsewhere (Hilson \& Potter, 2005; Banchirigah, 2006; Banchirigah, 2008; Siegel \& Veiga, 2009; Bolay, 2014). The livelihood opportunities presented by ASM increasingly became a necessity across Africa in an age of Structural Adjustment Programmes and of efforts to attract large-scale mining investment in a context of economic reform (Hilson and Potter, 2005; Banchirigah, 2006; Banchirigah, 2008). Combined with rising commodity prices, these dynamics led tens of thousands of people economically and/or physically displaced by LSM to become involved in ASM activities (Banchirigah, 2008). ASM livelihoods continue to be under threat from, and are being actively eliminated by, LSM, including as a result of governmental measures that favour LSM (Hilson \& Potter, 2005; Banchirigah, 2006; Banchirigah, 2008) and/or seek to control ASM through legalisation (Hilson \& Potter, 2005). The large-scale appropriation of agricultural land and/or sites previously mined by artisanal miners have made unemployment much worse in the countryside (Hilson \& Potter, 2005; Banchirigah, 2006; Banchirigah, 2008), not only in farming but in other livelihood activities as well. Many artisanal miners have been left with no choice but to operate in restricted zones: the majority of ASM is "illegal" in that it takes place in concessions granted to LSM firms (Banchirigah, 2008). 
Yet miners' grievances would not be sufficient to result in ongoing conflict if companies were able to exclude these miners altogether which, as the literature mentioned above shows, they are often not, for a range of reasons. Therefore, grievance as the primary factor in leading to conflict is a necessary but not sufficient explanation for conflict incidence, as I discuss in more detail in the presentation of property rights theory in the theoretical chapter. This study builds on these analyses of artisanal miners' grievances and of the overarching/structural causes of conflict, to examine in detail the dynamics underpinning the variation in conflict incidence at and around specific mine sites over time. An adapted form of PR theory makes it possible to systematically examine the impact of miners' grievances on conflict incidence, including why grievance is necessary, but not sufficient, to lead to conflict.

\subsubsection{Policy Solutions to Grievance in the Corporate Social Responsibility Literature}

Articles dealing with conflict between LSM and ASM often offer policy solutions on how conflict can be mitigated (e.g. Hilson \& Potter, 2005; Carstens \& Hilson, 2009). Carstens and Hilson (2009) point to the need for negative impacts on communities' livelihoods to be addressed if conflict is to be avoided. Consequently, the focus of much of the literature on LSM in Africa is on corporate social responsibility and the social license to operate. Some authors argue that improved CSR can help reduce conflict around LSM sites. Idemudia (2017) describes how, in an attempt to obtain the social license to operate, Shell has drawn on corporate social responsibility measures that have the objective of directly and indirectly making a contribution to peace within local communities. Abuya (2016) argues that CSR is one of the means that can be used to alleviate conflict between local communities and mining firms. Aubynn (2009) describes how Abosso Goldfields Limited in Ghana chose a pragmatic strategy for dealing with incursions by artisanal miners and accepted to accommodate a number of artisanal and small-scale miners in its concession. However, Aubynn does not address the extent to which the limited number - in the hundreds - of miners who became registered at the site are representative of the majority of miners, whose numbers were in the thousands. Hilson and Yakovleva (2007) describe a situation in Ghana in which the mining company had little incentive to clear artisanal miners from an unused concession, but also little incentive to regularise or formalise the situation in any way. Bolay (2014) notes that AngloGold Ashanti in Guinea views CSR as a way to prevent violations of the Voluntary Principles on Security and Human Rights. After the non-sustainability of the company's efforts to expel artisanal miners, the company moved towards a strategy of tolerance (Bolay, 
2014). Yet arguments based on assumptions about CSR and peace overlook the fact that confrontations between artisanal miners and security forces tend to persist (Nyame \& Grant, 2014). What does the literature have to say about why CSR efforts may not satisfactorily address LSM-ASM conflict?

Some authors see CSR as a tool to disguise and "greenwash" the fundamentally destructive nature of mining (Slack, 2012; Farrell, Hamann, \& Mackres, 2012; Mutti, Yakovleva, Vazquez-Brust, \& H. Di Marco, 2012; Siegel, 2013). The best of the CSR literature "seeks not simply to address whether or not [CSR] is 'good for business', or [...] 'good for development', but the power relationships and moralities involved, as well as the unintended consequences" (Gardner, Ahmed, Bashir, \& Rana, 2012, p. 169). The real objective of CSR practices is frequently to ensure that communities buy into projects rather than attempting social resistance (Mutti, Yakovleva, Vazquez-Brust, \& H. Di Marco). The social license to operate, "said to exist when a mining project is seen as having the broad, ongoing approval and acceptance of society to conduct its activities" (Prno, 2013, p. 577), is problematic because it suggests that most or all members of a community will support a mining project if the company's efforts are sufficiently fine-tuned. Yet certain elements may continue to resist a mining project (Prno, 2013). In a given community, certain members may be somewhat better off as a result of corporate investment, while others are unequivocally worse off (Hönke \& Thomas, 2012).

With respect to artisanal miners, as Campbell (2012) argues, some "measures in the name of CSR [...] do not address the origins that give rise to such problems" (p. 142). The presence of thousands of artisanal miners constitutes a key fault line for conflict at and around LSM sites, yet these miners are typically excluded from structures set up for CSR purposes (Hönke, 2018) in contexts like the DRC where LSM is favoured over ASM (Hönke, 2009; 2010). Frederiksen (2019) similarly argues that "Inclusionary CSR in conditions of exclusive political settlements is clearly a challenging proposition and few mines took this up." (p. 168) As Hönke (2018) argues, MNCs have a tendency to "discipline dissent” by framing some interlocutors as legitimate and others not. At times, as noted, miners are criminalised (Hönke, 2018) through the use of terms like "illegal artisanal and small-scale miners" (Okoh, 2014), "illegal miners" (SOMO, Afrewatch, ACIDH, and Premicongo, 2016), or, as used by the press and LSM companies in Guinea, "illegal gold diggers coming from abroad"” (Bolay, 2014, p. 117). In the DRC, companies do not recognise the legitimacy of artisanal miners' claims and do not include them in CSR efforts, or do so only in a limited way, as shown by Geenen \& Hönke (2014) - an interesting divergence from Frederiksen's (2009) statement that 
the "opportunities CSR programmes afford are aimed at those with the greatest capacity to disrupt operations rather than those with the greatest need." (p. 168) When miners have been included, such measures tend to centre on alternative livelihood suggestions to get miners out of ASM altogether (Banchirigah, 2008; Carstens \& Hilson, 2009; Hönke, 2009; Hönke, 2014; Geenen \& Hönke, 2014; Kilosho Buraye, Stoop, \& Verpoorten, 2017).

Research on LSM in Africa therefore demonstrates the limitations on the ground of CSR discourse and promises, particularly when it comes to engagement with artisanal miners. Following on Okoh's (2014) diagnosis of conflict as the result of encroachment on company land by miners from elsewhere in the country, Okoh contends that attempting to resolve such disputes based on a grievance-based understanding of the situation (through redistribution of land) may not be effective, given that Ghanaian law does not allow AngloGold Ashanti to grant any of its land to miners. Okoh refers to the creation of the Obuasi Municipal SmallScale Miners Association as a successful solution. Yet his description of the organisation's objectives and activities is ambiguous in terms of concrete achievements, though the company has hired some of the miners as casual security staff. Geenen and Hönke's (2014) analysis of the case of gold-mining firm Banro in the DRC casts doubt on the long-term viability of policy solutions that rely on hiring artisanal miners for casual roles. According to Geenen \& Hönke, many of Banro's CSR efforts were not in line with transnational standards for firms; some of these activities reinforced the power of a small group of elite individuals. Banro's arrival negatively affected the livelihoods not only of the approximately 6000 artisanal miners working in the area, but also their families, and people who provide goods and services to the miners. Banro met with intense resistance by the population. Local political dynamics had a significant impact on the fairness of Banro's measures for creating jobs and alternative livelihoods for artisanal miners (Geenen \& Hönke, 2014). Geenen (2016) on Ghana also describes within-community variation with respect to the implementation and impacts of CSR and highlights the negative impact on communities of the interruption of artisanal mining, upon which the local economy previously relied. Kilosho Buraye, Stoop, and Verpoorten (2017), too, view the provision of social services, including alternative occupations for artisanal miners in the DRC, as a means to purchase social peace. Yet one of the solutions they propose (the creation of new Artisanal Exploitation Zones) is fraught with obstacles linked to the DRC's political economy, including the fact that the central government prefers large-scale mining over artisanal mining (Hönke, 2009; 2010). In the case of Guinea's ASM gold miners, Bolay (2014) highlights the need for formal recognition of miners' presence and activities in areas legally within the company's sphere of responsibility. Yet in southeastern 
DRC, there is little overt flexibility towards artisanal miners of the kind that Aubynn (2009) describes in the case of Ghana (Hönke, 2009; 2010). Property rights theory can help fill the gap between the positive predictions of some of the CSR literature, and the more complex and messy reality.

\subsubsection{Artisanal Miners' Claims Vis-à-Vis Corporate Enforcement}

Following on this discussion of the removal of ASM miners from LSM concessions, I contend that the fact that artisanal miners continue to press their claims even in the face of company enforcement strategies is a key part of the conflict puzzle. Companies cannot fully exclude these actors from their concessions, but regularly use force to try to do so, and conflict persists. Some of the literature (e.g. Geenen and Claessens, 2016) has framed these dynamics as resistance to corporate enforcement practices. As noted, scholars and observers have described a process in which mining concessions across Africa have been cleared of "unauthorised" occupants. Yet at Congolese mine sites actors with fewer resources, like artisanal miners, frequently continue to exercise de facto rights to resources. Studies that focus on the practices of actors with fewer resources include Geenen (2014); Geenen and Hönke (2014); Bolay (2014); and Geenen and Claessens (2016). Geenen and Hönke (2014) describe how "'local communities', this heterogeneous group of farmers, miners, traders and others, exercise some agency", as "exemplified by the violent protests, barring of the streets, participation in the petition, and reoccupation of artisanal mining sites." (p. 14-15) Companies are therefore not the only actors to draw on a range of practices to enforce their property rights: artisanal miners, despite having been excluded from LSM concessions, continue to press their claims. Less examined in the literature have been the practices miners employ to (re)gain access to those sites after evictions. Scholars who deal with artisanal miners' practices include Geenen and Hönke (2014) and Geenen and Verweijen (2017). Geenen and Claessens (2016) refer to artisanal miners' fragmented "access maintenance" strategies (p. 261), namely "allying themselves to certain power holders, refraining from doing so, resisting against a planned privatisation or against ongoing violence [...] or deciding to engage with the corporate-state coalition and get the best of out the deal.” (p. 261) As Geenen and Claessens note, their piece focuses more on local elites' efforts to control access and less on artisanal miners' access maintenance approaches, which points to a need for further research. What practices do artisanal miners employ to press their claims at LSM sites? Property rights theory can help shed light on the less-examined practices, coalitions, and alliances that allow actors 
with less power and fewer material resources, like artisanal miners, to press their claims to mineral resources in LSM concessions that have, in theory, been closed off.

\subsection{Other Corporate Practices and Conflict: Securing Large-Scale Mining Sites}

Scholarly analyses of LSM-ASM conflict, including those that emphasize artisanal and small-scale miners' grievances vis-à-vis LSM companies, contain multiple themes that show property rights theory's suitability as a theoretical framework for studying LSM-ASM conflict. One of mining companies' top priorities is to ensure a stable operating environment (Geenen \& Hönke, 2014). Several authors have considered security practices that companies employ to enforce their property rights over mining concessions in areas of limited statehood (Hönke, 2009; Hönke, 2010; Hönke, 2012; Hönke \& Thomas, 2012; Hönke \& Börzel, 2013; Abrahamsen \& Williams, 2017; Hönke \& Thauer, 2014). A subset of this literature focuses on the use of private security (e.g. Abrahamsen \& Williams, 2009; Schouten, 2017) in parts of Africa where statehood is limited or rhizomatic. Abrahamsen and Williams (2009) look at the global spread and privatisation of commercial private security services in Sierra Leone and Nigeria, through the lens of global security assemblages. Schouten (2017) examines the relationship between political order and private security companies in the $\mathrm{DRC}$, focusing on the use of PSCs by humanitarian actors. Abrahamsen and Williams (2017) analyse the use of private security at large-scale gold mines in Tanzania.

While some scholars have focused on mining companies' use of private security, Jana Hönke (2009) considers the whole range of practices that companies use to secure their extraction "fortresses" at the local level. Hönke (2009) makes a distinction between approaches based on force and the range of less visible economic and political practices. Companies use "soft" (engaging with communities and implementing CSR measures) and "hard" practices (such as in-house or state security forces) to protect their access to resources (Hönke, 2009). Companies secure the social license to operate through official and unofficial channels. They create alliances at the local level with customary authorities, local government officials, members of the community, and more, to ensure their extraction activities are not threatened or compromised (Hönke, 2018; Geenen \& Hönke, 2014). Like Hönke I conceptualise CSR, which is often theorised on its own, as just one tool to enforce mining companies' property rights and manage conflict that could result in visible, costly - including for their reputations - clashes. Following property rights theory, CSR is a strategy to exclude using second-party measures, or an "informal norm-based order or a coalition of interests". (Fitzpatrick, 2006, p. 1000) Examining the range of practices avoids the pitfalls of 
concentrating on a single facet of how companies engage abroad. Hönke (2013), in her book, provides a systematic formulation of the dynamics surrounding corporate (security) engagement by distinguishing between "three transnationalised meaning systems: the CSR discourse, the expertise and routine practices associated with the global field of security professionals, and the institutionalised practices of clientelistic exchange in the "politics of the belly'." (p. 17) These logics overlap and at times act in contradiction to each other. Multiple actors are involved in the implementation of security professionals' knowledge and practices, including private companies and the state police or armed forces. Mining companies' priority is to ensure the viability of their investments, even if it means employing clientelistic exchange measures (Hönke, 2013) that undermine the formal structures of accountability they ostensibly seek to promote (Hönke, 2018; Geenen \& Hönke, 2014).

Hönke (2013) and Hönke and Börzel (2013) highlight the importance of understanding how companies actually engage in areas of limited statehood. Hönke and Börzel contend that understanding MNCs' role in governance at the local level in such areas, specifically regarding if and how their dedication to voluntary standards has an impact on security practices locally, makes it necessary to espouse a different viewpoint on transnational initiatives than typically found in the literature. They contend that actual corporate behaviour and its impact on collective security locally should be the starting point for analysis, including security practices that comply with voluntary standards and those that do not. Rather than only examining examples of successful corporate involvement, they argue that there is a need to focus on the wider range of governance activities, including those that could undermine or even clash with transnational requirements (Hönke, 2013; Hönke \& Börzel, 2013). These scholars' work highlights areas where a rigorous application of property rights theory - which theorises the range of practices actors engage in to try to enforce their property rights - would shed further light on MNC investment in southeastern DRC.

\subsection{Company Characteristics}

Following on this discussion on the range of company practices to enforce their property rights, I now examine what the literature has to say about factors that determine what practices companies implement at the local level. Much of the scholarly literature on largescale mining in Africa concentrates on large, Western multinational corporations' practices for securing their concessions and resolving conflict (e.g. Hönke, 2010), but mining companies that invest in places where statehood is rhizomatic vary along a number of dimensions. Companies can differ on a range of characteristics, including size; national 
origin; what stock exchange they are listed on; target market (Börzel, Hönke, \& Thauer, 2012); senior vs. junior; state-owned vs. private; time frames; experience in mining; contract terms and conditions; and more. In the DRC, for example, large extractive firms are present but from a quantitative point of view, "juniors", sociétés de négoce [trading companies], and Asian economic immigrants dominate the former province of Katanga's southern region (Carter Center, 2012). Researchers have posited that differences between companies matter when it comes to corporate policies, including competence (Gewald \& Soeters, 2010), national origin (Oskarsson \& Lahiri-Dutt, 2018; Haglund, 2010; Lee, 2010; Hönke 2009, 2010), international capital relationships (Gewald \& Soeters, 2010; Hönke, 2009; 2010) and size (Slack, 2012; Hönke, 2009; 2010). According to Slack (2012), bigger companies generally have more resources and greater expertise to address issues linked to corporate social responsibility. Slack adds that smaller companies are frequently faced with a shorter time horizon for their mining activities, which means they have less time for CSR and consulting with communities. Luning (2012) distinguishes between the "juniors" and "seniors" in the mining sector when it comes to CSR but contends that juniors have also started paying attention to CSR, if only to compete with "major" mining companies.

Some media coverage and literature on LSM in Africa has emphasized the importance of companies' national origin in determining how they behave. One example is concerns about the expected negative influence of Chinese oil companies on CSR standards (Pegg, 2012) and of Chinese investment in Africa generally (Pilling, 2019). Oskarsson \& Lahiri-Dutt (2018) contend that Indian mining investments overseas reflect domestic standards instead of global norms. Pegg (2012), on the other hand, suggests that while Chinese oil companies are different from Western companies, the difference is not as significant as popular discourse would seem to suggest. In response to the question "are Chinese oil companies really different on CSR?" Pegg (2012) replied "yes, but the differences are not all that big nor do they matter that much." (p. 160) He attributes this reality to the fact that observers have overestimated Western companies' CSR contribution and achievements and exaggerated the difference in outcomes between Western and Chinese corporate involvement. In Zambia, even in a context of corporate proliferation, there were indications that companies - including Chinese firms are converging towards international principles and practices (Haglund, 2010). Lee (2010) noted that all new investors in Zambia's post-privatisation context cut down on the work force and increasingly relied on casual contracts or sub-contracting. At the same time, of all the major mining firms, the Chinese paid the lowest salaries. Yet while China's presence in Africa has been described as enclave-like, "there are significant variations among these 
enclaves, some more socially embedded and integrated with the local society than others." (Lee, p. 133) A four-year study by researchers at the School of Oriental and African Studies, meanwhile, found that "national, sector and economic context are more important in understanding labour conditions in Africa than the country origin of the firm itself." (SOAS University of London, 2019) Hönke (2009, 2010), writing on the DRC, argues that companies' size and where they are listed matters. Yet in Katanga, DRC, all the major international companies relied on coercive enforcement at one time or another (Hönke, 2010).

The literature on LSM in Africa is therefore ambiguous on the importance of companies' characteristics in determining how they behave when it comes to security practices and CSR, but there is evidence to support the argument that company characteristics are not as important as other contextual factors. The ambiguity in the literature indicates that on-the-ground conditions matter a great deal. The literature highlights the need to focus on what companies actually do and the impact of their actions, rather than, as in some of the CSR literature, what they should do (Hönke \& Börzel, 2013) or, as in much of the "business for peace" and CSR literature, on the "best" or most "successful" company examples (Hönke, 2014). Consequently, this study employs a comparative perspective between three mine-site case studies: one from the Global North and two from the Global South.

\subsection{New Modes of Governance and Elite Involvement}

As shown, much of the literature on LSM-ASM conflict focuses on companies and their security or CSR actions. Yet there are many other actors that play a role in the host countries where these firms invest. According to Hönke (2009), a multiplicity of political authorities and of sovereignties outside the state has emerged in Africa. There has been not only a pluralisation of de facto sovereignty, but also a transnationalisation of sovereignty. Many studies seek to disentangle plural and ostensibly new configurations of actors, and the extent of company governance. Hönke argues that there have been few studies on the changes over time in corporate involvement in the governance realm - though some scholars have started examining recent developments in how companies perceive and deal with insecurity and contends that the Congolese government views "the new governance regime of industrial mining in Katanga" (p. 12) as a means to discharge local governance. In response to policies of privatisation since the $1980 \mathrm{~s}$, discharge was a way for the central state to consolidate its power by governing indirectly. The state did so through the delegation of state tasks like the provision of collective goods, and by using indirect means - like encouraging corporate authority and responsibility - to exert influence on the private sector (Hönke, 2010). 
Corporate bodies' growing involvement in security governance at the local level can be conceptualised as a new kind of discharge in which state tasks like the enforcement of private property rights are outsourced to firms. Companies seek new ways to govern the security of extraction, which includes "development and community policies as well as more classical activities of protection, law enforcement, and social ordering” (Hönke, 2009, p. 8). Big MNCs began to engage with new actors locally and transnationally (Hönke, 2009). In the DRC, the Congolese government has used investment in LSM to reassert control over areas previously beyond its reach. There are a number of powerful political actors involved in struggles for control of the country's resource-rich areas, including with local elites (Geenen \& Hönke, 2014). Therefore, other actors' efforts to secure access to resources also matter. As noted, in some of the literature LSM-ASM conflict is sketched out as between LSM and ASM actors, with state security forces deployed as a tool of companies but generally not exhibiting much agency - other than in acts of violence against artisanal miners. Yet miners are embedded in a much broader socio-political context.

As noted, some scholars have argued that there has been a process of state retreat or failure in Africa, particularly in areas of limited statehood like the DRC. Yet when it comes to natural resource management, Sikor, He, and Lestrelin (2017) do not point to the disappearance of the state. Instead, they argue that far more social actors are now involved in managing resources than the local communities previously analysed by property-rights theorists like Schlager and Ostrom. These actors include organisations at the international, national, or international levels, whether public, private, or non-governmental. States are made up of a range of actors with differing interests, resources, and mandates. Sikor, He, and Lestrelin conceptualise property rights as many different types of relationships between actors, as these relationships relate to objects. Hönke (2009) argues that the manner in which the state has been reconfigured is better conceptualized not as a retreat but rather a change in governance and states themselves, as foreign firms begin to carry out a range of governance tasks locally. Nor does the new manifestation of discharge imply that companies are independent of the state (Hönke, 2009). Hönke argues that the distinctiveness of the new topographies for the governance of security is not the nature of the actors involved but rather "the new rationalities and technologies of governance. The new topography is more flexible and combines the fortress-like protection of narrow pockets of production with selective development interventions in communities in the vicinity of the mine" $(2009$, p. 4). Largescale mining enclaves continue to be areas of state and company governance (Hönke, 2010). Indeed, the mining areas of southeastern DRC have long formed part of the so-called "useful 
Africa" and are characterised by the presence of powerful local elites (Geenen \& Hönke, 2014). According to Geenen \& Hönke (2014), in South Kivu, DRC, it is not the case that "external investors are all-powerful and co-opt local elites as if the latter had no agency in these matters. The case of Luhwindja illustrates that local elites play an active part in negotiating and appropriating external opportunities." (p. 14-15) Hönke (2009) contends that in Katanga, institutions of the state that appear to have failed and to be devoid of capacity are actually highly successful at providing political groupings with commercial opportunities. Diemel and Cuvelier (2015) similarly argue that some policy actors in the mining sector in the former province of Katanga have greater capacity than those in the provinces of North and South Kivu. NGO reporting, such as by Amnesty International (2013) and Enough Project (2018), draws attention to the involvement of state and/or armed actors in artisanal mining in the former Katanga.

NGO analyses tend to focus on the conflict and human rights implications of state actors' involvement, neglecting the potentially redistributional (rather than just exploitative) implications of such arrangements. $\operatorname{Li}$ (2018), for instance, argues that "[i]n view of the immense wealth that large rural enterprises such as plantations and mines generate, it is not surprising that people living in or around these enterprises seek to capture rent, which I define as unearned wealth gained by the exercise of power." (p. 329) Yet her use of terms like "predatory system" and "mafia system" cast such dynamics in a negative light that somewhat obscures their potentially redistributional function, as well as the agency of artisanal miners who participate in these activities. Indeed, Olivier de Sardan made the argument in 2008 addressed by many scholars since then, including Hoffman and Kirk (2013) - that researchers, while very aware of ideas about "real governance" in Africa, such as informality, clientelism, and neopatrimonialism - have much less knowledge about the positive impact of "real governance", such as public policies that may benefit the poor.

Finally, Sikor, He, and Lestrelin (2017) emphasize the importance of understanding property rights as applied in practice, a bottom-up approach to the governance of natural resources that complements more government-centric investigations. Their call for an indepth contextual understanding shows the appropriateness of a fine-grained analysis of the multifaceted dynamics at and around LSM sites, which a modified property rights approach provides. In line with Sikor, He, and Lestrelin, the theoretical approach I propose in this study takes into account the relationships between the multiplicity of actors that employ a range of practices to define and enforce their rights and/or claims to property.

In addition to its spatial emphasis on the within-mine space, this present study has a 
different thematic emphasis from some of the literature discussed above. As noted, much of the literature on LSM in places where statehood is rhizomatic in Africa focuses on how companies enforce the property rights granted to them by central governments, including by legitimising these rights through CSR. Some of the literature, including on the DRC specifically, looks at the impact on state authority or on local politics. I do not propose further in-depth research on the reach of state presence and/or governance, but focus on what happens with conflict incidence at and around LSM sites (though engagement by central state and local authorities is a key part of the picture) following the process of enclosure of LSM concessions. Like governance dynamics at the local level in the former Katanga (Hönke, 2009 ; 2010) relations and conflictual encounters at, around, and within LSM sites are also in the process of shifting and changing. These fluctuating realities include the impact of institutional dynamics on conflict at and around mine sites, such as the fact that "[i]n the mining areas of Southern Katanga, state agents are omnipresent, but largely pursue private interests" (Hönke, 2010, p. 117). As recommended by Hönke (2009; 2010), this study focuses on the impact of plurality, rather than just describing the proliferation of actors. The impacts of MNC security measures on local communities have been ambiguous (Hönke, 2009; Hönke, 2010; Hönke, 2012; Hönke \& Thomas, 2012; Hönke \& Börzel, 2013; Hönke \& Thauer, 2014), which shows the importance of teasing out local impacts on conflict incidence once artisanal mining within LSM sites has been criminalised, and large parts of these sites placed behind fences and walls.

\subsection{Enclaves and Property Rights}

As demonstrated, mining companies put a great deal of effort into enforcing their property rights (Hönke, 2009; Hönke, 2010; Geenen and Hönke, 2014; Bolay, 2014). In the DRC, because PSCs are not allowed to be armed, the mining sector relies on state security for operations requiring force. The firms pay for the security forces' services, a de facto privatisation and commercialisation. To defend their offices and concessions, mining companies construct small fortresses (Hönke, 2009) or, as Ferguson (2005) notably referred to them, enclaves. Yet despite the mix of practices they employ, companies are not always able to exclude actors they do not want in their concessions. Geenen \& Hönke (2014), in their piece on MNC involvement in South Kivu, DRC, describe competing claims to resources as predicted by theories of property rights "failure" (Fitzpatrick, 2006). In South Kivu, artisanal miners have continued to operate on concessions granted to an MNC for large-scale mining, leading to frequent skirmishes between security forces and miners. The "trespassing" was a 
protest against the firm's actions, in a setting in which most of the population relies on artisanal mining. To ensure social peace, the company allowed them to operate for the moment (Geenen \& Hönke, 2014).

The coexistence of fortress protection and endemic conflict is puzzling. Conflict suggests, first, that a segment of the population remains unsatisfied with a given resource distribution and second, that these local actors are able to continue to press their claims. Given the persistence of conflict at LSM sites, how relevant to LSM-ASM conflict in Africa and the DRC is the theory of enclaves that previously dominated - and continues to inform - some of the literature on the extractive industries? James Ferguson's classic analysis describes a shift towards "the intensive exploitation of separately administered enclaves", leading to "an increasing acceptance of the idea that effective mineral production and endemic violence can coexist.” (2005, p. 379) What Ferguson argues has occurred is not a homogenous incorporation into the global economy. Instead, he contends, foreign investment in mining has increasingly taken place in enclaves cut off from the broader economy and nation, and protected by private security forces. These arrangements allow for uninterrupted mineral extraction in segregated enclaves, even as the broader national context is characterised by armed conflict and crisis. Yet Ferguson was arguing that enclaves could exist side by side with conflict; his important influential thesis does not address the question of why conflict erupts within the enclave itself - whether or not it spills out into, or has repercussions for, the wider area.

Research on governance in areas of limited statehood in Africa that offers tools for the description and analysis of multilayered governance scenarios highlights the limitations of the enclave approach in a broad governance-related sense. Ostrom (2009), for example, in her discussion of "polycentric governance of complex economic systems" (p. 408) refers to "multiple nested layers" of governance activities (p. 422). Schneckener (2011), in a discussion of statebuilding in areas of limited statehood, points to the development of new kinds of governance at the local level. Outside actors don't always fully understand that local ordering is already in place and benefits certain parts of the society. Given the involvement of foreign actors, these new governance forms can be described as transnational, bringing together internal and external actors as well as state and non-state players (Schneckener, 2011). Schuppert (2011), in the same volume, notes that when a deterritorialisation of political rule occurs, the result is a proliferation of norms and regulations, whether mutually reinforcing or in competition with each other. Schuppert highlights the importance of researching the institutional groupings that play a role in providing governance. Abrahamsen and Williams 
(2017), in their discussion of global security assemblages, avoid a dichotomy between private security actors beyond the state, and public actors imbued with the authority of the state. They call for a focus "on the multiplicity of actors, the different forms of power and resources available to them, and the manner in which they come together in a contingent whole to exercise powerful effects in specific sites." (p. 15) Research on public authority and hybrid governance in transitioning contexts/areas of limited statehood encourages empirically thick descriptions of how governance actually operates on the ground (Hoffman \& Kirk, 2013). Hoffman and Kirk (2013) emphasize the need for a detailed, empirically-informed analysis of how authority is produced in areas affected by conflict and/or transitioning. These nuances offer a more contextual understanding of property rights enforcement dynamics than the state/non-state dichotomy presented by Fitzpatrick (2006).

The "enclave" view is also changing in the study of governance, politics, and security at and around LSM sites in Africa - though Radley (2019) "refutes the claim by consensus proponents that new mining industry practices render enclave concerns obsolete", at least when it comes to industrialisation. Multiple scholars (Hönke, 2009; Hönke, 2013; MüllerKoné, 2015; Côte and Korf, 2017) have called attention to the interplay and embeddedness between international corporate action and dynamics at and around mine sites. As Hönke (2009) notes, IR, anthropology, and area studies scholars have begun to engage in local-level investigations of "glocal governance nodes in African extraction enclaves and of the emergence of global assemblages of governing security", describing "a pluralisation and transnationalisation" of security governance at the local level in enclaves of extraction (p. 7) She contends that mining areas are indeed "transnationalised spaces par excellence in which state-based sovereignty and law, a globalized mode of production, and local polities, norm systems and identities overlap, merge, and get into conflict." (p. 4) Côte and Korf (2017) argue that these so-called enclaves are not actually distinct areas, because in these spaces capitalism is intervowen in far more subtle ways in "local political economics and social relations" (p. 466). Côte and Korf, too, raise doubts about the assertion that the power of the state yields to the power "of large-scale international private investments in the new resource rushes" (p. 1). Hönke (2009) argues that there is a need for tools to further advance accounts of the intricacy and multiplicity of intersecting systems of ordering in "glocal" spheres, like the field of extraction, and describe the asymmetries and power relationships within these transnationalised domains.

It is my contention that different authors have highlighted the limitations of the enclave approach in Africa, and the DRC, both by looking at how mining companies extend 
the scope of their activities outward from the mine site and into the community (Hönke, 2014), and how ASM miners push inward into LSM sites (I consider the latter in more detail in the following section). Bolay (2014) describes how CSR programs "extend the scope of influence of the S.A.G. from the spaces of gold extraction to the neighboring villages and mining camps." (p. 124) Geenen \& Hönke (2014) focus on the impact of LSM investment and land appropriation (and of transnational regulations and norms) by the Canadian company Banro in South Kivu, eastern DRC, on national and local politics. In the same region, Geenen (2014) examines the "messy" dynamics and local impacts of the expansion of large-scale mining in eastern DRC. Hönke (2009; 2010), while focusing on the "community belt" around the "fortress" of LSM sites in Katanga, mentions the occurrence of numerous violent clashes with artisanal miners, showing that Ferguson's "armed conflict and crisis" occur at and within mine sites as well. In the decade or more since large-scale mining companies renewed their interest in the former Katanga region, there has been a great deal happening within the fortress itself that merits further research, which Geenen and Verweijen (2017) also show. It is not just that mining companies extend their presence into the communities around their sites, but also that the communities around these sites, miners from elsewhere in the DRC, and authorities literally extend their presence into these mine sites as well.

According to Hönke (2009), enclaves of extraction like the Katangese Copperbelt have been very much part of an increasingly global economy since industrial mining began. Capital from abroad played an instrumental role in shaping security governance and local political dynamics. Even in a context in which the government largely leaves mining companies to address local-level conflict on their own, the extractive industries cannot detach themselves from the political and social milieu. The zones of governance by multiple stakeholders that surround the mines are intertwined with political networks at the local level. State actors constitute a risk factor for companies to handle as well as collaborators in the enforcement of private property rights and repression of dissent (Hönke, 2009). These insights into, and caveats on, the "enclave" approach provide one of the starting points for this study. As Bierschenk (2019) argues in the case of public services, including the police, they do not have stable borders and represent a multiplicity of actors' continuous effort. LSM concessions, too, at first glance resemble impenetrable enclaves, but in some respects are in fact fluid and constantly negotiated. These researchers' work further show the need to disentangle the complex interactions at and around mine sites, including how mining investment and company practices co-constitute PR regimes. As discussed, several authors have described the aftermath of the process of clearing LSM concessions in Africa and in the 
DRC of their artisanal-mining occupants. After miners were evicted from LSM sites across the region, a kind of status quo developed, albeit one in which many miners returned to sites from which they had been evicted. As noted, some studies have examined ASM mining that continues within LSM concessions after these sites were officially "cleared" of miners (Hönke, 2009; 2010). Many artisanal miners remain active at LSM sites in the region. The number of artisanal miners shows no sign of abating, and, as Banchirigah (2006) argued for sub-Saharan Africa, may even be increasing. Based on the potential areas for further research identified above, there is a need for additional analysis of ASM-in-LSM, that is, of ASM mining that takes place "illegally" at LSM sites, and of the conflict that at times accompanies these practices.

\subsection{Conclusion}

In this chapter I first considered literature on conflict between mining companies and artisanal miners in Africa, and the DRC specifically. Building on the multiple strands of literature discussed above, then, this dissertation studies mining investment as just one component of the property rights regime at and around mine sites in Haut-Katanga and Lualaba, DRC. I examine the interaction between actors' property rights and claims - and how they are enforced - and conflict. I argued that grievance is an important factor underpinning LSM-ASM conflict, given the economic displacement of tens of thousands of artisanal miners and their dependents. Yet grievance, I argue, is not a sufficient factor to explain specific occurrences of conflict at variable moments across time. Policy proposals that rely on addressing miners' grievances, including through corporate social responsibility, have also had their limitations in practice, including in terms of what governments and mining companies are prepared to concede to miners.

I then moved from the somewhat more optimistic nature of some of the CSR literature to make the case that property rights theory can be a useful tool for examining the whole range of property rights enforcement strategies - as highlighted by several scholars - on which companies rely, and which are not limited to CSR. Next, I considered the potential impact of company characteristics on their property rights enforcement practices at the local level - a debate on which much has been written - and highlight the ambiguity of the literature. The emphasis on company characteristics neglects the importance of new modes of governance and elite involvement, which I highlighted in the next section. I then considered the extent to which companies are able to create and maintain enclaves, in keeping with James 
Ferguson's influential work. Finally, I argued for the usefulness of property rights theory in examining how artisanal miners continue to press their claims to resources at LSM sites, even once they have been forcibly removed from those sites. How they do so and when is, I argue, part of the conflict picture. My research contribution includes looking at what happens with conflict dynamics within the enclave itself rather than assuming that mining concessions are impenetrable, and therefore characterised by negative peace. Rather than simply describing the multiplicity of actors at and around LSM sites I also focus on the impact of these dynamics on conflict and distributional outcomes.

Building on the multiple strands of literature presented above, this study addresses the identified areas of potential and scope for further research. In the next chapter I build on themes highlighted in this chapter, including elite involvement in LSM-ASM relations and conflict, and artisanal miners' different strategies for pressing their claims to resources. In the following chapter I present the theoretical framework, which centres on the property rights regime at mine sites in Haut-Katanga and Lualaba. These dynamics are linked to the broader political economy of the country as a whole. As discussed in this chapter and as I argue in the next, despite property rights theory's limitations, PR theory is a useful tool for addressing some of the further research areas raised above. 


\section{Chapter 3: Theoretical Framework}

To lay the groundwork for answering the "why conflict?" question, this chapter presents the theoretical framework that informed the data collection and that provides the supporting structure for the main argument. Using a critique of traditional property rights theory as a starting point, I use an approach that draws heavily from Fitzpatrick's (2006) work on contested access in the Global South: this PR framework emphasizes the persistence of multiple facets of a property rights regime. In this chapter I lay out the arguments and expectations from the theory. The theoretical framework includes the systems and mechanisms through which artisanal miners' access to large-scale copper- and cobalt-mining sites is governed, whether such access is granted or denied. Finally, I discuss the theoretical foundation of the distributional impact of greater or lesser exclusion of artisanal miners.

I first provide relevant definitions from property rights theory. Building on the critique of property rights theory and on the work of Daniel Fitzpatrick and Esther Mwangi in particular, I theorise different features of a plural property rights regime. The specific property in this case centres on resource access - which includes access to LSM sites - as well as on the minerals and other resources. I apply an adapted property rights framework to the specific PR regime at and around the selected LSM sites. I describe multiple components of a plural regime rather than different and separate regimes because the different components of the PR regime are inextricably entangled. Different claims are defined and enforced to different degrees and at different times. I consider, in turn: corporate practices; artisanal mining in LSM concessions; and the role of local elites. The boundaries between the components of the regime are fluid and continuously in flux. While these categories are analytically useful, the distinction is often not clear in practice, given the overlap between the actors involved. The different facets are at times in conflict and at times work together to achieve common objectives even if, from the outside, they appear to conflict. I then turn to a discussion of plurality and of "unsuccessful" exclusion with respect to conflict. Finally, I present the variables and main hypothesis that guided this research, before concluding the chapter.

\subsection{Property Rights Theory and Definitions}

Property rights are the "formal or informal rules that govern access to and use of tangible assets such as land and buildings, and intangible assets such as patents and contract rights" (Anderson \& McChesney, 2003, p. 1). PR underpin and structure economic life: by "defining the parameters for the use of scarce resources and assigning the associated rewards 
and costs, the prevailing system of property rights establishes incentives and time horizons for investment, production, and exchange." (Libecap, 1986, p. 227) PR do not imply full and exclusive control over a resource (ownership); they can be better conceptualised as a bundle or web of interests (Meinzen-Dick \& Mwangi, 2009; Ostrom, 2009). Property rights can include use rights (the right to access, withdraw from, or exploit a resource) and rights to control or make decisions about a resource (management, exclusion, and alienation - by renting, selling, or giving away - of rights) (Libecap \& National Bureau of Economic Research, 1999; Anderson \& McChesney, 2003; Ostrom, 2009; Galiani \& Schargrodsky, 2011). Nyamu Musembi in 2007 argued that definitions of property rights often excessively emphasize land's identity as a commodity. Yet in rural environments dominated by smallholders, land represents a lot more than just an additional input in a farming business, and its sale often represents an option of last resort. She argues that there is a "different social vision of property as primarily a means through which social responsibilities are met" ( $p$. 1469). Finally, in keeping with that breadth this study considers a range of rights that span both legal (enshrined in "formal" law) and "informal" rights or claims, and multiple categories including access, exploitation, and control rights (which can all be both "formal" and "informal"). Sikor, He, and Lestrelin (2017), too, update the concept that property is a bundle of rights. They describe the advent of new kinds of rights, particularly use rights that come about from the delivery of indirect benefits and "authoritative rights defining the scope of control rights" (p. 346), though they note that the local population continues to be refused rights of control and authoritative rights over natural resources.

Jesse C. Ribot and Nancy Lee Peluso's (2003) contribution, A Theory of Access, represents a potential alternative theoretical framework. In what follows I engage with the authors' critique of the limitations of property rights theory and with their theoretical approach to explain why PR theory is still an appropriate choice. Ribot and Peluso argue that the property literature does not provide a full enough theorization of access. For the authors, access refers to the capacity individuals have to derive benefits from a range of things. In their view, focusing on ability instead of on rights the way property theorists do makes it possible to elaborate on a broader set of social relationships that may allow people to gain benefits from resources, or limit their ability to do so. They view property as simply one array of relationships, among others, that allow people to access resources. Yet as shown, scholars who have applied property rights theory to dynamics in the "Global South" present - as the authors themselves acknowledge -a more nuanced picture of what falls under the definition of property rights than simply legal rights. As described, while PR theorists often emphasize 
formal, legal title - e.g. to land - property when conceptualised as a bundle is much broader and can include access rights, both formal and informal. Nonetheless, I draw on Ribot and Peluso's range of factors that help explain why companies are so successful at deriving benefits from resources.

A property rights regime (PRR) is a set of institutional arrangements through which claims over objects, namely property rights, are defined and enforced, with more or less success. The PRR includes elements like whether the property in question is private property, common property, public property, or open access; the degree of formality and informality involved; the resource(s) claimed; who claims the resource(s); the nature of the claim(s); the quality of the definition and enforcement of the claim(s); and tenure security, which includes legitimacy, institutional backing, clarity, and excludability (USAID, 2006). Property rights are grouped into two sub-categories: private and collective rights. Transitioning from one type of property holding to another is rarely simple. When it comes to land rights, legal rights "are not the only set of rules and norms that guide land rights in practice." (Galiani \& Schargrodsky, 2011, p. S332) Customary law retains relative strength and relevance in diverse ways across different countries (Galiani \& Schargrodsky). Fitzpatrick (2006) shows the importance of systematically considering the practices parties - which in this study include mining companies and artisanal miners - use to enforce their property rights or claims.

In southeastern DRC, where different actors attempt to define and enforce their property rights in different ways, "property" can mean a number of things. Access to mine sites is a precondition for extracting and selling minerals (e.g. Geenen \& Claessens, 2016). Miners' presence is disputed not only because they extract or collect minerals from LSM sites, but also because of the bad publicity companies risk facing if miners die in an accident or are killed or injured by security forces (Hilson \& Yakovleva, 2007; Bolay, 2014). Therefore, mine site access is an important first resource that can be distributed among different parties, and in terms of which there is a distributional outcome. A second resource is the minerals themselves: unprocessed copper and cobalt. ${ }^{6}$ However, the stakes are not equivalent for mining companies and artisanal miners. Given the volume of the minerals that LSM companies extract, process, and export, artisanal miners and traders value smaller

\footnotetext{
${ }^{6}$ While LSM-ASM conflict has been described as "land use conflict that pits artisanal miners and local communities on one side and mining firms and the government on the other" (Nyame \& Grant, 2014, p. 82), I concentrate on mineral resources rather than land, though they are inevitably linked. While many community members have been displaced from their land by LSM, many miners do not have rights to or make claims on the land itself, but rather to the minerals within the land. Given that many miners are mobile and move from site to site, they often lack a direct connection to the land they mine, which represents a potential for conflict with those who have such a connection.
} 
amounts of minerals more, while companies rypically tolerate and include in their bottom line a certain amount of mineral losses (community relocation consultant, interview, March 25, 2017).

Minerals are not the only physical resource at stake. Multiple respondents reported that certain actors take fuel and vehicle spare parts from LSM sites. There were differing views, however, on who takes these items. Not all respondents agreed that it's the miners who take these items. Some of them, like miners themselves, linked these practices, particularly the taking of fuel, to actors known as "Qaddafis" (miner, February 17, 2017; three miners, second interview, March 13, 2017). Several respondents made a distinction between those who are artisanal miners and those who are not but enter LSM sites to take items like computers. When there's a theft, one interviewee reported, people tend to accuse artisanal miners: it's difficult to identify people, among the general population of miners, who take non-mineral items. There are many miners, especially at site $\mathrm{C}$, and they do not all know each other (three traders and an ex-miner, interview, February 4, 2107). An ex-trader estimated that about $20 \%$ of people enter mine site $\mathrm{C}$ to take fuel and electric cables, while $80 \%$ do so for mineral products. He argued that those who enter to dig have never been arrested (interview, February 17, 2017). Not all respondents distinguised between those who take fuel and those who extract minerals, arguing that artisanal miners also take cables, batteries, fuel, replacement parts, computers, and other items (LNI representative and Mine Police representative, interview, March 20, 2017; journalist at site C, interview, February 7, 2017). It is likely that some miners do engage in such practices after failing to find minerals at LSM sites, leading them to take cables or other items instead (Mine Police representative, second interview, March 24, 2017). A company B security officer was keen to emphasize that in his view creuseurs, since they operate in the "black market", are happy to take anything, including cables, fuel, and even pumps that provide water to the community (interview, January 27, 2017). The 123 attacks reported in 2016, the company B security officer said, were not carried out for digging minerals, but organised by "criminal" elements. A company A employee added that it is not only mineral "theft" that occurs, but also theft of work tools. He made the claim that artisanal miners collaborate with the opérateurs des engins to steal fuel, electrical wires, and parts (company A exploration staffer, interview, October 19, 2016).

A fourth "resource" is financial: typically cash, but minerals also play the role of money at times. Money facilitates a myriad of interactions within the systems and processes that govern both corporate enforcement - such as when companies pay the security services, chiefs, and other actors to help enforce corporate PR - and authorised clandestine extraction. 
Finally, symbolic capital also plays an important role. Companies are more or less, depending on the specific firm, concerned with their reputations, including potential bad publicity linked to miner injuries or deaths. Customary leaders, including land chiefs, project themselves as repositories of traditional histories and values, both to defend their communities and, at times, for personal gain. Artisanal miners at times play on aggressive behaviour and on others' fear of them in order to achieve their goals.

The multiplicity of stakes adds to the complexity of property rights dynamics at and around the selected LSM sites. The nature of the conflicts is context-specific and should not be assumed to be strictly about minerals or land or something else, but carefully investigated.

\subsection{Critique of Property Rights Theory}

I now turn to the literature on classical property rights theory and provide a critical assessment, in three key thematic areas, of central assumptions and propositions of that theory. The three areas that I consider in turn are: enforcement and conflict; efficiency; and distributional impact. I also engage with the extent to which this body of theory applies to different aspects of LSM-ASM relations and conflict.

Classical property rights theory is predicated on a belief in the greater efficiency of clearly defined, well-enforced - often legal, formal and/or private - PR. A key underlying assumption of the property rights literature is that "there might be aggregate or collective economic benefits to a secure and well-defined property rights structure" (Libecap \& National Bureau of Economic Research, 1999, p. 4). Much of the literature on property rights to land contends that PR that are well defined and secure result in more efficient resource allocation and improved economic outcomes, whereas their absence is considered a hindrance for economic development. Demsetz (1967), in his influential Toward a Theory of Property Rights, notes that since under communal PR anybody can use a given plot of land, taking costs and benefits - i.e. negative and positive externalities - into account means everyone involved has to agree on how the land will be used. Demsetz in turn argues that with private property, negotiating costs will be much lower as there are far fewer parties involved. Galiani and Schargrodsky (2011) argue that security of land rights leads to more efficient allocation of resources as it reduces the likelihood of expropriation and promotes investment. They contend that secure land rights make resource allocation more efficient by enabling market transactions. PR theory rests on the belief that for resources of a high value, when there are many competitors and, frequently, new entrants, more clearly delineated and enforced resource governance arrangements, namely property rights, are needed. It is contended that 
the state's authority is typically needed to augment informal checks on resource use and access (Libecap \& the National Bureau of Economic Research, 1999). Libecap and the National Bureau of Economic Research argue that some parties - like, in this study, artisanal miners - resist changes because of their perception that they do better under the existing arrangement. Feeny, Berkes, McCay, and Acheson (2000) argue that some users' noncompliance and the resulting de facto open access has led some to assert that property rights can be better protected when the property regime is private rather than state managed. They contend that privatising a resource typically results in incentives for resources to be exploited in a rational manner. PR theory therefore embraces well-defined, well-enforced and often, though not always, private - rights to property. Yet as I show below, several scholars have argued that communal property rights do not mean unregulated access to land for all.

Early PR theorists as well as some working more recently argue that private property is economically efficient, compared to resources that are open for access or communally managed. Conventional property rights theory developed for Europe and North America predicts that as resource values rise, the benefits to private ownership will eventually be greater than the associated costs, and private property rights will naturally emerge (Demsetz, 1967; Fitzpatrick, 2006), i.e. the "evolutionary theory of property rights". As Fitzpatrick (2006) argues with respect to Demsetz's work, “[1]aw-and-economics orthodoxy suggests that the emergence of property rights is a story of evolutionary success." (p. 998) According to this approach, rational actors will see that factor prices are changing or new technology is emerging, and will want to capture the benefits (Mwangi, 2007). As Fitzpatrick notes, while many of the examples supporting Demsetz's arguments were cases from North America and England, the same theoretical predictions could also be expected to apply in the rest of the world. Another well-known property rights theorist, Ronald Coase, Fitzpatrick notes, argued that "when transaction costs were sufficiently low, it would not matter which resource user was allocated a property entitlement or assignment of liability. So long as the allocation was authoritative and enforceable, market bargaining would produce the most efficient result.” (p. 1006) Demsetz concluded that private rights to property would develop as a reaction to altered conditions related to costs and benefits, a relatively seamless process (Fitzpatrick, 2006). The institutionalisation of private property has been linked to variations in prosperity across the world's regions (Acemoglu and Robinson, 2012; Libecap, 1986; Frederiksen, 2019). In development theory, Acemoglu and Robinson (2012) argue that the evolution of 
favourable economic institutions, namely a relatively equitable allocation of PR, provided the impetus for investment and innovation in countries like the US.

PR theory, as noted in the literature review, has been frequently applied to land and other natural resources. This body of theory has also been extensively critiqued and adapted, by scholars within and outside the field, particularly when it comes to dynamics in the Global South. Property rights enforcement in the context of LSM investment comes with distinct theoretical and ethical implications not fully developed in or captured by earlier versions of property rights theory: later adaptations provide useful insight. In the following sections I present three critiques of property rights theory, linked to its applicability to LSM in Africa.

\subsubsection{Part One: Enforcement and Conflict}

As noted, PR theory argues that when the value of a resource goes up, demand for property rights increases. Property rights, the theory goes, make it possible for investment to benefit society, and for resources to be well managed. Yet this approach presumes that resources are not already well managed through other mechanisms than clearly defined property rights and, more importantly, that property rights are supplied and enforced. As Daniel Fitzpatrick argues, the supply of property rights is not always a given in regions where statehood is rhizomatic. My property rights-based theoretical framework builds on different scholars' critiques of PR theory and their applications of the theory to evidence from the "Global South".

Demsetz made optimistic predictions regarding the emergence of private property in contexts of appreciation of resource values. Yet this early formulation of property rights theory can't be assumed to apply everywhere around the globe. Many of the dynamics around mining investment are not well captured by the predictions of early PR theorists, much of whose work was developed to explain the emergence of private property in Europe and North America (Fitzpatrick, 2006). It is not only the demand for PR definition and enforcement that matters, but also the extent to which governments have incentives to supply property rights (Alston, Harris, \& Mueller, 2009). In much of the "global South", the state cannot or will not enforce rights to private property in a way typically associated with the Weberian state Haddock, 2003; Fitzpatrick, 2006; Brozus, 2011). Early property rights theory therefore has limitations when it comes to shedding light on LSM in the DRC, but later theorists' work provides insight into the fact that the granting of mining concessions to LSM companies often leads not to favourable economic outcomes but to persistent conflict. In many resource-rich 
countries of the "global South", where the growing population and the expansion of trade have - in line with PR theory - led to rising resource values, Fitzpatrick argues, many "property systems remain plagued by widespread legal uncertainty, resource conflicts, and environmental degradation.” (2006, p. 999) Customary social norms that previously allowed for the rational management of resources in common have become degraded, often as a result of state intervention where the state is characterized by weakness or illegitimacy. Multiple actors lay claim to resources but are unable to enforce the exclusion of other parties. The result is a long-lasting situation of "contested access" (Fitzpatrick, 2006, p. 1047). Local norms and institutional arrangements remain highly relevant (Bruce \& Mearns, 2002; Ostrom, 2009). ASM, as argued by Siegel and Veiga (2009), "nearly always progresses in advance of the legal system, which arrives only after customary practices and informal social arrangements are established.” (p. 52)

To argue that the reality in the DRC is different is not to buy into modernisation approaches according to which the Global South is, or should be, evolving towards European or North American "modernity". The key point is that PR transformation is messy and highly unlikely to be as simple as a government setting aside a large concession for a mining company. Artisanal miners who rely on mineral deposits in concessions granted to large-scale mining lack livelihood alternatives that can employ sufficient numbers of miners (Hönke, 2014) or, simply, that are acceptable to them. Miners therefore continue operating in these concessions, leading to repeated confrontations with private or public security forces (Hönke, 2010). Complexity, contestation, and conflict endure, companies' efforts to fine-tune their CSR notwithstanding (Katz-Lavigne, 2016). The persistence of overlapping, unresolved claims to resources demonstrates that as Mwangi (2007) argues, the transition to private property is far from smooth. Theorising property is therefore crucial when it comes to LSM in the DRC. Despite its limitations, property rights theory describes several approaches available to parties to secure and defend their rights to property (Fitzpatrick, 2006), which makes it a useful analytical tool for understanding the range of "hard" and "soft" practices through which MNCs enforce their property rights (Hönke, 2009; Hönke, 2014).

Fitzpatrick (2006) also points to the importance of the supply of property rights, not simply the demand for PR on which the theory typically concentrates. He points to "the inherently contested nature of formation and change in property rights systems [...] property rights are both a result and a cause of resource conflicts.” (p. 1008) Property rights are therefore processes and outcomes of continuous bargaining, contestation, and cooperation. According to Fitzpatrick, Demsetz and Coase don't take into account the fact that the process 
of defining and enforcing a given allocation of PR will itself lead to externalities manifested as social conflict. Since attempts to establish and secure property rights lead to new manifestations of conflict, he argues, the normative implication that states in the Global South should seek to create secure property rights is impractical. Fitzpatrick contends that the literature on law and economics has not sufficiently considered exclusion, i.e. the enforcement of rights vis-à-vis the rest of the world. In the Global South, as Fitzpatrick contends, "[u]nless social order is established, most commonly through legitimate and capable government, the process of allocating and enforcing property rights will tend to cause conflict because different claimants will resort to competing legal, normative, and coalitional enforcement mechanisms." (p. 1010) In many societies throughout the Global South, non-state systems for governing resources (like those based on kinship networks) have developed independently of, and frequently in a manner contradictory to, institutions of the state. The fact that property rights are protected in law doesn't necessarily mean they're legitimate in the eyes of the population, simply that they have legal status (Fitzpatrick, 2006). Therefore, property rights like legal rights to land may be granted but will not have much impact on the ground if not enforced (Libecap \& National Bureau of Economic Research, 1999; Galiani \& Schargrodsky, 2011; Feeny, Berkes, McCay, \& Acheson, 2000). Fitzpatrick concludes that the result will be open - or, perhaps more accurately, contested - access rather than property rights of a secure nature.

Fitzpatrick's contention can be applied to the granting of legal property rights for large-scale mining in Africa: LSM overrides large numbers of existing rights and claims, including those associated with ASM. While ASM is often viewed as the factor resulting in conflict between LSM and ASM, the attempt to grant PR to companies in such contexts is the initial spark. Governments may define the rights of indigenous peoples and/or artisanal and small-scale miners but are often unwilling or unable to ensure that these rights are enforced or compensated for (Carstens and Hilson, 2009). As Diemel (2017) describes, the DRC in its 2002 Mining Code

officially recognised artisanal exploitation and trade, allowed for the creation of artisanal mining zones (zones d'exploitation artisanale) and established a Mining Registry (Service du Cadastre Minier) responsible for promoting mining property security and the transparent handling of applications through standardised licensing procedures. (p. 109-110)

Yet in southeastern DRC, the creation of areas of artisanal extraction has been very limited. Fitzpatrick's point that the distributional effects of (land) titling are the cause of enduring conflict in the first place is therefore relevant for LSM: land dwellers or users have 
been dispossessed by groups with more wealth and power. In the case of LSM-ASM conflict in the DRC and elsewhere in Africa, state intervention has included the granting of large mining concessions to LSM companies. Crucially, the new holders of these titles, and the structures in place for state enforcement, have been unable to prevent the previous occupants from encroaching for reasons including the fact that they have typically not recognised artisanal miners' claims or provided them with compensation for lost access. The persistence of plural, intersecting and contested property rights regimes globally therefore highlights the limitations of some formulations of PR theory (Fitzpatrick, 2006).

Fitzpatrick (2006) contends that while an approach focused on the cost of PR creation and enforcement can contribute to an explanation of the non-emergence of PR, it is not sufficient to explain contested or open access. He argues that it is necessary to take into account institutional processes. Drawing on Robert Ellickson's three categories for grouping mechanisms of social control, Fitzpatrick refers to first-, second-, or third-party means through which parties can enforce their rights to property. Actors can utilise first- (selfenforcement), second- (coalitional), and third-party (drawing on the state or another powerful actor, like an armed group) approaches to enforce their property rights. First-party measures involve unilateral enforcement, which does not have to include force but could simply involve fencing off land against encroaching parties. Defensive mechanisms of the self-help variety often lead to the loss of resources. If first-party enforcement is not possible or is against the law, or those who claim property seek to minimise costs, second-party measures imply working in collaboration with other claimants to come to a private arrangement. Alternatively, property claimants can engage in third-party measures, which involve recourse to intervention by an outside actor - generally the state, though in contexts where statehood is rhizomatic parties may seek assistance from the state less often. The possibility of defending a resource given a heightened risk of incursions will hinge on the accessibility and type of coalitional backing, and "sociopolitical authority" (Fitzpatrick, 2006, p. 1019).

According to Fitzpatrick, conflict is likely to remain unresolved in the following circumstances: the two groups seeking to control the resource are an even match and the state cannot, or will not, assist one of the groups to fully exclude the others; the resource is so economically and socially significant that neither of the two parties is willing to transfer it; the production arrangements utilised by the two groups are incompatible; the issue is high-stakes; and there's a sufficiently large number of resource users to make it impossible to come to agreement on how the resource is to be used. Shifts from common to private property that are not consensual may necessitate enforcement by a third party like the state, but they could also 
be enforced through first- or second-party means. There is an assumption in this theoretical finding that agencies of the state are to a certain extent willing and able to engage. Yet state bodies have their own limitations on the supply side. Therefore, Fitzpatrick contends, pluralist interactions between law and norms are crucial for comprehending widespread land conflict in the Global South. Even when states are benign - often not the case in the DRC - state bodies may simply favour their own interests. In a context of state capture by "minority interest groups", state organisations "may grant rights to cronies without necessarily incurring an obligation to compensate dispossessed occupiers, because those occupiers either lack formal property rights or sufficient access to judicial institutions.” (p. 1041)

In much of Africa, the formal legal system is not the only - nor, in some cases, main institution responsible for the allocation of property rights. In a number of countries PR to land have long been allocated through informal institutions like customary authority and artisanal-mining systems of functioning (Geenen, 2012; Geenen, 2013; Bolay, 2014). In the $\mathrm{DRC}$, the national legal system is being increasingly used to allocate PR to foreign investors, displacing informal institutions for PR allocation, which includes the dispossession of ASM (Katz-Lavigne, 2016).

Property rights theory therefore provides insight into continued ASM-LSM conflict. As noted, Libecap \& National Bureau of Economic Research (1999) contend that the poor definition of rights, or their weakening by a group of actors or by the state, becomes more severe if the parties involved are very different when it comes to key characteristics including expectations, expenditures, resources, and size. Resistant parties can be compensated with side payments, but there can be disagreement over the amount of the transfer; its timing and nature; and which parties get the payment. Information problems pose another challenge because the parties have to agree "on the value of current holdings and of any losses that some parties expect as a result of the new definition of property rights." (p. 11-12) The emphasis in some of the literature and in policy efforts dealing with LSM-ASM conflict tends to be the attenuation of MNCs' property rights due to artisanal miners' presence, rather than addressing the attenuation of ASM miners' rights. LSM companies frequently do not make side payments to miners that lose access to minerals, for reasons that include not only the cost but also companies" unwillingness to recognise "illegal" miners as legitimate actors and interlocutors. When artisanal miners' rights to resources have not been assigned, or are not recognised for mitigation or compensation measures, there is potential for conflict particularly when compensation is not provided or is not sufficient to satisfy all parties (Libecap, 1986). According to Alston, Harris, and Mueller (2009), in the presence of 
resistance to dispossession or of disputes over compensation, violence would not be expected where "the government allocates and enforces rights, reducing the potential for conflict because we assume that governments have a comparative advantage in violence." (p. 6) As noted above, that is not always the case in the DRC. Property rights theory therefore sheds light on the micro-dynamics of how overlapping and unsettled claims in the LSM sector can lead to persistent conflict, even as this conflict influences and reconfigures coalitions of interests that align to seek rents from what has been a profitable sector for some actors (Geenen, 2012; Geenen \& Hönke, 2014; Katz-Lavigne, 2016).

Fitzpatrick's argument, while detailed and well supported, has limitations. His contention that these dynamics will result in enduring uncertainty and conflict is overly deterministic and should be assessed against the empirical record. As I argue in this study, local resource governance mechanisms demonstrate persistence in adapting to even significant shifts in the property rights dispensation. Another limitation of Fitzpatrick's approach is the line he draws between "state agencies" and "nonstate coalitions" (p. 1043). As the discussions of statehood and governance above suggest and as I show in the empirical section, the state/nonstate distinction is not clear in the mining sector in southeastern DRC.

\subsubsection{Part Two: Efficiency}

As shown, several influential property rights theorists have argued that enhanced property rights, particularly private PR, lead to greater economic efficiency and improved economic outcomes from a societal perspective. Yet some scholars have argued that the connection made between common-property resources and the unsustainable exploitation of resources is problematic. Feeny, Berkes, McCay, and Acheson (2000) argue that while the specific property-rights regime for the management of a given resource does matter, simply knowing the nature of the regime is not enough information to "draw valid conclusions concerning behavior and outcomes." (p. 5) They argue that the conflation of open access and common property led to many misinterpretations. The authors assert that there is a need to understand a wide range of institutional arrangements that govern resource access and use. Feeny, Berkes, McCay, and Acheson argue that there is ample empirical support that social groups are able to create, employ, and adjust mechanisms of a frequently inventive nature in order to assign use rights to members. People have the ability to coordinate; monitor members' resource usage; assign members the right to use resources; and modify overall utilisation of the resource. Within the Institutional Analysis and Development (IAD) 
framework, Ostrom (2009) argues that there is a broad range of institutional assemblages that people develop for overseeing, delivering, and administering common-pool resources and goods of a public nature. Ostrom argues that groups and individuals are able to get organised and resolve social problems like the under-delivery of public goods.

According to this body of theory, clear property rights granted by central governments to MNCs should allow for productive investment in mining and increased economic efficiency. This is particularly the case when viewed in comparison with supposedly inefficient artisanal and small-scale mining, said to be characterised by low-quality property rights allocation and enforcement (Geenen, 2014). This body of theory has echoes in African policy-makers' assumptions regarding the larger overall contribution to the economy from granting PR to LSM enterprises, particularly compared to the seeming absence of clearly defined rights and responsibilities at ASM sites and the fact that they supposedly do not pay into national taxation systems. International financial institutions like the World Bank and the International Monetary Fund were instrumental in pushing for LSM-friendly mining codes in countries like the DRC (Geenen, 2012; Campbell, 2010).

In formal systems of law and PR theory, the emphasis has been on the ability to transfer rights (Meinzen-Dick \& Mwangi, 2009). Yet around the world, many societies view resources like land as held by a group rather than any individual, and therefore as more costly and difficult to transfer. Mwangi (2007) argues that

the process by which property rights change is so full of politics, that to better understand this process of change, we need to move beyond economic models of relative price changes and state enforcement, to models that accommodate competition by actors and the possibility that state actors may not necessarily provide the arbitration/enforcement that is often taken for granted. (p. 817)

Mwangi (2007) finds that the efficiency gains that property rights theory predicts will result from private or individual title may be much smaller than expected due to persistent competition and conflict. The form conflict takes, and how intense it becomes, is a function of the degree of concentration of benefits in the new dispensation, and the diversity of interests among parties. The results of bargaining are dependent not only on actors' influence and power, but also the extent to which the new distribution is congruent with institutional norms in place. Certain actors may have recourse to the state's authority to put an end to the conflict. Actors with more resources and a stronger position may be able to impose their will on weaker parties. Yet even parties with fewer resources - like artisanal miners - may have some influence, potentially resulting in recurrent conflict (Mwangi, 2007). Similar lessons can be applied to countries in which LSM investors are granted PR that overlap with existing claims 
(Katz-Lavigne, 2016). Mwangi's argument calls into question claims that LSM is the most efficient form of extraction.

Ideas surrounding the greater economic efficiency of LSM compared to ASM have informed policy in countries in Africa, including the DRC, where ASM is widespread. Policymakers have suggested that ASM should be formalised to make the sector more efficient and less exploitative (Geenen, 2014; Hilson \& Potter 2005; Banchirigah, 2008). By contrast, the LSM sector has been presented as more responsible, less chaotic, and less exploitative, including in recent policy initiatives in the cobalt sector (Katz-Lavigne, 2019). Rather than assuming that LSM is characterised by better-developed or enforced property rights and therefore automatically more efficient than ASM, there is a need for in-depth investigation. In the case of ASM, property rights are not necessarily insecure to begin with (Geenen, 2012). While ASM has been presented as poorly organised and chaotic (e.g. World Bank, 2016) due to the absence of clear rights to property, artisanal miners frequently operate on the basis of customary title to resources, which they typically view as more durable and legitimate than legal rights. In the DRC, artisanal gold mining is highly structured and locally adapted (Geenen, 2012; 2013). Implementing a "formal" system is likely to upend "existing dependencies, reciprocal relations and power balances" (Geenen, 2012, p. 324). LSM investment disrupts and reconfigures existing claims to resources, be they formal or informal, based on customary law or habitual usage (Geenen, 2012; 2013). The LSM sector in the DRC has also been characterised by large-scale corruption and mismanagement. LSM companies also take substantial amounts of wealth out of the country compared to the economic contribution they actually make in country (Campbell, 2013). Emerging research on the DRC examines the productivity of LSM compared to ASM, and how LSM is displacing the burgeoning, domestic ASM sector (Radley, 2019). These trends further highlight the need for empirical evidence on the actual economic outcomes associated with a given property rights arrangement (e.g. Campbell, 2013; Geenen, 2012; Radley, 2019).

Finally, Fitzpatrick (2006) argues that "law should support property norms when they are efficient" (p. 1012). One may not agree with his viewpoint on the importance of economic efficiency. Geenen (2012), for instance, questions whether ASM does in fact need to turn a profit and to be efficient. The fact that ASM is a lucrative business for local people, particularly compared to the available alternatives (Teschner, 2013) should be given more weight if local livelihoods really are a priority for policymakers. 


\subsubsection{Part Three: Distributional Impact}

The emphasis on conflict in some of the property rights theory literature, and in much of the literature on LSM and ASM, does not tell the whole story. The distributional impact of mining governance is a key part of the picture. I argue that the extent of exclusion at different sites has distributional effects for local communities, which are not sufficiently captured by some property rights theorists.

Much of PR theory does not interrogate the fairness of a given property arrangement, but focuses on economic efficiency and on the transaction costs that might make a supposedly more economically efficient private-rights arrangement difficult to enforce (e.g. Libecap \& National Bureau of Economic Research, 1999). Transaction costs are the resources needed to create and uphold property rights, and "include the costs of bargaining, information, measurement, supervision, enforcement, and political action" (Libecap \& National Bureau of Economic Research, 1999, p. 7). According to Coase, when property rights have been assigned - and given low or no transaction costs - bargaining can take place to ensure that resources are put to more productive uses. A version of property rights theory that acknowledges greater complexity came about following the new institutional turn in development economics, which brought recognition that the creation, definition, and enforcement of property rights is not transaction-cost free (Libecap, 1986). Therefore, given the complexity of private institutional transformation, change may be thrown off course by transaction costs. Negotiations may stall if the parties disagree about the net gains from institutional change or the distribution of benefits. These difficulties are expected to become more significant the bigger and more heterogeneous the group. The institutional change that would be expected in a context free of transaction costs might not happen. To create a stable (and supposedly more efficient) regime, therefore, it becomes necessary to provide side payments, or to restrict the rights given to other parties. Yet according to PR theory, these adaptations alter the planned regime's character as well as its capacity to foster new economic exchanges and investment (Libecap \& National Bureau of Economic Research, 1999).

Libecap and the National Bureau of Economic Research contend that insistence on compensation in a bargaining context indicates legitimate fears about a new PR regime's effects, as well as extortion or rent-seeking behaviour, but do not explain how they distinguish between legitimate concerns and rent seeking. The authors note that with respect to general efficiency, what matters is the extent to which property rights are completely defined, rather than the exact manner in which they are allocated. As noted, in a context of low transaction costs the way rights are initially attributed may not be of significance because the situation 
can be modified. Yet most market conditions are not like that: the structure of rights may have a lasting and potentially negative impact on distribution and production (Libecap \& National Bureau of Economic Research, 1999). The implication is still that the new, better-defined rights dispensation is likely to be more efficient, even as there is acknowledgment of the lack of guarantees that institutional modification will lead to rational use of resources and quick economic growth. The main concern is the potential obstacles to a supposedly more efficient PR arrangement, rather than its fairness. Distributional concerns are taken into consideration to the extent that they affect the regime's overall efficiency. While Ostrom (2009) and Galiani \& Schargrodsky (2011) address the informal title that prevails in much of the "Global South" - a situation in which smallholders' plots of land are vulnerable to expropriation - such analyses are to some extent concerned with how agricultural production can be enhanced, not fairness as such (Nyamu Musembi, 2007; Akram-Lodhi, 2007).

In later research on the development of property rights and why so-called "efficient" regimes do not always come about, there is some recognition that distributional issues, not typically taken into consideration by economists, matter and that "[h]ow the proposed rights arrangement blends with existing distributional norms affects its popular support and legitimacy.” (Libecap \& National Bureau of Economic Research, 1999, p. 3-4) Redefining authority over the making of decisions regarding the use of resources leads to changes in how wealth and political power are distributed. Yet again, the focus is divergence from a property rights allocation seen as necessary for complete efficiency (Libecap \& National Bureau of Economic Research). Galiani \& Schargrodsky (2011) do mention the endogenous nature of property rights, arguing that the way property rights are assigned across households is typically not random, but "based on wealth, family characteristics, individual effort, previous investment levels, or other mechanisms" (p. S336). In the Akwapim region of Ghana, Galiani $\&$ Schargrodsky argue, powerful people benefit from property rights more secure than those of others, like farmers.

These arguments show the need for evidence on the distributional consequences of a given property rights arrangement, not only because of the implications for conflict - the degree to which the community believes in the legitimacy of private rights to property has an impact on how much enforcement costs (Feeny, Berkes, McCay, and Acheson, 2000) - but also for fairness and equity reasons. When elites capture the state, poor or disenfranchised people's property rights to land are often weakened (Galiani \& Schargrodsky, 2011). The fact that local resource users are at times able to enforce communal rights to property, in certain contexts, does not preclude resource appropriation by groups with political or military power. 
Resource appropriation and the disruption of communal systems of organisation, as shown, have parallels in the realm of LSM-ASM conflict (Feeny, Berkes, McCay, \& Acheson, 2000). When African governments granted large-scale mining companies legal rights to mining concessions, many artisanal miners were cleared from their work sites without compensation. The lack of legitimacy of LSM mining contracts and concessions in places like the DRC (Hönke, 2010) is an issue to which the concept of transaction costs of enforcing a property rights arrangement perceived to be illegitimate by a significant share of the population does not do justice.

Yet, I argue, the absence of violence does not point to the inherent "justness" of a given distributional arrangement, but only shows the capacity of a set of governance mechanisms to define and impose a given allocation of resources. Completely barring all "unauthorised" parties from mining concessions would represent a very exclusionary arrangement, but a peaceful one, at least in the limited sense of negative peace and the absence of physical violence (Galtung, 1964). A focus on conflict restricts the analysis to those with the capacity to disrupt existing arrangements, yet large-scale mining has much wider distributional consequences (Katz-Lavigne, 2016). There is some recognition in PR theory of the link between an uneven wealth distribution, and conflict. Whether parties agree to a new structure of rights depends on the wealth distribution that results. Arrangements that are very distorted may result in insistence on resources being redistributed through additional negotiations; the failure to enforce ownership already in place; so-called "theft"; and violence (Libecap \& National Bureau of Economic Research, 1999). As Siegel (2013) argues, mining is lacking in an ethical framework. He notes that activity of

[T]his order of magnitude leaves no room for multiple uses of land and resources, especially the [...] mining economies upon which people depend in mineralized places. Endemic poverty, conflict, and ecological collapse in these regions are rooted in the inequitable allocation of resources. In such cases, winwin solutions are an illusion. Somewhere in the equation, somebody has to give something up.

Whether the profitability of mining is mutually exclusive with accepting the presence of large numbers of artisanal miners is, as I show, an empirical question. Arguably, what is lacking is a moral centre, or what Siegel refers to as the "missing ethics of mining". There are other criteria by which distributional outcomes resulting from LSM investment should be assessed - like whether this form of economic activity allows for a sufficiently high standard of living for local people (Geenen, 2012; Teschner, 2013) - rather than whether the cost of conflict is too high for an economically efficient outcome. However, as I contend in this dissertation, 
certain PR configurations at time result in more breathing room for artisanal miners. This doesn't necessarily mean that companies have taken a "moral" approach: they might have no choice for reasons including the size of their concessions, the number of miners, and - linked to the first two - the cost of adequately securing these sites.

Yet granting formal property rights is not necessarily a viable or desirable solution, particularly when solutions are imposed from outside by government officials (Ostrom, 2009). Ostrom's point that simple policy recommendations, like handing resources to a government to privatise, may not work is relevant in the context of the DRC, where the state's presence is often repressive. Galiani \& Schargrodsky (2011) also argue that the conclusion that increased security of tenure seems to lead to more investment and higher productivity in the countryside doesn't automatically mean land titling should be put into place. Some long-standing structures of land tenure, they contend, might be most advantageous after factoring in the transaction costs of administering land, which is to a large degree dependent on how strong the existing informal rights are. Some individuals may favour an arrangement in which property rights are not completely specified, which would make it possible for more redistribution to take place. If there is fairly open access - if people have prospects for mobility of an economic and social nature - there may be fewer demands for redistribution (Libecap \& National Bureau of Economic Research). In the DRC context, formalising ASM may lead to worse outcomes for the majority of miners (Geenen, 2012).

Understanding exclusion sheds light on the impact of LSM companies' security arrangements on distributional dynamics at the local level and therefore also on conflict. This emphasis does not mean successful exclusion of artisanal miners is desirable. Less "effective" corporate PR enforcement practices are likely to represent a more inclusive and equitable distribution of resources, and to be less conflictual. Companies whose property rights are better enforced and whose sites have less artisanal miner traffic contribute to a more unequal distribution of resources. A relatively "open" mine site for artisanal miners represents a fairer distribution than a relatively "closed" site. Security practices that result in greater exclusion from mine sites - when companies will not consider flexible options - have a significant impact for artisanal miners with few livelihood alternatives. Conflict highlights that distributional arrangements at the local level are not satisfactory in the eyes of some parties, who seek a more equitable arrangement through whatever means they can. The failure to compensate artisanal miners who have lost access to resources and to ensure a distributional outcome viewed as legitimate makes conflict more likely. Policy initiatives around LSM investment that focus on ending conflict should therefore consider the distributional 
consequences. While conflict is costly in human and material terms, a more conflictual situation may be more equitable.

In summary, distributional concerns underpin any given property rights arrangement (Libecap, 1986). There are distributional consequences to enclosing large areas previously mined by local inhabitants, including the configuration and reconfiguration of coalitions of actors in the different phases of a mining project (Fleury \& Davies, 2012). Rather than skipping over the messy middle, there is a need to examine the actors involved and the extent to which they influence or mediate processes of enclosure (Mwangi, 2007). Artisanal miners, communities and companies often claim the same resources, with a significant power differential between the parties (Libecap). Understanding the varying endowments of competing groups is important to infer how these endowments will impact the political and property rights outcome (Alston, Harris, \& Mueller, 2009).

\subsection{Applied Property Rights Framework: The Property Rights Regime}

The theoretical approach applied in this study, centered on how PR are enforced in contexts of overlapping claims, considers the measures on which mining companies and other resource users, like artisanal miners, rely to define and enforce their rights or claims to property in the DRC's LSM sector. As shown, earlier formulations of property rights theory are of limited usefulness for understanding the impact of LSM investment in contexts like the DRC. The granting of mining concessions to LSM companies often leads not to favourable economic or social outcomes but to persistent contestation and conflict over different forms of property. Theorising property is therefore important when it comes to LSM.

The theoretical framework applied in this study recognizes and takes into account multiple, intersecting and disputed elements of a PR regime (Fitzpatrick, 2006). As discussed, property rights are enforced through first-, second-, or third-party measures (Fitzpatrick, 2006) by a range of actors including companies, artisanal miners, and government officials. The question then becomes whether and how these practices or combinations of practices are related to more or less conflict. When does the existence of unresolved claims, in which no one claimant to a given resource can successfully exclude or co-opt the others (Fitzpatrick, 2006), lead to conflict?

Contexts such as southeastern DRC are broadly characterised by a political economy and structural features that increase the likelihood of conflict, like poor governance and rentseeking institutions; the large-scale misuse of public funds; significant inequality; and limited 
economic opportunities for the population. Yet these factors are not sufficient to explain why outbreaks of conflict happen at certain times, rather than continuously as Fitzpatrick (2006) predicted. I relate the incidence of conflict, and distributional outcomes in terms of different groups' access to, or exclusion from, mineral and other resources, to more proximate causes: the interaction between different facets of the property rights regime. Conflict at and around LSM sites in southeastern DRC is linked to the multiplicity of systems and networks that mediate artisanal miners' access to mine sites without company permission, and how these arrangements and systems interact with the practices of key players like companies and artisanal miners. I describe these networks in plural terms because they are multiple, overlapping, and frequently reconfigured. This plural property rights regime includes the corporate component (company practices); artisanal and small-scale mining; and local elites including customary authorities. I address each of these elements in turn, describing categories that I examine in more detail in the conflict chapter.

\subsubsection{Corporate Practices}

I conceptualise the corporate component of the property rights regime as the means companies employ, more or less successfully, to define and enforce their legal claims to minerals by deterring unwanted incursions. To the extent that there is a corporate component of the regime, it exists in hybridised form (Hönke, 2014). Schneckener (2011) refers to the security arrangements, of an informal or formalised nature, that emerge from external actors' need to work with local actors, and notes that these national-, regional-, or communal-level arrangements are often persistent. He uses the term nodal governance to describe a situation in which external actors become embedded in local politics in a way that can alter their role and/or identity. These outside actors may no longer be in command and control. This is a key point for, as Hönke (2013) highlights with respect to the security practices of transnational corporations, external actors' involvement and interventions of a liberal nature result in "hybrid regimes of practices", with ambiguous results when it comes to security at the local level, and political order, in different areas of the postcolonial realm (p. 21). I therefore do not use the term "local" to describe the constituent parts of the property rights regime at and around LSM sites or assume that transnational companies bring principled global practices and philosophies into local contexts characterised by corruption. As Hönke (2013) demonstrates using the case of southeastern DRC, corporate investment is neither purely local nor transnational, but a state of hybridity. Additionally, the Congolese economy and LSM 
sector have been tied to the global economy for so long, including during the colonial period (Geenen \& Hönke, 2014), that distinctions like "local" vs. "international" or "global" have limited analytical and empirical usefulness.

The need for companies to enforce their own property rights arises from, among other things, the fact that the selective enforcement of LSM property rights and of Congolese legislation on mining exacerbates social tensions and inequalities at the local level (Hönke, 2009). The Congolese state may be missing or ineffective when it comes to conflict resolution, so companies end up having to manage a range of security issues linked to the political economy of the DRC (Hönke, 2010). Mining companies operating in countries in Africa where statehood can be described as rhizomatic commonly employ first-party (selfenforcement) measures, including fencing off concessions. Mining companies create "fortresses" to keep out unwanted actors (Hönke, 2013), through the use of high security walls paired with razor wire (Abrahamsen \& Williams, 2017). Abrahamsen and Williams (2009) refer to a shift in how criminality is understood, which has led public authorities to make increased use of "techniques of crime control based on efficiency, surveillance, and spatial design" (p.4) - a point that can also be applied to how mining companies secure their concessions.

Firms involve multiple actors, like company security and private security companies, in their self-enforcement practices. The corporate investment realm showcases what Chojnacki and Branovic (2011) refer to as commercialised security. The authors contend that in areas of limited statehood, there has been growing fragmentation of actors participating in security markets, while security is becoming increasingly complex and fluctuates between a public and private good. When the state does not provide security, an alternative approach involves the state delegating protection tasks to commercial providers. The private sector becomes responsible for providing security, and protection is allocated only to those able to pay for it: one example is multinational corporations seeking to ensure resource access. In this type of context, statehood is transformed through processes of transnationalisation, privatisation, and commercialisation of state functions. Private and commercial security providers may be empowered (Schneckener, 2011). Brozus (2011) similarly explains how in what Chojnacki and Branovic (2007) describe as areas of strategic (in-security), security is not a public good but a scarce and privatised commodity. Abrahamsen and Williams (2009) also address the privatization of security and rapid expansion around the globe of private security as a commercial service. They describe the advent of "global security assemblages", i.e. "settings where a range of different global and local, public and private security agents 
and normativities interact, cooperate and compete to produce new institutions, practices, and forms of security governance." (p. 3) The authors make the case that the state's changing role in a context of neoliberalism has led to a situation in which security tasks once viewed as the state's dominion have been "privatized and outsourced" (p. 4), with a close connection to the proliferation of private security. The private sector becomes a third area when it comes to the provision of security, functioning in conjunction with the state's policing and corrective institutions.

The rapid expansion of private security, as noted, does not imply a disappearance of the state or of the public domain (Abrahamsen \& Williams, 2009). It may in fact (re)empower state bureaucracies and security bodies. In the DRC, the law does not allow PSCs to be armed. Therefore, mining companies rely on the national security forces for operations involving force (Hönke, 2010). What Hönke (2010) refers to as "indirect discharge" of duties from states to MNCs applies the other way around as well. Mining companies also tend to "discharge" some of their security duties to public security forces hired on a contract basis, like the Mine Police or the army. The Congolese police, for instance, provide support to the PSCs when there is a public demonstration or clashes with artisanal miners. Given that companies in the DRC have to work with the police, this type of "discharge" is a pattern across mine sites. By drawing on the public security forces, companies are also able to "discharge" responsibility when things go wrong and injuries or deaths occur.

Companies' need to position themselves as responsible corporate actors in a context of international scrutiny means they typically can't rely on self-enforcement or coercive measures alone. Second-party, private governance, also know as coalitional measures, in contexts where statehood is rhizomatic refers to the interplay of actors involved in the management of competition around the various claims. This governance takes place through informal agreements by actors that can include company representatives; local communities; artisanal miners; local and national authorities; workers' unions; and more. Companies' coalitions of interests (Fitzpatrick, 2006) or enforcement coalitions consist of the minimum number of actors required to secure a claim to resources. There is no institutional recipe; each coalition reflects the local context. The company simply seeks to build a coalition sufficiently strong to ensure the claim is respected. The creation of such coalitions can be based on norms, but also "purchased". Payments or benefits to officials (Frederiksen, 2019), pressure tactics and coercion, the hiring of certain individuals or groups, and the selective distribution of benefits are all coalitional, second-party approaches. Corporate social responsibility also falls into this category. Companies draw on community development plans, and include 
international NGOs, leaders from the local community, and policing actors who are not part of the state, to ensure corporate security using community engagement and development (Abrahamsen \& Williams, 2017). As Frederiksen (2019) argues, companies' CSR efforts "offer an important vector for gaining support from local elites and can help "glue" a political settlement together, improving operational security for large metals mines” (p. 164). By forming alliances with political authorities, companies strive for stability; MNCs engage with communities to limit discontent at the local level (Hönke, 2014). Yet if an enforcement coalition is not strong or sustainable, it may break down, in which case even powerful MNCs' claim can be - at least temporarily - challenged (Szablowski and Campbell, 2019). As Fitzpatrick (2006) points out, the "nature and availability of coalition support" matters (p. 1019). If coalitional measures are insufficient or fail, companies are likely to turn to the state for enforcement.

The corporate component also includes efforts to disrupt and undermine artisanal clandestine mining even as corporate investment makes it necessary for this mode of extraction to become clandestine in the first place. It is my contention that companies' choices are based on an assessment of the conditions at and around their mine sites as well as the resources and options available to them. Company representatives are aware - to a greater or lesser extent, since perfect information is expensive to gather (Anderson \& McChesney, 2003) even for a mining corporation - of the PRR and potential impact of certain choices in the security domain. Corporate operating procedures and principles matter but are enacted in consideration of the PRR. Mining companies' priority is to ensure the viability of their investments (Hönke, 2018), even if they have to rely on "institutionalised arrangements of clientelist exchange between firms and local power holders" (Hönke, 2013, p. 4), which includes corporate support for leadership by conservative traditional leaders with the aim of silencing local dissent. Companies employ indirect rule and also use co-optation as a strategy. They collaborate with powerholders at the local level to create social order, whether or not these actors are viewed as legitimate (Hönke, 2013). Corporate investment and mining firms' property rights enforcement practices are both key constitutive components of the PR regime and respond to the functioning of the regime in which they play a major role.

With respect to third-party measures (recourse to the state), offficials and representatives of the police or even the army, and officials at the local level, are often called upon to help enforce companies' PR. Yet in the DRC, the state primarily does so on a contractual basis in exchange for payment (Hönke, 2014). Companies' use of state security forces like the police to enforce their property rights can therefore be viewed as a first-party 
(self-enforcement) measure disguised as state enforcement, given that state agencies act like a private security firm for hire (Hönke, 2010). State actors' involvement - often based on private interests (Hönke, 2009) - can also be viewed as second-party or coalitional measures, rather than the broadly accepted, legitimate third-party state action often assumed in property rights theory (Fitzpatrick, 2006).

Another option for companies is to enforce their property rights only in part. Withdrawal can be viewed as a strategy for corporate security (Hönke, 2014) and/or protecting shareholder or reputational value. As Fitzpatrick (2006) describes, if a resourcerich area represents a vital supply in terms of resident groups' rituals, livelihoods, and social insurance, keeping those communities out might lead to so much conflict that companies will rationally decide not to try to fully exclude other parties. The other groups claiming the resource value it so highly that it is prohibitively expensive to try to exclude them completely. The outcome could be a stable one, with the firm choosing not to exclude these parties from (for instance) some areas of the mine site (Aubynn, 2009).

\subsubsection{Artisanal Mining in LSM Concessions and the Role of Local Elites}

The theoretical framework takes into account the practices, coalitions, and alliances put into place by artisanal miners - who have far less power and fewer material resources than mining companies - to ensure their access to mineral resources. Miners, too, deploy first-, second-, and third-party measures to enforce their claims vis-à-vis mining companies. Miners' first-party (self-enforcement) measures can be non violent, like sneaking into a mine site. Their practices may also include aggressive behaviour (loud speech, threats, etc.) or the use of force: throwing stones and hitting, or even injuring someone with a mining tool. Miners' second-party approaches include coalitional measures that draw on other resource users. In line with Chojnacki and Branovic (2011)'s discussion of "commercialized security" (p. 93), artisanal miners, too, have to pay for security provided by the state or the private sector. State security forces and PSC guards don't just act as footsoldiers for MNCs but have significant agency and the ability to implement their own agendas as well. Many artisanal miners operate in LSM concessions with assistance and protection from the security forces. Therefore, artisanal miners, too, have to pay for PR enforcement and protection. Since miners pay for this access, these types of practices can be viewed as self-enforcement, but also as coalitional measures. Artisanal miners rely on alliances with other actors or resource users, particularly the security forces that guard the mines, which include alliances they pay for. Schuppert 
(2011) provides theoretical insight into artisanal miners' entry into LSM sites, facilitated by the security forces. In a discussion of statebuilding in areas of limited statehood, Schuppert argues that "private ordering" (p. 67) can make it possible to address conflict without having to appeal to a third party like the state. If regulation is demanded and can be provided in an efficient manner by networks, networks already in place will tend to adapt to fill the need. Schneckener (2011) notes that there is variation in terms of the level of formalisation and institutionalisation of such "transnational governance" arrangements, as well as their duration. Li (2018) describes how government representatives and a number of other actors, including brokers, benefit financially from plantations through a range of illicit measures like corporate bribes. As Li demonstrates in the case of oil palm plantations in Indonesia, "law, government, livelihoods and the scope for protest action are progressively subordinated to plantation logics" (p. 330). At LSM sites in southeastern DRC, customary authorities, local elites, the central administration, and local and global NGOs all shape outcomes in the mining sector (Geenen \& Hönke, 2014).

Like companies and artisanal miners, therefore, local elites and authorities also implement strategies to secure access to resources. They apply a mix of first- (selfenforcement), second- (coalition), and third-party (drawing on state authority) practices to enforce their rights and claims to resources and associated rents. In the DRC, since the mining sector relies on the state security bodies when it comes to the use of force (Hönke, 2010), police officers and, sometimes, members of the army have armed access to lucrative LSM concessions. PSC employees are also deployed to these sites and regulate access to them with tools like batons and guard dogs, or simply the corporate authority instilled in them. Regarding coalitional measures, elites and other local actors draw on alliances with companies, which negotiate with local powerholders like customary chiefs. Local elites use these arrangements to benefit from LSM (Geenen \& Hönke, 2014; Frederiksen, 2019). Companies' and other actors' coalitions of enforcement are not mutually exclusive, but overlap: actors responsible for securing mining concessions often play a dual role in allowing outside parties to access mine sites, as shown by the Glencore example (Peyer, Feeney, \& Mercier, 2014) and Ngoie Mwenze (2009)'s discussion of the Gécamines case. Rather than a clear distinction between public actors playing public roles and public actors pursuing private interests, there is overlap in the case of LSM sites, as I argue when it comes to the governance of clandestine mining. Local actors called upon by companies to secure their concessions play a role as gatekeepers for less prosperous members of the community, including artisanal miners. Local elites therefore ally themselves, at times, with artisanal miners. I elaborate on 
this blurring of roles in the substantive chapters. Finally, in terms of third-party (state) enforcement measures, while the Congolese state has a limited physical presence in some areas, it possesses political and economic reach when it comes to lending authority to firms' PR or to local authorities' claims to clandestine mining rents. Even when the state cannot enforce these rights, they have political effects, like allowing companies to claim their actions are legitimate even if they violate national legislation (Premicongo, 2015).

Olivier de Sardan's (2008) analysis of governance and what he terms "practical norms" in Africa and Bierschenk's (2019) historical and contemporary assessment of policing around the world provide important insight for understanding governance and security practices at LSM sites. These practices differ from an ideal type of security, policing, and potential complete exclusion of ASM miners, unlike the common assumption that company security functions the way companies intend it to. In Olivier de Sardan's examination of "practical norms", he argues that scholars often use too-general, catch-all terms like "clientelism", "neopatrimonialism", and/or "informality" to describe "real governance" in Africa. Olivier de Sardan notes that the vast literature, in a range of fields, on the African state, administrations, and public services agrees on one key point: there are significant gaps between the official norms that institutions are governed by, and how these institutions' agents actually behave. Neopatrimonialism refers to the non-respect in practice of distinctions between public and private property, while clientelism describes favouritism practices, including granting employment, that diverge from an official norm regarding impartiality. According to Olivier de Sardan, these terms provide an incomplete understanding of the reality they are meant to describe. Such catch-all terms obscure a much more diverse set of practices, which require in-depth research to move beyond easy generalisations about African cultural practices that neglect colonialism and other factors. While "real governance" does exhibit many characteristics associated with neopatrimonialism, clientelism, and informality, he emphasizes that this type of governance is not homogenous, but multidimensional and resulting from several types of microdynamics (local, sectoral, and individual). According to Olivier de Sardan, practical norms - unlike social norms - are informal in that they are left unsaid and untaught. He refers to a "vertical" plurality that operates alongside the "horizontal" plurality that is better known: in vertical plurality, practical professional and social norms are hidden beneath the "official" or "formal" professional and social norms. Practical norms can be further classified according to how consensual they are; who is involved; whether they are explicit or implicit; and more. Some practical norms that contradict the "official" ones may be nearly formalised, like - importantly for my purposes - 
illicit gains shared among members of the police. These rents benefit local elites but are also passed up the chain in keeping with the typical Congolese system of rapports (two miners, interview, March 16, 2017; Mine Police officer, interview, April 14, 2017; two miners, a trader's wife, and a woman who sells firewood, interview, April 10, 2017; Thill, 2019). The rapport is a common reality across different Congolese public bodies and elsewhere in Africa (Thill, 2019), as Blundo and Olivier de Sardan (2001) described for West Africa.

Olivier de Sardan also argues that researchers have much less frequently studied the potential positive impacts, such as economic growth and public policies that could benefit the poor, of different elements of real governance. As Hoffman and Kirk (2013) note, "much of the literature neglects to ask why clientelism and patrimonialism leads to fragility in some cases, while in others it may be integral to more positive transitions.” (p. 6). Brozus (2011) argues that challenges in areas of limited statehood include the fact that political authority is not dependably restrained and there is under-provision of welfare benefits. Yet according to Brozus, some rudimentary governance services may still be provided without "modern" Organisation for Economic Co-operation and Development (OECD)-type statehood. In the LSM sector, artisanal extraction is likely to be more locally legitimate than corporate alternatives that rely on formal employment and CSR programmes of limited scope and reach (Geenen \& Hönke, 2014; Hönke, 2014).

\subsection{Plurality and "Unsuccessful" Exclusion}

As shown, companies and other actors draw on a range of context-specific practices to try to enforce their legal rights. The combination depends on factors including the extent to which competition over the resource is intense (Alston, Harris, \& Mueller, 2009) - the demand side - as well as factors related to the supply of property rights, such as state capacity or the capacity and legitimacy of companies, customary authorities, or any other actor. The main point is that despite multiple practices and tools, mining companies operating in contexts like the DRC are not always "successful" at enforcing their legal property rights.

Yet plurality, or the coexistence of multiple components of the regime, does not mean that dysfunctionality and conflict are inevitable. A situation in which a company chose not to enforce its property rights (or decided to do so only partially) could be "peaceful" to a large extent, at least in Galtung's (1964) sense of negative peace as the absence of violence. Similarly, if artisanal miners decided not to press their claims to mineral resources at LSM sites, there would be little conflict escalation. If communities resist corporate enforcement, however, companies' "hard” practices (Hönke, 2009) may be more likely to result in violence 
(Steinberg, 2015). Conflict implies actions on both sides to enforce claims and rights that are perceived as mutually exclusive, which neither party is able to successfully enforce to the full extent. Informal arrangements may be fragile (Katz-Lavigne, 2016). If the different components' rules are not consistent with each other, or overlap, conflict can result.

From PR theory, Ostrom's (2009) factors that differentiate PR regimes that last from those that are unsuccessful provide additional insight on LSM-ASM conflict in the DRC. First, while LSM companies define their borders in a clear manner through "fortress protection" (Hönke, 2013), the literature on ASM-LSM conflict suggests that there is no clear boundary between mineral resources and the wider social-ecological system, given the continued pervasiveness of ASM as a livelihood activity for local people. Regarding whether rules for provision and appropriation of a resource are in harmony with social circumstances, the presence of tens of thousands of miners operating within LSM concessions in southeastern DRC demonstrates the lack of harmony between property rights for LSM companies, and the reality many local people want. As for the distribution of costs and benefits, as shown in the literature review, local people disproportionately bear the costs/negative impacts of LSM, while seeing few of the benefits. With respect to participation in rule making, the resource regime associated with LSM affects many members of the local population, but they frequently have no or limited input in the creation of the rules. Settings and opportunities for conflict resolution, meanwhile, are not always available when it comes to ASM-LSM relations, and LSM companies at times engage in little consultation with local communities (Hönke, 2018). Finally, in the DRC, the government is resistant to having the local population weigh in on how resources should be managed.

What Fitzpatrick (2006) describes as contested access may therefore result when, as in much of Africa, states provide commercial actors with licenses, with little agreement or involvement by the local population. Communities dependent on the resource have specific normative ideas about property. They may place such a high value on the resource that they are willing to use significant resources to gain access to minerals. Mining license holders may not be able to deter incursions from artisanal miners (Fitzpatrick, 2006). Yet artisanal miners dependent on minerals in LSM concessions cannot press their claims as much as they want to, given that state bodies provide backing for the holder of the license, and corporate resources far outweigh those available to miners. The outcome of the clash between "legal and normbased systems is likely to be community resentment and acts of sabotage or encroachment in the concession zone - in short, a regime of open access based on incomplete or deadlocked acts of exclusion by resource users." (Fitzpatrick, 2006, p. 1020) 


\subsection{Variables and Main Hypothesis}

The dependent variable (DV) is the level of conflict. The focus is on conflict generally rather than on violence or violent conflict, though the latter is a significant part of the conflict phenomenon at and around the case-study sites. Media coverage of conflict at LSM sites in southeastern DRC tends to focus on high-profile incidents, yet conflict between companies and artisanal miners also includes many lower-level manifestations. Conflict is therefore a continuum rather than a binary. Defined in broad terms, conflict "is a struggle or contest between people with opposing needs, ideas, beliefs, values, or goals" and "denotes the incompatibility of subject positions" (Pia \& Diez, 2007). These incompatible positions are quite stark in the case of LSM and ASM, as large-scale mining companies seek to keep to themselves a valuable resource to which artisanal miners also lay claim, and have done for years - though as I argue, in the context of clandestine extraction there are also some overlapping interests. Operationalising this variable for the purposes of this study, however, requires narrow down the definition to some extent. For the purposes of this study I approach the conflict variable as including a range of manifestations, from no conflict, to tense interactions and the implicit threat of violence, to the explicit threat of violence, to the use of force to injure or sabotage and, finally, the use of force to kill, whether or not death results from the action. I acknowledge that conflict is a multi-faceted phenomenon and has broader manifestations than laid out in this study's operationalisation of the variable, including as highlighted by Galtung (1969) in his analysis of the phenomenon of structural violence. Conflict also reflects overlapping issue areas and governance dynamics, as argued by Mathys and Vlassenroot (2016) in their discussion of land and conflict. These aspects of conflict are foregrounded at various points in the dissertation, yet for clarity of analysis, I focus on more immediate manifestations of conflict that occur periodically at and around the mine site.

The independent variable (IV) used in this study is the functioning of the property rights regime. Specifically, the IV centers on the quality of the property rights, namely the extent to which these PR are defined and, most importantly, enforced. This factor depends, as discussed, on the cost of PR provision. Daudelin and Ratton (2018) define an overt market as one in which "physical exchanges [are] public, visible, and usually grounded in a particular space (even if that space "moves around" - within a certain area" (p. 31). Supplying property rights is less costly when a given market is covert. The overtness-covertness dimension is a key factor that influences conflict incidence, which is particularly salient when it comes to conflict between corporate extraction and authorised clandestine mining. Conflict results in cases when corporate patrols threaten to render covert clandestine extraction practices 
unexpectedly overt, or when a mine collapse and the deaths of multiple miners draw publicity to miners' presence at LSM concessions. At such times, second-party coalitions (which include formal and informal property rights arrangements) that govern clandestine extraction at and around the case-study sites tend to break down as the cost for the security forces of providing PR to miners rises too high. Second, the openness-closure dimension is of relevance when it comes to conflict between authorised and unauthorised clandestine mining. According to Daudelin and Ratton (2018), “An open illegal market involves actors that do not know each other. Without an authority to regulate transactions, mistrust prevails, and the probability of fraud, for both buyers and sellers, is high." (p. 49) The costs of providing PR are also higher in a more open market. The large number of artisanal miners means there is always a potential threat of aggressive or violent tactics by miners to gain entry to an LSM site, which trust relationships are only partially able to mitigate. Distributional dimensions are also at work as the different security forces use aggressive tactics to close clandestine mining to non-payers - whether artisanal miners, traders, or other actors.

The main hypothesis guiding this study is therefore that at a given mine site, conflict along a continuum of conflictual encounters can be conceptualised as the outcome of the interrelationship between the property rights regime, which includes corporate and other actors' practices to define and enforce their property rights and claims. If the abovementioned coalitions break down, and companies and other actors mainly use first-party approaches to secure their access to resources - which include artisanal miners' aggressive behaviour - more visible, violent manifestations of conflict are expected to result, in line with Steinberg (2015). On the other hand, if there is a second-party coalition at or around a mine site that operates relatively interrupted, there will be less visible, violent manifestations of conflict at a given time. Finally, the dynamics of the property rights regime are expected to have differential distributional impacts on different categories (gender, occupation, ethnicity, origin, etc.) within communities at and around mine sites.

\subsection{Conclusion}

In this theoretical chapter, building on the critique of traditional property rights theory as not particularly helpful in the context of large-scale mining in the DRC, I drew on the work of Fitzpatrick (2006) and Mwangi (2007), which highlights the persistence of multiple components of a given PR regime. I then provided theoretical insight into the arrangements and processes that govern artisanal miners' access, or lack of access, to LSM sites in southeastern DRC. I discussed the theoretical underpinnings of the multidimensional property 
rights regime at and around these LSM sites, including the arrangements and processes that govern artisanal miners' access or lack of access. I linked conflict and distributional dynamics to the property rights regime, which includes multiple components including corporate enforcement; artisanal miners' efforts to impose their PR; and the involvement of local elites for purposes including rent seeking. I sketched out and examined the theoretical implications of mineral governance for conflict incidence as well as distributional dynamics in terms of who can access resources including unprocessed copper and/or the proceeds from selling these minerals. I laid the groundwork for the next chapter, which systematically presents the different aspects of the property rights regime at and around the three LSM sites - while acknowledging that the property rights regime is broader than the three sites.

The theoretical framework that I apply in this study acknowledges incomplete enforcement of all parties' rights as well as the persistence of multiple overlapping components of the regime. In Haut-Katanga and Lualaba, competing claims to resources have led to conflict as companies have refused to tolerate the presence of artisanal miners, but been unable to keep them out entirely. The violent contestation that unfolded in Katanga when multinational corporations sought to exclude artisanal miners from open mining pits (Hönke, 2009; 2010) highlights the limitations of corporate fortress protection (Hönke, 2013; 2014) and of coalitional arrangements whose purpose is to manage and limit conflict. The persistence of conflict suggests that for reasons including principal-agent issues, the need to be perceived as good corporate citizens, and the absence of other viable livelihood options for artisanal miners, companies' exclusion of miners is not always complete. At a mining site where a company successfully restricted access to its concession through an overwhelming show of force, and/or local parties made no attempt to encroach, little or no open conflict would occur. If companies granted increased access, less conflict would be expected.

In the DRC, a key factor underpinning the persistence of violence in and around LSM sites is therefore the lack of recognition of certain types of claims, such as those based on historical occupation by artisanal miners; the lack of consideration for locally legitimate claims that the state unsuccessfully attempts to forcefully eliminate (or coopt); and the incomplete enforcement of associated rights (Katz-Lavigne, 2016). Yet, as Geenen (2012) argues, artisanal mining does not have to be formalised for miners to benefit. Artisanal miners who rely on mineral deposits in concessions granted to large-scale mining lack livelihood alternatives and companies often refuse to compensate them financially, so many miners don't accept to stop operating in these concessions, which in any case they consider to be illegitimate (Hönke, 2010). In the absence of compensation for expropriation of artisanal 
miners' claims to resources, conflict is likely to persist in southeastern DRC. Yet compensation may not be sufficient to induce miners to leave LSM sites either, particularly given incompatible understandings of the financial value of an artisanal-mining livelihood. Some miners will not be wiling to "sell" their livelihoods, at least not on the terms offered. Alternative livelihoods like agriculture or selling baked goods are longer-term activities, whereas people often desire faster options (company A manager, interview, September 22, 2016). Miners typically prefer to mine because it offers a faster, daily return than agriculture (journalist, interview, February 7, 2017); miners, group interview, April 3, 2017).

Environmental pollution from mining has affected communities' plots of land, and the government has poorly enforced corporate remedy (doctoral candidate, interview, February 1, 2017). In the Lubumbashi area, there is limited land available; communities have also been displaced from agricultural land as a result of mining investment (miners, group interview, April 3, 2017). Employment with mining companies is limited and tends to be granted to a preferred few, like relatives of the local chief (civil society representative, interview, January 24, 2017; doctoral candidate, interview, February 1, 2017) or people from other areas; companies reportedly do not wish to hire miners (miners, group interview, April 3, 2017). Many miners do not speak French and most did not finish school; many have children to support (LNI representative and Mine Police representative, interview, March 20, 2017). The lack of livelihood alternatives helps explain why artisanal miners are adamant about being granted entry to LSM sites despite the risk. Many miners would prefer not to do clandestine mining, but the lack of other work leaves them no choice, combined with the fact that they have been excluded from sites that were previously open (two miners and their mother, interview, March 31, 2017; miner and his wife, interview, March 31, 2017; miners, group interview, April 3, 2017). The imposition - definition and, to some extent, enforcement - by central (and local) governments of MNC property rights to mining concessions in the DRC's context of rhizomatic statehood, legal uncertainty, and competing norms therefore leads to imperfect exclusion and conflict. 


\section{Chapter 4: The Research Puzzle: Similarities in Conflict Dynamics Across Different Sites}

\subsection{Introduction}

This chapter outlines the key empirical puzzle from which the two research questions were derived: all three sites in this study are owned by companies with significant differences in terms of corporate characteristics and corporate social responsibility approaches, yet have exhibited similar dynamics in terms of conflict incidence and intensity over the years. Companies employ a range of security practices to minimise potential disruption to their activities from conflict between artisanal miners and the security forces. Yet while companies in Haut-Katanga and Lualaba have been able to maintain a relatively low profile when it comes to public reporting about conflict and violence in their concessions, these types of confrontations are a regular occurrence across sites (Mine Police representative, interview, October 7, 2016; Mine Police officer, interview, March 10, 2017; LNI officer and Mine Police officer, interview, March 20, 2017). A number of individuals described occurrences in which large groups of miners have entered sites A and B: these situations quickly overcame the capacity of unarmed private security guards and led them to call for police reinforcements (company A security officer, October 11, 2016; occasional miner, interview, March 21, 2017; two miners, interview, March 16, 2017; LNI officer for company A and Mine Police officer for company B, interview, March 20, 2017; former miner, interview, November 25, 2016; journalist, interview, April 12, 2017; two traders, interview, February 25, 2017; miner and his mother, interview, March 29, 2016; PSC representatives, interview, March 20, 2017). These findings are puzzling in light of the fact that, according to many respondents, the different security forces with contracts at LSM sites in southeastern DRC are instrumental in granting access to miners. Yet at times, the security forces at LSM sites do prevent artisanal miners from entering these sites, which can lead to conflict.

What accounts for the concurrent existence, and ebb and flow, of dynamics of both conflict and cooperation at large-scale mining sites owned by companies with different characteristics on a range of different dimensions? What causes conflict in contexts in which security forces regularly collaborate with artisanal miners to grant them access? Explanations for conflict incidence should be able to account for both the security services' mandate and institutional need to maintain a certain level of performance for their mining-company clients by keeping miners out, and the systematic nature of clandestine entry and extraction. What is the explanatory power, when it comes to conflict, of different guards and police officers' 
individual characteristics: are some more "diligent" in their work and less accommodating of artisanal miners than others?

The key line of inquiry for this study concerns cross-time, within-site variation in conflict incidence: what explains the occurrence of conflict, and its manifestations, over time and at different LSM sites? This line of investigation involves the identification of similar themes that recur across sites. All three sites have experienced significant variation over time in the incidence and intensity of conflict but exhibited similar manifestations of conflict and peace at different times. This chapter presents and analyses the empirical puzzle that underpins and drove this research: conflict and distributional outcomes do not map neatly onto company characteristics and corporate social responsibility practices, particularly given the considerable variation over time at each site compared with significant continuity in terms of corporate characteristics. During the time period covered by this study, incidents of a similar nature and intensity have occurred across all sites at different times despite the differences in corporate characteristics and CSR practices. The empirical puzzle therefore relates to the fact that cross-time conflict dynamics do not map neatly onto companies A, B, and C's characteristics. Building on other scholars' arguments that there is an ambiguous link between company characteristics and corporate practices on the ground, I argue that company characteristics are not sufficient to explain either conflict incidence or distributional outcomes. This chapter informs my overarching argument that conflict incidence and distributional outcomes follow a pattern and are the outcome of the interaction between the different facets of the property rights regime at and around LSM sites. In what follows I first recap each company's characteristics. I then discuss the potential expectations, in terms of conflict dynamics, from each company's characteristics. Finally, I turn to a detailed explanation of the puzzle before concluding the chapter.

\subsection{Recap of Company Characteristics}

To recap the three companies' characteristics, companies A and B in the Lubumbashi region both have headquarters in the Global South. Company A is from the Global South and is Global South-based but has significant ties to the Global North through the head of the company (Global Witness, 2006; World Bank, 2007). The larger investment group is United Arab Emirates-registered (Mthembu-Salter, 2011): the "[redacted] headquarters are in Dubai, with operating offices in London, India, China and across Sub-Saharan Africa." (Redacted, n. d.) For several reasons I place this company in the Global South category. 
Until 2012, a South African mining firm headquartered in Johannesburg owned company B; a Chinese investor bought the majority share in 2012. After the purchase in 2012, shares belonging to the firm that used to own company B were not traded on the Johannesburg Stock Exchange anymore. In November 2013 the purchasing company merged the firm that previously owned company B into its subsidiary, which is listed on the Hong Kong Stock Exchange. The subsidiary that bought company B is a Chinese state-owned entreprise. However, company B is still managed by its former owner (the South African firm), which means there is some continuity in the pre- and post-2012 periods (Redacted, 2013). Unlike companies A and B, company C's ownership was based in the Global North for most of the period covered by this study. Until late 2016, the company's majority owner was an American firm with headquarters in the United States. A Canadian firm held the next biggest share (Redacted, 2016). In May 2016 the American owner announced the sale of its interests, in the firm that owned $80 \%$ of mine $\mathrm{C}$, to a Chinese company. Given that this study centres mainly on the period before, and during the transitional period after, the purchase which was gradually implemented over the last few months of 2016 and into 2017 (company C officer, informal discussion, September 28, 2016) and expected to take one year (Mine Police representative, interview, December 3, 2016) - company $C$ for the purposes of this study falls into the Global North category.

Companies A and B have relatively small concessions (company A exploration staffer, interview, October 19,2016) while company C's concession is much bigger than A and B combined. Company C's concession includes more than 300 hills, while A and B have a small number of open-pit mines each. The three companies are also different in terms of the mineral volumes they produce: in line with its bigger concession size, company C's production is much higher than that of companies A and B. Finally, before company C was sold in 2016, the company followed the Voluntary Principles on Security and Human Rights and submitted reports every year, until November 15, 2016 when the new owner took on legal responsibility for site C operations (Redacted, 2017). Company A and B do not adhere to the Voluntary Principles (company B employee, email, August 15, 2018; former company A employee, email, August 15, 2018).

When it comes to corporate social responsibility, firms A and B's non-adherence to the Voluntary Principles is part of a bigger pattern. A and B are known, in the Lubumbashi region, for their limited efforts in the CSR realm. Both companies have been accused of polluting the environment by multiple international organisations, civil society associations, and local communities (Carter Center, 2012; ACIDH, 2012; SOMO, Afrewatch, ACIDH, and 
Premicongo, 2016; civil society representative, interview, September 8, 2016). However, company A is said by several academics and civil society respondents in Lubumbashi to be the worst on the CSR dimension and to operate with significant impunity, while company B is said, at least in certain respects, to place more emphasis on environmental and social responsibility.

Company A is said to have links with the Congolese president. According to one interviewee, company A is "covered" [protected] by the Congolese presidency: the head of company A has a link with the presidential family, which means the company head is able to behave with impunity. This respondent expressed his belief that the company doesn't care at all about the community, noting that the International Finance Corporation isn't involved with them through financing and therefore cannot punish them if they do not behave well (community relocation consultant, interview, August 9, 2016). A civil society representative described company A as a "bad student" when it comes to pollution and respect for human rights (interview, September 2, 2016). Another civil society delegate remarked that in 2009, when there was an accident at the company's sulfuric acid plant and civil society carried out advocacy, company A's Director-General (to whom this individual referred as "a real bandit") stated publicly that he has the Congolese authorities in his pocket (interview, October 10, 2016); a former miner corroborated his statement to that effect (interview, November 25, 2016). ${ }^{7}$ One respondent expressed the belief that when the parliamentary commission for the environment visited company A because of an accident that caused significant environmental damage in the area, the company paid off the commission (civil society representative, interview, September 8, 2016). A security officer from company B said that company A is more dictatorial by nature and doesn't care about international principles or costly standards (interview, January 27, 2017). A private security company officer argued that company A is the owner's personal property and that the owner manages it the way he wants (interview, May 12, 2017), while a local government official similarly said that company A belongs to a single person: what the boss decides is what will be executed (interview, October 26, 2016). Another local government representative said that company A really doesn't care much about the community and that the company is very "complicated". This representative contended that with company A, it was "really impossible" and that unlike with company B, they had never even had a meeting with the company (interview, May 21, 2017). A representative of a

\footnotetext{
${ }^{7}$ A community activist made a similar claim about company B, arguing that the company made a similar point when it came to community complaints about the company - that the government is in their pocket (interview, October 15, 2016).
} 
copper-processing company said that company A would not be open to participating in my research (interview, September 9, 2016). A Mine Police representative echoed that argument, saying that security is very sensitive for company A, and that they hide many things. He said that without authorisation it would be difficult to do research on the company, and necessary to rely on personal connections with employees (interview, October 7, 2016). He was right: I was able to interview several company A employees, but through informal rather than official channels (i.e. without the knowledge of the company head). At company B, by comparison, I was asked to provide an official letter from my department in addition to proof of ethics clearance from my university. A community activist raised several negative community-level impacts linked to company A's operations, including the use of explosives for mining (interview, October 15, 2016). A manager from the private security company deployed at both sites B and C reported that the PSC used to have a contract with company A as well, for two years, but that company A then cancelled the contract. He mentioned that company A is "Indian" and argued that their decision was political: the former governor Moïse Katumbi, or his son, had a PSC and wanted company A to hire that company. Company A accepted and hired that company instead. He told me that even afterwards, when firm A broke the contract with the PSC that replaced his company, his PSC did not want to start working with company A again because, he said, they aren't in line with his PSC's values and do not respect the Voluntary Principles on Security and Human Rights (three PSC managers, interview, March 20,2017). While some of these claims are uncorroborated, multiple civil society representatives' and other respondents' beliefs about company A are revealing.

Additionally, company A's CSR measures are limited: several of the initiatives a social manager showed me in 2016 dated back to 2014 or earlier. Several were questionable examples of CSR, like donations to the local chief (interview, September 21, 2016). The investment group that owns the mining company operates an eye clinic in downtown Lubumbashi that at one point reportedly offered free care in the community (community activist, interview, October 15, 2016). ${ }^{8}$ At an August 2016 workshop in Lubumbashi for the Investissements Durables au Katanga (IDAK) tripartite forum of civil society, government, and mining companies, on the theme of CSR engagement by companies, no company $\mathrm{A}$ representative was present (unlike for companies B and C) for the two-day meeting.

A 2012 Carter Center report similarly described company A's greater negative impact on human rights compared to company $\mathrm{B}$, which the report linked to differences in corporate

\footnotetext{
8 There is indeed such a clinic in downtown Lubumbashi, but I did not visit.
} 
culture. Comparative research from August 2010 to November 2011 revealed permanent confrontation, with communities, in both cases (A and B). However, company B was seen in a more favourable light than company A, not only because the community was able to engage in discussions with firm B, but also because part of the neighbouring community said that in certain neighbourhoods the quality of life had improved in some areas (health services, education, water), though another part of the same community complained about house evictions and expropriation of their fields. The Carter Center report links the differences between the two companies to their organisational culture. Company B representatives did accept to participate in the research, but company A did not (Carter Center, 2012).

Company B is therefore said to be at least somewhat better in the CSR domain than company A. A civil society representative noted that company B is concerned with appearances and has an environmental department that takes the time to meet and discuss (interview, October 10, 2016). Company B's CSR efforts are also relatively limited on the ground, though the company has provided water and electricity to some residents, installing a transformer that provides electricity to a community neighbouring the mine (community activist, interview, October 21, 2016). In a 2011 letter responding to criticism from a local NGO, the company said that it had installed five 500 MVA transformers locally. Company B also reported having dug 10 boreholes in different neighbourhoods and put in the necessary infrastructure to provide drinking water for the area adjoining the mine. One artisanal miner said that he does not enter company B's concession because the company provided the neighbourhood with water and electricity (interview, March 31, 2017). The company's letter also mentioned support to the local military hospital (ACIDH, 2012). Other measures include the construction of a building for the local judicial institution (parquet in French), where I saw the sign showing the company's contribution. However, support for the justice system also benefits the company: the parquet handles cases linked to arrested artisanal miners (three parquet representatives, interview, December 1, 2016). Company B's reputation is also far from untarnished, particularly within the communities living around the mine. A community activist raised a number of complaints, including little or no compensation for land appropriation (which he personally experienced in the case of 48 hectares of his family's land); fraudulent implementation of the compensation process; incomplete community displacement and compensation; damage to people's homes from the use of explosives in mining; repression and cooptation of protest and community dissent; deaths of miners at the hands of the security forces and, despite the company's good reports on environmental measures, pollution and the loss of people's crops (interview, October 15, 2016). 
Civil society respondents in Lubumbashi did not express the same concerns about impunity, or the concentration of power, as with company A. No interviewees mentioned company B links to the presidency in the same way as for company A, though one respondent did state that company B called the central government in Kinshasa on one occasion when community members protested negative impacts of the company's presence (communitybased group, interview, November 3, 2016). While the company's CSR efforts are also limited on the ground, company B did send a representative to the August 2016 workshop of the IDAK tripartite forum, who presented on the firm's environmental efforts. The company also reportedly learned its lesson from the violent eviction of miners at site A, so company B paid each miner 200 USD to leave. The removal of miners from site B was reportedly more peaceful than at site $\mathrm{A}$ as a result (miner and his wife, interview, May 31, 2017). While a civil society representative noted that company $B$ takes advantage of the fragility of the Congolese state, and that the firm's Assistant Director-General said he doesn't understand NGOs' actions [to hold companies accountable for negative local impacts] because it is important not to discourage investment, several company employees did meet with this representative (interview, September 8, 2016). Company B was said to be "better" than other companies with the same (Chinese) national origin because it was previously owned by a company from a country with a better investment reputation (South Africa), and was still managed by that company (IDAK tripartite forum workshop, August 17, 2016). Finally, a company B employee noted that in order to qualify for the financing it receives from Standard Bank South Africa, the company must meet certain standards, and therefore emphasizes good management and good environmental governance (meeting, August 30, 2016; email, August $15,2016)$ which suggests a certain level of oversight of company activities.

In comparison with companies $\mathrm{A}$ and $\mathrm{B}$, respondents made much more positive assessments of corporate social responsibility efforts by company $\mathrm{C}$ which, as noted, is run by a large multinational corporation headquartered in the Global North. One interviewee referred to company $\mathrm{C}$ as "one of the best situations" when it comes to community relocation and as a case study in effort and attention, arguing that companies listed on stock exchanges in London, France, the U.S., and Canada behave in almost the same way, compared to Chinese companies and companies with Australian capital (civil society representative, interview, August 11, 2016). A land chief whose lands are in site C's concession said that among all the "minings", company $\mathrm{C}$ is excellent, though he added that even company $\mathrm{C}$ doesn't achieve the goal of zero discharge of acid (interview, September 2, 2016). A June 2014 joint report by RAID, Bread for All and Fastenopfer described company $\mathrm{C}$ in favourable terms, noting that 
the company "has posted its entire environmental and social impact assessment on its website." (Peyer, Feeney, \& Mercier, p. 74) The report also describes how, in the case of road closure, company $\mathrm{C}$ implemented a bus service. Company $\mathrm{C}$ is also said to have implemented better community relocation and compensation measures than other firms in the region (civil society representative, interview, August 11, 2016). In the region, company $\mathrm{C}$ has the reputation of implementing better CSR than other companies (civil society representative 2, interview, August 23, 2016; civil society representative, interview, March 4, 2017) and of respecting international norms, reportedly allowing artisanal miners to go about their activities with relative freedom to operate (community relocation consultant, interview, August 9, 2016; university researcher, interview, August 13, 2016; three traders and a former miner, interview, February 4, 2017; trader/miner, interview, February 14, 2017). The company, which as noted adheres to the Voluntary Principles on Security and Human Rights, has an often-mentioned - including by artisanal miners - emphasis on human rights that reportedly means the company does not want miners to be injured (miner, February 17, 2017; PSC officer, interview, March 15, 2017; company C security employee, interview, May 27 , 2017; PSC representative, interview, May 22, 2017). The security forces in the concession are not permitted to harm artisanal miners and get in trouble if a miner gets harmed (PSC representative, interview, May 22, 2017) ${ }^{9}$.

\subsection{Conflict Expectations from Company Characteristics and CSR Profiles}

Based on these categories and in keeping with the predictions of some of the literature on company characteristics, one might expect the least amount of conflict at site $\mathrm{C}$, a large, Western corporation with a reputation for prioritising corporate social responsibility and the treatment of artisanal miners. I would expect medium conflict at site B, a Chinese-owned company managed by a South African firm in keeping with the Equator Principles and the International Finance Corporation guidelines, and that to some extent emphasizes corporate social responsibility and public outreach. Finally, the expectation would be that company A, a relatively small firm also listed in the Global South and whose owner has an apparent disregard for the imperatives of corporate social responsibility, would have the highest level of conflict.

\footnotetext{
${ }^{9}$ Not everyone shared this positive assessment of the company and its actions (journalist, conversation, February 8, 2017; two traders, interview, April 13, 2017; community relocation consultant, interview, March 25, 2017; three international NGO representatives, interview, August 31, 2016).
} 
Yet as I now demonstrate, the data collected from August 2016-May 2017 do not neatly fit the conflict predictions resulting from the three different companies' corporate characteristics and CSR profiles.

\subsection{The Puzzle in Detail}

First, the frequency and similarity in terms of the incidence and intensity of conflict across sites suggests that explanations based on company characteristics are not sufficient to explain conflict outcomes at the three sites. In interviews with artisanal miners living in the Lubumbashi region near sites A and B, similar types of incidents were reported as having occurred over the years since the companies acquired these sites at both A and B, including arrests; confrontations between miners and the police, with shots fired; the beating of captured miners by members of the security forces; and other incidents on the more violent end of the conflict scale, like injuries and deaths of miners.

In January 2017, a company B security officer provided statistics on conflict incidents at the mine site that show significant and growing conflict in the previous two years. In 2015 116 people were arrested in the concession, and in 2016139 arrests were reported. The number of arrests represents a small proportion of miners actually stopped in the concession, he said, because these figures refer to judicial arrests. For the company to arrest someone in a judicial manner and send them to the parquet means they have either re-offended or behaved in a violent manner, or caused damages or engaged in sabotage. He said that generally, the petit creuseur (ordinary artisanal miner) is arrested by the police, and then released. He argued that the company could never manage to follow up on all the cases. In 2015, data was gathered on 31 attacks; in 2016, 123 attacks were reported, a nearly 400\% increase. As the security officer explained, company B's definition of “attacks" refers to an organised group of people with a particular objective, like stealing cables or engines or other objects, that does so in a violent manner. He said that these groups are organized with machetes and other armes blanches (non-lethal weapons). The fact that the company only tracks significant incidents of a violent nature suggests that the incidence of conflict (including non-violent conflict) is much higher than their statistics capture, particularly if security forces involved in clandestine mining do not report some incidents. The security officer noted that these statistics refer only to incidents of a violent nature, adding that the number of intrusions in the concession is enormous; the company doesn't even track those statistics, which would be in the thousands. In 2016 there were 64 injuries (of security guards), which the security officer said was a never-before-seen figure (the numbers for 2014 were similar to those from 2015). With 
respect to miners or individuals seeking batteries or fuel from company vehicles, he mentioned that injuries from dog bites tend to occur. He estimated five cases of individuals bitten by dogs over the year. In 2016, according to the statistics, there were 60 seizures of items, whether unprocessed or processed minerals, cables, fuel, or other goods (interview, January 27, 2017). A police officer deployed to site B reported in March 2017 that in February 2017, there had been 94 artisanal miner attacks and 30 arrests (LNI officer, interview, March 20, 2017). The UN-run radio station reported on 12 November 2013 that five people had been injured, by bullets, in clashes in the neighbourhood around company B's concession. Those injured were artisanal miners who attempted to use force to enter the concession's facilities to take minerals. The company said that during the incident, about 200 artisanal miners carrying armes blanches (non-lethal weapons [possibly refers to their digging equipment]) tried to enter the mine site by force. Unable to stop the miners, the company called on the police. According to company representatives the police reportedly attempted to dissuade the miners but faced with the miners' refusal and throwing of stones, the police fired shots in the air. Four people sustained gunshot wounds, and a company guard dog bit a fifth individual. Those injured denied being artisanal miners and said they were only neighbours of the company, and that they were hit by bullets in their homes ("5 personnes blessées", 2013).

At company A, which has exhibited more continuity in terms of ownership than companies $\mathrm{B}$ and $\mathrm{C}$, there has similarly been an ebb and flow in the incidence and intensity of conflict over the years since the company took over the mining concession. From significant clashes and, reportedly, deaths at site A in December 2012-January 2013, interviewees reported that fewer incidents on the violent end of the continuum had occurred at site $\mathrm{A}$ in the past several years. Confidential data obtained from company A, tracking artisanal miner entry to site A over time, lends support to this account, suggesting that factors other than company characteristics and CSR practices have an impact on conflict levels, in this case in the form of miner arrests. As the tables below show, there was a significant drop in mid-2015 in the number of miners caught each month (with seasonal spikes), despite the fact that company A did not change hands in terms of ownership, nor did it apparently significantly alter its CSR practices. 
Fig.1

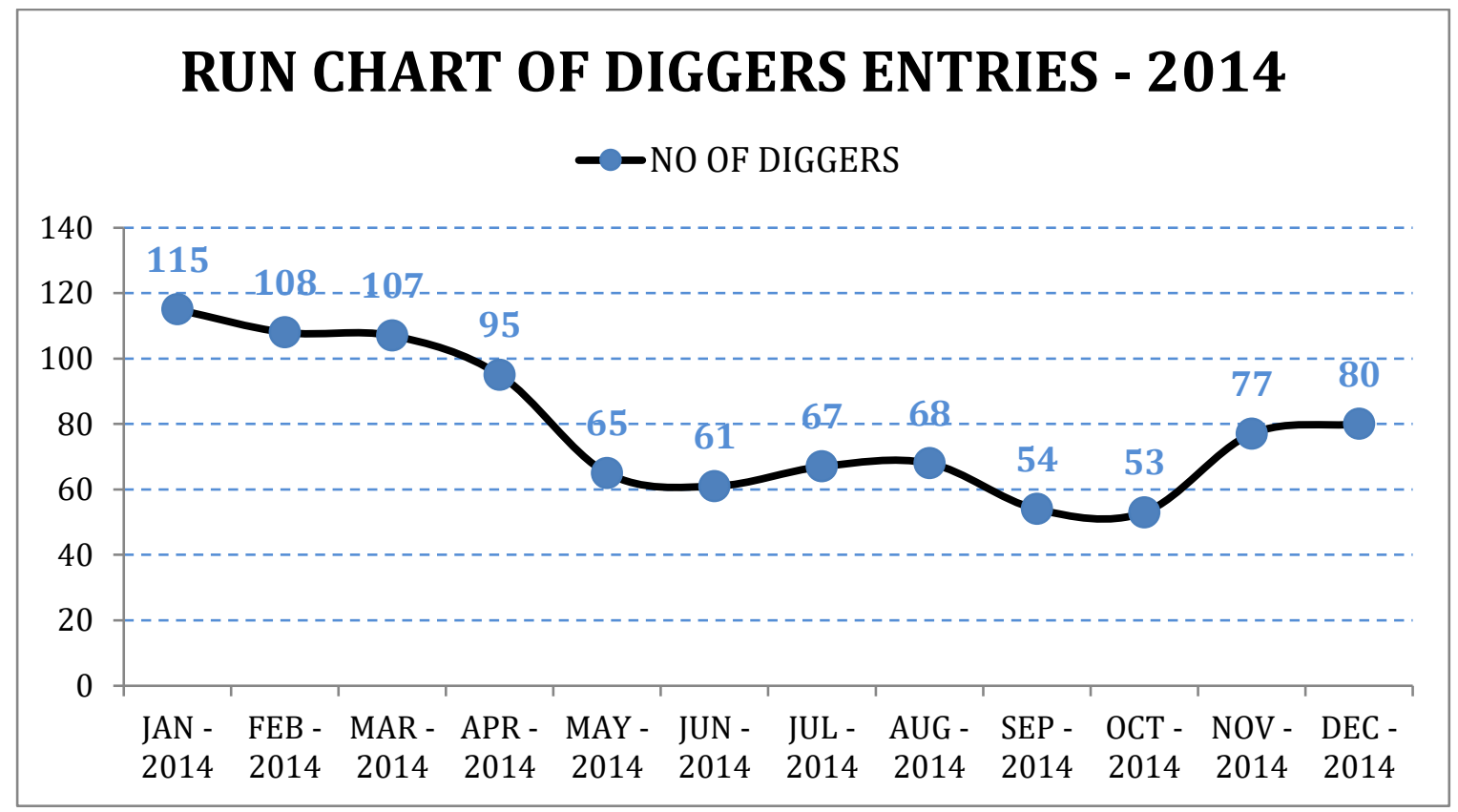

Fig. 2

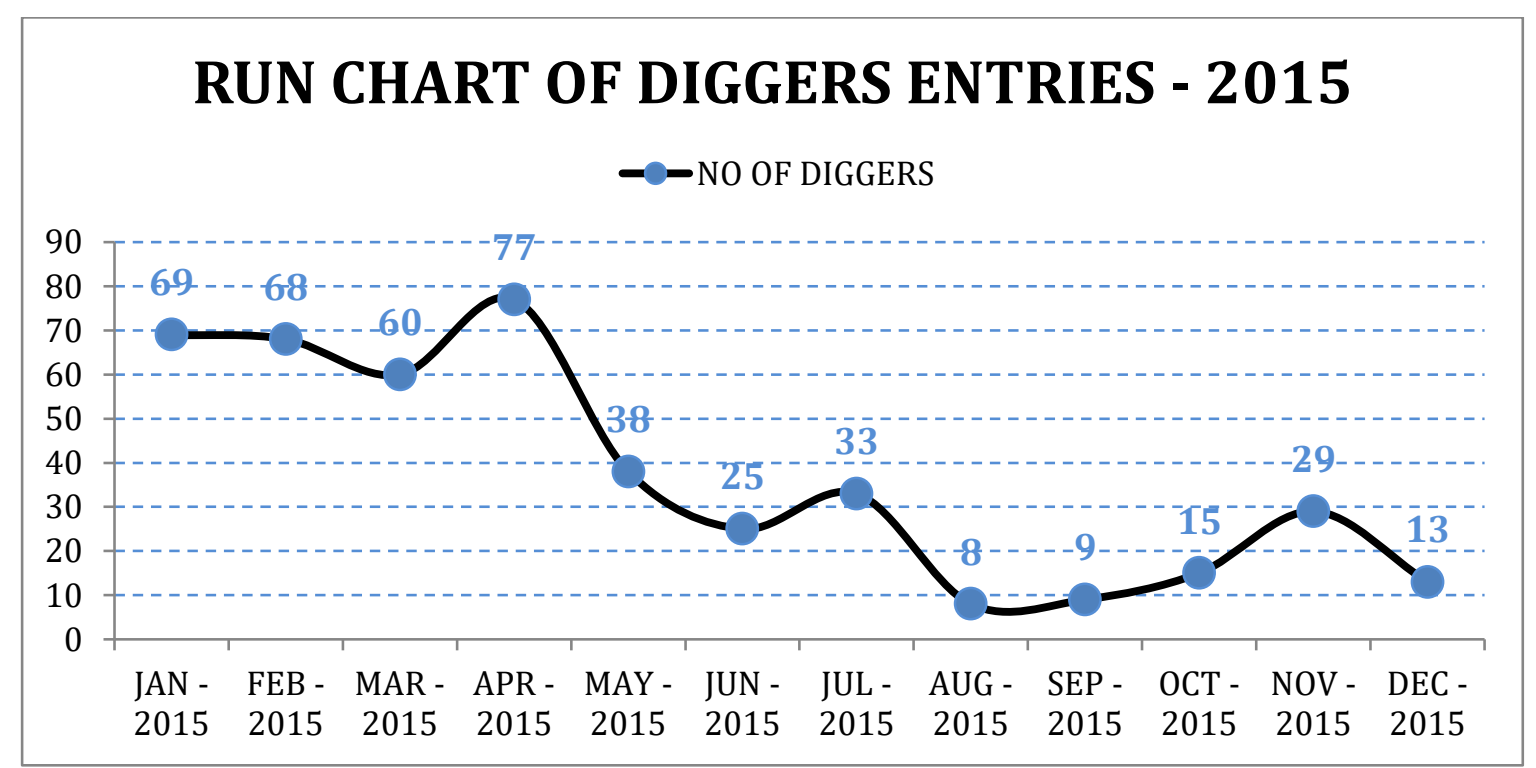


Fig. 3

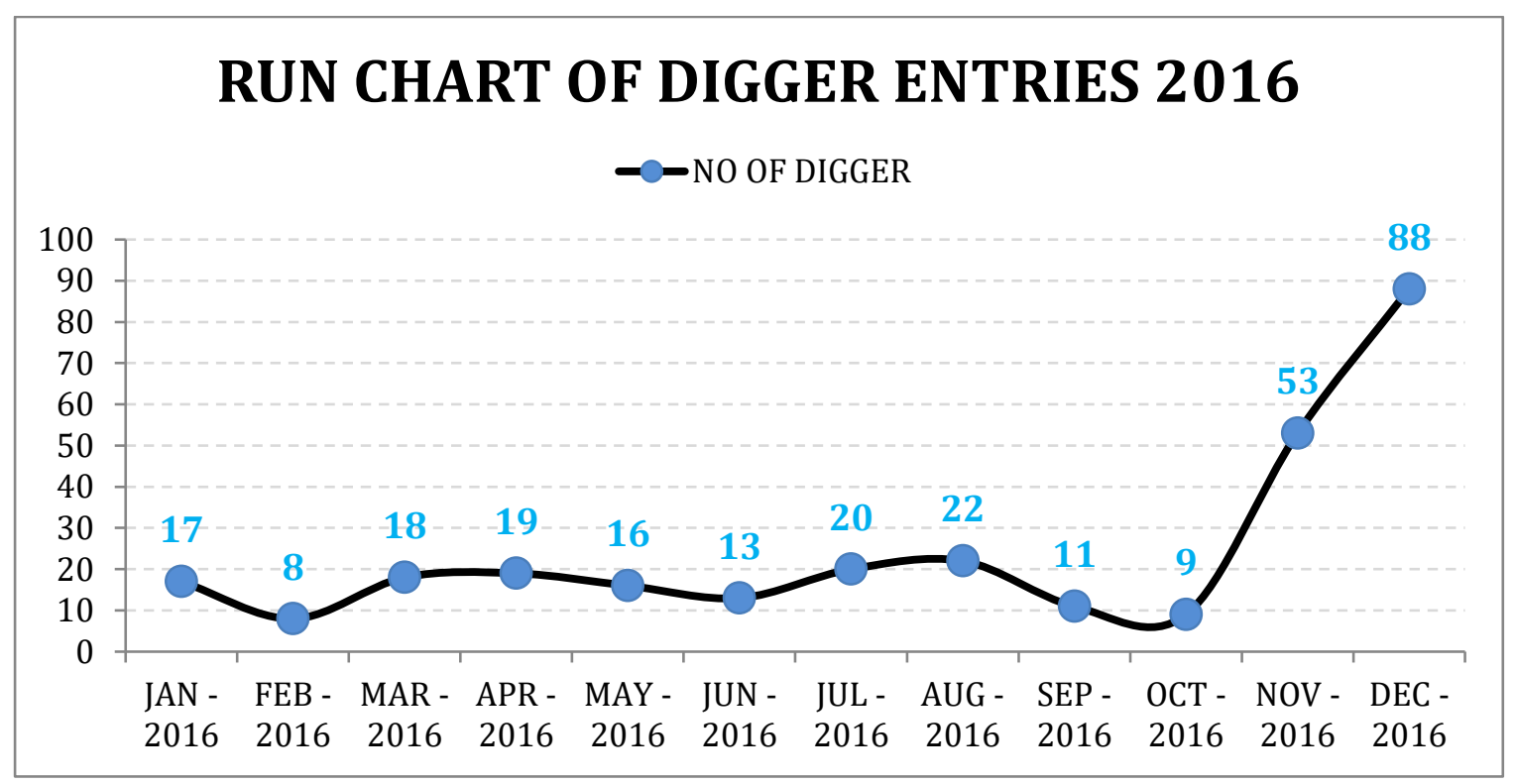

Therefore, interview and company data suggest that despite its seemingly more socially responsible profile, site B in recent years has been at least, if not more, as affected by conflict, including conflict at the extreme end of the scale, as site A. In keeping with the contention that site $\mathrm{B}$ is at least as affected by conflict as site A, according to one artisanal miner, since December 2012, the security forces at company A have not killed any miners, other than accidents caused by its vehicles and leading to deaths (two miners, interview, March 16, 2017). While the methodology used in this study does not make it possible to draw any definitive conclusions concerning that claim, and while there are evidently conflict indicators other than deaths of miners, the belief itself is informative.

At site $\mathrm{C}$, many artisanal miners have settled and live in temporary rented housing in the multiple villages and towns over which the concession was superimposed. Thousands of artisanal miners operate in the concession, digging principally on hills that the company has not yet begun to mine, of which there are hundreds. ${ }^{10}$ Clandestine mining is an open secret across LSM sites in Haut-Katanga and Lualaba, but even more so at site C, where miners live and travel the roads more or less undisturbed even in daylight, and where informal settlements have sprung up in several areas. Fewer artisanal miner respondents at site $\mathrm{C}$ reported that they had been personally arrested or injured by security forces, compared to miners working at

\footnotetext{
${ }^{10}$ According to one respondent, 282 hills (two local socio-cultural association representatives, interview, April 12, 2017).
} 
sites A and B, or that they knew of the killing of other miners. ${ }^{11}$ On the surface, then, the dynamics at site $\mathrm{C}$ fit with the expectations raised by the company's characteristics and CSR policies.

Yet conflict dynamics at site $\mathrm{C}$ are more complex than initially meets the eye. Despite company C's origin in the Global North; its adoption of the Voluntary Principles; and its reported embrace of human rights values, similar conflict dynamics - including multiple largescale confrontations as well as smaller scale but violent encounters - were described at site $\mathrm{C}$, just like at A and B. Several visible and some less visible incidents of open conflict, pitting miners against the company's security forces and/or involving damage to community infrastructure by miners, have taken place over the years, particularly at site $\mathrm{C} 3$, a town in company C's concession with a high number of active artisanal miners (PSC officer, interview, March 15, 2017; miner and his wife, interview, March 31, 2017). Company C's Voluntary Principles reports document injuries and deaths of miners and security guards as well as major clashes in the concession. Among the incidents reported by the company, several of which were corroborated by my research in the area, were killings (Redacted, 2014; 2015; 2016) and injuries of artisanal miners (Redacted, 2015; 2016), an “intruder" (2013), and at least one civilian (Redacted, 2011) by the Mine Police; the death of a member of the Mine Police (Redacted, 2015); extensive damage to the company's community liaison bureau at C3 and associated temporary shut-down of the mining pits at C3 as well as of areas in the vicinity (Redacted, 2016); dozens of injuries of unarmed security guards and contractors and a number of injuries of members of the Mine Police (Redacted, 2016); and non-fatal skirmishes between artisanal miners and the Mine Police (Redacted, 2010; 2011). ${ }^{12}$ The more highprofile incidents represent an ebb and flow of conflict: periods of upheaval followed by periods of relative calm. While the (relatively) low incidence of high-profile incidents such as the damage at multinational corporation C's community liaison bureau could give the impression that conflict is in, in fact, rare at site $\mathrm{C}$ or elsewhere, lower-level encounters (less serious instances of conflict and clashes between miners and security guards) are frequent, and may often not be reported and/or recorded if they come to a rapid end and/or don't result

\footnotetext{
${ }^{11}$ That said, given that company $\mathrm{C}$ has a much larger concession and a far greater number of miners operating at - and indeed living in - its concession, an appropriate quantitative methodology would be needed to draw valid conclusions from this small sample. With a larger number of miners, there may simply be less of a chance of speaking to miners who have been involved in confrontations. The presence of more miners at a given site could also potentially imply a higher frequency of confrontations (at site $\mathrm{C}$ ), but that must also be weighted against the fact of much smaller (and therefore more easily secured) mine sites in the Lubumbashi area.

${ }^{12}$ Interestingly, it's the quality of their Voluntary Principles reporting that makes it possible to ascertain the extent of what's happening, and has happened, at site C. Therefore, companies A and B are potentially at an advantage as information about incidents at their sites is not publicly available.
} 
in casualties - for instance, because miners simply run away (Mine Police officer, interview, March 10, 2017). What factors make it possible for artisanal miners to operate more or less peacefully at mining companies' concessions at certain times, and what dynamics result in conflict?

In summary, it is puzzling that all three of the case-study sites involve companies with different corporate characteristics and policy approaches but share similar realities in terms of conflict incidence over time. Company characteristics and even practices, which do not change quickly, do not provide a satisfactory explanation for dynamics that exhibit significant variation and tend to change rapidly. While the three companies studied have experienced changes, there has been significant continuity during the period of study: company B was sold in 2012 but was still managed by its former owner. Company C was sold in 2016, but much of the data presented in this dissertation relates to the period prior to the sale. I contend, therefore, that confrontations and conflict at each site are linked to a wider property rights regime as well as to the unique characteristics of the specific PR regime at each site. In this sense I broadly distinguish between structure, actors, and processes. Actors, through their choices and behaviour, co-constitute the property rights regime at and around a given LSM site, which means their characteristics do matter. However, when actors with markedly different characteristics end up doing the same, or similar, things, there must be a more structural explanation at work than simply the factor of companies' agency, as discussed in Hofferborth (2017).

\subsection{Conclusion}

In this chapter I presented the empirical puzzle that motivated and underpins this study, identified through desk-based research as well as interviews and observation at the case-study sites. While the three sites have different corporate characteristics and corporate social responsibility practices, each site has, over time, experienced similar dynamics when it comes to the incidence of conflict. Therefore, corporate practices cannot necessarily be inferred from company characteristics, but require in-depth analysis. This study highlights the importance of moving beyond a "good company" / "bad company" dichotomy, and of further probing corporate engagement and its effects in areas where statehood is rhizomatic. The functioning of the PRR, as I have shown in this chapter, can result in unexpected outcomes across sites as well as over time.

How can we explain the incidence of conflict at, around, and across mine sites? In other words: why does conflict erupt at certain times and at certain large-scale mine sites in 
the provinces of Haut-Katanga and Lualaba? What accounts for the similarities between conflict dynamics across sites in a context in which all companies' practices have evolved, and in which they have attempted to address and forestall conflict, in the decade or so since they began operating? Each of these sites has, at times, experienced less or more conflict. Why are so many interactions between artisanal miners and the security forces at the different sites characterised by little or no conflict, while others are far more conflictual? What do these realities have to tell us about the impact of interactions between the different components of the property rights regime, which include but are not limited to property rights enforcement security practices at mine sites? These are questions that I address in what follows. 


\section{Chapter 5: Research Methodology, Ethics, and Researcher and Participant Safety in a High-Risk Environment}

\subsection{Introduction}

In this chapter I present the research design and methodology and the many limitations of its implementation. I also engage with a range of issues linked to the ethics and safety of implementing the research design in a relatively high-risk environment. I first explain the rationale for the case selection. Second, I discuss my approach for data collection on the property rights regime at and around mine sites, which involved the use of snowball sampling as a participant recruitment tool. I then move to a discussion of the interview process. Next, I address issues of reflexivity linked to my identity and positionality as a white, middle-class, Western woman. I reflect on the potential impact of my positionality and identity on interactions with the people who participated in this research, and on the impact these factors may have had on my results. I then move to a discussion of ethics, access, and security, which is particularly salient given the challenging context of the DRC and the sensitivity surrounding research on the mining sector. In a related discussion, I then describe the significant additional limitations I encountered in the course of this study, and how I dealt with them. I conclude with a discussion of reliability and internal and external validity.

\subsection{Case Selection}

The technique of "structured, focused comparison" involves posing carefully selected questions in a consistent manner across cases (George and Bennett, 2005). This approach makes it possible to contrast different cases; each mine site constitutes a different case. For site $\mathrm{C}$, where the company has been granted a very large concession encompassing many villages and towns, I refer to, and describe specific dynamics of, three different sub-sites $(\mathrm{C} 1$, $\mathrm{C} 2$, and $\mathrm{C} 2$ ), but I do not systematically compare different sites within $\mathrm{C}$.

My initial aim was to choose six mine sites for a systematic comparative analysis. Upon arriving in Lubumbashi, it soon became clear that with the proposed time frame of nine to ten months of fieldwork (and particularly when, for several reasons, that was cut to 7.5 months) it would not be feasible to compare six sites with sufficient depth. I dropped to four sites and finally three as it became clear that identifying sites to study and then doing the research would be more gradual and time-consuming than I initially thought. Additionally, I spent time at three different locations within site $C$, which means that there were actually three parts within the overall case study. Another issue was that the initial scope of my 
research design was too broad. I started out looking at employment, land, and artisanal mining across the different sites. I soon realised this was too much, and decided to focus on artisanal mining, but I was already halfway through my research in the DRC by then.

When I first arrived, I had had little time in advance to identify and contact individuals to speak with because immediately after defending my $\mathrm{PhD}$ prospectus, I travelled to western Kenya to do fieldwork for a different project. I arrived in Lubumbashi over a month later having made only one prior contact, a $\mathrm{PhD}$ candidate who helped me organise housing. Fortunately, having previously conducted research in environments where I had few contacts, I knew I would not have a problem using snowball sampling. Though it took about a week to set up my first meeting, once I did that I had a set of contacts that then allowed me to begin branching out. Things moved very quickly after that when it came to meeting with civil society, academic, and company contacts and, later on, communities at and around LSM sites.

Choosing the companies to study and gaining access in the sense of being permitted to set up interviews with company employees, and to visit these firms and their mine sites was, unsurprisingly, more of a challenge than setting up meetings with academics and civil society. For company C, for example, it was not until the end of September (I started my research in Lubumbashi on August $8^{\text {th }}$ ) that I was invited for an official, multi-day visit to the site, staying in company housing. It then took several more months before I was informed that I had not been granted permission by the head office to interview company $\mathrm{C}$ employees. Nonetheless, throughout my stay I managed through local connections to interview several company $\mathrm{C}$ security officers. In one case I saw a man on the street wearing a company security uniform; I gave him my card and asked him to call me, and he did. At least one other company in the Lubumbashi region also appeared to play the delay game, but by then I had already chosen two other companies in the area to study. Different companies reacted differently to my request, and I had to adapt my strategy. An academic at the University of Lubumbashi who I met in the early days of my research warned that I could either research company $\mathrm{C}$ from "within", in which case I would be housed by the company and the community would likely be unwilling to talk to me, or from "without" (i.e. based in the community), in which case the company would refuse to engage with me. Yet his prediction did not come true at all the companies I chose. Company $\mathrm{C}$ did refuse official access to their employees, but at company B I had official permission to interview company staffers and spoke with a range of people in the communities surrounding the mine site. After seeing that company B had sent a representative to the tripartite IDAK forum workshop in August 2016 on the subject of corporate social responsibility, I approached the company through official channels and was 
ultimately given official permission to interview company employees. In the case of company A, I was able to interview a number of company employees - in fact, more than at B or C but through "unofficial" channels: a civil society contact of mine went to the same church as a company A employee.

\subsection{Data Collection Approach}

The first step in the data collection involved a review of the primary and secondary sources available online that examine conflict, including violent conflict, at LSM sites in Haut-Katanga and Lualaba. Sources of this nature were relatively limited. Even in the region, where you can find sources available only locally/in hard copy, there was not a significant amount of published information to be had, though I did meet several doctoral students working on these issues. The fact that some documentation is available only in hard copy including some local NGO reporting on corporate engagement and the negative consequences of LSM - also means anyone researching these issues without being on the ground is at a disadvantage.

Once in the DRC and as I narrowed down my choice of cases, I gathered as much information as possible on companies' specific enforcement practices. This included the careful study of publicly available documentation on corporate activities - including environmental, social, and human rights reports, company websites, and news items - for the selected case-study sites, to lay the groundwork for interviews with company representatives.

The process of identifying, contacting, and following up with mining company officials involved doing as many interviews as possible with company representatives to understand the process that led to their practices, and to any variation between cases. I had aimed for a minimum of five interviews with company staffers per site, which would have added up to a total of 30 if I had chosen six case studies. In the end, with only three case studies, however, I interviewed nearly the 30 representatives I had targeted, though several of those interviewed worked for relevant companies other than the three case studies chosen. In my original research plan, I planned to assess the differences between high-level corporate policies/strategy, and the realities of how companies engage on the ground (Hönke, 2013), which was going to include speaking to both headquarters officials as well as to local employees. In the end, however, I focused on what was actually taking place on the ground following, as discussed in the literature review, recent academic scholarship on MNC investment in areas of limited statehood - and limited myself to interviewing in-country representatives. This decision was also partly strategic, given the challenging process of 
identifying and getting permission to interview company employees. That said, when I was trying to organise research on company $\mathrm{C}$, I was informed that I could not interview employees but that I could send a questionnaire and the company would send responses. Therefore, the official responses from company $\mathrm{C}$ arguably reflect high-level "policy" rather than the nuances of on-the-ground practices.

This area of research is a sensitive one in which companies and the security forces have an incentive to portray their actions in the best possible light and minimise publicity on abuses and deviations from procedure. A crucial aspect of the methodology was therefore triangulation - complementing the information provided by company representatives with information from a range of other sources like NGOs/civil society organisations, community members and/or people involved in ASM, and the Congolese press. I also carried out "unofficial" interviews with company employees. Gathering this additional information was also necessary given the challenges in getting company representatives to speak to me and/or to share information beyond the company's official line. An advantage of the way my research project was formulated is that it focuses on the political economy and property rights regime at and around mine sites - of which company practices form only a part, albeit a significant one - and on the arrangements through which mine sites are governed, rather than on company characteristics and how these impact corporate practices. Therefore, while gathering information directly from mining companies was an important part of the research, limitations to the amount of data I could gather from companies did not pose a serious threat to the project. In terms of documentation publicly available online, there was little standardisation in reporting across the three case-study companies. Company $\mathrm{C}$ has made far more material available online than the other two, including environmental/social impact assessments and reporting to the Voluntary Principles on Security and Human Rights. During initial meetings with company $\mathrm{C}$ representatives, I was handed documentation on different dimensions of the company's corporate social responsibility. Companies A and B had far less material publicly available online and offline.

The second step of my research project, after gathering publicly available information on each of the case-study companies, therefore involved interviews and focus group discussions, with individuals from a range of occupational and social categories, at and around mine sites and in urban and rural mining areas. The aim of these interviews was to map out the property rights regime in place at and around mine sites, the evolution of the situation over time at each site, and factors contributing to conflict. Over a period of 7.5 months from the beginning of August 2016 to the end of May 2017, I conducted more than 
200 (nearly 210) interviews in Lubumbashi as well as at and around LSM sites A, B, and C, a number of which were group interviews with multiple respondents. I interviewed a mix of respondents that included mining company employees, government officials, customary leaders, community members, representatives of artisanal mining cooperatives, artisanal miners, traders, representatives from the justice system, and transporters. This total does not include repeat - second or even third - interviews with respondents whose input was particularly useful. The artisanal miners themselves include only men: in this region women are not allowed to go into mining pits, for socio-cultural reasons including belief systems. Therefore, I made sure to interview women from different walks of life, including company staffers; one higher-up official from the Congolese national police; female traders; artisanal miners' wives and mothers; and women from the community surrounding mine sites. However, inclusion of women, and a more in-depth gender analysis, in this project remains a weakness of the research design.

These interviews, in addition to site visits and observation at sites A, B, and C, yielded a wealth of information on the property rights regime. The aim was not to do random sampling or ensure representative sampling, since I did not have the training or means to do so, but to build up a picture of conflict dynamics at and around LSM sites and triangulate my findings in a range of ways.

\subsection{Reflexivity and Access}

I now move to questions of reflexivity with respect to my identity, positionality, and privilege as a white, middle-class, Western woman and researcher. Working in the area by myself meant depending to a significant extent on local assistance and support, yet my positionality also reflected the fact that I was significantly more privileged than many of the people I worked with or interviewed.

In the Congolese context - particularly in the context of the mining sector where foreigners wield a significant amount of money, power, and privilege - foreignness, and especially foreignness with white skin, opens a lot of doors. The colour of my skin undoubtedly gave me a lot of access to respondents, especially high-level respondents, who might not have had any interest in meeting with me if I were a Congolese PhD student. While I'm not in a position to prove that conclusively, there was significant interest in my presence and in learning about what had brought me to the DRC all the way from Canada. This is likely to have been reinforced by the fact that I'm a white woman: patriarchal values that position women as needing men's help are, in my experience of parts of the DRC, strong. 
While being white may have gotten me access to people to whom I would not otherwise have had access, it is not clear whether this access led to more or richer information, or less, than if I were Congolese. The impact is likely uneven. While some people may have felt more comfortable sharing sensitive information with an "outsider", particularly people with some familiarity with academic research and its ethical principles, others were understandably wary about not knowing who I was or how I was positioned in the political economy of the region. For example, my research assistant at site $\mathrm{C}$ mentioned that some people at site $\mathrm{C} 2$ probably thought that I worked for the mining company, even though I arrived on the back of a motorcycle and not in a company vehicle. More than once, I showed up to an interview with an artisanal miner or trader only for them to say that they were not, in fact, involved in the business, though my research colleague who knew them and had set up the interview assured me they were. The greater access afforded by my white skin was also to a large extent outweighed by my inexperience and lack of deep knowledge. Nothing drives this home more than my discussions with one researcher working on a comparative $\mathrm{PhD}$ study on the coproduction of security at sites A and B. This person's access to and knowledge of police activities at LSM sites was astounding. Their project and findings were both theoretically sophisticated and extremely rich in terms of empirical data. While I did gain a solid understanding of certain sets of dynamics, one can't develop profound knowledge based on truly knowing a place, and instinctively understanding its inner workings and contradictions, in a 7.5-month period. I therefore relied a great deal on others to verify and validate information I had collected.

Equally, being a (white) woman presented both opportunities and challenges. While, as noted, some men were keen to assist me in every way possible and were very helpful, others took an unhealthy interest and I had to fend off unwanted advances and intrusions into my personal time and private life, particularly at the beginning before I learned how to handle these issues better. Some artisanal miners also made unpleasant and unwelcome comments as I walked through their villages and towns; I did not feel comfortable entering site $\mathrm{C} 2$, or roaming around town $\mathrm{C} 3$, without being accompanied by a research colleague. To a certain extent I was insulated from these comments by the fact that I didn't understand what the miners were saying to me in Swahili, but my research colleague told me later.

My financial status also placed me in an ambiguous position. I interviewed a number of poor people and families from a place of significant privilege and wealth, with all the moral and ethical responsibility that comes with that. However, engaging with a number of people in the mining sector and with government officials at the provincial level meant that I also 
interacted with several people who, at least in the context of southeastern DRC, were living a more obviously wealthy lifestyle than $\mathrm{I}$, as a $\mathrm{PhD}$ student on a limited budget in an expensive city, could afford. This led to some amusing situations in which people seemed surprised that I did not have my own vehicle to get around and was using taxis instead, or offered me rides. While I bought many a soda or beer for company or government interviewees whom I met at bars in town (for more sensitive interviews when they did not want to meet at their official places of work), at times it was others offering to buy me drinks or a meal. One friend in particular - a research assistant at the University of Lubumbashi - set up several interviews and even drove me in some cases, without asking for or accepting anything in return other than a gift from Canada after the holidays. Another Westerner told me that if my newfound Congolese friends were to visit me in Canada, I would be expected to do the same for them.

Overall, because of my specific positionality and despite my significant access, I likely only scratched the surface of some of what I was hoping to learn. It helped a great deal to have locally embedded interpreters/research colleagues who brought their own insight and detail to what respondents told me. For this project, the results are therefore imperfect and partial, and I do not claim otherwise. In presenting the results I endeavour not to make any claims unless, given the time and resources available, I was able to gather significant empirical support for them.

\subsection{Ethics and Security}

The DRC in general is a context in which research is challenging and potentially sensitive, given the country's typically tense political environment and recent history of armed conflict, which continues to persist in the eastern part of the country and elsewhere. The mining sector in particular is a sensitive area for research given the Congolese government's reliance on LSM for a significant share of its revenue. My area of study, artisanal miners who enter LSM sites to mine without company permission, is particularly sensitive given that these activities are illegal according to Congolese law. One concrete example of this unfolded in the middle of my second research stay, when I was trying to get permission to speak with representatives from the Groupe mobile d'intervention, an intervention unit of the Congolese police with a base not too far from company B's site. I tried for some time to get permission to meet with the GMI before the official I was dealing with beckoned me into a private space and told me that he was afraid. Weighing the usefulness of speaking to GMI representatives versus the responsibility of potentially jeopardising this officer's career, I dropped the attempt there and then. Given the sensitivity 
of this research and the possibility of negative repercussions for the people involved, from the beginning I had to be mindful of the risks both to myself and to others. Having gone through the process of gaining permission for this research from Carleton University's Research Ethics Board (CUREB), I had already been thinking about the implications of, and potential risks linked to, my research in terms of potential harm to participants and to me.

As many researchers before me have discovered, there is always a difference between research plans and carefully thought-out ethics approaches, and what is possible on the ground. I had explained to CUREB that oral consent would be sought, and fortunately this was accepted. I knew that although it would be desirable to have a clear statement for participants to read and sign regarding the details and possible risks of participation in my research, it was not practical in this environment to ask people to sign anything. Instead, I explained key concepts like the objectives of the research, its voluntary and non-remunerative nature, the time frame for withdrawing participation, and the measures in place to protect people's identities; I also provided my contact information.

One of the main risk management strategies I implemented was to limit the amount of personal data I collected, particularly from artisanal miners and community members living at and around mine sites and therefore potentially exposed to the most risk. Though I knew the names of some of the miners I interviewed, with the help of my research colleague, in the communities around sites A and B in the Lubumbashi area, in most cases I did not even have a record of their names. One exception was, as in at least one case, if I ended up gathering a more detailed narrative of that particular miner's life. Other than occupational category I never recorded any names or other identifying details, like location of a miner's home, in my notebook. When typing up my notes I assigned each interview a unique number based on the date of interview, again omitting any personal identifying information about the interviewee. I kept an Excel file, with identifying information, separately from the actual contents of each interview, on my laptop, which is password protected and was always under lock and key or with me. However, some measures that I had originally planned to implement as described in the documentation submitted to CUREB, namely storing data on an encrypted USB key, did not happen. I had an encrypted USB but did not take the time to figure out how to use it, a mistake to avoid in the future. In terms of data storage, I uploaded my interview notes and recordings to the Carleton cloud whenever I could, but this was not always possible due to the quality of Internet in Lubumbashi. These limitations demonstrate the importance of working out not only the principles of a research, data collection, and ethics plan, but also a clear plan for implementation, and sticking to it despite the challenges and stresses fieldwork brings. 
The way I implemented the research was influenced by the sensitivity of the topic and the need to avoid certain subjects to ensure my own safety and that of my interviewees. For instance, some people at times ventured into discussions of artisanal and small-scale mining sites owned or operated by members of the presidential family. I deliberately chose not to pursue this as an in-depth line of inquiry, not only because of the lack of immediate relevance to my research question but also because of the sensitive nature of investigating any involvement of the presidential family in business activities like mining. The possibility of danger did not only come from the government, however. Someone with extensive knowledge of company $\mathrm{C}$ told me that the company would be aware when I was in the area and would have informed themselves on who I was and what I was doing there.

Another tactic was to change the emphasis of my questions depending on the person I was interviewing and going with "easy" questions or questions on which they would have a lot to say, so they wouldn't see me as a journalist or investigative reporter. When speaking to a mining company employee I would start out by saying that I was looking into artisanal miners' activities in their concessions, while with representatives of the public security forces I would talk about looking at company investment. In this way I was able to gain different perspectives on the same issue without raising too many red flags, which was very useful for triangulating my data. Each actor was unlikely to point to human rights abuses or deviations from procedure that they themselves had committed but was more likely to do so regarding another party. I was then able to take stock of all the information I had collected and weigh the evidence both in terms of what others had said and what I was able to observe myself.

While I was very mindful and aware of the security situation and potential risks to participants, I nonetheless found myself in several situations that led to risks both for me and for others, which demonstrated the ongoing limitations to my understanding of, and ability to navigate, the risks. The first of these occurred during a group interview at site $\mathrm{C} 2$, a small town in company $\mathrm{C}$ 's concession that I visited a number of times and where many artisanal miners live and work. Given that I was doing a group interview with a family of traders and miners, sitting outside where they live, I did not think too much of it when - although I started the interview speaking to two traders - others came to join our conversation, so many I stopped counting. At one point a woman wearing ordinary clothes appeared. I have often been in group discussions where a lot of people arrived that I did not know, and I have trusted that the people with me would let me know if there was something to worry about. It turned out that this was perhaps not the best strategy to adopt, and that I should have discussed security measures and potential risks with them before beginning the interview. After the woman's 
arrival, without sufficient awareness of my surroundings or who might be listening, I decided to ask if my interviewees knew about killings of miners. The woman started angrily saying that she was with the Congolese army, the FARDC, and that I should have signalled my presence in the village to the FARDC or to the police. She said it was not sufficient to have done so in the main town $(\mathrm{C} 1)$ because we were at $\mathrm{C} 2$, and that my assistant had given me bad guidance in this regard. She and my assistant had a long, drawn-out argument in Swahili and some of the people present at the interview tried to defend me, which backfired somewhat when she asked why they were defending the white woman. Finally, I asked her to identify herself and she said that she was from the détection des anti-patries of the FARDC, which was alarming. Her colleague, who had arrived by then and was half in uniform, was from the Bureau 2, the intelligence agency of the Congolese police. Fortunately, after a long and acrimonious discussion mainly between my assistant and the others, we took motorcycles back to the main town to meet with the commander. The commander checked my paperwork and the situation was resolved, even though the woman wrongly told him that I had been taking photographs. My assistant told me afterwards that she was just trying to get money out of me and that she ended up looking silly, since it seemed that we could have sorted it out at site $\mathrm{C} 2$. One of the officers even tried to ask for me money as I was leaving, for the supposed cost of communicating with his superior officer, and I ended up giving him 1000 francs (less than 1 USD). ${ }^{13}$ While the situation was amusing in a way, it could have been much more serious: the woman accused me of being a mercenary. Foreigners have been imprisoned in the DRC on accusations of spying, and a number of local journalists (and two UN Group of Experts researchers) have been killed. Paradoxically, my past experience in the DRC may have contributed to my taking this scenario less seriously than I should have. Previous experience being confronted by the military in northeastern DRC gave me the belief that I could talk my way out of anything, which is not ideal in a situation in which other participants are involved and potentially at risk. In the end, I was fortunate in that there do not seem to have been any longer-term repercussions for anyone involved in the incident.

Another incident in which the outcome was not so benign took place in Lubumbashi. At a mineral-buying site near site A, I met a trader who I was able to interview later on. He very kindly offered to take me to a mineral-buying depot in Lubumbashi the next day so I could see what went on. I asked him if this would not cause problems, and he said it wouldn't, so we arranged to meet the next morning outside the depot. The two security guards at the

\footnotetext{
${ }^{13}$ At the time of the research the exchange rate was approximately 1 USD $=1400$ Congolese francs.
} 
entrance seemed okay with my presence; my companion told them that I was his friend who came to visit. But as I was starting to observe what was happening, a man (not in uniform) started asking what I was doing, if I was doing research. He told my companion and me that this wasn't allowed, that if I was going to come and do research he had to ask him, the man, for permission first. My companion said I was not doing research and we promptly left. I spoke to the trader after the incident and he said that they confiscated his minerals and had still not returned them (but he thought they would). He seemed more upset about the fact that the two guards at the entrance, with whom he collaborated well, were replaced. Moreover, he had been forbidden from doing his activities at that depot. Ultimately, his minerals were returned to him, but 100 kilos of minerals (out of 450 kilos) were not returned. The two guards were removed for good from that particular depot site because they had allowed me in. However, they did not lose their jobs, he said, but were simply moved. This incident made clear that even though the trader assured me that taking me to visit the depot would not lead to problems, I should have taken the possibility for trouble far more seriously. I now see the need for consulting others in a risk assessment process before visiting potentially sensitive sites like mineral depots, which could include asking contacts in civil society or academia whether a depot visit was too high-risk.

I became convinced over time that some of the artisanal miners - one in particular, who had been shot in the arm and beaten - might be suffering from trauma linked to abuses by the security forces. I had told CUREB that I would carry a list of human rights NGOs with me should anyone express the wish to report something. When I tried to mention human rights NGOs to a small group of miners whose friend had been killed, however, my research colleague told me not to mention it. I asked him why afterwards, and he explained that if miners heard me talking about an NGO they would just want money. That may be, but miners likely also have reasons for not wishing to report certain violations. It may be too risky for them and doing so might jeopardise their precarious livelihoods. They may also feel there's nothing in it for them. That's one possible explanation for why miners sometimes rise up in protest and reportedly attack company property if one of their own dies - it's a quick and direct way to get retribution and/or a response.

Other risks to my safety that I did not properly assess include those associated with poor infrastructure and unsafe forms of transport, a common problem in the DRC. To keep costs down and because it was the easiest option, in company C's concession I was in the habit of taking hired motorcycles with my research colleague, to get from one town to the next. I was used to doing this from taking motorcycles around Goma, eastern DRC, in a 
previous role. However, while this was mostly fine, if a little nervewracking - especially in town C3 where I experienced a hair-rising ride on a bumpy path - a couple of incidents put my safety at real risk. In the first, I accidentally got on the back of a drunk driver's motorcycle, and he started speeding up wildly, even more so when I screamed at him to slow down. He drove very fast past a number of trucks on the too-narrow road, and we were at risk of colliding with one of them. He was going so fast that some artisanal miners on the road tried unsuccessfully to stop him. While I miraculously made it safely to my hotel a terrifying tenminute ride away, the outcome could have been very different. In a second incident, I was stepping out of a taxi when I came within two feet of being hit by a man who had lost control of his motorbike. I saw him out of the corner of my eye and stepped out of the way just before he crashed (the people in the vicinity speculated that he was drunk). Amazingly, he seemed unharmed and, after tinkering for a while, repaired his motorbike and got on his way. Lesser incidents included getting into a taxi in which the driver had an open can of strong beer beside him. These incidents highlight the not-insignificant dangers of research in the DRC and demonstrate the importance of a proper risk assessment. Yet as the second incident demonstrates, risks can't always be avoided, especially given often-poor infrastructure and limited enforcement of traffic safety laws in the DRC.

\subsubsection{The Question of Remuneration for Research Participants}

When working in the Global South, the question of whether researchers from universities in the Global North should pay research participants has generated, and continues to generate, much debate (this is also the case in international development studies and programmes). Having an "international development" background and having worked with listening groups in the Democratic Republic of Congo and the Central African Republic, I was aware of the arguments for and against paying participants. Not having run my own academic research project before, I contacted a researcher I know with significant academic research experience in eastern DRC. She told me that she generally didn't pay but would sometimes show her appreciation by buying a beer for an artisanal miner. I took this to mean that a flexible approach would be acceptable. When I started my research interviews in the community it was my habit to bring a small gift to interviewees, but only to the families/community members living in the vicinity of the mine sites, not civil society representatives or academics; I would buy the latter a beer or soda. I brought gifts like cooking oil or flour particularly when I knew I would be interviewing women, from whom I 
was taking up time with my research. With group interviews I brought sodas and sometimes biscuits. This kind of gesture is not only appreciated but, admittedly, was a way to alleviate my persistent feelings of guilt for taking people's time to participate in research from which they would likely see few tangible benefits. However, Lubumbashi is expensive and ordinary household items like cooking oil or flour are not cheap. After a while I had to cut back on these expenses for budget reasons, and in any case, I had started to interview artisanal miners, who at least have a way of earning some money.

While I felt comfortable providing small gifts to community members, an incident with a local chief revealed my biases and lack of preparation to deal with requests for money. A chief and a couple of his associates showed me around an area in Lubumbashi that was a village before a mining company displaced it. After our time together, I was told that payment was expected for the chief. My brain switched into the mode of thinking this was not a legitimate request, since the chief is a representative of the community and should speak on behalf of his community without payment: a very Western perspective on authority and especially on chiefly authority. In the end I gave them 5000 francs, only about enough for two beers. Afterwards, it occurred to me that I had reacted the wrong way. I should have behaved with more respect and given enough money to show my respect for the chief's authority. After all, he had taken the time to show me the place and explain its history. From my Western perspective I had failed to understand and recognise the chief's power and importance - which, ironically, is a complaint sometimes made about mining companies. My reaction may have been partly due to the fact that several people had mentioned this chief's limited power in the urbanised Lubumbashi context. In the case of a different chief, a land chief whose lands are in company C's mining concession, I instinctively showed more respect and deference. Many people had talked to me about his prominence and continued authority even in the wake of rapid change linked in part to the mining sector. On one occasion I waited for him for nearly four hours at my hotel for a meeting before giving up. On another occasion, he was short some money to pay for drinks when I had a beer with him and his entourage after he took me to visit a nearby village. I willingly gave him the money in order to avoid embarrassment, and because it was only fair after he'd taken me on a visit to the village and, in a way, sanctioned my presence there.

\subsection{Research Limitations: Documenting the Past}

In this section I delve in depth into the multiple research limitations that I faced, often related to the challenging environment but also at times linked to a lack of sufficient 
preparation. Several limitations relate to gathering and assessing the data on conflict incidents, given the language-related and other tools available to me at the time. These efforts were complicated not only by the challenges of on-site research in general, but also the specific difficulties of the Congolese research context, particularly when researching largescale mining in general and miners' incursions into LSM sites specifically.

The fact that I do not speak Swahili was a significant limitation. It was my intention to learn Swahili before starting my research. I unfortunately did not achieve this goal before arriving in the DRC for reasons including the demands of two years of a full course load, followed by a year developing my project (including a semester abroad) and writing articles for publication. Though I signed up for a Swahili class in Lubumbashi, my frequent travel to site $\mathrm{C}$ meant I had to drop out. Consequently, I was reliant on interpreters. As a result, the issue of research colleague training and capacity played a more important role. My Lubumbashi interpreter had not done this type of work before, and I was relatively new to academic research and ensuring quality interpretation. In the Lubumbashi region I hired a young research assistant who lives near one of the case-study mines. His research strengths include local connections and excellent knowledge of the local context and neighbourhoods around the LSM sites. However, given his lack of experience with research support and, more importantly, because I did not allow for thorough training, certain challenges presented themselves. He would often interject and give his own views, and I had to tell him several times not to, but he didn't always remember and would sometimes get carried away. At times he would use a different word than the respondent, and I would have to catch it. The insufficient training was partly due to the short time frame, but also to my assumption that my objectives and way of working would be clear, despite knowing that he didn't have experience of working with an international researcher. Similar issues at times arose with my research colleague in the site $\mathrm{C}$ area, who despite significant experience as a community journalist would at times play the role of a respondent rather than of an interpreter. On the other hand, the large number of interviews is a mitigating factor, because it made a misunderstanding or misinterpretation in any one interview less of an issue. This experience demonstrated to me how important it is to build in sufficient training for interpreters and most importantly - to clearly distinguish between the very different roles of interpreter and respondent when working with local research colleagues with significant knowledge of the context. That said, these local colleagues' access and knowledge was invaluable in gaining access to respondents and it would have been nearly impossible to gain such access without their support and dedication. 
The empirical record on conflict and violence at LSM sites in the DRC is a challenge to determine including getting data on, for instance, deaths of miners. Some incidents of deaths or injuries of miners have been covered in the local media including the United Nations Organization Stabilization Mission in the Democratic Republic of Congo (MONUSCO)-run Radio Okapi, but not all that were reported to me were in the news: while large-scale incidents get coverage, there is a lack of coverage of lower-level or less "visible" incidents. In general, there's a relatively external limited flow of information from these sites, unless incidents are high profile (involving casualties) and/or spill out into the community. The Congolese mine police have an incentive to conceal confrontations from the companies, while artisanal miners at times lack information on what has happened to their friends and colleagues, particularly if these individuals are arrested at night. Companies have an incentive to hide information about accidents or violent incidents in their concessions (civil society representative, interview, August 22, 2016). Mining companies do not want publicity for deaths in their concession, though company $\mathrm{C}$ has written about such incidents in its Voluntary Principles on Security and Human Rights reporting. One private security company representative expressed the view that miners are wounded or killed by the police on a regular basis and that when this happens, everyone is aware, but the company never allows the information to spread (interview, May 22, 2017). A journalist who lives in town C1 reported that sometimes miners who die in accidents, or something else, are buried without people knowing. Miners at times report these incidents and the disappearance of their colleagues, but many of the miners are not from the area. Therefore, these deaths are sometimes not known locally. Miners frequently enter mine sites at night, so incidents often occur under cover of darkness. Miners are sometimes also afraid to denounce these deaths because of their clandestine status (interview, February 7, 2017). Gathering independent information to triangulate miners' reports proved a challenge, for reasons including the fact that I was conducting research on past, sometimes several years past, events. Before I began the research, I intended to focus on the five years prior. However, once I began it became clear that I would have to go further back to a key historical event: the clearing of sites A, B, and C nearly ten years before. While certain interviewees had difficulties recalling some events, incidents like the violent clearing of site A by the security forces left indelible imprints on respondents' memories. In other cases, respondents struggled to remember the specific month or even year in which a miner friend died.

Concealing information is not limited to companies: an attempt to seek information about miner injuries or deaths from a medical professional at a health centre in a mining town 
in company C's concession yielded little information (medical professional, interview, March 9, 2017). While the medical personnel at the health centre in town $\mathrm{C} 3$ were very friendly and I was given a tour, the nurse I asked first said that miners injured in accidents are indeed brought to the health centre. If they die, they are brought to a diffierent location where their families can collect their bodies. Regarding other kinds of injuries, the nurse said that this happened when they got into fights among themselves but did not admit to other types of injuries such as the security forces injuring or killing miners. My research colleague added that they would not be able to say that miners arrive at the health centre with gunshot wounds because the company gave the "great gift" of the health centre, which he said might be one of the best places for healthcare in the DRC. A doctor was also reluctant to share information about injuries (medical professional, interview, and site visit, March 9, 2017). ${ }^{14}$ This reluctance, as mentioned by my research colleague, is likely linked to the fact that the mining company built and sponsors the health centre.

Artisanal miners were often more open about incidents, whether they had experienced conflict or violence or heard of it happening to friends, teammates, or acquaintances. ${ }^{15}$ Yet they did not always have perfect information. The colleagues of one artisanal miner told me he had disappeared some time ago and suspected he had been killed. When I talked to one company security representative, however, that representative mentioned the man's name without being asked about him and said he had been in jail but had recently been released (company B security officer, interview, January 27, 2017). Not long after, his release became known among his former associates; soon after that, I was able to meet him in person (miner and his mother, interview, March 29, 2017). One miner who had stopped going to site B because of the risk remarked that, in order to hear about incidents involving the death of a miner, he would have to actually enter the site (interview, February 13, 2017).

Local human rights organisations lack capacity and resources to do investigative work at and around these sites, particularly given their reliance on funding from international partners, while the politically sensitive nature of large-scale mining in the DRC poses challenges. There is a history in the former Katanga province of threatening and intimidation of human rights activists and other civil society representatives, by government officials, for activists' involvement in calling attention to human rights abuses and corruption in the mining

\footnotetext{
${ }^{14}$ For reasons including lack of time, I did not attempt to replicate health centre visits in the Lubumbashi region.

${ }^{15}$ Given that artisanal miners are now forbidden to enter mine sites previously accessible to them, and due to their frequent and recurrent clashes with security forces, they potentially have an incentive to portray mining companies in a negative light and embellish the scale and scope of conflict-related incidents.
} 
industry (Global Witness, 2006). While interviews in Lubumbashi suggested that the situation has improved, in part due to the involvement and activism of international partners, abuses remain a sensitive topic. Many respondents (including a number of artisanal miners) asked that their voices not be recorded while several individuals, particularly those working for large-scale mining companies, were keen to ensure that their identities would not be revealed in any publications due to potential risk to their employment. Even a MONUSCO human rights representative was unwilling or unable to provide in-depth information on conflict and violence at mine sites, deferring to a local partner organisation (interview, November 10, 2016). Yet my evidence shows that companies do have data, sometimes very good data, on incidents, at least to some extent and for some companies. As one company representative said, they have to collect such data in order to respond properly (company B security officer, interview, January 27, 2017).

To some extent, my concern about establishing the "truth" and the "right" facts about killings took on too much importance given that the research was supposed to be more about general trends rather than specific incidents, though establishing the empirical record is part of identifying trends. I was concerned about obtaining accurate information about killings of miners at LSM sites (which are, after all, serious accusations), but I spent too much time trying to confirm events - sometimes years after the fact - that were difficult to verify without additional research. Another problem was that I had anticipated that gathering a list of incidents and asking participants about their own arrests and experiences of conflict and violence would make it possible to determine how the three sites stack up in terms of conflictuality. However, given my reliance on snowball sampling and the relatively limited number of people interviewed, and of specific incidents, it was difficult to ascertain whether either site A or B was (or had been) more conflictual than the other, though respondents' answers suggested trends. I should have included a question about whether interviewees themselves thought that site A or B was more affected by conflict, but self-reporting would not have been conclusive either given the methodology. Therefore, while processing and analysing the data afterwards it became clear that I would need to concentrate more on general trends.

\subsubsection{Snowball Sampling}

As mentioned by Daudelin and Ratton (2018), snowball sampling is a useful tool but has potential limitations if sampling always occurs within the same network(s). In their 
discussion of methodology, they explain that "To avoid being trapped in closed networks, we recruited participants through distinct and unrelated snowball chains." (p. 9) That challenge was a significant limitation to this research. First, the fact that this was my first experience setting up and implementing my own academic research project meant that I did not have sufficient awareness of the perils of what could be called single-strand or single-chain snowball sampling, or of possible options for getting around this limitation. Second, given that I worked alone with part-time support from research assistants/interpreters, I did not have the same kind of access to different starting points for snowball sampling in neighbourhoods surrounding LSM sites A and B in the Lubumbashi region. This was partially a reflection of the context rather than of methodological limitations, however: when I asked civil society interviewees in Lubumbashi during preliminary interviews in the beginning stage of the research, several people pointed me to the same community representative/activist who has been working on advocacy vis-à-vis company B for a number of years. Therefore, though this man could not be referred to as a member of the "elite" by any stretch of the imagination, he did in a sense function as a "gatekeeper" when it came to research in the communities surrounding site B. This dynamic was further reinforced when I decided to hire someone he knows well as a part-time interpreter/research colleague for reasons including that person's knowledge of the area and of artisanal miners who work at sites A and B. A more robust methodological approach would have involved interviewing a greater number of people living near site A, though I remedied that situation to some extent by interviewing several traders (and one landowner) that I met at a trading spot near the mine site.

Despite these challenges, I made efforts to cast a wider net during the snowball sampling process than just the artisanal miners and traders to whom my assistant was able to introduce me based on his personal knowledge/connections. At one point, I was walking around one neighbourhood with my research colleague when we came across a group of young men that he identified as working in artisanal mining. I asked them if they would be willing to talk to me for a little while, and someone ended up kindly bringing us some chairs so we could sit and have a chat. As often happens when an obvious stranger is interviewing people in public, other miners soon came to join us, and we ended up with quite a large group (too big for a comfortable group interview). Another way to get around the problem of related snowball chains was the obvious one of interviewing people from the company itself - a distinct snowball chain, if not totally unrelated to the community: the community activist mentioned above, for example, had long known a company B employee whom I interviewed. 
I also visited the local judicial institution, the parquet, to gather additional information, which, as a different institution, represents a separate line of inquiry.

Another challenge related to the snowball sampling process in the Lubumbashi area was the difficulty of finding active artisanal miners to interview, or even miners active in the recent past. At times I would begin an interview only to find that the person in question had not entered an LSM site for quite some time. Part of these challenges were linked to safety issues: miners were understandably worried about telling their stories to an outsider. While initially frustrating, I soon came to see these challenges as part of the research findings, as they showed the extent to which miners in the region struggle to gain access to sites sold to LSM companies.

\subsection{Reliability and Internal and External Validity}

My study findings have a significant amount of reliability and internal validity given the amount of triangulation I did and the number of interviews in which I repeated the same questions to interviewees from all different walks of life, yielding a significant amount of consistency in people's answers across questions and across cases. Unfortunately, due to poor planning, I ran out of time to arrange a validation session with academics at the University of Lubumbashi, as I had originally planned, before leaving Lubumbashi at the end of May to attend a conference I was helping to organise. Fortunately, I had validated my results on a semi-regular basis during the year on a one-on-one basis with academic friends from the area who were working on similar topics, which helped to reinforce the internal validity of my findings. This experience underscored the importance of developing and sticking to a clear plan for validating results with local academics.

In terms of external validity, the ubiquity of the involvement of the security forces along with other government and public- and private-sector actors - in securing LSM mining concessions but also in seeking rents, suggests that there is likely to be significant external validity. Similar dynamics are likely to occur in the many other contexts in Africa in which, as discussed in the literature review, LSM and ASM coexist in an uneasy fashion. However, research in these other contexts is necessary before making definitive claims.

\subsection{Conclusion}

Ultimately, my 7.5-month reseach stay in the DRC was, as I expected, intense, difficult, and rewarding, and raised a number of ethical, moral, and research questions - some of which I have discussed here - to which I am still searching for the answers. In this 
challenging research context, working on a sensitive topic, I faced a number of research limitations. Some of these issues, like advanced training for research assistants, could have been addressed with better preparation, while others, like unexpected threats to physical safety, were more difficult to predict and prevent.

What the above discussion should make clear is that this research project was and is very much a collaborative effort. Without the support of research assistants and local friends and colleagues, and the willingness of a wide range of people to participate in the many interviews I conducted, I would not have been able to collect the fine-grained, often sensitive data on which this dissertation relies. Therefore, while I typically talk about "my" research and "my" findings, given that this project was built on collaboration with and involvement by a wide range of actors, the term "our" might be a more appropriate one to use. 


\section{Chapter 6: The Property Rights Regime: Laying the Groundwork for Understanding Conflict Incidence at and Around LSM Sites}

\subsection{Introduction}

As noted in the literature review, large-scale mining corporations have been a central element of southeastern DRC's economic and social life for a long time (Hönke, 2009, 2010). Firms do not invest or operate in a vacuum: mining companies co-constitute a property rights regime (PRR) in which are rooted state officials at several levels; public and private security forces; company (middle) management and security employees; artisanal miners; traders; transporters; customary authorities; mineral buyers; and other actors. Authorities at the local, regional, and provincial levels, as well as security guards and police officers at different levels of hierarchy, do not only facilitate but are instrumental in organising the extraction of minerals from LSM sites without company authorisation ${ }^{16}$. The removal of minerals from LSM sites is systematically organised and/or facilitated by agents of the state, PSCs guards, and employees of mining companies, whether small scale (miners carrying bags of minerals out on their shoulders) or large scale (trucks of ore smuggled out of the site). Those responsible for implementing and enforcing Congolese law, particularly the Mine Police but other police units as well, are instrumental in organising and upholding clandestine extraction. These practices are systematic despite the formal, legal framework that privileges LSM and grants property rights to mining companies, and according to which the national Congolese police must safeguard «les personnes et leurs biens » on the entirety of national territory (Kankolongo Mbombo, 2017). While this regime represents a significant amount of historical continuity with previous systems of functioning in the mining sector in southeastern Katanga (e.g. Ngoie Mwenze, 2009), the regime exhibits significant dynamism and adaptation to changing circumstances such as rapidly fluctuating mineral ore prices, rising global demand for copper and cobalt, and evolving corporate security practices (Mine Police official 1, interview, November 8, 2016).

In keeping with the property rights framework, this chapter focuses on the practices of a multiplicity of actors, rather than on any single element like company, miner, or state practices. As described in the theory chapter, a state-sanctioned framework simultaneously serves at times contradictory goals: enforcing companies' property rights - which serves the

\footnotetext{
${ }^{16}$ While the concept of "company authorisation" is complicated by the reported systematic involvement of company employees in clandestine extraction, I am referring here to formal, official authorisation and approval from the company.
} 
interests of the central government and its local representatives - and gaining access to rents from the clandestine sale of minerals from LSM concessions. The Congolese security forces work with other actors to uphold and enforce these structures and ways of functioning, with force if necessary.

In this chapter I lay the groundwork for the next by describing the three key components of the property rights regime. I present, in turn, the key elements and functioning of corporate enforcement, overall and by company; authorised clandestine extraction, the wide range of actors who participate in it, and its well-entrenched rules and regulations; and unauthorised clandestine extraction, namely miners' myriad strategies for getting around and/or resisting the authorised form of clandestine mining.

\subsection{Description of the Property Rights Regime and Its Components}

Despite corporate efforts to disrupt and dismantle clandestine extraction arrangements, public and private security and clandestine miners continually find ways to collaborate for the successful and frequently peaceful removal of unprocessed ore from LSM sites. Yet the overlapping of the different components - the authorised system for extracting minerals without company permission, and miners' unauthorised efforts to access mine sites and minerals, each of which at different times become overt rather than covert or clandestine create an inherent instability. In what follows I present the key elements of the property rights regime at and around LSM sites in southeastern DRC, based on the empirical data collected at and around sites $\mathrm{A}, \mathrm{B}$, and $\mathrm{C}$.

\subsubsection{Corporate Enforcement}

This component of the PR regime denotes the institutional means that companies employ, more or less successfully, to define and enforce their legal claims to minerals. The regime's corporate enforcement component varies from site to site: there is no single institutional recipe across firms in southeastern Katanga, though companies share information and learn from each other's security approaches (company A exploration staffer, interview, October 19, 2016). The central government plays a significant role in this facet by signing contracts with companies for LSM concessions in the first place. The different security forces at LSM sites are instrumental in propping up corporate enforcement. The centralised system of government in the DRC, and its political economy, heavily favour large-scale mining companies' property rights. This central government preference filters down to the local level, 
where the private and public security forces deployed to LSM sites uphold companies' PR through a range of means including the use of force.

First, companies draw on first-party - self-enforcement - measures to secure their property rights. These are not only forceful measures but include non-violent defensive measures too. All three companies have set up some type of "fortress protection" at their mine sites (Hönke, 2013; company B security officer, email, May 8, 2017), though these typically correspond to their extraction sites, mineralised areas, and company facilities rather than to the boundaries of their entire concessions, which tend to have people living in them (company B officer, interview, February 6, 2017). For site B, for example, according to a company officer, the population has moved closer and closer to the mine site over time, and part of the community is actually within the concession (company B manager, interview, February 6, 2017). Community members, for example, cross a trench separating them from site $B$ in order to access a water source; simply crossing the trench does not allow easy access to where minerals are found. In its enormous concession, company C's approach is to secure the priority areas (access forbidden) and to secure other zones somewhat less (restricted access) (mining consultant, interview, February 28, 2017). Company A has fully walled and fenced off its mine site (company A manager, interview and site visit, September 24, 2016; company A manager, interview, September 22, 2016) and placed security guards around the wall (LNI representative and Mine Police representative, interview, March 20, 2017; miner and his mother, interview, March 29, 2017). Company B, which relies on fencing rather than walls, is behind fences over a large proportion, though not all, of its perimeter (company A exploration staffer, interview, October 19, 2016; company B security officer, email, May 8, 2017), with security posts every 500 metres (LNI representative and Mine Police representative, interview, March 20, 2017). Company C relies on fences and barbed wire to physically secure its installations and activities (Mine Police representative, interview, February 7, 2017). The sheer size of companies' concessions, however - particularly site C - means that LSM firms can't wall off everything, particularly since many of these concessions overlap with or have communities, villages and even towns within them (company B manager, interview, February 6, 2017). As Fitzpatrick (2006) noted, "Mining license holders may not be able to deter incursions from artisanal miners, including if the "concession area is simply too large, rugged, or densely forested" (p. 1020). MNCs therefore focus on securing extraction sites and company facilities as well as areas where high-value minerals are found (Mine Police official 1, interview, November 8, 2016; trader/miner, interview, May 19, 2017). Companies also use other design elements to secure their sites. At site A, near the fence, the company has a large 
remblai [dike] of stériles [tailings] as a barrier against "thieves" (company A exploration staffer, interview, October 19, 2016); company B places tailings around its site (company B manager, interview, February 6, 2017; multiple site visits). Surveillance techniques also fall into the category of self-enforcement measures. Company B has surveillance cameras, which the PSC contracted by the company is responsible for fixing (three PSC managers, interview, May 12, 2017; occasional miner, interview, March 31, 2017). Company C also covers the entrance to miners' dug pits so they cannot return (miner, conversation, March 3, 2017; businessperson, conversation, March 3, 2017). A businessperson based at site C1 mentioned in March 2017 that in June 2016 company C accidentally closed up a mining pit with artisanal miners still in it; the miners' cries could be heard, resulting in an emergency response by high-level authorities, in the middle of the night, to get the miners out alive (conversation, March 3, 2017).

Yet while both sites A and B are physically secured to a significant extent, both mine sites are also physically open in some places. Miners frequently break holes in the brick wall around company A's concession. On a November 2016 site visit I saw that holes had been broken into the wall in several places, and one of the holes was big enough for a person to walk through without bending down (site visit, November 2016; company A exploration staffer, interview, October 19, 2016, and Mine Police official 1, interview, November 8 , 2016). 


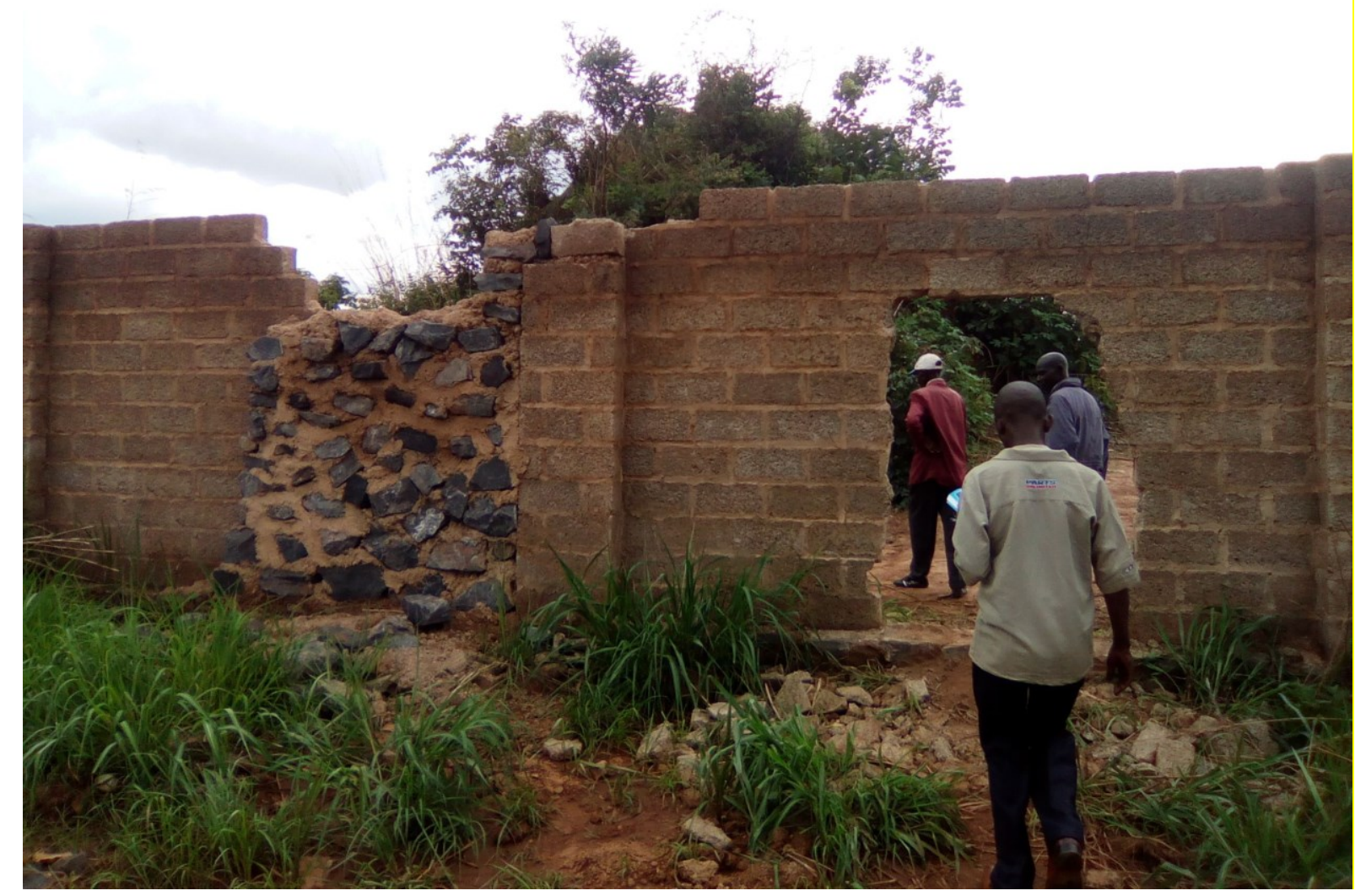

Image 1: Hole in company A’s wall, Sarah Katz-Lavigne, November 2016.

Part of company B's mining concession is separated from the community by a trench dug in the soil, as shown in the photograph below. A Mine Police representative argued that at site $\mathrm{B}$, there is security and fences, but along the perimeter, miners can enter in the 500-metre distance between security posts. In 2014 company B dug a trench to separate the mine site from the community, and prevent people from crossing into it, because artisanal miners had taken parts of the fence (ex-trader/former miner, interview, February 17, 2017; LNI representative and Mine Police representative, interview, March 20, 2017; company A exploration staffer, interview, October 19, 2016). The trench doesn't prevent people from crossing into the site (ex-trader/former miner, interview, February 17, 2017; LNI representative and Mine Police representative, interview, March 20, 2017). 


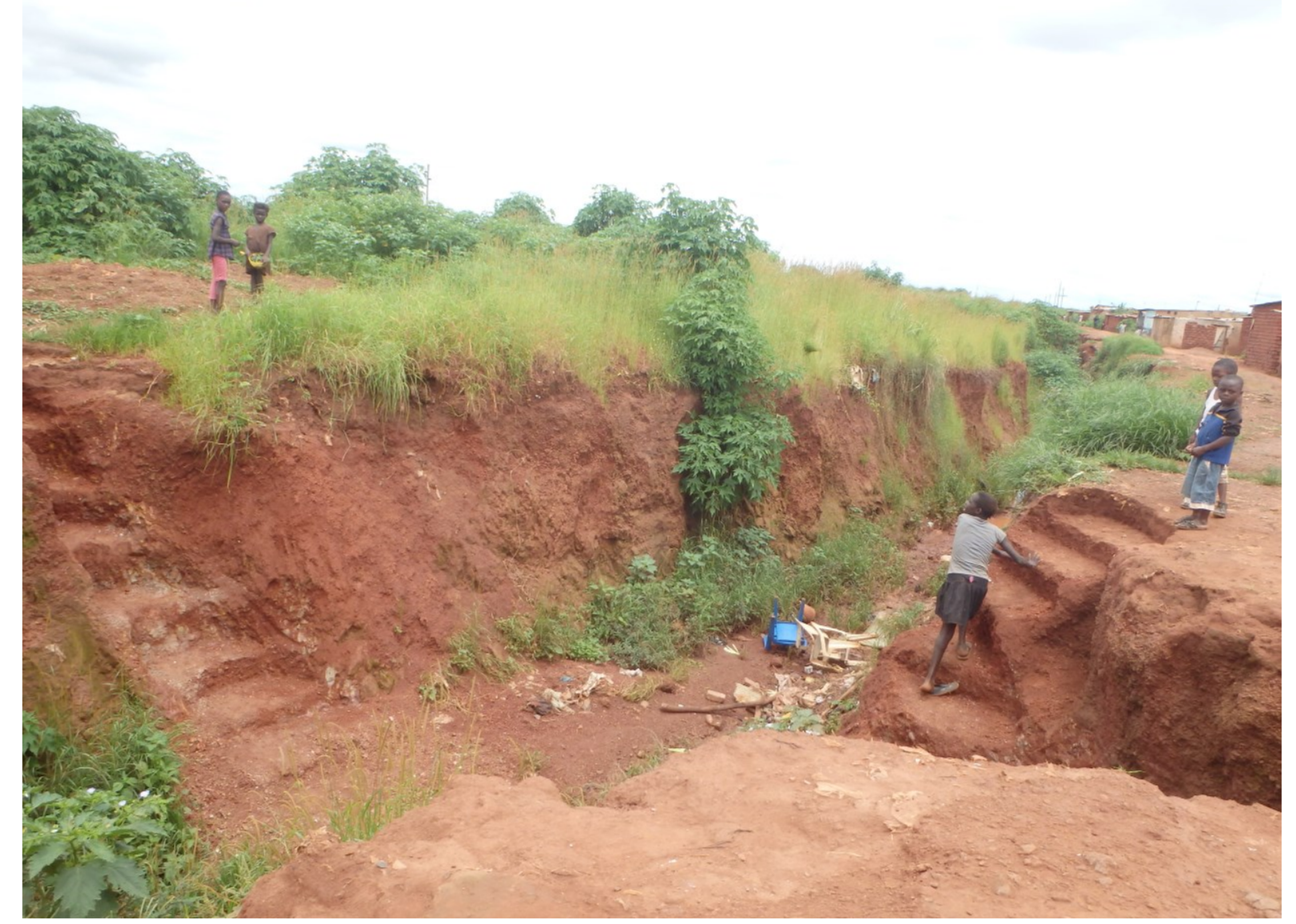

Image 2: A trench separating company B from the local community, Sarah KatzLavigne, February 2017.

Corporations' first-party measures also include recourse to state action, which companies present as third-party measures though they are complex and contain significant elements of self-enforcement. Companies rely on state bodies, particularly security actors like the police, not only because they find it necessary to work with the police due to the DRC's legal framework - given that PSCs cannot be armed - but also to give legitimacy to their selfenforcement practices. While the Congolese state is often portrayed as "failed" or "fragile", as noted, scholars including Geenen and Hönke (2014) have pointed to the projection of central state power and authority on significant stretches of Congolese territory, even far from the capital. The government administration in the new provinces of Haut-Katanga and, to a lesser extent Lualaba (where the full implementation of devolution has taken time), also has relatively more capacity than elsewhere in the DRC, as shown by Diemel and Cuvelier (2015) for the provincial administration, and associated public and private policy actors, in the former Katanga. These dynamics again point to the appropriateness of the "rhizomatic state" categorisation for the DRC. 
Companies' approach to securing their concessions therefore typically includes a combination of one or more private security companies, which may employ guard dogs; company security guards, often referred to in the region as the Industrial Guard or GI, which stands for garde industrielle in French (Mine Police official 1, interview, November 8, 2016; Congolese National Police official, interview, December 7, 2016; company B security officer, interview, January 27, 2017; PSC manager, interview, March 15, 2017; Rubbers, 2019); and state security, usually the Mine Police (the Police des mines et hydrocarbures, PMH). Companies place representatives from multiple security bodies at fixed posts throughout the mine site, often with mixed security at each post, such as one or more PSC agents and at least one police officer. They combine these fixed posts with a mobile strategy: regular vehicle and/or foot patrols. Companies' approaches evolve over time. For instance, company A used to have two PSCs in addition to its company security, as well as two police units (the LNI and the Mine Police), all at the same post (Mine Police representative 2, interview, February 16, 2017). At the time of the research, company A only had one PSC on contract (company A security officer, interview, October 11, 2016).

Companies draw heavily on private security, particularly company $\mathrm{B}$, for whom, at the time of interview, $80 \%$ of security tasks were performed by one PSC (Mine Police representative 2, interview, February 16, 2017; trader, interview, February 14, 2017). The PSC currently deployed at site A to guard the storage area and the barrier is also one of the PSCs on contract with company C (PSC manager, interview, May 22, 2017). Some companies have more than one PSC on contract, as company $\mathrm{C}$ does (PSC manager, interview, March 15, 2017) and as company A has in the past (Mine Police representative, interview, 16 February 2017). Company B only has one PSC on contract (company B security officer, interview, January 27, 2017). There were previously 450 PSC agents at company B, but at interview in May 2017, I was told that there were between 200 and 300. A manager from the PSC at site B said budget cuts were the reason for the lower numbers, and the Chinese owners who purchased the company in 2012. Another PSC manager present during this interview said that the Chinese are "more capitalist"; my main interviewee said that "they reduce everywhere they can” (three PSC managers, interview, May 12, 2017). Companies also divide up duties between different security services. Company $\mathrm{C}$ dispatches a PSC to the extraction site and its own company security to main entrances and barriers (PSC manager, interview, March 15, 2017), while a different PSC guards the processing facility (PSC manager, interview, May 22, 2017). The PSC deployed at company B also has a contract at company $\mathrm{C}$, where there are four PSCs deployed alongside company $\mathrm{C}$ security (PSC 
manager, interview, March 15, 2017; three PSC managers, interview, March 20, 2017; three PSC managers, follow-up interview, May 12, 2017). That PSC has what the PSC manager referred to as "le gros morceau" - the big piece - meaning they secure the mineral deposits (PSC manager, interview, March 15, 2017). At company C's site, that particular PSC has 200 guards; they replace 50 of them at a time to prevent people from becoming familiarised with the guards (three PSC managers, follow-up interview, May 12, 2017).

While, as noted, PSCs and company security guards in the DRC are unarmed in that they are not allowed to carry firearms (Mine Police official 1, interview, November 8, 2016; Congolese National Police official, interview, December 7, 2016; Redacted, 2017), they are armed with batons (bâtons or matraques in French) (three PSC managers, interview, March 20, 2017; three PSC managers, follow-up interview, May 12, 2017; company C security employee, interview, May 27, 2019). The PSC involved in securing both sites B and C protects itself with matraques and guard dogs, as well as armed police, in case of an armed attack. The company, which has been trained for controlling a mass of people, also uses tear gas (three PSC managers, interview, March 20, 2017). This PSC has a specially trained section - the maitres-chien - for guard dogs, deployed at high-importance areas of the mine site. A representative of this PSC told me on May 12, 2017 that there were not yet dogs deployed at site $\mathrm{C}$ (three PSC managers, follow-up interview), though a manager from the same PSC told me on March 15, 2017 that the dogs would arrive at site C on Friday. At a May $9^{\text {th }}$ visit to the office of a different PSC, deployed at site C's processing facility, I saw writing on a whiteboard mentioning a dog deployment at site $\mathrm{C}$. The use of dogs is monitored: a company A security employee who used to work for a PSC with a dog service said that a guard would be punished, even fired, if a dog bit someone (interview, May 21, 2017). Therefore, there is evidence of convergence in different companies' security practices, as with companies B and C's use of guard dogs.

In-house company security, or the Industrial Guard, is also part of mining companies' first-party approaches. The Industrial Guard is a carryover from the Gécamines days (company B human resources manager, interview, March 22, 2017; Gécamines official, interview, March 24, 2017; Ngoie Mwenze, 2009; De Koning, 2009), and more or less present depending on the company. Company A has an in-house security service (company A security officer, interview, October 11,2016). Company B was in the process of significantly reducing the numbers of in-house security (company B officer, interview, February 6, 2017; three PSC managers, interview, May 12, 2017), having handed control of site security to its PSC (Mine Police official 1, interview, November 8, 2016) and largely doesn't have an Industrial Guard 
anymore (three PSC managers, interview, 30 March 2017). There are only 6 or 7 members of in-house security left, who check that company B's security partners are doing their work correctly. All that remains are company B's Officers of the Judicial Police (OPJ) (three PSC managers, interview, May 12, 2017). A PSC manager argued that company B's Industrial Guard was too expensive for the Chinese owners that purchased the company in $2012 .{ }^{17} \mathrm{He}$ described the move as an efficiency measure: with an Industrial Guard, the company can't easily fire a security guard for theft but if someone from the PSC steals, that guard can be removed right away. A member of the Industrial Guard, on the other hand, may not care because he [typically he, not she] gets his salary at the end of the month (three PSC managers, interview, 30 March 2017). A company A security officer similarly mentioned that a benefit of using agencies is that if theft occurs, the company can deduct money from the contract (interview, October 11, 2016). A company C security employee, too, said that company C prefers sub-contractors. In case of theft, they can ensure that those involved are removed from the company, if not from the agency (interview, April 13, 2017). Company $\mathrm{C}$, too, has an Industrial Guard (three PSC managers, interview, March 20, 2017) (Company C Security), members of which are required to have a state diploma (company $\mathrm{C}$ security employee, interview, May 27, 2017). According to a PSC manager in 2017, the Chinese purchasers of company $\mathrm{C}$ were in the process of reducing the numbers of in-house security. When members of the Industrial Guard are caught for theft, he said, the company replaces them with subcontractors (three PSC managers, interview, March 20, 2017). An employee working for company $\mathrm{C}$ security spoke both of human rights and of self-defense techniques. He argued that self-defense for a security employee at the mine involves using the means available: if your adversary has stones, you can use stones; if he has a stick, you can use sticks. The response, he said, must be proportional (interview, May 27, 2017).

Companies also call on the Congolese National Police (the Police nationale congolaise or PNC) for armed support, specifically the Mine Police, a branch of the PNC officially mandated to guard the mines (LNI representative and Mine Police representative, interview, March 20, 2017; company C questionnaire, April 17, 2017). In 2016 I was told that 10 years ago, the PNC guarded the mines, before the Mine Police was created. Mining companies are typically supposed to work with the Mine Police (Mine Police official 1, interview, November 8, 2016; Congolese National Police official, interview, December 7,

\footnotetext{
${ }^{17}$ A university professor contended that sub-contracting is actually more expensive than having an Industrial Guard (discussion, April 11, 2017), which suggests that other reasons are behind the move towards increased sub-contracting in security, including the ability to fire more easily if a security guard is accused of wrongdoing.
} 
2016). Yet as the case of company B shows, they can bring on a different unit of the police, like the Légion nationale d'intervention or LNI (Mine Police official 1, interview, November 8, 2016). Mining companies sign contracts with the Congolese police directly or through the private security companies (Congolese National Police official, interview, December 7, 2016). At company B, it was the PSC that contracted the LNI. According to a Mine Police representative, company $\mathrm{C}$ also deals with the police through the $\mathrm{PSC}$, whereas company $\mathrm{A}$ has a direct contract with the police (Mine Police official 1, interview, November 8, 2016). A company B security officer pointed to the evolution of "delinquent" behaviour as having made this police presence necessary. In 2005-2006, and even as late as 2008, he said, it was possible to use corporate security (the Industrial Guard) without a police presence. Prior to the financial crisis of 2009, there was a lot of money in the market and pressure from above, in clandestine networks, to supply copper. In his view, the situation evolved to one of criminality, with violent attack campaigns employing weapons like machetes and the sharpened metal tools artisanal miners use to dig for minerals. All the mining companies requested the support of the Congolese national police (interview, January 27, 2017). As a manager from the PSC deployed at sites B and C argued, the police supports the PSC: the unarmed security guard is backed by a "muscular" intervention team of dogs, armed police officers, and a vehicle (three PSC managers, interview, March 20, 2017). The language used by company $\mathrm{C}$ in a questionnaire highlights companies' ambiguous, yet on-going need to rely on the Congolese police: "[Redacted] utilizes a contracted private security workforce. In addition, [redacted] security personnel work closely with the social/community engagement teams to anticipate or preliminarily address potential security risks. [Redacted] security also uses the community engagement resources to communicate the hazards and illegality of ASM within the [redacted] concession. This private security force does not engage in lawenforcement activities, which legally reside with public authorities" (company C questionnaire, April 17, 2017, emphasis added). In its reporting for the Voluntary Principles on Security and Human Rights, the company ambiguously refers to the Congolese government "having assigned" a police presence to the concession.

The Mine Police is typically deployed at guard posts throughout the LSM site alongside the Industrial Guard, and/or PSC, at strategic locations like the central open-pit mine, where the engins extract high-value minerals (Mine Police official 1, interview, November 8, 2016; three miners, second interview, March 13, 2017). When there is high artisanal miner traffic, the Congolese National Police itself can intervene, or the company can call the PNC to secure intervention. In this way, companies can get reinforcements from other 
police branches like the intervention and anti-riot units: the Groupe mobile d'intervention and the Légion nationale d'intervention, respectively (Mine Police official 1, interview, November 8, 2016; Congolese National Police official, interview, December 7, 2016; trader, interview, May 10, 2017). The two GMI units in the Lubumbashi region are a reserve force of the Haut-Katanga's provincial police commissariat and trained in maintaining order. A PNC official referred to the GMI as a last resort, the "hammer": once the problems end, they leave the mine site. The GMI uses physical force or grenades lacrymogènes (tear gas). According to the official, PNC services are typically free, but the company can provide them with drinks and/or snacks. Headquartered in the Congolese capital, Kinshasa, the LNI, which is equipped and trained for anti-riot purposes, was originally deployed to Lubumbashi to reinforce the local police for public security reasons (PSC representatives, interview, May 12, 2017). A PNC official explained that the LNI were originally sent to support the response to the activities of the Maï-Maï armed group and had been in the area for two and a half years. Given the LNI's lack of means, he said, they are put at the mine sites pour se retrouver un peu (make some money). He mentioned that the LNI is given a small per diem, but his comments could also apply to the opportunity for clandestine extraction. The LNI is deployed for one month, and then returned to the barracks. The LNI as an anti-terrorism unit has special equipment. He added that both the PNC and the anti-terrorism police can use boucliers (shields) to protect themselves from stones, and that the response always depends on the threat. If the crowd is hostile, the police can use force - like shields and "tonfas" [a type of police baton (Euro Security Products, n.d.)]. If the violence overflows, the police can use nonlethal weapons like tear gas. In principle, then, the Mine Police is responsible for LSM, but if there is a lack of capacity, or a desire for other units to earn something, the commanders can enter into agreements to place other police units at mine sites - though he said that these are exceptions. He noted that artisanal miners are afraid of the LNI (Congolese National Police official, interview, December 7, 2016). Firms have even called in the Congolese army, the Forces armées de la République démocratique du Congo (FARDC), to deal with artisanal miners ("Woman killed in DR Congo", 2019; "Un mort dans des heurts", 2019; Congolese National Police official, interview, December 7, 2016), as well as the Republican Guard (company A security guard deployed at a different site, interview, May 21, 2017). Internal security is the police's responsibility, but the army can come provide support by requisition by the politico-administrative authority (Congolese National Police official, interview, December 7, 2016). These processes demonstrate state support for LSM companies' PR, as 
well as the fact that companies "discharge" responsibility onto state actors (Hönke, 2010; local journalist, interview, May 19, 2017).

The three companies do not all have the same approach for dealing with the police. At site A, the Mine Police patrol alongside company A security (company A manager, interview, September 22, 2016) and its PSC (company A security officer, interview, October 11, 2016) around the open-pit mine; they have vehicles and Motorola radios (company A exploration staffer, interview, October 19, 2016). Unlike at site B and C, the police at site A have a contract with the company itself (Mine Police official 1, interview, November 8, 2016; LNI representative and Mine Police representative, interview, March 20, 2017). Company A, a company security officer explained, relies on competition between security agencies, including a 24-hour police presence, to limit clandestine mineral extraction. The expected outcome is that with a mixed police-private security presence at guard posts, the different agencies will hold each other accountable. The company used to work with the same PSC deployed at sites B and C, but now works with a different agency (interview, October 11, 2016). Unlike at site B, where the police are called only for interventions, police officers and PSC agents at site A are jointly assigned to control posts (Mine Police representative 2, interview, February 16, 2017). Company A has also relied on the LNI in the past (Congolese National Police official, interview, December 7, 2016) and, according to confidential documentation obtained from a company source, the Republican Guard.

While companies A and C have the Mine Police at their sites, the PSC at site B contracted the LNI, a rapid intervention unit of the PNC. The LNI at site B is paid and fed by the PSC (Mine Police official 1, interview, November 8, 2016; police official, interview, February 18, 2017; three PSC managers, interview, March 20, 2017). Despite the fact that in principle, the LNI gets requisitioned for a short amount of time and then withdraws, at the time of interview, it had been around two years (Mine Police official 1, interview, November $8,2016)$. A company B security officer noted that the LNI is used as a second line of defense [after the PSC] (interview, January 27, 2017). At site B the LNI has a contract with the PSC rather than the mining company. Instead of being placed at fixed posts like the PSC, the LNI do intervention. The LNI have a Jeep donated by the mining company and are called by radio when needed. The fact that during an interview with a LNI representative, he received a phone call from a company B security manager, demonstrates the close link between the LSM company and the LNI (LNI representative and Mine Police representative, interview, March 20, 2017). The LNI also do patrols during the day and at night, even on foot, to dissuade miners. According to a LNI representative deployed at site B, interventions are frequently 
required, at least every few days and sometimes as often as every 1-2 days (LNI representative and Mine Police representative, interview, March 20, 2017). There are only 11 police officers at site B, who patrol with the PSC (three PSC managers, interview, March 20, 2017). According to a PSC manager, when a certain post at site B presents a lot of risks, the police are deployed there to intimidate the miners (three PSC managers, interview, May 12, 2017). At company $C$ there are over 100 police officers, headed by a major, who report to company C's Security Manager (three PSC managers, interview, March 20, 2017). At company $\mathrm{C}$, like at company $\mathrm{B}$, as noted, it is the PSCs that sign contracts with the police. With a direct contract the mining company requisitions the police and discusses matters with the police itself (Mine Police official 1, interview, November 8, 2016). In 2016, company C had 320 unarmed security staffers (company security); 810 unarmed PSC employees; and 112 Mine Police members on contract (Redacted, 2017). A Mine Police representative argued that the 112 police officers deployed at site $\mathrm{C}$ is a low number for the size of the concession (interview, December 3, 2016). It may seem puzzling that companies would seek to limit the numbers of armed police in their concessions, but police are expensive (three PSC managers, interview, May 12, 2017) and, as noted, often grant access to artisanal miners.

The use of force by security, including firearms use by police, is a key part of mining companies' first-party measures. The police have employed shooting across all three sites. During forced removal operations, when miners refuse to leave, shots are fired in the air to make the miners flee (LNI representative and Mine Police representative, interview, March 20, 2017). When site A was cleared, the police injured and killed several miners, though exact numbers of deaths are not clear (community representative, interview, October 15, 2016; company B officer, interview, February 6, 2017; former EMAK representative, interview, February 1, 2017). A miner who operates mainly at site A has been present several times when the police have fired shots in the air when a miner started to argue with a police officer (trader and her miner son, interview, February 27, 2017). At site B, when there is disorder at the security post the police officer clears the miners out by firing bullets (three miners, second interview, March 13, 2017). A doctoral candidate reported that a judge visited company C's concession three times in 2014 and 2015 to follow up on shooting cases. The interviewee saw a miner shot next to a hill; the miner died on the spot, while another was shot in the hand (interview, February 1, 2017).

Several miners expressed the view that companies give the police orders to shoot the miners, or authorise these practices (trader and her miner son active at site A, interview, February 27, 2017; miner based at site B and two ex-miners, interview, February 17, 2017). A 
journalist based at site $\mathrm{C}$ argued that the police, particularly the LNI but also the Mine Police, get bullets from the government for shooting: the LNI are ready to shoot, he said, and trained for that. Yet he did note that the government obeys if the company says not to shoot. Training does take place, he said, but what matters is the person himself (interview, February 7, 2017). One respondent who goes to site A and C contended that as an "elder" he had never been injured but had seen others injured or killed (miner and his wife, interview, March 31, 2017). Yet one miner said that while the police shoot bullets, they don't kill but simply chase the miners away (miners, group interview, April 3, 2017). While I did not find evidence that companies authorise a blanket use of force, on-the-ground dynamics are complex. Given the influx of miners, security is often overwhelmed (Mine Police representative, interview, February 7, 2017). A Mine Police officer deployed to site A said they use non-lethal weapons, namely tear gas, which the government gives them, and the miners are afraid of. He had a canister of tear gas hanging around his neck. Before, he noted, the police would simply shoot into the mass of miners, but they don't have the right to shoot anymore. However, officers can fire warning shots in the air if alone and overwhelmed (LNI representative and Mine Police representative, interview, March 20, 2017). Unlike with the Mine Police, the company has only mandated the LNI to use non-lethal weapons, like tear gas, to deal with miners (company B security officer, interview, January 27, 2017; LNI representative, interview, May 16, 2017). A LNI representative deployed at site B said that the LNI have firearms, but that the private security company doesn't authorise the LNI to use them. He said tear gas is used most often. However, the LNI representative remarked that firearms are only for "legitimate defense", and that all defense is proportional to the attack - different from no allowed use. There are instructions when it comes to a police officer firing, he said, but if the officer is isolated and injured, he may react in a negative way. Catching a miner can provide a chance to get revenge (LNI representative and Mine Police representative, interview, March 20, 2017; several miners and traders, interview, March 9, 2017). Yet such practices, he said, are not the custom (LNI representative and Mine Police representative, interview, March 20, 2017).

Similarly, a company B security officer pointed to weapons and dogs as necessary not for attack, but deterrence (also LNI representative and Mine Police representative, interview, March 20, 2017). A LNI representative deployed at site B said that it's forbidden to release the dogs on the miners because they would "tear apart" the miners (LNI representative and Mine Police representative, interview, March 20, 2017). Respondents argued that company C doesn't want the state to react violently, but tries to negotiate and discuss (interview, January 24, 2017; company B security officer, interview, January 27, 2017). Teams of police officers 
stationed at site $\mathrm{C}$ reportedly receive instructions not to shoot (doctoral candidate, interview, February 1, 2017). The police at site $\mathrm{C}$ have been asked not to use real bullets but to use tear gas instead (Mine Police representative, interview, February 7, 2017). Another layer of complexity is the fact that police officers technically answer to their commanders, not the company. At site B, the LNI police unit answers to the PSC. Yet during an interview I conducted with the LNI representative, he received a phone call from a company B security officer, which demonstrates an operational link (LNI representative and Mine Police representative, interview, March 20, 2017). There are other differences between company policy and reality. According to a company B security officer, the company requests that the police stay outside, entering the site for intervention only (there is a detachment nearby), and use only non-lethal weapons and ammunition (interview, January 27, 2017; LNI representative and Mine Police representative, interview, March 20, 2017). Yet on a February 3, 2017 visit to the site, I saw four police officers inside the entrance to the processing facilities area of the mine site, two with firearms. People were talking with some urgency, indicating there had been an incident. By the time I left, the five police officers were sitting at the mine and mineral stocks part of the site again (site visit, February 3, 2017). These examples highlight the ambiguity of on-the-ground realities.

The state and private security services do not only use forceful tactics. A Mine Police official at site $\mathrm{C}$ works with at least one informer who infiltrates the artisanal miners. At site A, a Mine Police representative dresses up in civilian clothing to get information about the miners' plans (LNI representative and Mine Police representative, interview, March 20, 2017). The Mine Police also employ persuasion or negotiation, in addition to their knowledge of artisanal miners. One representative explained that he tries to sensitise the miners about how they shouldn't do what they do (interview, February 7, 2017).

In addition to the threat or use of force, law enforcement is also part of companies' first-party strategies, and a further area of state reach into LSM concessions: companies make use of the Congolese justice system. When a company $\mathrm{C}$ security guard catches a miner, the miner is brought to the Mine Police, and then the parquet (local judicial institution) (company C security employee, interview, May 27, 2017). Companies also have dedicated Judicial Police Officers (OPJ) at their concessions. There is a distinction between OPJ à compétence restreinte - the Industrial Guard (local judicial official, interview, February 16, 2017; local judicial official, interview, April 12, 2017) - who operate within companies and private enterprises, and OPJ à compétence génerale who look after infractions à caractère minier (mining-related infractions) (local judicial official, interview, February 6, 2017; local judicial 
official, interview, February 16, 2017). The OPJ represent the public ministry and seek infractions (local judicial official, interview, April 12, 2017). An OPJ à compétence générale from the Mine Police was requisitioned by and assigned to company A to search for infractions in terms of minerals (local judicial official, interview, February 6, 2017; local judicial official, interview, February 16, 2017; police official, interview, February 18, 2017). Company B has an OPJ à competence restreinte (company B security officer, interview, January 27, 2017; local judicial official, interview, February 16, 2017). Because the normal guards are unarmed, a company B security officer explained, in-house security and the PSC depend on the OPJ (interview, January 27, 2017). There is also a security guard mandated to act as an OPJ at company C (company $\mathrm{C}$ security employee, interview, May 27, 2017).

A local judicial official at site $\mathrm{C}$ said that there were about 20 or 30 cases of mineral theft each month, and that company C's lawyers would lodge the complaint; artisanal miners, he said, don't have legal representation. A prison sentence can go up to five years. However, he added, there is a process in place. First, within the companies themselves are the police $\dot{a}$ competence restreinte. Then come the magistrats debouts (the judges who instruct the cases). After that are the magistrats assis. ${ }^{18}$ The OPJ, who represents the ministère public, searches for infractions. They examine the facts and instruct cases. They have 48 hours to instruct or can request another five-day period from the ministère public. The judge in charge of instructing the case examines what the OPJ did and fixes the case before the tribunal. The tribunal examines whether there are witnesses to confront the detainee; if there are no facts in the case, he can be acquitted. Some creuseurs accused of attempted theft of mineral substances say they were just going to their field by way of small paths. In that case, the justice official said, the miner may be freed. The company can appeal, but the appeals tribunal may confirm what the first judge decided. For example, if the miner is being accused of stealing 10 sacks, the ministère public has to be able to see the sacks. Artisanal miners may be acquitted given evidence of police involvement in their entry to the mine site (interview, April 12, 2017).

When miners are caught and arrested, there is a fine structure in place that allows them to pay for release. A police officer deployed to site A said that the fine for vol simple - theft during the day - goes from $\$ 50$ to $\$ 300$. If after the legally mandated 48-hour detention

\footnotetext{
${ }^{18}$ There is a distinction between the parquet, where the judicial officials are debout, and the tribunal, where there are magistrats assis. At the level of the parquet, the state deploys its coercive force: the ability to send people directly to the cachot. When people are sent to the tribunal, it's not the same. The tribunal can render a judgment and people can be sent to prison, but there may be an appeal (university professor, discussion, April 13, 2017).
} 
period, the miner cannot pay, the police transfer him to the parquet (local judicial institution). He added that the police may also give the poorest miners small tasks at the police station, like cleaning the toilets or cutting the flowers, before releasing them after 48 hours. This use of miners' free labour is another example of how the police benefit from corporate enforcement, even if miners can't pay. Vol qualifié, on the other hand, occurs at night and involves premeditation because it happens at the late hours. The parquet is supposed to punish crimes of vol qualifié (second interview, March 24, 2017). A local judicial official interviewed at site $\mathrm{C} 1$ mentioned that fines for clandestine miners can reach 50,000 Congolese francs. If the miner can't pay, he has to complete his sentence: he spends two months with the police and then is freed. Children can be freed without fees (interview, April 12, 2017). Several miners confirmed that fines are levied and if they cannot pay, they may be sent to prison. A respondent in the Lubumbashi region was arrested several times and brought to the parquet, which fixes the fine. If the miner can't pay, he may have to spend time in jail, though less time if his family can come up with the money (miner and two former miners, interview, February 17, 2017; miners, group interview, April 3, 2017). While there are official fine structures in place, given the way Congolese state institutions function and the weakness - linked to corruption - of justice in the region (company $\mathrm{C}$ security employee, interview, April 13, 2017) there is a question of how much of this money actually reaches the Congolese treasury. A company $\mathrm{C}$ security employee explained that if a miner is arrested, his case is often quickly abandoned. At the parquet, he said, the procureur de la République is there for money. The company's interest, on the other hand, is for the miner to go to the tribunal so he can be punished and stops taking minerals. There is therefore a clash with corporate enforcement. The security guard also contended that trouble arises between the parquet and the tribunal: if the parquet "eats" [by levying a fine], the tribunal also wants to "eat" (interview, April 13, 2017).

A respondent arrested at site $\mathrm{C}$ in 2016 explained that when miners are caught there, those who are "big" (adults) are put in the security vehicle while a miner who is "small" (young, a minor) is left behind. As a minor, he was let go (two miners and their mother, interview, March 31, 2017). This approach reflects Congolese law on the treatment of minors who get in trouble with the law. The law protects children (under 18), but children over 14 can be considered responsible from a civil perspective and kept in a detention centre for rehabilitation and reintegration. According to a local government official based at $\mathrm{C} 1$, though, they have no resources. A child, if caught, can't be sent to prison, so is handed over to that official to figure out what to do with. She tries to find the child's family in case he is caught 
for a second time at some point. He is not sent home, but there is an attempt to implement provisional measures for one, two, or three months, though the child cannot be put together with adults (local government official, interview, February 10, 2017). A PSC manager, too, explained that if caught, an artisanal miner who is a minor is sent to the judge, or to the bourgmestre of the commune, who calls the minor's parents (three PSC managers, interview, March 20, 2017).

On the more "unofficial" side, miners are said to spend less time in prison if they have connections (miner and two former miners, interview, February 17, 2017; LNI representative and Mine Police representative, interview, March 20, 2017). The clandestine nature of dealings also applies to certain "fines" and allows miners to get out of detention, but a cost. When company security catches a miner, he is brought to the company base at $\mathrm{C} 1$. If his team has money, someone can go to the base to pay for that miner to be released from detention. The sum of 50,000 Congolese francs is paid to the Industrial Guard for the miner's release; otherwise, he may go to prison. This is not an official "fine" authorised by the company: it is paid in collusion with the police and the company's Industrial Guard and goes into the pockets of inspectors working for the company and the police (miner, interview, February 17, 2017; miner, interview, April 3, 2017).

In addition to "purchasing" central state support for their property rights, companies rely on coalitional - second-party - arrangements, like alliances with local customary chiefs, to calm the population or resolve problems that arise at the mine. Before starting operations, companies typically ask the chief to organise a ceremony. According to one respondent, company $\mathrm{C}$ spent a lot of money dealing with one land chief, in the process of moving one community from the project area to a different location, before they realised they should be dealing with a different land chief (community relocation consultant, interview, March 25, 2017). LSM firms also draw upon "civil society" actors to help secure their concessions. At site $\mathrm{C}$, the company is in regular contact with the local civil society, which reports security incidents to the firm involving the town's significant population of artisanal miners (civil society representative, interview, September 2, 2016). Academic partnerships and consultancies are another significant feature. While doing research in the DRC I encountered several academics and consultants who had worked or continued to work for mining companies, considering that mining companies have extensive resources to fund such research. Companies also ally themselves with other state and private/commercial actors and bodies. Company B, for example, worked with the Service d'Assistance et d'Encadrement du Small Scale Mining (SAESSCAM), the state agency responsible for artisanal miners, and the 
Association d'Exploitants Miniers Artisanaux du Katanga (EMAK) ${ }^{19}$, a prominent miners' cooperative, to organise the miners' departure when the company took over the site (company B official, interview, February 6, 2017; community activist, interview, October 15, 2016). Company A also worked with cooperatives to deal with the artisanal miner "problem" (company A exploration staffer, interview, October 19, 2016).

State authority and support (third-party measures), though uneven in the DRC, are also part of the picture. Companies point to the central state's authority to legitimise their activities; since the mining sector constitutes about $30 \%$ of the state's budget, the state has significant incentives to participate in the definition and enforcement of corporate PR. When there is conflict with local communities, the companies tend to say that everything they do is legal and they have paid their dues. The state is much less supportive of communities around LSM mines (local NGO representative, interview, September 2, 2016). Representatives of the state at the local level, including authorities like the mayor or bourgmestre, also lend their authority to companies' property rights when these PR are threatened. According to a Mine Police official, company A had trouble when it walled off its concession, because they blocked off a route people used to go to their fields, so people even started breaking holes in the walls. The bourgmestre came to intervene to calm the situation (Mine Police official 1, interview, November 8, 2016). As noted, SAESSCAM, the state body tasked with assisting artisanal miners, also lends authority to companies' PR (company B official, interview, February 6, 2017). Yet SAESSCAM, as a government body tasked with overseeing artisanal and small-scall mining, has no official jurisdiction in LSM sites - where artisanal miners are not supposed to be - which means they can't carry out important tasks like verifying the safety of miners' mineral extraction in the deep pits they dig (two traders, interview, February 9, 2017). However, because of continued artisanal miner activity within LSM sites, SAESSCAM has helped LSM companies remove artisanal miners from their concessions. A SAESSCAM representative told me that at a different mine site in the Lubumbashi region, SAESSCAM was hired to deal with the presence of artisanal miners (interview, August 19, 2016; government official, interview, May 24, 2017). The way in which government agents discuss with miners is arguably an example of their authority and/or legitimacy. These dynamics are another example of how companies outsource functions to government bodies rather than always the other way around.

\footnotetext{
19 The Ministry of Mines authorised EMAK's creation on February $19^{\text {th }}, 1999$, giving it responsibility for supporting both artisanal miners and traders and providing security at artisanal-mining sites granted to it by Gécamines (UNEP/OCHA, 2004).
} 
Finally, depending on the specific area within the mine site, companies sometimes choose not to fully enforce their PR. As noted, a number of respondents commented on site C's flexibility and tolerance of artisanal miners. Yet a company $\mathrm{C}$ security employee specified that the company does not allow artisanal miners to be left alone; the security guards are expected to chase these miners away, and bring their minerals to the company (interview, May 27, 2017). To some extent, however, companies' need to keep security costs at a certain level, and the vast size of some mining concessions, mean that there is inevitably some laissez-faire (three international NGO representatives, interview, August 31, 2016). A smaller-sized concession is easier and less costly to secure. Costs matter because although LSM companies have significant resources, these companies are focused on profit maximisation and, according to a company B security officer, the cost of providing security for mine sites in the DRC is already much higher than it would be elsewhere, like in Europe (interview, January 27, 2017). As the company C security employee explained, there are not many security officers given the number of miners (interview, May 27, 2017).

Site C's vast size in particular makes monitoring challenging and costly, and in places the green colour of copper can be seen from the road; these factors make it nearly impossible to prevent all of the artisanal miners from entering. One civil society representative tellingly commented that some people ask themselves how the company can block the artisanal miners when they aren't even in the process of extracting minerals [in certain areas] (three international NGO representatives, interview, August 31, 2016). Miners are often able to enter poorly lit and less-secured areas without being seen by stationary security guards, guards on patrol, and the police. Given the costs, the company doesn't hire enough personnel to guard the entire concession, but focuses on hot spots where miners have a tendency to enter (doctoral candidate, interview, February 1, 2017; mining consultant, interview, February 28, 2017) and/or areas where the company is currently extracting minerals and company goods could be stolen or lost (miner and his wife, interview, March 31, 2017). There isn't a consistent number of police throughout the concession: the company secures current zones of extraction (Mine Police representative, interview, February 7, 2017). At site $\mathrm{C}$ there is a distinction between zones de restriction, where access is restricted, and zones d'interdiction, where access is forbidden and there is a heavier security guard presence (mining consultant, interview, February 28, 2017). The geography of concession $\mathrm{C}$ is also a factor: much of it is forested and includes rivers, bushes, and large trees. Even if the company is aware that there are miners at a certain location, they may overlook it to avoid conflict, so miners don't pose a risk to company facilities or property (doctoral candidate, interview, February 1, 2017). The 
company tells its security officers not to stop unauthorised mineral transports in the village, but only at the barriers on the national road, to avoid potential incidents like the destruction of a company vehicle. In the urban area, according to the company, no one can stop minerals except the police with a warrant from the parquet. This measure is meant to protect the security guards (company C security employee, interview, May 27, 2017).

Different companies have different policies, but all of them to some extent advise their employees not to confront artisanal miners. Company A tells its guards to keep themselves safe - what is known as auto-sécurisation - by avoiding confrontations with miners, for example if there are ten miners and only two guards. A company security guard may allow a miner to enter the site but then inform the intervention team to get the miners out (company A security guard, interview, May 21, 2017). Company C doesn't allow guards to confront miners, instructing them to call for reinforcements instead, to ensure the guards do not injure the miners (company C security employee, interview, April 13, 2017; miners, interview, April 3, 2017). The company tells the PSC guards not to fight back against the miners, but to stay calm; otherwise, the company makes a report and the guard gets in trouble (PSC manager, interview, May 22, 2017). A trader/miner argued that when miners have extracted minerals at site $\mathrm{C}$, they are asked to leave calmly, because if a miner dies, it's the police officer who suffers the consequences (interview, February 14, 2017). According to a Mine Police representative, the police have told company $C$ that for a concession of more than $1500 \mathrm{~km}^{2}$, about 100 police officers is insufficient (interview, February 7, 2017). Another respondent argued that at site $\mathrm{C}$ there is zero tolerance: the guards are forbidden to hurt any miner. The guards' mission is simply to show themselves to the miners, so the miners are afraid to enter, and flee instead. On the other hand, if the guards chase away the miners, and miners are injured, the guards are held responsible. Instead of the miners running away, it's the guards who flee in order not to be reprimanded. As a result, the miners find themselves in a context of partial freedom, able to profit from the minerals (miners, group interview, April 3, 2017). Finally, a company $\mathrm{C}$ security guard said that if artisanal miners are going to get in the way of the extraction machinery, they call company security headquarters for intervention. However, sometimes it's too late and by the time the intervention arrives, the miners have already taken what they came to take and run away (interview, March 4, 2017).

\subsubsection{A Note on Unauthorised Large-Scale, Corporate Extraction}

Corporate actors and government officials in southeastern DRC typically view miners in a negative light. Company B in the Lubumbashi region tries to be very clear in 
communicating that they do not accept artisanal miners in the concession (company B security officer, interview, January 27, 2017). In the Lubumbashi region, there is little overt flexibility towards artisanal and small-scale miners of the kind that results from site C's specific PR configuration or, as shown in the literature review, due to company policy at some sites elsewhere in Africa. Among other factors, companies have financial constraints that make them unlikely to fulfill demands that exceed what they perceive to be their limited responsibility towards local communities and artisanal miners, particularly in the context of the 2015 fall in the copper price (three international NGO representatives, interview, August 31, 2016; "Copper price", 2015), which led several companies in the region to cut production (“Congo copper production down", 2015; "Dangerous battle for influence", 2017) and lay off workers.

\subsubsection{Authorised Clandestine Extraction}

The second major facet of the property rights regime is the clandestine extraction authorised and participated in by a range of different authorities and actors working together at different times and in different configurations. Mining company and private security employees collaborate with the Congolese police - particularly the Mine Police, but other branches as well - artisanal miners, and other actors, to arrange the clandestine removal of minerals from mine sites without company permission. According to my interviewees, the actors involved in clandestine mining - in various configurations depending on the site include

- The Mine Police (site C visit, February 8, 2017; several traders and miners, interview, March 9, 2017; university researcher, interview, March 29, 2017; two traders, conversation, April 6, 2017; police officer, interview, April 14, 2017)

- Company security - the Industrial Guard (local government official, interview, February 10, 2017; youth representative, interview, February 11, 2017; mining consultant, interview, February 28, 2017; group of miners, interview, March 4, 2017; several traders and miners, interview, March 9, 2017; university researcher, interview, March 29, 2017; group of miners, interview, April 3, 2017; two socio-cultural association representatives, interview, April 12, 2017; site C3 miners' committee member, interview, April 13, 2017; village chief and multiple village residents, interview, April 11, 2017; community relocation consultant, interview, March 25, 2017, miner, conversation, March 3, 2017)

- Other LSM company employees (university researcher, interview, March 29, 2017; site C3 miners' committee member, interview, April 13, 2017) 
- Private security companies (mining consultant, interview, February 28, 2017; group of miners, interview, April 3, 2017; miner, conversation, March 3, 2017; trader, interview, May 18, 2017)

- The Agence nationale de renseignement, ANR (the Congolese national intelligence service) (civil society representative, February 9, 2017; mining consultant, interview, February 28, 2017; civil society representative, interview, March 4, 2017; two traders, conversation, April 6, 2017; two sociocultural association representatives, interview, April 12, 2017; Mine Police officer, interview, April 14, 2017)

- The Police nationale congolaise, PNC (the Congolese national police) (journalist, interview, February 7, 2017; civil society representative, interview, February 9, 2017; mining consultant, interview, February 28, 2017)

- The Bureau 2, an investigation service within the Congolese national police ("Pour stopper les arnaques", 2017) (civil society representative, interview, February 9, 2017; several traders and miners, interview, March 9, 2017; site C3 miners' committee member, interview, April 13, 2017; Mine Police officer, interview, April 14, 2017).

- The Légion nationale d'intervention unit of the Congolese police (occasional miner, interview, March 21, 2017; miner and his mother, interview, March 29, 2017; miner, interview, April 3, 2017)

- Customary chiefs including land and village chiefs, particularly at site $\mathbf{C}$ (Mine Police officer, interview, April 14, 2017; miner, conversation, March 3, 2017)

- Local government officials (civil society representative, interview, March 4, 2017; journalist, interview, February 7, 2017);

- Subcontracting companies that do mineral extraction (company A exploration staffer, interview, October 19, 2016)

- Traders (trader and two associates, interview, March 4, 2017; two sociocultural association representatives, interview, April 12, 2017; site C3 miners' committee member, interview, April 13, 2017)

- Motorcycle transporters (civil society representative, interview, February 9, 2017; trader and two associates, interview, March 4, 2017)

- Bicycle transporters (bicycle transporter, March 9, 2017)

- Owners of transport vehicles (two socio-cultural association representatives, interview, April 12, 2017; site C3 miners' committee member, interview, April 13, 2017)

- Mini-bus [called Noah or Dubai] drivers or owners (two socio-cultural association representatives, interview, April 12, 2017; Mine Police officer, April 14, 2017)

- Local judicial institutions (parquet, tribunal) (Site C3 miners' committee member, interview, April 13, 2017; Mine Police officer, interview, April 14, 2017) 
- Owner of land where products bought and sold (landowner, interview, May $15,2017)$

- The Congolese army, the FARDC (mining consultant, interview, February 28, 2017; two traders, conversation, April 6, 2017; two trotteurs, interview, April 13, 2017; site C3 miners' committee member, interview, April 13, 2017; journalist, interview, February 7, 2017; civil society representative, interview, February 9, 2017)

- The Republican Guard (two traders, conversation, April 6, 2017)

The Mine Police, which are mandated to guard the mines, are often cited as a key part of clandestine extraction (company A security officer, interview, October 11, 2016; company A exploration staffer, interview, October 19, 2016; company B security officer, interview, January 27, 2017; February 8, 2017 site visit in company C's concession; civil society representative, interview, February 9, 2017; youth representative, interview, February 11, 2017; mining consultant, interview, February 28, 2017; group of miners, interview, March 4, 2017; site C3 miners' committee member, interview, April 13, 2017; company A security guard, interview, May 21, 2017; PSC manager, interview, May 22, 2017). The Industrial Guard and private security agencies are also deeply involved in the structures and processes of clandestine extraction though, allegedly not to the same extent (two traders, interview, February 9, 2017; miner and two former miners, interview, February 17, 2017). The Mine Police and the company's Industrial Guard guard the hills, granting access to miners in exchange for payment. The presence of artisanal and small-scale miners within LSM sites therefore cannot be termed "illegal" or "illicit" in any meaningful sense, and miners cannot be referred to as hors-la-loi (outlaws) (e.g. civil society representative, interview, August 27, 2016) in a context in which clandestine mining is sanctioned by the state and other actors. Yet the "illegality" of clandestine mining is a crucial factor as members of the different security forces at times invoke the "illegal" status of the minerals to justify their demands for payment in exchange for allowing minerals to travel to the selling points (two traders, interview, February 9, 2017; member of the miners' committee at site C3, interview, April 13, 2017; Peyer \& Maillard, 2011). LSM sites are arguably areas of intensified statehood and/or governance or, as Côte and Korf (2017) argued, of enhanced regulation.

I therefore call this component of the regime "authorised" because it is authorised by a number of actors who draw upon different forms of power, including state power, to legitimate their involvement and activities. Generally speaking, the same private and state security agencies contracted to protect LSM sites are instrumental in organising the 
clandestine removal of the minerals they are mandated to protect. Some agencies, like the Mine Police, are said to be more systematically involved than others, like the Industrial Guard or PSCs, and there is also individual variation, but clandestine extraction itself is bigger than any one institution and/or set of operational priorities. The authorised and highly organised system for the "illicit" extraction of resources from LSM sites is in that sense another side or facet of the regime's corporate enforcement component. Actors who secure mining concessions also often allow artisanal miners access to these sites. Representatives of the security forces and other actors do not simply passively collect rents from clandestine mining but are actively implicated in governing, establishing access rules and regulations for, and enforcing claims to property including minerals and rents. Though I use the term "clandestine extraction" I also problematise the term, given the significant legitimacy of clandestine extraction across the three case-study sites and the fact that those at the highest echelons of the LSM companies are the only ones who seem opposed to the practice at all. A civil society representative referred to the authorities' practice of illegally "taxing" artisanal miners as "quasi-fiscal" (three international NGO representatives, interview, August 31, 2016).

In southeastern DRC, the widespread and highly organised techniques through which artisanal miners gain access to LSM concessions are often referred to as la frappe or frapper [I translate these French terms as the noun "hit" or "strike" or the verb "to hit" or "to strike"] (Mine Police representative, interview, October 7, 2016; several traders and miners, interview, March 9, 2017). This terminology used by those who engage in these activities is a demonstration of how these practices are perceived: as rapidly executed and forbidden as a violation of Congolese law granting corporate property rights. Yet at the same time, clandestine mining is, as I demonstrate below, often highly organised - as when artisanal miners work in sponsored teams - which highlights the fact that these practices are more than simply "raids". La frappe as a set of practices is widely accepted, tacitly if not openly, and participated in by a range of actors, groups, and institutions. In many ways, these activities constitute an overt secret of an ambiguous nature, but one that does rely on covertness at certain times and vis-à-vis certain parties. For instance, higher-level mining company officials involved in clandestine mining are concerned about information leaks and the possibility of being accused of such practices (site C3 miners' committee member, interview, April 13, 2017). Authorised clandestine mining therefore represents, as I examine in more detail in this chapter, a combination of strategic overtness and covertness (Daudelin \& Ratton, 2018).

Ultimately, companies as a whole have more power and authority than any single other actor and benefit the most from mineral extraction. Moreover, companies have a whole 
operational toolkit in terms of policies and standard operating procedures, of which company C's decision to complete a questionnaire rather than allow me access to any of their employees for interviews is just one example. Yet companies are not unitary: some employees, including the Industrial Guard (company security), engage in clandestine mining in a way not authorised by headquarters - what in political science and economics is referred to as a "principal-agent problem". Members of the Industrial Guard use the authority granted to them by the company for personal gain in the form of rents, or because other actors pressure them to do so. Company sub-contracting, too, poses a challenge to views that companies operate as unitary actors in countries whose statehood is rhizomatic. Companies do not just contract out security, but other functions as well, including mineral extraction (company A exploration staffer, October 19, 2016; LNI representative and Mine Police representative, interview, March 20, 2017; Rubbers, 2019).

Clandestine extraction extends well beyond open-pit mines, with a multiplicity of services and actors, including transporters and traders, facilitating clandestine extraction along transit routes to the point of sale. In company C's concession, the minerals have to pass through multiple company and state barriers along the national road as they are transported to mineral depots in Kisanfu but also Kolwezi and Lubumbashi (civil society representative, interview, February 9, 2017; site C3 miners' committee member, interview, April 13, 2017; Mine Police officer, interview, April 14, 2017; doctoral candidate, interview, February 1, 2017; local judicial official, interview, April 12, 2017). At site C2, which I visited several times and where minerals are loaded and dispatched, there are many artisanal miners, traders, and mineral depots. A Mine Police officer named five services involved at site $\mathrm{C} 2$ : the Mine Police, the Bureau 2, representatives of the chief, the parquet, and the ANR (interview, April 14, 2017). Though this facet of the PR regime relies on its authorisation by a range of state and non-state actors who possess authority, artisanal miners play a pivotal role because clandestine extraction is reliant on their labour. Arrangements that take place at company A, for example, include artisanal miners and the Mine Police, as well as artisanal miners and security guards (company A exploration staffer, interview, October 19, 2016). In the DRC, people who can afford not to don't expose themselves to the risks and poor working conditions of ASM in LSM concessions or elsewhere.

As discussed, clandestine mining has evolved in response to a situation in which the vast majority of valuable mining sites in the DRC have been taken over by LSM companies, while artisanal-mining sites have become increasingly rare (Congolese National Police official, interview, December 7, 2016). Multinational corporations do not allow artisanal 
miners to operate in their sites, while other privately-owned sites where extraction has not yet begun are similarly unwelcoming of ASM (company A exploration staffer, interview, October 19, 2016). Some ostensibly artisanal sites are controlled by political figures and/or the military (former EMAK representative, interview, February 1, 2017; civil society representative, interview, January 24, 2017; artisanal miner, interview, February 27, 2017) and/or have the Republican Guard on site (three international NGO representatives, interview, August 31,2016$)$. The demand for minerals, the market for clandestinely-mined products, and the limited enforcement of measures to prevent mineral smuggling (site C3 miners' committee member, interview, April 13, 2017) are major facilitating factors. Clandestine mining, both authorised and unauthorised, takes advantage of a significant local market for copper and cobalt ore for local smelters. A proliferation of Chinese, Indian, and Lebanese comptoirs purchase minerals (company A manager, interview, September 22, 2016; three PSC managers, interview, March 20, 2017), and don't ask where the minerals came from (doctoral candidate, interview, February 1, 2017).

Multiple categories of négociants - traders - exist and have different relationships with the buying houses. A trader doesn't have to have a relationship with a buying house but can be independent. One female trader, whose husband is also a trader, buys from miners who go to sites A and B. She started with just $\$ 100$ and, after paying security and transport, made a $\$ 70$ profit the first time (two traders, interview, February 25, 2017). A marketeur is a mineral buyer who receives money directly from comptoirs to purchase minerals (trader/miner, interview, February 14, 2017; Mine Police representative, February 16, 2017). The home of a marketeur that I visited at site C3 was very nice and he had a large stack of money with which to pay security - of which he gave some to his nephew, a trader - which is an example of the relatively significant status of the marketeur (two traders, interview, February 9, 2017). A trotteur is a lower-level trader (trader/miner, interview, May 19, 2017): trotteurs buy minerals from the miners and sell to the négociants (traders) who sell to the smelters (two trotteurs, interview, April 13, 2017; miner, discussion, May 18, 2017). The marketeurs work closely with the Chinese buyers, whereas the trotteurs do not. The marketeurs borrow money from the buyers and when they have minerals, they pay something to the trotteurs and bring the minerals back to the Chinese buyers, who reportedly pay the marketeurs a bonus like 45000 Congolese francs per tonne of minerals. Unlike the marketeurs, I was told, trotteurs start with their own money (two trotteurs, interview, April 13, 2017). One former trotteur argued that in company C's concession, traders don't exist because they are clandestine. In addition to 
digging for minerals, he said, he is also a trotteur on a "fraudulent" basis (interview, May 19, 2017; two trotteurs, interview, April 13, 2017).

The different security forces and other authorities grant miners access to LSM sites in exchange for payment. These rents allow police officers, security guards, and other actors to top up what are often low salaries (community activist, interview, October 15, 2016; journalist, interview, February 7, 2017; Mine Police representative 2, interview, February 16, 2017; Mine Police officer, interview, April 14, 2017; also PSC representative, interview, May 22,2017 ), or simply to meet the standard of living to which many aspire (university professor, discussion, April 13, 2017; Mine Police representative, interview, April 12, 2017; Mine Police representative, interview, December 3, 2016). Some of those who guard company C's concession, a journalist based in town $\mathrm{C} 1$ argued, are not well paid, earning only 250 dollars a month, plus two small bags of flour. Because they want to build homes and drive vehicles like others, they become involved in allowing artisanal miners to enter LSM sites despite risks for their employment (journalist, interview, February 7, 2017; also civil society representative, interview, February 9, 2017; community relocation consultant, interview, March 25, 2017; university researcher, interview, March 29, 2017). Mine Police officers in particular are poorly paid (company C security employee, interview, April 13, 2017). One respondent affirmed that company $\mathrm{C}$ security employees are relatively better paid (civil society representative, interview, February 9, 2017). According to a PSC manager, when the PSC started at company $\mathrm{C}$, company $\mathrm{C}$ had the second-best paid guards, after one other mining company (three PSC managers, interview, March 20, 2017). A doctoral candidate who has done extensive research on clandestine mining in company C's concession explained that a security guard working for company $\mathrm{C}$ may receive at least $\$ 400$ per month. A Mine Police officer sent to site $C$, however, receives much less: possibly $\$ 100$ or $\$ 150$ per month. The high-placed Mine Police representatives reportedly share the majority of the money destined for salaries, including what the company pays for the police, and the ordinary police officers at the mine site only receive $\$ 100$. To top up his salary, a Mine Police officer lets miners access the site at night in exchange for, for example, 100,000 Congolese francs for 30 miners (interview, February 1, 2017). Indeed, a member of company $\mathrm{C}$ security said that a security guard can earn up to $\$ 400$ or $\$ 500$ per month; their specific salary depends on the number of school-aged children they have, because the company pays for their schooling. The company also provides its employees with healthcare at the hospital in town $\mathrm{C} 1$ in addition to flour and, if production is high, a bonus. The security employee added that at the PSCs, in contrast, the guards only get $\$ 100$ per month, and do not get healthcare or flour: this applies to all four of 
the PSCs deployed at site $\mathrm{C}$ and given the salaries, they cooperate with the miners (interview, April 13, 2017). According to a company $\mathrm{C}$ representative, private security guards don't receive the salary they are supposed to as per the PSC contract, but are only given $\$ 50$ a month, so both they and state agents scheme with artisanal miners. Each week, he said, the miners give them $\$ 300$ (interview, August 11, 2016). A parquet representative said that companies A and B have a reputation of paying their employees poorly, particularly company A: a chauffeur de benne only earns 200 or 250 dollars per month (three parquet representatives, interview, December 1, 2016). A company A security employee deployed at a different site (not site A) did not want to reveal his salary but said that a security daily worker can earn between 230 and 250 USD per month. In his view, he could not make ends meet (interview, May 21, 2017). Even a relatively well-paid employee may view their salary as too low: a company $\mathrm{C}$ security employee expressed the view that his salary was insufficient (interview, April 13, 2017). A Mine Police officer I met at site C2, who was there to collect money from the mini-buses transporting minerals, said that his salary was small but that through his involvement in clandestine mining he could earn $\$ 100$ from Monday to Saturday (interview, April 14, 2017). Relatively low salaries, particularly for the police, exist alongside a high cost of living, and of basic staples like flour, in places like Lubumbashi where a lot of goods are imported from Zambia. Allowing artisanal miners access to LSM sites is an easy, if potentially risky, way for security guards and police officers to top up their earnings. As a company B human resources manager pointed out, those involved risk their salary for a 20dollar payment (March 22, 2017), but given the salary figures provided above, 20 dollars is a significant amount. Additionally, with the numbers of artisanal miners involved, these sums may be significant.

The functioning of clandestine mining is also set up in such a way as to comply with the system of rapports - the practice of, and obligation to, pass illicit benefits up the chain of command to one's superiors. Upon leaving site C, for example, the Industrial Guard are deployed at the barrier, where they reportedly collect money for their chefs (bosses): 5000 francs per sack of minerals (two miners, interview, March 16, 2017) Even as heads of security and of the police claim to diligently enforce corporate PR, they too benefit from authorised clandestine extraction through the rapport.

As with corporate enforcement, actors involved in the clandestine extraction facet of the regime employ first-, second-, and third-party measures to enforce their claims. First-party measures are common, which in keeping with the PR framework can be linked to the unavailability of the impartial, genuine third-party (state) enforcement that, by definition, is 
unlikely to be provided in clandestine extraction. However, as Gallien (2019) shows for the case of smuggling in North Africa, third-party enforcement by state actors may indeed be present even in the case of informal institutions like smuggling; I return to the question of state involvement in clandestine extraction further down.

When it comes to authorised clandestine extraction, first-party measures do not have to be forceful. As discussed, clandestine mining is a market for services including security. The security forces' first-party measures therefore include keeping this market covert, at least to the extent possible given that miners' presence at open-pit mines can be relatively easily seen, as I personally witnessed and as shown in these photographs taken in company C's concession:

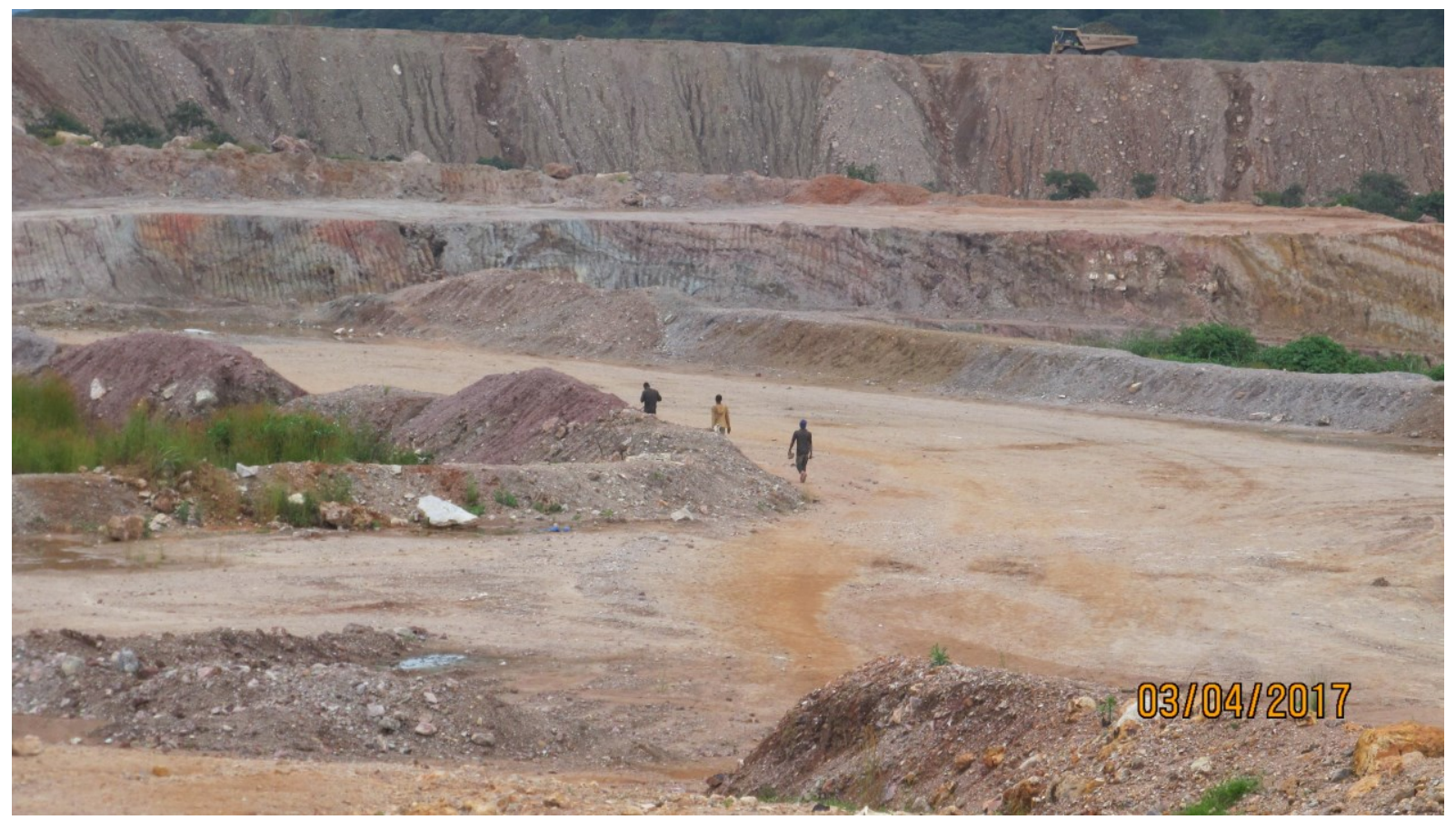

Image 3: Miners at company C's extraction site, Sarah Katz-Lavigne, March 4, 2017. 


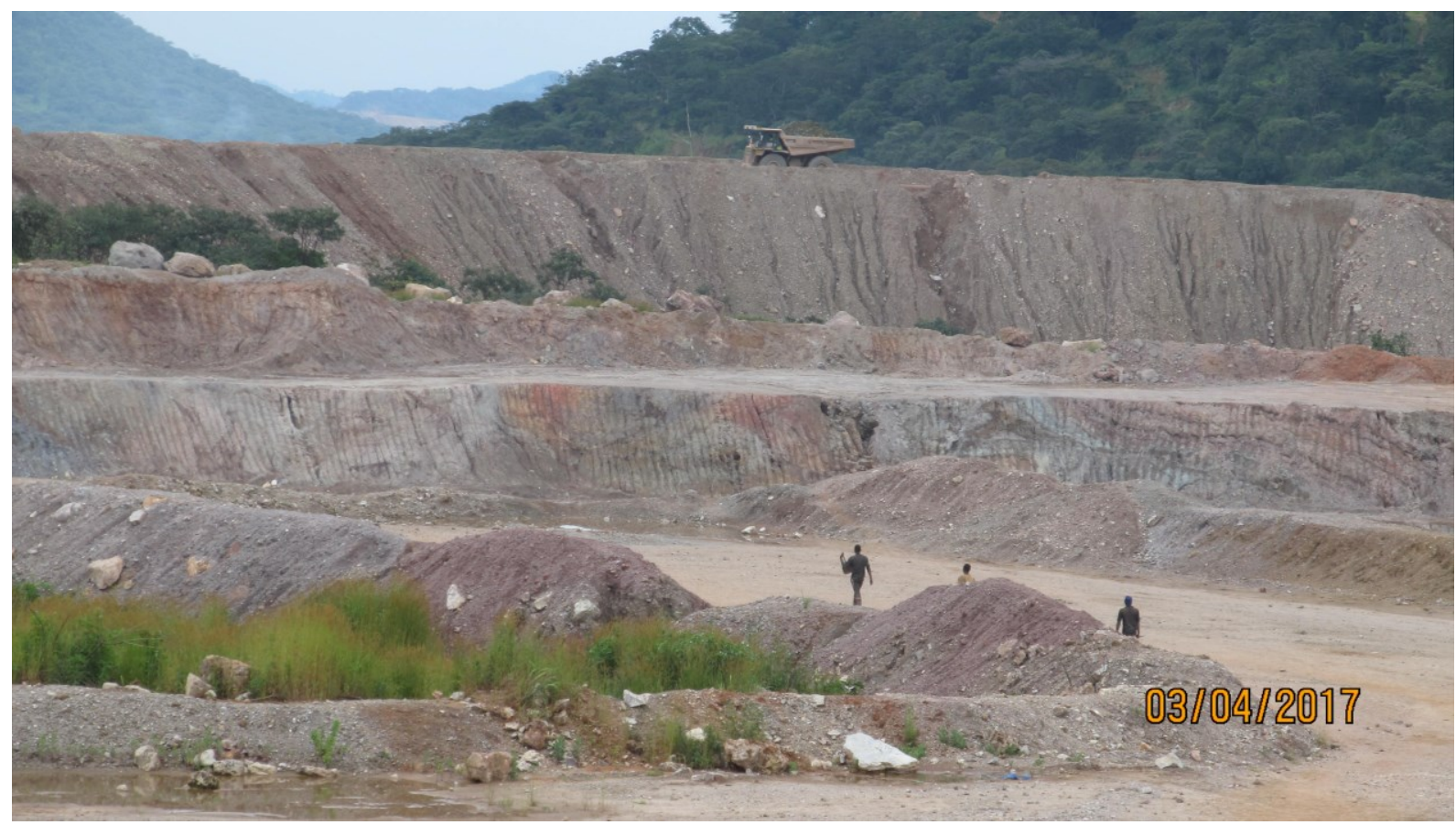

Image 4: Miners at company C's extraction site, Sarah Katz-Lavigne, March 4, 2017.

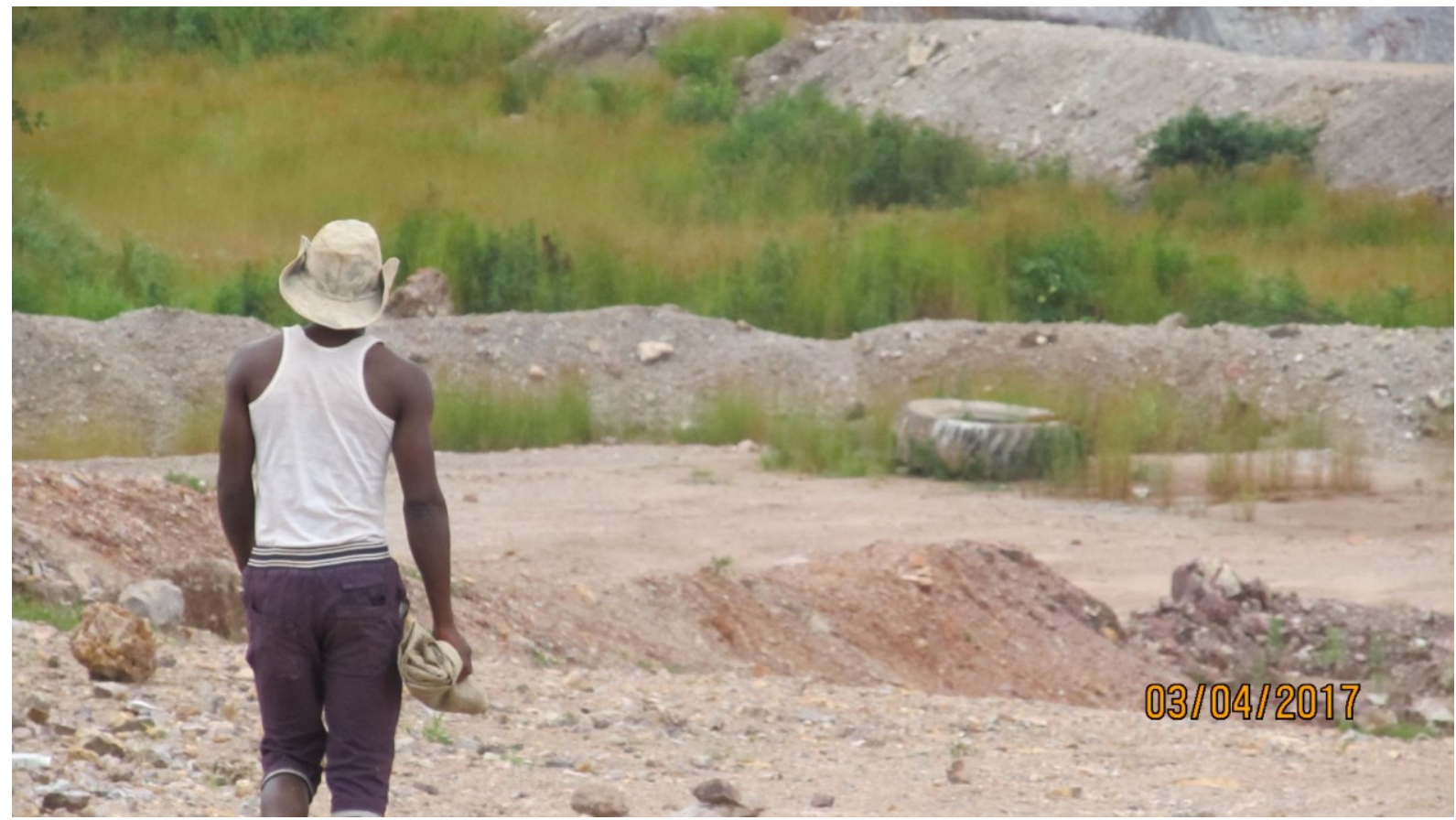

Image 5: Miner at company C's extraction site, Sarah Katz-Lavigne, March 4, 2017.

When security forces allow miners to enter, they tell them where they can go and when, and warn them if another security representative or supervisor is approaching, so the miners can hide (trader and her miner son, interview, February 27, 2017; three miners, second interview, March 13, 2017; two miners, interview, March 16, 2017; miner and his wife, interview, April 
9, 2017). The high-level actors in company's concession, including ANR and Bureau 2 representatives, reportedly have teams of creuseurs working for them, whom they tell to enter at night (site C3 miners' committee member, interview, April 13, 2017). When miners are sponsored by a trader and enter an LSM site in collaboration with the security forces, there has to be a distraction, so the company heads don't know miners have been at work (two miners, interview, March 16, 2017). A Mine Police officer at site C2 - a village where many artisanal miners have come to live in temporary or rented accommodations - mentioned that company $\mathrm{C}$ security do come to check on the situation, but that the Mine Police is informed beforehand. Otherwise, he said, company representatives themselves might be arrested for involvement in clandestine mining. Indeed, he told me that when I first came to $\mathrm{C} 2$ he was informed; he thought I was working for the company. He added that he hadn't heard of any cases in which the Mine Police got in trouble with company $\mathrm{C}$ for clandestine mining (interview, April 14, 2017).

The way the state security forces, and PSC and company security representatives, interact with artisanal miners and each other at times resembles first-party measures much more, while at other times these interactions are more like second-party interactions between fellow resource users. The different security forces at different times use persuasion, coercion, and force in enforcing the rules and regulations of clandestine extraction, whether in giving miners permission to enter an LSM site, or denying it to them (Mine Police representative, interview, February 16, 2017). The police tend to play on the fact that they have weapons. Consequently, it can be difficult for unarmed security agents in mixed groups to resist the requests or intimidation of armed police officers who want to grant entry to artisanal miners for a fee (trader, interview, February 14, 2017; PSC manager, interview, May 22, 2017). As noted, PSCs are also armed with non-lethal weapons, and they also often exhibit forceful and/or violent behaviour towards artisanal miners, which includes beatings.

For an artisanal miner, paying and getting access to an LSM site is only part of the process. Artisanal miners' physical strength and mining abilities are also part of the picture when it comes to miners' second-party strategies: miners are often chosen for teams because of their strength and abilities. At site $\mathrm{C}$, miners sometimes go to the open-pit mine to collect minerals, but they often also dig pits on the many hills the company has not yet touched, which means they need strength, skill, and experience. At sites A and B, where the companies do open-pit mining, miners either take minerals from stockpiles or the tailings, or from the mine itself. Each mode of extraction - digging pits and collecting minerals from the open-pit mine - has its own challenges and difficulties, not least of which includes walking or running 
with a heavy sack full of copper ore on one's shoulders. At site B, for example, where the minerals are found at increasing depths in the open-pit mine, it is challenging to carry minerals back up as much as 80 metres (occasional miner, interview, March 21, 2017).

Second-party measures are a key strategy that actors use to enforce their claims to resource access within the clandestine mining component. A range of actors involved in this form of extraction draw upon other resource users in coalitional approaches. Rather than one uniform, overarching network, clandestine mining typically operates like a proliferation of different networks, which helps to explain the multiplicity of approaches and configurations that actors, sometimes the same actors, employ. At site $\mathrm{C}$, for example, where there are at least 285 hills where minerals may be found, there are multiple networks (journalist, interview, February 7, 2017). Therefore, a given LSM site may in fact be many sites, each potentially with distinct conflict dynamics, rather than just one.

Due to the technically illegal nature of clandestine mining and given the involvement of the security services tasked with guarding LSM sites, this mode of extraction relies heavily on trust relationships and covert dealings, including deals made away from the mine site itself. The importance of second-party, trust relationships in this context is in keeping with property rights theory (e.g. Ostrom, 2009). Connections, repeated encounters, and trust relationships are a way to lower transaction costs that might otherwise prevent actors from entering into mutually beneficial arrangements. Many respondents talked about the importance of connections, or connaissances as they are often known locally, for the everyday functioning of clandestine mining. These connections allow them to more easily participate in the risky business of clandestine mining and to try to avoid conflict and negative consequences (miner, conversation, March 3, 2017). These trust relationships are a way to navigate an uncertain and risky environment. In this milieu, if artisanal miners deal with the wrong person, it can lead to negative consequences like the loss of money, beatings, and/or arrests. For members of the different security forces, particularly those employed by a mining company, the result can be the loss of employment, particularly for those employed by a mining company (the Industrial Guard) (two traders, interview, February 9, 2017; police official, interview, February 18, 2017) or a PSC (two traders, interview, February 9, 2017). Police officers, as one respondent commented, are less afraid of losing their jobs, unlike everyone else at site A (Mine Police representative 2, interview, February 16, 2017; Mine Police officer, interview, April 14, 2017).

An incident involving two security guards provides a snapshot of the importance of connections in this context. A LNI representative deployed at site B described how two 
guards who work for the PSC that guards the mineral extraction sub-contractors were recently apprehended leaving the pit with a $30-\mathrm{kg}$ sack of minerals each. The detained guards were brought to the LNI base but released after two days upon a phone call by the commissioner of the National Congolese Police in the province of Lualaba. The LNI representative speculated that the two guards were potentially friends with the commissioner; he may be the owner of the PSC, or the guards may be on his personal security detail. As he is a chef (boss) and colonel, his orders "have to" be followed (LNI representative and Mine Police representative, interview, March 20, 2017). Parties involved in clandestine mining notably use their connections to make arrangements, as people call them in French: agreements between those who guard LSM sites or have access to resources in another way, and those who wish to gain access to resources or rents (civil society representative, interview, 24 January 2017; journalist, interview, February 7, 2017; Mine Police representative 2, interview, February 16, 2017; university professor, discussion, April 11, 2017; community activist, interview, May 9 , 2017). Clandestine mining frequently exhibits significant organisation, which demonstrates that there can be a high level of order and regulation even in contexts not only of informality, but also of "illegality". The multiple types of arrangements that make up this mode of extraction, including those put into place by artisanal miners, vary along dimensions that include their level of institutionalisation and their duration. In their discussion of partnerships between nonprofits and business, Seitanidi and Crane (2008) define institutionalisation as "the extent to which the partnership, its programmes, and processes become accepted as part of the organisations involved.” (p. 420-421) An example of the relative institutionalisation of clandestine mining is the fact that the trade and transport of minerals is well organised: if a trader pays money to the police, he is given a code (two traders, interview, February 9, 2017; a trader and two associates, interview, March 4, 2017).

Despite their important role, artisanal miners' activities are heavily policed, including by the corporate enforcement apparatus. Therefore, artisanal miners, too, draw on a range of second-party, coalitional approaches to participate in authorised clandestine extraction (police official, interview, February 18, 2017). As noted, connections with members of the security forces and other actors at LSM sites facilitate miners' participation in clandestine extraction. Artisanal miners gain authorised access to LSM sites in several ways (Mine Police representative, interview, February 16, 2017). The governance of clandestine extraction processes includes the multiple mechanisms through which miners gain access to LSM sites; the specific constellations that arise depending on the actors artisanal miners work with, or are supported/sponsored by, to gain access to LSM sites; and whether miners enter ASM sites 
alone, in groups, or in teams. These processes are dynamic and multifaceted rather than fixed, but there are clear patterns (Gallien, 2019).

Once a miner knows that a certain person works at company B and will be posted near the open-pit mine, the miner can go see that person - for example, a police officer - in the cité (town) to collaborate. The officer and his colleagues assess when they can bring the artisanal miners in and where the miners can work. When the officer is going to enter the site, he informs the miner (Mine Police representative, interview, February 16, 2017). Alternatively, a miner knows someone who works at the site [as security]. The miner arrives with his friends and they all give something to the man, who speaks to his colleagues (trader and her miner son, interview, February 27, 2017). Miners can also simply arrive at the mine site without being called or making a pre-arrangement (two miners, a trader's wife, and a woman who sells firewood, interview, April 10, 2017). Artisanal miners may also collaborate with actors other than the security forces. According to a company A exploration staffer, artisanal miners collaborate - make arrangements - with those who operate the engins [the extraction machinery], who are sub-contractors, to steal fuel, electrical wires, and spare parts (interview, October 19, 2016). A PSC manager echoed the view that artisanal miners make arrangements in the cité with the drivers of bennes [trucks with loading bins] (three PSC managers, interview, March 20, 2017).

Many miners make arrangements with a trader for entry to LSM sites, which can include borrowing or a more structured arrangement like working as a team sponsored by a trader (group of miners, interview, April 3, 2017; two miners, interview, March 16, 2017). A trader may, for example, arrange with security for his group of ten miners to enter the site. The trader cooperates with security and tells them to let his group in. If a trader sends the group of miners, they always go as a team. When I asked one group of miners that goes to sites A and B whether the security forces try to limit the number of groups that enter, I was told that the size of the group, within reason, doesn't matter as long as the sponsor - the trader - has paid (group of miners, interview, April 3, 2017). However, one respondent cited an upper limit of 50 miners to enter site B (miner and two former miners, interview, February 17, 2017). Once the miners finish working, they sell their minerals to the trader, who takes back the money he spent on security and anything else and gives them the rest. Some miners depend on a trader for the money to pay off security. Some miners work with the same trader while others simply work with whichever trader has money for entry on a given day. Other miners just go to the site with whatever money they have, knowing that if they get arrested they can pay off the parquet and be let out (group of miners, interview, April 3, 2017) - 
another example of the state's at times poor enforcement of companies' PR. Some traders work together, lending each other money or buying minerals from each other's teams of miners. For instance, if a trader who operates at site $\mathrm{C} 3$ has someone he trusts, he can go to Lubumbashi and leave that person $\$ 1000, \$ 2000$, or even $\$ 3000$ with which to continue his activities while he's away (two traders, interview, February 9, 2017).

Larger-scale processes of clandestine extraction also take place (Mine Police representative, interview, February 16, 2017), but appear to be more covert, which suggests that despite their higher stakes they unfold with fewer complications, presumably because of the positions of those involved in organising these activities and the sums of money that these activities engage. As one respondent described, either a trader makes a proposition or the police make contact with the trader, since the trader has a lot of money. That money is distributed among the different services, he said, including the mineurs [those who do extraction] and the geologists. He added that this money can add up to $\$ 10,000$ or $\$ 15,000$. The collaborators bring out one or two trucks - for example, 20 tonnes - of minerals. The operator of heavy equipment participates as well. The minerals leave by the barrier; the police front or "cover" the operation (Mine Police representative, interview, February 16, 2017; two traders, interview, February 9, 2017); journalist, interview, February 7, 2017). A Mine Police representative, noting that it's not just the creuseurs clandestins who are involved in soustraction fraduleuse de minerais, spoke of " grands bwanas ». Those who transport minerals are covered by someone. He referred to the grands bwanas as white-collar criminals who have means and who trade in minerals without autorisation. He spoke vaguely of political influences, but didn't want to get down to specifics (interview, February 18, 2017). The finding of higher stakes but fewer complications is in line with Daudelin and Ratton's (2018) findings on why middle-class drug markets are relatively more peaceful than the market for crack.

Clandestine mining doesn't just refer to the extraction site but also to the process of getting minerals out of company concessions without permission. At site $\mathrm{C} 3$, a civil society representative said, the motorcycle drivers begin transporting minerals out at 6 p.m. (interview, March 4, 2017). As noted, site C's concession is extremely large, and company as well as other security actors police the barriers on the national road to ensure that raw minerals aren't being taken out (which is part of corporate enforcement). A Mine Police officer interviewed at site $\mathrm{C} 2$ was tasked with making sure the minibuses pay before loading. When they are loading the minerals, he goes and gets the money from them. Otherwise, he said, the buses run the risk of getting caught at the barrier $20 \mathrm{~km}$ before the location where 
many buyers are found. Once they have paid, a call is made to ensure they pass. If they don't pay, the person stationed at the barrier won't allow them to go on. When this officer collects money, he has to call the captain by the end of the day, and the captain tells him where to send the money. The captain tells the police officer to keep some and send the rest (interview, April 14, 2017).

Therefore, security services posted at LSM sites and traders do not passively receive miners but often actively call on miners and offer or accept to provide protection for artisanal miners' claims to resource access. Representatives of different private and public security forces therefore cannot be portrayed as "victims" of artisanal miners" aggressive claims to entry at mine sites. At site B, for instance, miners may have to successfully cooperate with up to four services: the PSC, company security, the police, and undercover officers (two miners and their mother, interview, March 31, 2017). To some extent miners' options are limited to where they can arrange entry, which depends on factors including where the security services allow them to work (three miners, second interview, March 13, 2017).

As noted, trust relationships facilitate transactions and the flow of rents and minerals. Yet these relationships are typically not sufficient when it comes to the functioning of clandestine extraction and avoiding conflict, given different actors' reliance on rents or the sale of minerals. The rules and regulations of clandestine mining also include the fact that payment is required for a range of services including mine site access: connections matter, but are often limited in their usefulness, particularly for the artisanal miners at the bottom of the supply chain. As Gallien argues in the case of how smuggling is regulating in North Africa, there is therefore a significant degree of impersonality to the functioning of the regime (Gallien, 2019) even though much of it, especially at higher levels of authority, is predicated on repeated interactions and relationships, which lower transaction costs. As one respondent argued, even if a security guard is a miner's "brother", one respondent argued, that guard is part of a team and won't let the miner enter site $\mathrm{C}$ without paying, for the other security forces will demand something (four miners active at site $\mathrm{C}$ and a journalist, interview, February 8 , 2017). Money, whether actual or in kind, like minerals, is a key facilitating component of the market that is clandestine mining: artisanal miners generally have to pay for mine site access. A miner who is not known by a security guard but who has money can gain entry to an LSM site, but a miner who is known is not allowed in without paying (three miners, second interview, March 13, 2017). At site C, where the concession is much larger and miners typically dig pits over a much longer period of time, access similarly depends on connections but also on financial means. While connections play an important role, it's not who a miner 
knows that ultimately determines whether he is granted access, but whether he has money. If miners have money, even if the guards don't know them, they will be able to enter (four miners, interview, February 8, 2017; two miners and their mother, interview, March 31, 2017). When the security guards or police officers are rotated after one or two weeks, going to the new guards and paying them helps miners get to know them (miner active at site A, interview, February 13, 2017). Some miners enter without paying, for example in areas where companies store the tailings (two traders, interview, February 25, 2017). As I discuss in more detail below, miners who try to avoid the obligatory payment, particularly when trying to enter areas where high-value minerals are located, take greater risks (group of miners, interview, April 3, 2017).

The amounts to be paid depend on the site and which "right" - e.g. mine site access or authorisation to transport clandestinely mined minerals - is purchased. Miners pay before entering, for access to LSM sites (civil society representative, interview, March 4, 2017), but often have to pay upon taking minerals out as well. Whether miners pay before entering can depend on the particular sub-site. While there is a significant amount of consistency and organisation to clandestine mining, respondents described a range of different amounts. These differences demonstrate variation and room for negotiation, but also a degree of unpredictability and opportunism that sows potential for conflict. In the Lubumbashi area, where work at sites $\mathrm{A}$ and $\mathrm{B}$ is much more expensive than at site $\mathrm{C}$, miners may have to pay not only the police, but also mining equipment operators, security guards at posts, and company employees. It costs a group of 10 miners at least $\$ 500$ or $\$ 700$ - i.e. at least $\$ 50$ per head - to enter site A or site B (miner and two former miners, interview, February 17, 2017; miner, interview, February 13, 2017): one respondent cited an amount as high as $\$ 200$ per miner (two miners, interview, March 16, 2017). At site A miners pay half upon arrival and upon exiting, give another sum of money to leave. For a group of ten people they may have to pay 600,000 francs $-400,000$ Congolese francs before, to enter, and after working, the remaining balance - whether or not they have found something. If other security services or representatives arrive, the miners have to pay them too (group of miners, interview, April 3, 2017). The size of a group can even go up to 15 or 20 miners, depending on the money they have (miner, interview, February 13, 2017). 15 to 20 teams may enter in a night, which means significant amounts to be paid: $\$ 5000, \$ 8000$, or even $\$ 10000$ (two miners, interview, March $16,2017)$. At site $\mathrm{A}$, in addition to paying for entry, miners have to pay 5000 or 10,000 Congolese francs per bag of minerals they remove (trader and her miner son, interview, February 27, 2017; two miners, interview, March 16, 2017; occasional miner, interview, 
March 21, 2017). At the barrier, on departure, it costs 5000 francs per sack of minerals. After that barrier and once outside, there's another péage [toll] where one is asked for 1000 francs (two miners, interview, March 16, 2017). A former trader/miner interviewed in the Lubumbashi region said that he had never gone to mine in the area because miners are asked to pay 100,000 or 150,000 Congolese francs for just three hours at the mine site, unlike at site C, where entry is free and people can enter at all hours - 7 a.m., midnight, 3 p.m. - "like they're at home" (ex-trader/former miner, interview, February 17, 2017). Upon leaving site B, miners may also have to pay 10,000 Congolese francs for each of three services outside the site: the ANR, the Bureau 2, and l'escadron: FARDC or Republican Guard officers outside the concession (miner and two former miners, interview, February 17, 2017).

According to a former trader/miner, at site $\mathrm{C}$ a miner can enter without paying and then pays the Mine Police and Industrial Guard a small amount of money, un petit rien, to exit the site (interview, February 17, 2017). In the site C2 area is granted in exchange for money: payment is made daily, at each entry, even if the miner did not find anything. At each hill the PSC has a tent, accompanied by a police officer (two miners, a trader's wife, and a woman who sells firewood, interview, April 10, 2017, interview, April 10, 2017). At C2, the Mine Police ask for 5000 francs per team of miners per day (four miners, interview, February 8 , 2017). A group of miners at site $C 3$ explained that they enter without paying: it works differently than at site C2. At C3, they pay the Industrial Guard and Mine Police on the way out from the hill as they leave with their products. When miners dig pits, one miner explained, the police, Industrial Guard, and/or PSC are not aware of it. When the miners start bringing products, like malachite, out because the pit has started producing, the services come and ask for money. At that point, miners have to start paying to enter (several traders and miners, interview, March 9, 2017). Some miners at site C3 explained that to enter the site there is a barrier and "soldiers", and they experience many difficulties. To take their products out, they have to pay 3000 Congolese francs per sack to the Industrial Guard, police, and Bureau 2 (group of miners, interview, March 4, 2017). In some cases, there is flexibility in terms of payment. According to a miner who goes to site B infrequently, to collect minerals for subsistence purposes, the amount is negotiable and depends on what the miner collects. If he is only able to make 20,000 francs' worth, for example, he can keep 10,000 francs after paying out small amounts for security (occasional miner, interview, March 21, 2017).

The price differential for mine site access between site $\mathrm{C}$ and the two sites in the Lubumbashi region can be linked to factors including the vastness of the site and ease of entry. As mentioned, the size of site $\mathrm{C}$ makes the site difficult and expensive to monitor. 
There are some fenced-off areas and some areas that are not; miners tend to operate in the latter areas, near C3 (ex-trader, interview, February 17, 2017; miner and his wife, interview, March 31, 2017). Company A and B's concessions are much smaller. At site B there are only three open pits (bassins) (ex-trader/former miner, interview, February 17, 2017; LNI representative and Mine Police representative, interview, March 20, 2017). An ex-trader pointed out that company B wants to get back its expenses because it paid a lot for the site, which is not enormous. In contrast, there are more than 300 hills at site $\mathrm{C}$, and the company has only extracted minerals at a few of them so far. He never operated in the Lubumbashi region because security bothers the miners and catches them (company B security officer, interview, January 27, 2017).

Other factors that may help explain price differentials between different areas and sites include the extent to which security is present as well as teneur (mineral quality) (community relocation consultant, interview, August 9, 2016). Mineral quality varies across locations at the mine site. The tailings may contain the low or no-value substance that remains after mineral processing. The company stores, and moves by conveyor belt, the real minerals. To access areas where rich minerals are found, miners pay more, for example, 200,000 Congolese francs. Therefore, what miners have to pay also reflects the amount of minerals they can collect. If minerals are already identified at a given location, the miners can collect rich minerals in large quantities, so the police officer asks for a lot of money. However, in the general mine area where it's necessary to search with a lamp for the colour green (copper) or black (cobalt), there's a risk that miners won't find anything, so the maximum the miners accept to pay is 20,30 , or 50,000 francs, and per person 5 or 10,000 . If they're down in the mine and the patrol passes, the security guard disavows knowledge of the miners. Since there's a risk of arrest, miners negotiate the price of entry downwards. There is some room for miners to negotiate amounts with the security forces, given that they may not find anything to sell and that they may not have as much as security is asking. However, the negotiation process is not always successful (doctoral candidate, interview, February 1, 2017; miner, interview, April 3, 2017). Similarly, a miner who goes to site $C$ said that miners can either go where the company already extracted minerals and then abandoned the site, or where the company is working. To go where the company is still working and has its equipment and machinery, it is necessary to "cooperate" with the security guards by paying. The miner can enter for just 20 minutes, collect minerals, and leave. Where the company has already finished working, there may be no guards (two miners and their mother, interview, March 31). 
Finally, members of the Industrial Guard in particular might allow miners to enter the site for a few minutes to collect minerals, but in order to help the miners, not for money. The Industrial Guard may even refuse miners' money but allow them access for a few minutes, which points to the risk to their jobs if they are found to have taken money from miners (two traders, interview, February 9, 2017), and the fact that not everything is for sale.

At site $\mathrm{C}$, to bring the products to the maison d'achat, minibuses called "Dubai" are used for transport: one pays 2500 per sack to transport. On the road, there are several barriers, including those of the chefs and what a miner called "vultures", who ask for 20,000 francs per minibus (two miners, interview, March 16, 2017). After the miners have paid whatever the various security services ask for, both at site A and outside, traders also have to pay some money: 5000 or 10,000 francs. For one sack of minerals, the service takes at least 4000 or 4500 francs. For the transport, it is at least 4500 more (trader, interview, May 10, 2017). According to one trader who operates at site $\mathrm{C}$, when a bicycle transporter transports clandestinely mined minerals, Bureau 2 representatives ask for 1000 Congolese francs per bicycle, which the trader pays. The bicycle transporter takes the minerals to the trader's house. Motorcycles are then used to take the minerals to the maisons d'achat, he explained (trader and two associates, interview, March 4, 2017). Minibuses known locally as "Noah" are also used to transport minerals (Mine Police officer, interview, April 14, 2017). To exit through the multiple barriers on the «nationale » - the main, national road running through the company's concession - a trader explained at site C3, a trader or individual who sponsors a team of miners must pay security 80,000 Congolese francs; 10,000 francs per sack of minerals (for a maximum of six sacks for motorcycle); and 60,000 francs to the motorcycle driver (trader and two associates, interview, March 4, 2017; journalist, interview, February 7 , 2017). In March 2017 a trader also at C3 said that per motorcycle the cost is 75,000 francs (several traders and miners, interview, March 9, 2017). Another trader cited the lump-sum amount of $\$ 500$ for a truck of minerals (three traders and a former miner, interview, February 4, 2017). Along the road, the Bureau 2 of the police may stop the vehicle with minerals and bring it to the police HQ in central Lubumbashi, asking for 200 or as much as 500 dollars. The trader may try to negotiate, and the police may accept 300 dollars. The minerals are then brought to the maisons or dépôts. If the problem is not solved and the minerals are seized and brought to police HQ, it can cost much more - the trader may be asked for as much as $\$ 5000$ (trader, interview, May 10, 2017).

A miner can enter without paying, pay with his own money, or take a trader's money to enter the site (miner, interview, April 3, 2017). In terms of specific trust relationships, 
artisanal miners can reduce the risk to their physical safety by allying themselves with a sponsor: traders have money and can sponsor individuals or teams (four miners, interview, February 8, 2017; several traders and miners, interview, March 9, 2017). Many miners enter by going to see a trader, who pays the security guards/police so they can enter (two traders, interview, February 25, 2017). Traders tend to work with a group, for example of ten miners (miners, group interview, April 3, 2017). At site A, traders give money to miners to pay security, and when the miners return they sell to those traders (two miners and their mother, interview, March 31, 2017; doctoral candidate, interview, February 1, 2017). If a miner is loyal to a trader, the trader gives the miner money and buys his minerals. If there is no trust between the two parties, the trader won't give the miner money. A miner at site $\mathrm{C}$ kept bringing one trader products for sale, so the trader began to give him money for entry (two miners and their mother, interview, March 31, 2017). An association with a trader may also allow miners to get more money. When a trader works with miners he brings them to the site and, a group of miners in the Lubumbashi area explained, they get more products than those not working with a trader (miners, group interview, April 3, 2017). As one respondent explained, a miner won't know where the rich products have been brought by truck; someone from inside the site has to give him this information (PSC manager, May 22, 2017). A group working with a trader can reportedly leave with as many as 100 sacks - depending on the number of members and how skilled they are - whereas the miner on his own may leave with only a small sack. Such an arrangement is therefore advantageous to traders and miners (miners, group interview, April 3, 2017). A trader similarly reported that when he pays the police, for example $\$ 100$, and his team enters site $C$, the benefits are significant: they can even get 20 sacks. The trader gets his investment back and whatever is left is divided in two between the trader and the miners (three traders and an ex-miner, interview, February 4, 2017). To some extent miners' options are limited to where they can arrange entry, which depends on where the traders send them. A group of miners in the Lubumbashi area go where the trader sends them, and then bring their products to him. The trader buys the minerals, subtracts his money, and gives the miners the rest. Whether the miners go to site A or B often depends on the trader. The trader takes his group of ten to security and tells them to let the miners enter (miners, group interview, April 3, 2017). Therefore, traders, along with the security forces, are also involved in governing and regulating clandestine mining. Traders also provide support for miners in other ways. If an artisanal miner dies at an LSM site, a "committee of traders" may intervene (three traders and an ex-miner, interview, February 4, 2017) if the state or company does not. 
Not all traders are willing to finance miners' access to LSM sites. Many traders prefer not to give money to miners, so the miners have to save up for entry instead (miner, interview, April 3, 2017) - or enter by force (group of miners, interview, April 3, 2017). One miner who goes to site A, and his wife, said that at the moment, few traders lend money to miners (miner and his wife, interview, April 9,2017). While some in a group of miners in the area where sites A and B are found reported that it is easy to find traders to work with, others said that at the moment, there are not many (two miners and their mother, interview, March 31, 2017; group interview, April 3, 2017), and few lend to miners (miner and his wife, interview, April 9, 2017). More are reportedly present around site A, where access is easier (two miners and their mother, interview, March 31, 2017). A miner who goes to site A reported that the only interaction between miners and traders is when miners bring minerals for purchase (trader and her miner son, interview, February 27, 2017).

Working with a trader also has disadvantages that lead some miners to avoid doing so. Miners must reimburse the funds borrowed from traders. If a trader pays off the police, the trader takes back his or her money from the minerals collected before the rest is divided up between the trader and miners (three traders and an ex-miner, interview, February 4, 2017; civil society representative, interview, January 24, 2017). Miners argue that traders share the minerals collected in an unfair way. The trader first takes out the expenses he paid, including site entry, and then takes significant profit before sharing whatever's left among the miners. One respondent argued that traders claim they had a number of expenses when moving the minerals, like transport costs and avoiding arrest, so they can take a bigger share (two miners, interview, March 16, 2017). Traders and other lenders in the community - someone in the community who has a small food store or a kiosk, or simply has money to lend - reportedly also charge interest, which was said to be very high (miner, interview, March 21, 2017; miner and his wife, interview, April 9, 2017). A trader can impose his sale price, whereas a team that goes it alone can take the minerals to sell themselves (interview, February 17, 2017; miner, interview, April 3, 2017). According to one respondent, few miners work with traders because those who do so only get access to the site once or twice a week. When a miner enters in association with a trader, everyone is aware of it: the security guards from the highest to the lowest level receive money. Afterwards, it's necessary to leave some time before miners are allowed to enter through that particular trader again, so they may decide to enter without going through security (two miners, interview, March 16, 2017).

From traders' perspective, conflict between traders and miners at times means that traders are more likely to work only with trusted individuals. Some miners borrow money 
from a trader for site entry and, instead of bringing the minerals to that trader, disappear. The trader doesn't know how to find the miner (given that many are from elsewhere) and may find him later by coincidence, at which point conflict erupts between the trader and the miner and the trader may get the police involved. Some miners are more reliable (two traders, interview, February 9, 2017; two miners and their mother, interview, March 31, 2017). Miners who are unreliable or that the trader doesn't know are more likely to have difficulties finding a trader to borrow money from.

Some miners therefore have different strategies, including saving, to earn the money they need to pay for access (miners, group interview, April 3, 2017). One miner's team uses the minerals they extract to cover expenses like paying to get a miner released when he is caught by company security. When a group of miners has money and one of them is caught by company security, someone can go to the company base and pay to get the miner out. The miner argued that miners who work with traders are those without funds (interview, February 17, 2017; miner, interview, April 3, 2017). If a miner has a bit of money, he can pay for his freedom at the parquet if arrested (miners, group interview, April 3, 2017).

Some miners at site $\mathrm{C}$ - where unlike at $\mathrm{A}$ and $\mathrm{B}$, miners frequently dig pits on hills where the company has not yet begun extraction - work with one or more pit managers ${ }^{20}$. Pit managers provide miners with money for expenses and pay the security services. Connections also help miners to work with a pit manager. A miner active at site $\mathrm{C}$ said that while three miners he works with had gone to site C3, where people can work easily, he had to stay at site $\mathrm{C} 2$, where he had connections. Without connections, he said, people can prevent a miner from working by saying they don't know him; he needs connections among the responsables de puits, the people who manage the pits. He added that personal relationships matter. A miner can be privileged if a family member has a pit at the site. Anyone with enough money can have a pit (miner, conversation, March 3, 2017), which shows that money can help make up for a lack of connections. Family connections may make up for the lack of a relationship with a trader. A miner who operates at site B sometimes borrows 50,000 Fc from his mother to pay security and reimburses her once he's collected the minerals (miner and his mother, interview, March 29, 2016). Political figures reportedly also assemble and sponsor two, three, or as many as five teams of artisanal miners. The political figure makes arrangements with the security forces so the miners can enter without difficulties and pays for food and equipment for the miners and motorcycle transport for the minerals. A university researcher noted that a

\footnotetext{
${ }^{20}$ The pit manager doesn't work with a trader; traders deal directly with miners.
} 
national-level MP whose constituency is in company C's concession made the money for the hotel that he owns through his involvement in artisanal mining (interview, March 29, 2017). Mine Police representatives are said to work with miners at a pit (trader and two associates, interview, March 4, 2017), as are ANR and Bureau 2 representatives (site C3 miners' committee member, interview, April 13, 2017).

There are different configurations through which artisanal miners access LSM sites, including alone; in small or informal groups that arrive at a site together or come together on the spot (group interview, April 13, 2017); and as teams that work together on a regular basis, particularly at site $\mathrm{C}$ where artisanal miners often dig pits instead of collecting minerals. At site $\mathrm{C}$ miners tend to pay for access as teams (village chief and multiple village residents, including miners, interview, April 11, 2017). Being part of a team is a second-party, coalitional tactic artisanal miners employ to gain access to minerals. Just as individuals can negotiate and pay for access to an LSM site, so, too, can teams (miner, conversation, March 3, 2017). Teams come together in a variety of ways. According to one group that works together, a team can start out as just two people who enter the site together and work. While working they see that another group, too, works well, and then band together (group interview, April 13, 2017). Another miner, too, attributed the choice of group members primarily to whether a miner works hard or is skilled (three miners, second interview, March 13, 2017; miners, group interview, April 3, 2017). One respondent added that miners have to be able to endure suffering, so they don't become afraid when arrested. Second, the group has to be headed up by someone who knows a security guard (three miners, second interview, March 13, 2017). One group of miners active at site $\mathrm{C}$ came together on the main road, at the stop for C3, where traders seek a team of miners among those arriving (two miners and their mother, interview, 2017). Differences in how miners extract minerals affect the extent to which artisanal miners organise into groups or teams. At sites A and B in the Lubumbashi region, and at the open-pit mines at site $\mathrm{C}$, the companies use machinery to dig and blast, which brings out minerals that miners then collect (trader and her miner son, interview, February 27, 2017): artisanal miners do more collecting than actual mining. Miners can't dig pits because there's nowhere to dig. At site $\mathrm{C}$, structured teams of miners dig pits on the many hills from which the company has not yet extracted minerals (ex-trader/former miner, interview, February 17, 2017).

Actors involved in clandestine mining also rely on state authority to define and enforce their claims to resource access. As discussed, while the DRC is often portrayed as an area of limited statehood, state authority does exist, albeit often in highly repressive form, but 
the authority of the Congolese state does not derive solely from force or coercion. State security forces like the police lend authority derived from state power to corporate PR and authorised clandestine extraction, to varying degrees of coerciveness. The fact that state actors play several roles within the property rights regime adds to the complexity of defining state actors' involvement in clandestine mining as first-, second-, or third-party measures. At different times and in different contexts in this PR regime, state actors variously act as enforcer of formal property rights; resource claimant and/or competitor, and enforcer of informal rules and regulations - and sometimes play more than one role at the same time. Given the rhizomatic nature of Congolese statehood, and LSM companies' significant power and resources in this region - particularly compared to the Congolese state - LSM companies in a way act as arbiters of clandestine extraction, since they lend their authority and resources to actors who are instrumental to its functioning. I discuss these dynamics in more detail below.

Finally, there are situations in which entry to certain areas, particularly certain hills in company C's vast concession, is not controlled by anyone, even in an informal manner. These dynamics can be linked to the fact that the company does not have unlimited security. Companies secure high-value areas but if they have not begun extracting minerals in a given area, security may not yet have been deployed. Equally, once the company has finished extracting minerals in a given area, they may withdraw security from the area (two miners and their mother, interview, March 31, 2017). A respondent at site C2 mentioned that some hills don't have security tents on them, and miners can go there without paying. However, there are many miners and not everyone can go to a small hill where there's no security (two miners, a trader's wife, and a woman who sells firewood, interview, April 10, 2017). A miner reported that where company $\mathrm{C}$ has finished extracting minerals, entry is free (two miners and their mother, interview, March 31, 2017). These situations also provide evidence of the symbiotic relationship between corporate enforcement and authorised clandestine extraction: the deployment of security at a given area, and their ability to justify their presence there, allows them to charge for access.

\subsubsection{Unauthorised Clandestine Extraction}

The unauthorised component of the mineral rights regime refers to artisanal miners' activities that fall outside of the remit of the authorised clandestine extraction of resources, in that they are not authorised or sanctioned by the Congolese police, mining companies, private 
security agencies, or other actors. A number of artisanal miners regularly attempt to evade or get around not only corporate enforcement, but also the rules and procedures of the clandestine, yet "authorised" element of the property rights regime. Miners draw on first- and second-party approaches to gain unauthorised clandestine access to LSM sites. By definition they cannot draw on state support for these claims: not only is (unauthorised) clandestine mining against Congolese law, but state security forces actively police, and attempt to prevent, this type of resource access. Like authorised clandestine mining, unauthorised clandestine extraction plays on two different registers: the covert (as when miners decide to hide from the security forces) and the overt (when they use aggressive behaviour to secure resource access).

Some traders and artisanal miners referred to unauthorised clandestine extraction as "fraud" and to the miners who engage in such fraudulent pursuits as people who commit fraud (trader, interview, May 10, 2017). Terms like "fraud" and "fraudulent" are problematic due to their pejorative nature and limited applicability in the complex and fluid legal and moral landscape of southeastern DRC. Nonetheless, these terms highlight the legitimacy, in many actors' eyes, of authorised clandestine extraction, and how entrenched these practices are. Yet many artisanal miners resent how their activities in LSM concessions are governed and taxed, sometimes excessively. Miners put themselves at risk by accessing forbidden areas: mine collapses at areas that are "off limits" regularly cause multiple casualties at site C. Yet traders and buyers benefit more from miners' labour than the miners themselves. At the same time, instead of addressing these issues, the number of government services involved in clandestine mining to collect rents has grown (civil society representative, interview, February 9, 2017). In response, some miners employ strategies to gain access to LSM sites without paying off security guards or police officers. In addition to the cost of mine site access, miners are also afraid that those agents might then turn around and betray them, like in case of a security inspection, even if the miners have paid for entry. Miners have issues not only with the payments required and the risks associated with making their presence known in circumstances that are often unpredictable and prone to rapid change - including the breaking of agreements by the security forces - but also with restrictions imposed on the frequency and length of time allowed for miner access.

Artisanal miners who engage in clandestine extraction are some of the least powerful actors in the mining supply chain and are exploited overall, including by traders. The "illegal" status of artisanal miners who do clandestine mining puts them in an even more precarious position (Mine Police representative, interview, October 7, 2016). For reasons including their 
“illegal” status, miners typically lack chiefly, governmental, civil society, and/or community support - though as I discuss later on, some individuals and groups, like certain customary authorities, benefit financially from their presence. One interviewee argued that because of the financial benefits involved, civil society looks to the mining company rather than supporting artisanal miners (PhD candidate, interview, September 6, 2016).

The weakness of miners' claims and rights also reflects the fact that while the DRC has a legal framework in place for artisanal mining, this framework is not well implemented by the state. At an August 12, 2016 company-sponsored workshop in Lubumbashi ${ }^{21}$, one participant explained that while the population of miners has a legal right, they have no actual rights. The vast majority of mining concessions have been sold; there are few sites available for artisanal mining, despite the fact that the Congolese Mining Code contains provisions for the national Ministry of Mines to create and allocate artisanal mining concessions or Zones d'exploitation artisanales (ZÉA). ZÉAs, if indeed they exist (journalist, interview, April 12, 2017) are often created in places where the mineralised layer is so deep that artisanal miners can't reach it, since the Mining Code caps the allowed depth of an artisanal pit at 30 metres. In other cases, ZÉAs are granted but are inaccessible and poorly mineralised. If a good mineral deposit is found, the site is sold to an industrial company and the miners pushed out. The miners seek artisanal sites elsewhere, or go to LSM sites (civil society representative 2, interview, August 23, 2016; civil society representative, interview, January 24, 2017; doctoral candidate, interview, February 1, 2017; trader and her miner son, interview, February 27, 2017; artisanal miner, interview, February 27, 2017). Miners' determination to enter LSM sites, at time accompanied by aggressive words and actions, reflects the larger context in southeastern DRC.

There is therefore an imbalance between artisanal miners' demand for property rights, and the supply of PR, which means miners have to organise their own property rights enforcement. When it comes to this facet of the regime, first-party measures are predominant and include damaging company walls or fences. In company C's concession, miners sometimes tear down fences the company has put up. In February 2017, a Mine Police representative showed me a large segment of fence he said had been cut. At site $\mathrm{C} 3$, where the community is right next to where the company stocks minerals, miners cut and took away barbed wire (interview, February 7, 2017). First-party measures do not have to involve the use of force but can be as simple as hiding from the security forces. If miners in the $\mathrm{C} 3$ area of

\footnotetext{
${ }^{21}$ Not one of the case-study companies.
} 
company C's concession see a Mine Police officer, they try to hide. If they see him, they run away (Mine Police officer, interview, April 12, 2017).

Artisanal miners' tactics to gain entry to mine sites without paying include trying to circumvent the security forces altogether (Mine Police representative, interview, April 12, 2017). Miners get around the payment and behavioural rules in place through subterfuge. They enter a site while avoiding places where they know security guards and/or police officers are deployed, or at a time when they know guards' presence is limited - for example, during break times or changes of shift (two miners and their mother, interview, March 31, 2017). Some miners prefer to enter the mine site during the rainy season because they can more easily enter without being disturbed by security. During the rainy season, the guard leaves his post and hides so as not to get wet. Miners may be working three metres away, but the guard will not want to go see what's going on (three miners, second interview, March 13, 2017; Mine Police representative, interview, March 24, 2017; two miners and their mother, interview, March 31, 2017). ${ }^{22}$ If miners are unsuccessful at hiding, they run away if security arrives and they don't have money to pay (village chief and multiple village residents, interview, April 11, 2017). The physical vulnerabilities in each site's "fortress" also make it easier for miners to get around the security forces without paying.

With respect to first-party measures, miners at times exhibit persuasive, forceful, and even violent behaviour. According to a Mine Police representative deployed at site A, if security is reinforced, the miners ask for forgiveness and plead that they don't have money or school fees (LNI representative and Mine Police representative, interview, March 20, 2017). They point to their unemployed status and tell members of the security forces that while they have jobs, the miners do not (company $C$ security manager, interview, May 27, 2017). If miners feel blocked from accessing the LSM site, they may resort to aggressive behaviour, including rough speech, throwing stones, and reportedly even the use of slingshots or barres de mine, to gain access (doctoral candidate, interview, February 1, 2017; group of miners, interview, April 3, 2017). If miners are not allowed to enter the mine site, they may fight to enter rather than risk getting nothing (four miners, interview, February 8,2017 ). If the security forces refuse this access, disorder can result (civil society representative, interview,

\footnotetext{
${ }^{22}$ One police respondent deployed at site B, however, argued that the number of miners increases during the dry season because it's easy to dig and there's less risk of a collapse: some people travel hundreds of kilometres to the mine site. Miners have difficulties during the rainy season; some take objects including batteries instead (LNI representative and Mine Police representative, interview, March 20, 2017). One miner reported that during the rainy season he avoids site $\mathrm{C}$, where miners dig pits, because of the risk of collapse, and prefers site $\mathrm{A}$, where he can collect minerals instead of digging (trader and her miner son, interview, February 27, 2017).
} 
February 9, 2017; interview, February 13, 2017; group of miners, interview, April 3, 2017). A LNI representative deployed at site B said that miners often injure police officers by throwing stones (LNI representative and Mine Police representative, interview, March 20, 2017) or with their barres de mine (Mine Police official 1, interview, November 8, 2016). A journalist said certain miners enter site $\mathrm{C}$ without paying either because they don't have money or, in some cases, are "stubborn" (interview, February 7, 2017; also police official, interview, February 18, 2017) and may take drugs before entering the mine. When miners have taken drugs, he argued, they may choose to confront security instead of paying (interview, February 7, 2017; site C3 miners' committee member, interview, April 13, 2017). Those who do not have money for entry may use aggressive behaviour as a strategy (interview, February 7 , 2017). Another respondent noted that miners are prepared to die for their needs (civil society representative, interview, August 10, 2016). If a police officer tries to chase a miner out in order to be given more money, the miner may argue and fight (trader and her miner son, interview, February 27, 2017).

Traveling to LSM sites in groups is another strategy miners use to increase their chances of gaining access to the site, and reduce their risk (occasional miner, interview, March 21, 2017). Groups of miners are prone to behave in an aggressive manner to get into an LSM site when refused access or ordered to leave before they are finished working. When miners are denied entry because a security inspection is imminent, or they do not wish to pay for entry, they may become aggressive or exhibit violent behaviour like throwing stones, particularly in a large group (Mine Police representative, interview, February 7, 2017. ${ }^{23} \mathrm{~A}$ Mine Police representative reported that miners may try to take pieces of equipment, or to damage company machinery and vehicles, if prevented from taking minerals - particularly as they're frequently in groups of a dozen to as many as 100 (interview, February 7, 2017; company B officer, interview, February 6, 2017). When artisanal miners enter an LSM site en masse, the security is afraid, and the police tend to fire weapons (site C3 miners' committee member, interview, April 13, 2017). The fact that company employees and unarmed guards are told not to interfere with miners' activities to avoid risking their safety (doctoral candidate, interview, February 1, 2017) points to the effectiveness of group entry as a strategy.

I contend that some miners' aggressive behaviour constitutes a first-party response to the lack of protections - whether by the state, the companies, or other actors - for their rights

\footnotetext{
${ }^{23}$ That raises the question of whether they're more aggressive because they're in a group, or if those who are more aggressive are more likely to move around as a group.
} 
to life, safety, and livelihoods. Miners tend to rise up in anger not only when they can't access mine sites, but also when fellow miners die as a result of action by security forces or in an accident (journalist, interview, February 7, 2017; civil society representative, interview, March 4, 2017; PSC manager, interview, May 22, 2017; trader/miner, interview, May 19, 2017). Miners often run away when confronted and don't resist but can become dangerous if a police officer fires in the air to make miners flee and a stray bullet hits someone. When the miners see that one of their own is injured, they get angry and may attack the officer (trader and her miner son, interview, February 27, 2017). Aggressive or violent responses are also a visible form of efforts to "transgress" the rules and regulations that govern clandestine extraction, specifically the demand for payment and the imperative to keep these practices covert by limiting where, when, and for how long miners can enter LSM sites.

Yet not all miners engage in aggressive behavior or confrontations (miner, conversation, March 3, 2017). Many miners are, instead, victims of coercion and violence, particularly given the imbalance between police officers' firearms, and miners' armes blanches. Frequently, during encounters between security forces and miners, the security forces deploy forceful measures, while miners do not resist but run away, in which case the conflict ends rather than escalating. In some cases, a refusal by unarmed security guards or police to allow miners to enter is sufficient to deter them (miner and his mother, interview, March 29, 2017; miner, interview, February 13, 2017; doctoral candidate, interview, February 1, 2017; trader and her miner son, interview, February 27, 2017). One miner, unwilling to take the risk of physical violence or even death, in which case his family would not know what happened to him, abandons the site if the situation goes wrong (interview, February 13, 2017). One trader argued that the miners are not aggressive, except if provoked, for example, if the trader offers a certain amount for the products and the miners want more (three traders and an ex-miner, interview, interview, February 4, 2107). If a police officer tries to chase a miner out in order to be given more money, the miner may avoid or run away from the officer, because he's armed (trader and her miner son, interview, February 27, 2017). Therefore, like LSM companies, miners at times choose not to enforce their PR, to protect themselves, which diffuses conflict.

The security forces also likely generalise about miners. While interviewing a Mine Police representative at site $\mathrm{C}$, he brought me to five recently detained miners. He told me that miners attack people with their barres de mine (the metal bars used to dig for minerals), but what had been confiscated from the five men were two metal shovels and a pointed (but flimsy-looking) flat silvery metal tool (interview, February 7, 2017), which didn't look like a 
typical barre de mine I have seen miners carry. There is a need for caution regarding the pervasiveness of aggressive behaviour because employing such tactics significantly increases miners' risk of arrest or being harmed. Some artisanal miners are afraid of the police precisely because they're armed (two traders, interview, February 9, 2017). Political leaders also reportedly stir artisanal miners up into violent protest for their own benefit (“Au moins un mort”, 2019). Such tactics may be considered to be first-party measures, using artisanal miners as a "tool". Therefore, miners' aggressive and/or violent actions may not be "spontaneous" outbursts of anger, but a component of a larger property rights regime that policymakers should take into account. As discussed below, such actions may be part of local authorities' efforts to enforce their claims within the authorised clandestine mining facet.

Artisanal miners also implement coalitional - second-party - strategies involving other resource users, namely other artisanal miners. Because by definition artisanal miners can't rely on third-party enforcement for unauthorised clandestine entry to mine sites, they frequently band together with other miners. Several interviewees argued that artisanal miners are in solidarity with one another (civil society representative, interview, January 24, 2017; trader and her miner son, interview, February 27, 2017). If a miner trying to enter without authorisation sees the police at the site, for example, he may run away and tells others not to enter without paying (trader and her miner son, interview, February 27, 2017). At other times, however, miners use first-party measures to defend their claims against other miners, including, as I discuss below, miners from elsewhere against miners from the former Katanga.

\subsection{Conclusion}

I have highlighted the presence of three key components of the property rights regime at the selected LSM sites, namely the first-, second-, and/or third-party approaches implemented by a range of actors. The corporate enforcement regime involves the strategies put into place by company officials abroad and in country, public security forces, private security agencies, and more. The authorised clandestine component includes public security forces, private security agencies, company security officials and guards, non-security company employees, artisanal miners, traders, transporters, and more. Finally, while miners' unauthorised access to mine sites centres principally on the miners themselves, other actors, such as security guards, are involved to greater or lesser degrees, albeit in a conflictual manner. These miners' practices can be ranged along a continuum from non-violent efforts such as hiding, to aggressive or even violent actions to gain unauthorised entry. Each facet has its institutional dynamics and organised patterns of functioning, but there are also exceptions, 
and each component of the regime is dynamic and in flux. In the next chapter, I analyse how the interactions between the three facets relate to conflict incidence. 


\section{Chapter 7: Conflict Dynamics between Corporate Enforcement, Authorised Clandestine, and Unauthorised Clandestine Mining}

Why are so many interactions between artisanal miners and the security forces at LSM characterised by little or no conflict, while others are far more conflictual? This chapter provides an explanation for the incidence of conflict across time at and around LSM sites, examining not only why conflict erupts at certain times and not others, but also the different forms it takes. In southeastern DRC, the acquiring, occupation, and clearing of large-scale mining concessions granted by the central government to multinational corporations were foundational events that set off a range of conflicts between MNCs and artisanal miners (Hönke, 2009). Some miners returned to work at these sites after the concessions were initially cleared. Many artisanal miners continue to operate at LSM sites, though they are often not successful in securing access. Young boys grow up and enter the mining business; men travel from other parts of the region or country to seek opportunities, while many women rely on the ASM supply chain for their livelihoods. The fact that artisanal mining - previously sanctioned or tolerated by state authorities and engaged in by large numbers of people in a relatively unrestricted fashion (EMAK representative, interview, February 1, 2017) - has been criminalised has fundamental implications for miners' ability to access resources; how that access is governed; and whether miners' access unfolds in a conflictual or peaceful manner. The prevalence of conflict dynamics across LSM sites is illustrated by figures from site B, where in February 2017 there were 94 miner "attacks", 30 arrests, and two cases of theft. In February 2017 the LNI police unit intervened on a daily basis at site B, sometimes even three times a day, with an arrest every day (LNI representative and Mine Police representative, interview, March 20, 2017). The conflict phenomenon varies along a continuum that reflects the range and variety of everyday and periodic encounters between artisanal miners and members of the different security forces. The objective in this chapter is to unpack the broad category of "LSM-ASM conflict" to shed light on the causes of conflict and how it manifests; why it is often absent; and the consequences of conflict for artisanal miners and other actors who rely on artisanal mining for their livelihoods.

The overarching argument in this chapter is that conflict incidence is a function of the interaction of the different facets of the property rights regime at and around LSM concessions: the corporate enforcement, authorised clandestine, and unauthorised clandestine components, which interact at different times and in different ways. This chapter analyses the intersection of these different elements and the circumstances under which they result in 
conflict. Broadly speaking, conflict occurs when the rules and functioning of one or more features of the property rights regime are in opposition to and actively clash with one or more of the others, which happens frequently even though these same facets at times align and work in concert. Conflict incidence is not haphazard or random but results from the interweaving and, at times, incompatible functioning of the different components of the regime. The fact of miners' "illegality" is an important one in that such a definition imbues companies with the power to define whose presence is and is not legitimate within the the confines of the mine space, which gives the security forces and other actors significant authority to pursue companies' interests, or their own, at miners' expense. The overtnesscovertness and openness-closure dimensions are key factors. With respect to the first dimension, conflict frequently erupts when, first, corporate enforcement practices undermine the strategic (c)overtness of authorised clandestine mining. As a result, the cost of providing PR rises due to factors including increased risks to the employment of members of the security forces and/or mining-company employees, or companies' reputations. Miners may be arrested on the spot after being granted access, or they may fight back to resist expulsion from an LSM site. Concerning the second dimension, the different public and private security forces seek to maintain a certain degree of market "closure" to protect their flow of rents (and contribute to the objective of keeping their activities covert). Yet miners' numbers and determination to access LSM sites with or without permission from the security forces makes this a fragile entreprise, one that typically requires a significant amount of coercion to enforce, particularly when miners attempt to circumvent payment by stealth or aggression.

While conflict seemingly results solely from the clash between corporate enforcement and artisanal mining, the incidence of conflict between ASM and LSM therefore occurs at the intersection of the corporate component, the enforcement of state-sanctioned clandestine extraction, and artisanal miners' efforts to gain unauthorised entry either covertly or overtly. The conflict that arises from these clashing modes of functioning negatively impacts artisanal miners the most physically and is also a burden on them financially. Examining the functioning of the property rights regime is not only important for understanding conflict, but also makes a contribution to literature that views artisanal mining in contexts of LSM investment as embedded within a larger political, social, and economic system.

In what follows, I present the overarching argument that conflict incidence is to a significant degree a function of the interaction between different components of the property rights regime, which includes specific PR regime dynamics that may be unique to each site. Next, I lay out the multiple conflicts that arise between the different facets of the PRR. I build 
on the disaggregation of the property rights regime into three main, overlapping, components to analyse LSM-ASM conflict first through the lens of the interrelationship of corporate enforcement and (un)authorised clandestine extraction and second, of the interactions between authorised and unauthorised clandestine mining. In this way I point to the need to disaggregate the non-unitary categories of "companies"; the "security forces", and "artisanal and small-scale miners" when it comes to analysing LSM-ASM conflict. I first consider the clashes between the corporate enforcement and unauthorised clandestine component before turning to how interactions between corporate extraction and authorised clandestine extraction also at times result in conflict. Despite the emphasis on clashes between different facets, the corporate enforcement and authorised clandestine components at time work together and contribute to the enforcement of companies' property rights. I also discuss the fact that while artisanal miners sometimes successfully reassert their claims and in certain scenarios, miners are disproportionally affected by the physical risks associated with clandestine mining, whether authorised or unauthorised. Unarmed security guards - typically Congolese nationals from the mining area or from elsewhere in the region or country - also shoulder a significant portion of the physical risk despite policies that, at least in principle, prevent unarmed guards from confronting miners. Trust relationships or "connections", which in keeping with property rights theory lower transaction costs, play a key role in the functioning of authorised clandestine extraction and in limiting conflict. The picture is mixed, however, on the impact of ethnic connections in smoothing the functioning of authorised clandestine extraction. In the next section, I analyse conflict resulting from the intersection of the authorised clandestine and unauthorised clandestine parts of the PRR, which include institutional dynamics that lead to conflict. The second-to-last section of the chapter deals with the fact that mine sites in southeastern DRC are interdependent: artisanal miners often move from site to site. Changes in enclosure and/or conflict dynamics at one site often lead to repercussions at other sites. The final section concludes.

\subsection{Conflict between Corporate Enforcement and (Un)Authorised Clandestine Mining}

\subsubsection{Overview, Historical Background, and Conflict between Corporate Enforcement and Unauthorised Clandestine Mining}

This section focuses primarily on the causes of conflict between the corporate enforcement and unauthorised clandestine mining facets of the property rights regime, which, as discussed in the literature review, has received more in-depth detail and examination in the 
academic literature. As discussed in the literature review, analyses of LSM-ASM conflict have dealt extensively with miners' eviction from LSM sites and the associated grievances and conflict. Less examined have been the means artisanal miners and other actors have employed to (re)gain access to those sites after eviction, which include unauthorised - and, as discussed in the next section, authorised - means. The conflict dynamics I discuss in this section demonstrate the ambiguous, uneasy space artisanal miners occupy. Miners' presence is at times - by necessity - tolerated by some companies but, at other times, much less so. When the company has begun operations and reinforces its security in response to miners' presence, there is significant potential for conflict (doctoral candidate, interview, February 1, 2017).

The fact that artisanal miner entry to LSM sites became, according to Congolese law, "illegal" has two key consequences. First, it gives the police, different PSCs, and company security a reason to be at these sites, a mandate for enforcement, and associated authority. Second, removing miners from these concessions and placing mine sites under guard, under conditions in which ASM miners cannot be fully excluded, provides various authorities, officials, and guards with the means and incentive to govern clandestine extraction. Artisanal miners demand, from the different security actors at LSM sites, enforcement of their claims vis-à-vis LSM companies. Yet by definition, because Congolese law and mining company regulations forbid ASM in LSM concessions, such claims are partially unenforceable. In line with Fitzpatrick's arguments, these dynamics mean that miners' PR cannot always be supplied. If the artisanal miners do not abandon their demands for PR, the security forces then have recourse to dissuasive, coercive, and/or forceful measures against artisanal miners instead.

Prior to the takeover by LSM companies, sites previously owned by the state-owned mining entreprise Gécamines were to some extent also governed by actors who demanded that miners pay for access. For example, a former EMAK representative said that when thousands of artisanal miners used to work at Gécamines-owned sites A and B, miners had to be members of EMAK before they were allowed to work at the mine site. In addition to being of Congolese nationality people had to have a traders' card or a miners' card. There were two cards: a card given by the provincial Division des mines and an EMAK card. Therefore, miners had to pay to enter the mine site even before these sites were taken over by LSM companies (interview, February 1, 2017). Similar dynamics prevail at other artisanal sites. Peyer and Maillard (2011) described how in an area around Kolwezi where around 5000 artisanal miners were active, researchers found that the ANR, the Mine Police, and a PSC 
were all present, and each demanded payments from the miners. Other government agencies and other bodies were also present or represented, each wanting their share: the Ministry of Mines, l'Office des douanes, the mayor of Kolwezi, customary chiefs, and EMAK representatives. Peyer and Maillard argued that because of the unregistered, and hence "illegal", status of the majority of artisanal miners, they are especially vulnerable to pressure by the police and other authorities. Therefore, the property rights regime is broader than just LSM sites and some of these issues are systemic rather than inherent to LSM sites alone.

Artisanal mining in the southeastern region of the DRC has been ongoing at least since the AFDL rebel group arrived in Kinshasa in 1997, encouraged by former Congolese President Laurent-Désiré Kabila (two socio-cultural association representatives, interview, April 12, 2017). Artisanal miners began entering sites A and B around 1997. Around the 2000s, a community activist explained, there were more than 10,000 artisanal miners at site A and over 7,000 at site B (interview, October 15, 2016). Miners' presence at these sites since at least 1997 - a full ten years since the first eviction of miners, at site A in 2007 (interview, October 15, 2016) - adds symbolic weight to artisanal miners' claims vis-à-vis corporate PR. So does the fact that a local "autochtonous" - or originaire as they are sometimes known in the region (civil society representative, interview, February 9, 2017) - ethnic community has a much longer history of artisanal mining (community activist, interview, October 15, 2016).

A key event from the point of view of corporate enforcement and conflict analysis is the moment at which companies cleared "their" mine sites of artisanal miners in preparation for beginning industrial extraction (doctoral candidate, interview, February 1, 2017). These mine site sales caught many local resource users, like artisanal miners and traders, by surprise, particularly when they learned that their own government had sold these sites (former EMAK representative, interview, February 1, 2017). With the mining boom, many artisanal miners came to work at the Gécamines mine that later became sites A and B. Starting in 2002, when company A bought the mine, the company bought minerals from artisanal miners, until 2004. After the period of semi-mechanisation from 2004 to 2006, artisanal mining came to an end in 2006, and mechanisation began. Artisanal mining then came to be known as "theft" (company A exploration staffer, interview, October 19, 2016). Mining companies may "close their eyes" while artisanal miners present before the company signed a contract for the concession extract minerals. The miners believe the site has been granted to them and that they have a right to it. Yet once the company has finished building processing facilities and is ready to begin extraction, the miners have to leave. When the miners say it's their site, since they've been extracting minerals for years, the company turns to the state to help chase away the miners. 
The police give the miners a deadline for leaving the concession. On the day planned for their departure, miners may rise up in protest - which can include throwing stones at the police, burning trucks and tires, and blocking roads - in which case force may be used (doctoral candidate, interview, February 1, 2017). A company B officer remarked that it was difficult to convince the miners to move because losing the open-pit mine meant losing their jobs. Therefore, while the signing of contracts between LSM companies and the Congolese central government bestows enforceable legal rights on companies, a key event from a conflict perspective is the moment at which companies start to enforce those property rights through first-party and other measures.

Despite the legitimacy issues associated with companies' legal property rights, many miners accept these PR in principle, if not in practice. One miner, when asked about disorder at LSM sites in Lubumbashi, argued that company B's mine is une entreprise d'autrui [a company that belongs to someone else] and asked how a miner could create disorder at someone else's company. He argued that the person doing so would be caught because the company paid the miners $\$ 200$ before making them leave and telling them not to return. Now, he argued, when a miner goes to work there, it is "theft" (miner and his trader mother, interview, February 27, 2017). Even company B's limited gesture of paying \$200 per miner is therefore seen to have conferred property rights to the company that miners must respect, at least to some extent, by not causing "disorder". Another miner reported that from 2008 to 2016 he went into site B "fraudulently" (two miners and their mother, interview, March 31, 2017). Another miner also used the term "fraud" (miner and his wife, interview, April 9, 2017) to describe his activities in LSM concessions. On the other hand, some miners feel they own the land with minerals because it's the land of their ancestors (participant, companysponsored workshop, August 12, 2016; historian, interview, August 8, 2016; Mine Police official 1, November 8,2016 ). When young people mine in industrial-mining concessions they often say they're on their ancestors' land (civil society representative, interview, January 24, 2017; miners, group interview, April 3, 2017). Therefore, there are not only legal issues at play, but also issues of the legitimacy of corporate PR (civil society representative, interview, January 24, 2017).

The clearing of mine sites A, B, and C was a significant conflict event in the history of these LSM sites after privatisation. Different dynamics unfolded across the three sites. Company A removed the miners by force and according to some, without payment (community representative, interview, October 15, 2016; miner and his wife, interview, May 31, 2017; miner, interview, April 3, 2017). The Mine Police injured and killed some miners at 
site A (miner and his wife, interview, March 31, 2017; miner, interview, April 3, 2017; community activist, interview, October 15, 2016). However, a former EMAK representative said that the company gave each miner \$25 US and two bags of flour (interview, February 1, 2017). A company A manager reported somewhat different information, explaining that the company had to provide trucks for SAESSCAM to move the miners, as well as tarpaulins, tents, foam (mattresses), and food (flour) to evacuate the artisanal miners into the "bush" (interview and site visit, September 24, 2016).

Company B learned its lesson from the violent eviction at mine site A, so paid each miner 200 USD (miner and his wife, interview, March 31, 2017; miner, interview, April 3, 2017; community activist, interview, October 15, 2016; former EMAK representative, February 1, 2017; miner and his trader mother, interview, February 27, 2017). The company hired an international consultant and, for about a year, organised weekly meetings for miners' cooperatives, miners, the company, and government. The firm wanted to avoid the deaths and injuries that occurred when neighbouring site A was cleared. During that year, company B asked the miners to sell to the company, not the traders (company B officer, interview, February 6, 2017). A trader/miner who stopped buying minerals at site B because the mine had been bought confirmed that the traders and miners were given 200 dollars each and promised that the company would hire them. Some miners were hired, but only as security guards. The trader/miner argued that the company decision to hire some miners was just a tactic to get the others out (interview, February 14, 2017; company B officer, interview, February 6, 2017).

Unlike at site A, the removal of miners from site B reportedly unfolded relatively calmly, which demonstrates the possibility of coming to agreement when there is some recognition of miners' claims to resource access - though in this case, not compensation that is anywhere near adequate for their ongoing needs. Though it took more than 1.5 years for the miners to leave, a company B officer reported, there were no injured miners and no shots fired; the miners left on the scheduled date (interview, February 6, 2017). Yet the miners' departure was not without conflict ${ }^{24}$. According to the company B officer, when the company went to the mayor's office to distribute the money, a group of traders wanted to be given the money to distribute to miners. The deputy mayor created another "commission" on the grounds that not everyone was happy with the outcome. The traders who wanted to be given money had not been involved in the process and felt left out; they influenced the deputy

\footnotetext{
${ }^{24}$ A miner and his trader mother heard from miners that there was a "war" between the police and the miners in
} 2007 when site B was cleared (interview, February 27, 2017). 
mayor, who also had an interest in the situation. When the payments didn't start, the miners began to damage houses in the area neighbouring the mine, go after some members of their cooperative, and attack certain traders, concerned that the miners' leaders would only look out for their own interests. The mayor called the company back out of concern that a greater conflict would break out and asked that the miners be paid. The situation lasted three or four days. A company B officer nonetheless referred to the miners' departure as the firm's first successful operation (interview, February 6, 2017). A representative of EMAK provided a similar account, but argued that the conflict arose when SAESSCAM, the state body created to support miners and traders, incited some miners to refuse to leave the site because SAESSCAM, unlike EMAK, hadn't been involved in the agreement with the company (interview, February 1, 2017). While company B was able to avoid a more violent outcome through payments and reliance on local allies, therefore, some miners were dissatisfied with their representatives' actions. Similar dynamics have occurred elsewhere in the DRC (Geenen \& Verweijen, 2017).

As noted, companies use a range of frequently forceful approaches to deal with artisanal miners. Even at site C, where artisanal miners, due to the site's particular PR configuration, operate with some effective freedom (three traders and an ex-miner, interview, February 4, 2107; ex-trader, interview, February 17, 2017; member of company C security, interview, March 9, 2017), miners are frequently chased away or arrested (Mine Police representative, interview, February 7,2017) by the security team on patrol. Arrests are very common and many of the miners I interviewed had been arrested, particularly in the Lubumbashi region, some of them two or three times. The guards also beat the miners (four miners, interview, February 8, 2017; site C3 miners' committee member, interview, April 13, 2017), as do the police (occasional miner, interview, March 21, 2017). One miner in the Lubumbashi region has been detained three times. When asked if he was hit, he responded incredulously that a miner is always hit. Miners "have to" be beaten when arrested, so the miner becomes afraid and doesn't try to go to the site next time (three miners, second interview, March 13, 2017; miner, interview, April 3, 2017). If arrested, a miner is brought to company security and may have his photograph taken. His case is transferred to the police and the parquet, and he may be sent to prison. A miner active at site $\mathrm{C}$ referred to the territorial prison as the company's prison, and said many miners are there (conversation, March 3, 2017). One miner caught by company security at site A in 2014 was brought to the company processing facility and whipped by company security, the Industrial Guard. He was then transferred to the parquet, but they refused to take him because he was a minor; he was sent to 
Mine Police custody for two days and then transferred to the children's tribunal (two miners and their mother, interview, March 31, 2017). Miners therefore take risks just by entering the site (interview, February 4, 2017; three miners, interview, February 17, 2017; artisanal miner, February 27, 2017). A miner has to have le cour dur (a hard heart) to go mine because of the security-related risks. Miners have little choice because they don't have work (reference, interview, February 13, 2017; one miner and two ex-miners, interview, February 17, 2017). At site $\mathrm{C}$ there is relative "freedom" for miners, but the underground mines present a danger of collapse (a miner and two ex-miners, interview, February 17, 2017; miner and his wife, interview, March 31, 2017); at least thirteen miners died that way in November 2016. The open-pit mine is also risky from a security perspective. Therefore, going to site $\mathrm{C}$ is not a perfect solution to the problems at $\mathrm{A}$ and $\mathrm{B}$, particularly for risk-averse miners (miner and two ex-miners, interview, February 17, 2017).

Multiple respondents knew people who had died, in shooting deaths or from guard dog injuries, at the hands of the security forces. This includes several artisanal miners who had lost miner friends particularly at sites A or B (miner, interview, February 13, 2017; active miner and two former miners, interview, February 17, 2017; two miners and their mother, interview, March 31, 2017; former EMAK representative, interview, February 1, 2017). Even a local government official mentioned that deaths occur within the LSM sites in the Lubumbashi region, including at site B (interview, May 21, 2017). Shooting deaths are not always accidental and have reportedly occurred when the police are firing in the air to disperse the miners, and a stray bullet hits a miner (miner and his wife, interview, April 9, 2017). Miners are afraid of the guard dogs deployed at places like site B (miner, conversation, March 3, 2017). Several miners reported that friends had been injured or killed by dogs (miner, interview, February 13, 2017; miner and his wife, interview, March 31, 2017; two miners and their mother, interview, March 31, 2017). One woman's son left for site C in 2016 because in the Lubumbashi region, specifically site B, the security forces were chasing away and even killing miners, including young ones. Her son left in 2016 after the security forces at site $\mathrm{B}$ released the dogs and his friend died from a dog bite (two miners and their mother, interview, March 31, 2017). Another respondent reported two deaths at site B in 2016 resulting from guard dogs (former EMAK representative, interview, February 1, 2017). The fact that state security forces are deployed to back up companies' PR with firearms allows companies to deflect responsibility onto the government for negative consequences. For instance, when the LNI was deployed to site C3, it resulted in insecurity as the LNI fired shots in the air and people couldn't walk around after 7 p.m. The company reportedly declined 
responsibility, saying that the government had called the LNI (local journalist, interview, May 19, 2017).

The detention and arrest of miners for mining at LSM sites are therefore a frequent manifestation of conflict. These types of actions may not escalate if the miners do not continue to press their claims. Miners tend to rise up in protest in at least two key situations: first, when blocked from accessing a given site, and second, if one of their own is arrested or killed (doctoral candidate, interview, February 1, 2017; journalist, interview, February 7, 2017; two traders, interview, February 9, 2017; PSC manager, interview, May 22, 2017). Miners lack other, non-violent means to express their views and defend their claims to access to LSM sites, in line with Mathys and Vlassenroot's (2016) finding that "The options people have to settle their disputes in a peaceful, formal and durable manner are limited, not least due the state-led justice system's weak performance, which is experienced as corrupt, slow, biased or barely accessible" (p. 1). Consequently, miners' actions at times include throwing stones at guards or police officers (LNI representative and Mine Police representative, interview, March 20, 2017). One member of company $\mathrm{C}$ security said that miners were calm and happy if allowed easy access to mineral deposits, but that if refused access, they start to create trouble. He had seen miners injure police officers using barres de mine, and had had stones thrown at him (interview, March 9, 2017). A PSC manager whose agency is deployed at sites $\mathrm{A}$ and $\mathrm{C}$ argued that if miners have been attacked, chased away, or shot by police, they go to the barrier. They sing and make demands, he said, and can be aggressive. They may move the barrier, beat the guards, and even take radios (interview, May 22, 2017). A key factor in the miner deaths and injuries that have occurred at all three of the case-study sites is the disproportion between miners' stones and barres de mine, and the batons, tear gas, and firearms with which the security forces are equipped.

When miners die, whether in a mining accident/collapse or as a result of action by security forces, it often becomes a cause of further conflict. Conflict has broken out, particularly at site C, after miners' deaths in a mining accident/collapse or as a result of action by security forces. Miners tend to blame such deaths on the company (journalist, interview, February 7,2017 ) even if they were in a restricted area and/or had been warned about entering a specific area (civil society representative, interview, February 9, 2017). As noted, lacking state and company support for their right to life, safety, and decent livelihoods, miners at times engage in public demonstrations and/or company or community property damage. If one or more miners die in a mine collapse, other miners may enter the LSM site, by force, in their anger (LNI representative and Mine Police representative, interview, March 20, 2017; 
company C security employee, interview, April 13, 2017), particularly if the security guards refuse to bring out the body. Miners start to throw stones (miners, group interview, April 3, 2017). A community resident reported that after two artisanal miners died at site B in 2016 , miners barricaded the road and the police came to intervene (former EMAK representative, interview, February 1, 2017). In May 2016, the lifeless body of a young man was found in the tailings area at site B. After investigating, the prosecutor concluded that the man was killed outside of the site but that to cover up what happened, people took his body to site B. The miners say company B was responsible for his death, and reportedly injured four police officers with stones (LNI representative and Mine Police representative, interview, March 20, 2017). A company A manager interviewed in September 2016 mentioned the same incident, explaning that two months [he said] ago, artisanal miners had come to take minerals and the police had fired, killing miners (interview, September 22, 2016).

In 2015, following the death of an artisanal miner at the hands of the police during a confrontation, miners caused significant damage to company C's Community Liaison Bureau at site C3 (civil society representative, February 9, 2017; trader/miner, interview, May 19, 2017; Congolese National Police representative, interview, May 25, 2017; Redacted, 2016; Rubbers, 2019). The company's reporting on the incident describes how the miners were seen carrying a body out of the site before the damage to the bureau but does not explain the cause of the person's death (Redacted, 2016). The miners damaged the windows and the door, and burned the generator (civil society representative, interview, March 4, 2017). The damage, which as of March 4, 2017, the company had not repaired, included broken windows and the burned-out generator (see photographs). A company $\mathrm{C}$ security guard who was not there during the incident said that his colleagues fled to find refuge with the police next door. He said that the miners also took everything from a storage container on the site and stole the door in addition to taking pieces of, and damaging, the generator (interview, March 4, 2017). Therefore, conflict in the form of theft and/or property destruction results, in part, from miners' continued attempts to press their unfulfilled claims when prevented from accessing these sites, or from their anger when one of their colleagues is killed rather than having the right to work safely - another claim that miners commonly make. 


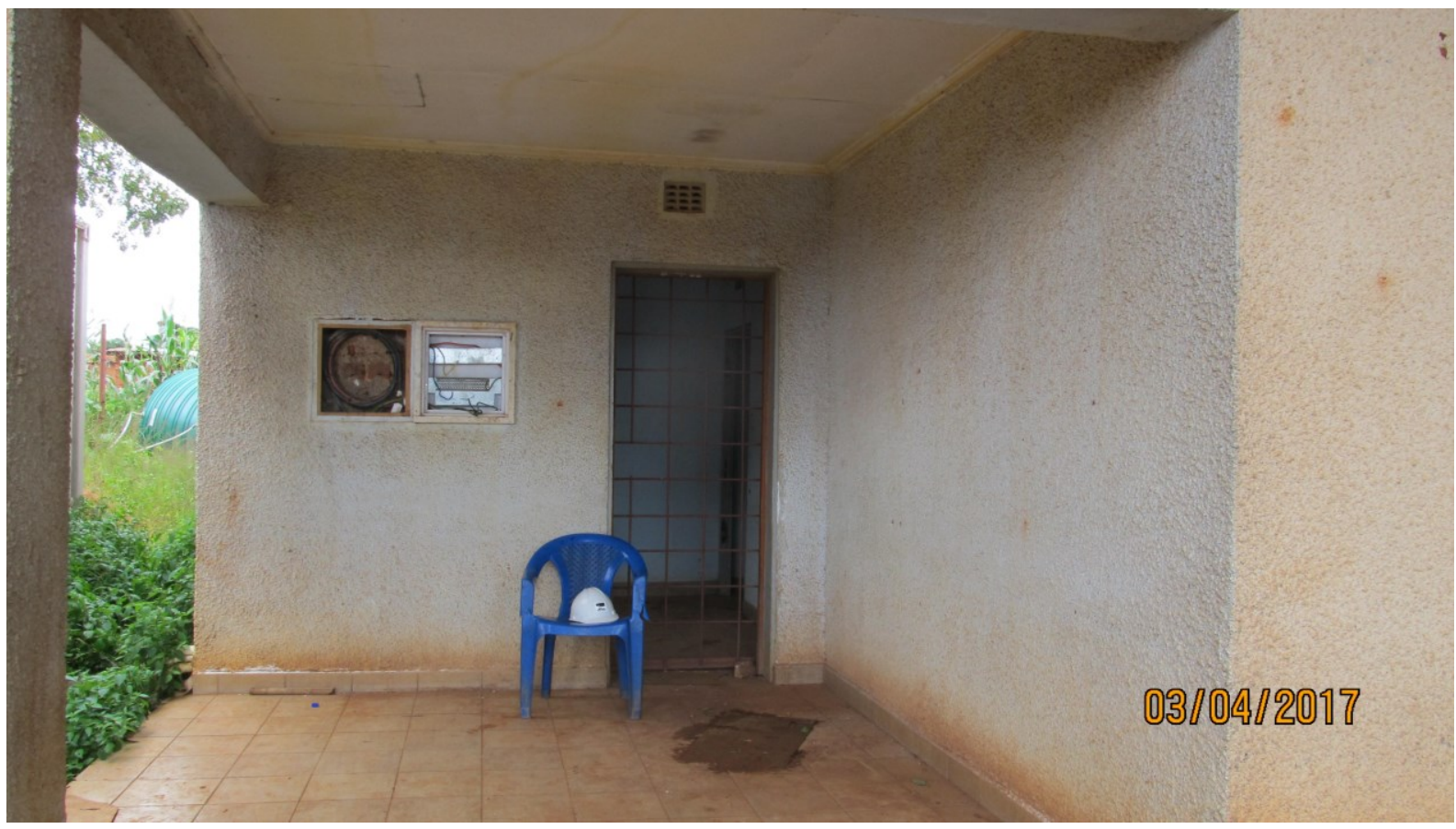

Image 6: Company C's damaged and abandoned community liaison office, Sarah Katz-Lavigne, March 4, 2017.

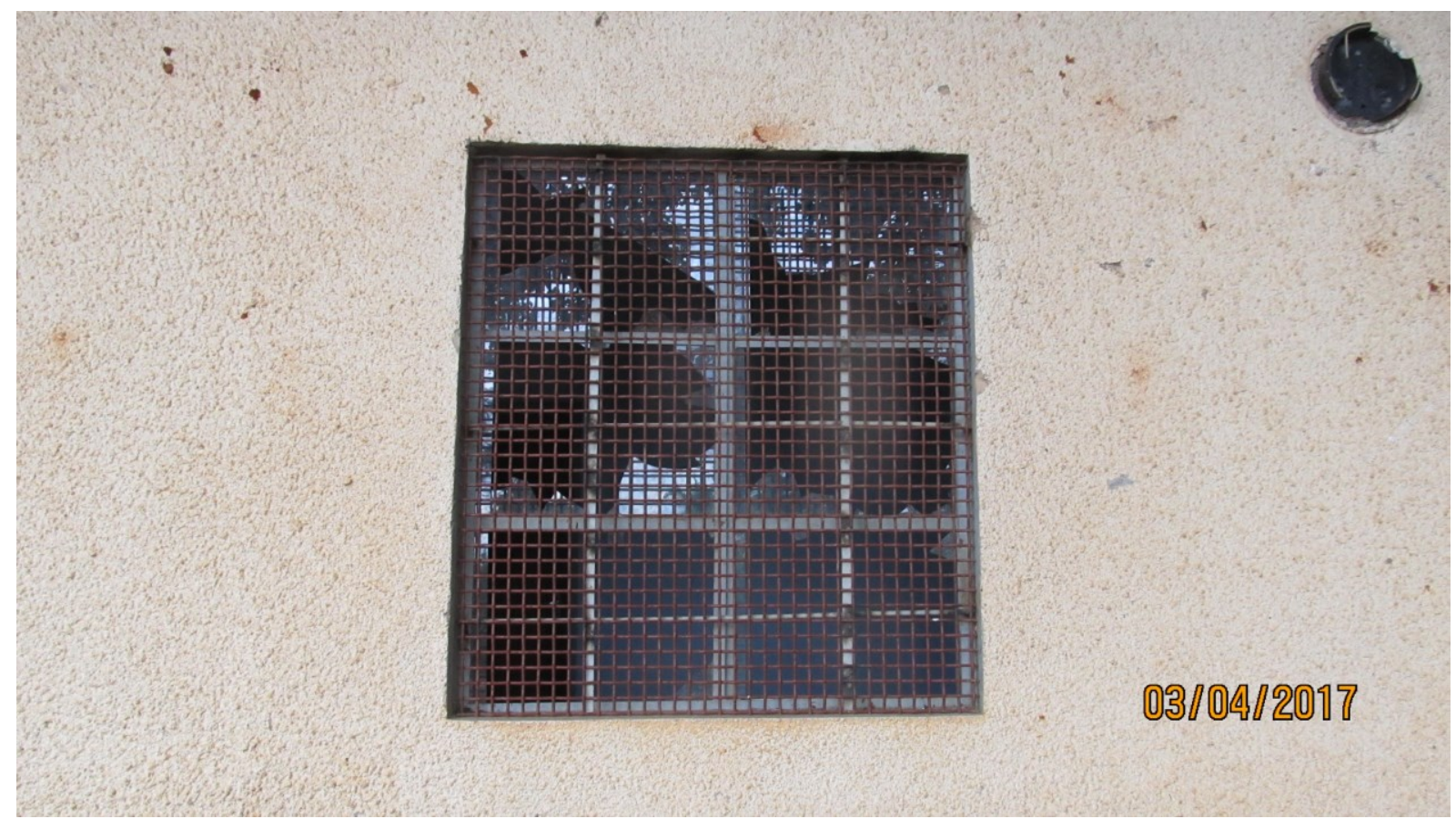

Image 7: Damaged window at company C's community liaison office, Sarah KatzLavigne, March 4, 2017. 


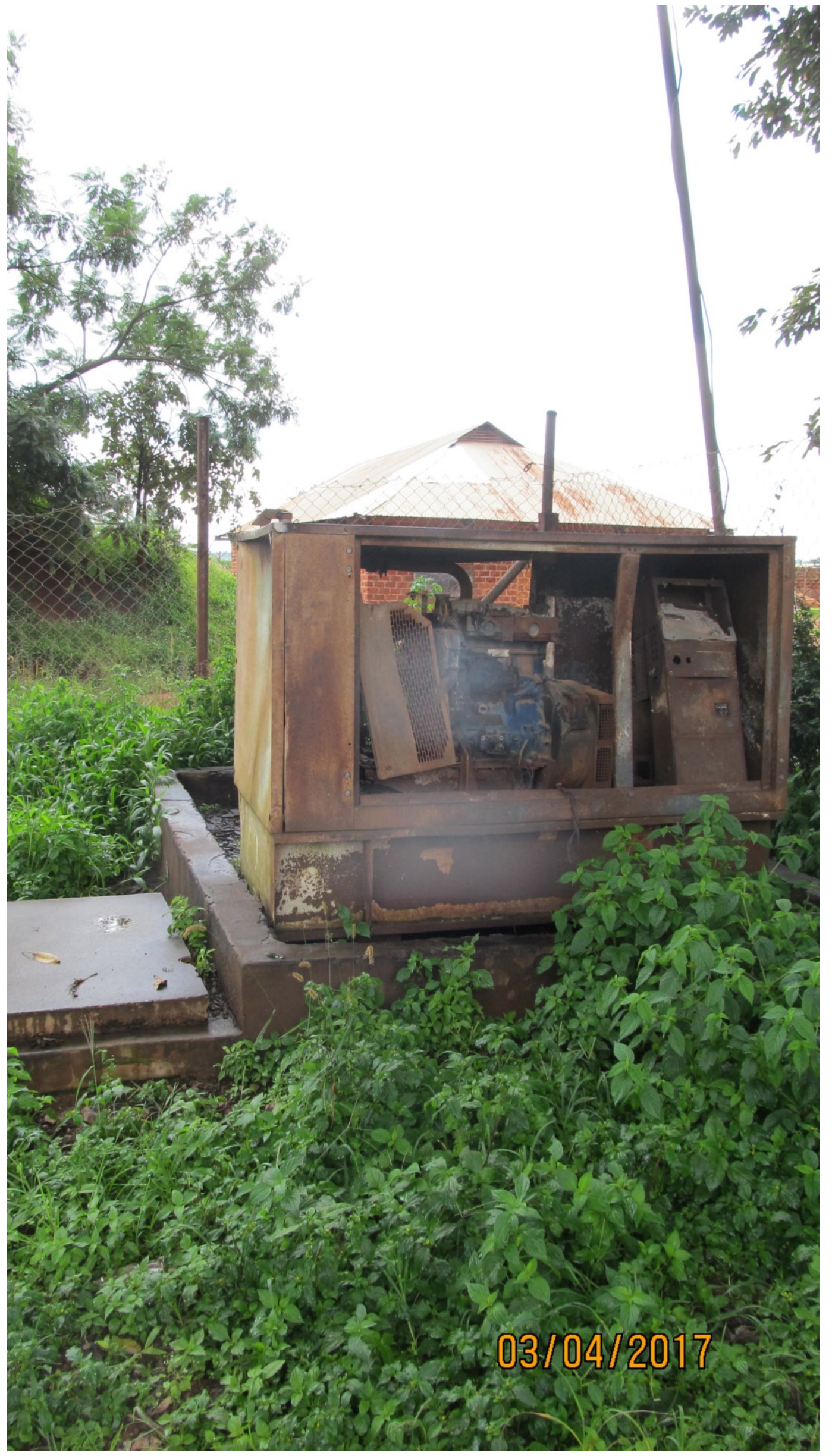


Image 8: Damaged generator at company C's community liaison office, Sarah KatzLavigne, March 4, 2017.

The size of different LSM concessions, as argued, is an important factor when it comes to the property rights configuration and contributes to different access and conflict dynamics. There is a significant difference between the far smaller sites in the Lubumbashi area, and the very large site $\mathrm{C}$ in the province of Lualaba. A miner in the Lubumbashi region argued that at the sites in the area, security deals harshly with the miners, firing on them: unlike at site C, miners don't have even tacit "permission" to work (three miners, second interview, March 13, 2017). A company B security officer explained that company C can afford to lose a certain amount of minerals to artisanal miners, and that it is not worth it for them to go to "war". Company B, on the other hand, may tolerate people taking minerals from the tailings pile, but not concentrated minerals; as he pointed out, the concession isn't enormous (interview, January 27, 2017). At site C, on the other hand, miners have some degree of access, which I have linked to the vast size of the concession. The large number of miners has the potential to pose a real security problem for the company and/or the community, making it necessary for the security forces, particularly unarmed guards, to operate with some degree of restraint. For example, the fact that the company's community liaison office was vandalised twice can be linked to the large number of miners and the company's relatively hands-off approach, among other factors like miners' grievances. Company C's hands-off approach, I argue, is a necessary but not sufficient condition for understanding the relative "flexibility" at site $\mathrm{C}$ and elsewhere. Clandestine mining, crucially, also plays a role given that miners get access from police and other services. This form of extraction plays a key role in creating stability in the concession - and the company undoubtedly knows it, which despite its official non-recognition of artisanal miners can help explain why the company has proven, at least in practice, relatively tolerant.

Even when miners are arrested, they do not always spend long in prison. At the August 12, 2016 workshop, a village chief said when there's an arrest for "theft" of minerals, the person is transferred to the prison. Three days go by, and the man finds his way back to the mine. Therefore, while paying a fine - "official" or "unofficial" - to be released from detention or prison is, as noted, a financial burden that not all miners or their families can afford, miners are often able to resume activities soon after arrest.

The risk of physical harm resulting from conflict does not only apply to miners. Miners have reportedly used force against unarmed security guards to gain access to mine 
sites. At company B in 2016, there were an unprecedented 64 injuries of security guards (security officer, interview, January 27, 2017). Miners at the train station once attacked a company $\mathrm{C}$ security guard, throwing stones at him when he was in uniform (interview, March 4, 2017). Company C, in its reporting to the Voluntary Principles on Security and Human Rights, has documented many injuries of unarmed guards and of company employees, as well as, to a lesser extent, police officers. A Mine Police officer deployed at company A described how a PSC security guard wearing civilian clothing had his personal items stolen by miners. The miners took his clothing and all his money; he had just received his salary (LNI representative and Mine Police representative, interview, March 20, 2017). During one period of heavy rains, many miners died in site C's concession, and the miners became angry. A member of site $\mathrm{C}$ security said that he would no longer go out in his uniform (interview, April 13, 2017). In addition to "discharging” (Hönke, 2010) security responsibilities to the police, therefore, companies also discharge a significant amount of risk onto individual unarmed guards and even police officers - actors whose pay is relatively low. According to a company B security officer, the types of policies adopted at site $C$ potentially put unarmed guards in a risky situation when they are asked to defend the company but not given the means to do so (interview, January 27, 2017). As a representative from a PSC deployed at both sites B and C described, the PSC is in a difficult position because LSM companies ask for the Voluntary Principles on Security and Human Rights to be respected. They ask the PSC to provide security, but they also ask them, he said, for the opposite of security. This reality puts the PSC in a very complicated position. He added that they have to find the middle ground (three PSC managers, interview, March 20, 2017). A Mine Police representative revealingly argued that at site $\mathrm{C}$ there are "too many" human rights. If the police attack a miner who has injured a police officer, he said, the company does not take it well. The MNC asks them to prevent miners from working, but the miners attack the police. ${ }^{25}$ He added that the company's Industrial Guard faces the same fate. At site $\mathrm{C}$, the miners fear the police, but an unarmed security guard can easily be attacked; these guards frequently run away. Therefore, there's always a police officer as well: company protocol is for the police to protect the Industrial Guard. Despite being unarmed, then, these security guards are not unprotected (interview, February 7, 2017).

Peaceful dynamics, not just conflict, also occur at and around LSM sites. As noted, the three companies, to a greater or lesser degree, at times choose not to engage with artisanal

\footnotetext{
${ }^{25}$ Yet he noted that cases of police officers being injured are rare.
} 
miners. This is particularly the case at company $\mathrm{C}$, though the company has little choice in the matter due to its specific property rights regime and the logistical issues associated with securing a concession of very large size (doctoral candidate, interview, February 1, 2017; two miners and their mother, interview, March 31, 2017). A local journalist argued that since there are at least 285 hills in company C's concession, it's easy for miners to work there. He added that the company doesn't suffer financially because the clandestine miners only mine manually, though the company complains because they see clandestine products leaving the site (interview, February 7, 2017). Reputational concerns are another key factor: the company is afraid of deaths and of having their products referred to as "blood copper" (land chief, interview, February 28, 2017). One miner even expressed the view that company $\mathrm{C}$ has compassion for the miners and sometimes leaves them free time to work. At other times, the company reinforces security, but, he said, they do leave time for the miners to make the money they need, unlike at site A (miner and his wife, interview, March 31, 2017). As a member of company $\mathrm{C}$ security described, it is not that the company gives miners permission to operate but rather that the company protects certain areas more than others. The company puts significant security where there is digging equipment, so that miners don't damage the equipment. Where there are no activities and no equipment, on the other hand - on the hills from which minerals have not yet been extracted - the company closes its eyes to the presence of miners. Because miners seek access to rich minerals, however, they tend to venture into areas where the digging equipment is working, which is when problems can arise (interview, March 9, 2017). A land chief similarly argued that it's not that company C allows the miners to mine, but that they have less security in areas that are less high priority, because due to the cost and the many pre-existing structures it isn't possible to fence the whole concession (land chief, interview, February 28, 2017). In the Lubumbashi area, there are greater limitations to corporate flexibility (miners, group interview, April 3, 2017). Company B clearly communicates that miners are not allowed in the concession (company B security officer, interview, January 27, 2017).

At the mine site, whether a miner is arrested also depends on the location where he is detained; this variable enforcement related to the value of the good is in line with property rights theory. There are areas forbidden to miners, as opposed to areas where their presence is simply discouraged. If a miner is found at the tailings embankment, security may be understanding and not keep him for long, because the tailings don't have much value (a miner and two ex-miners, interview, February 17, 2017). Yet because of this low value, many miners don't like to go where the waste products are stored (three miners, second interview, 
March 13, 2017). If a miner is stopped in areas like the processing facility (where minerals are stored and where there are cables and fuel); where minerals are being transported; or where samples are stored, he is more likely to be accused of a criminal motive (company B security officer, interview, January 27, 2017; a miner and two ex-miners, interview, February 17, 2017). After the company does blasting with explosives, high-value minerals under the surface are exposed at ground level. Police officers are authorised to intervene when miners go to these forbidden areas (trader and her miner son, interview, February 27, 2017). At site $\mathrm{C}$, too, miners typically prefer to go where the company has not already extracted minerals, where the minerals are richer and at more shallow depths. Once the company has extracted minerals at a certain location, a miner argued, they reinforce security, knowing that miners are now aware that that zone is mineralised (miner and his wife, interview, March 31, 2017).

Other factors include the nature of the resource: when people are caught with fuel, there's a worse punishment than for minerals (three miners, second interview, March 13, 2017). Yet multiple respondents argued that the security forces don't differentiate between the "Qaddafis" who take fuel for sale to Lebanese buyers, and miners (miner, interview, February 17, 2017; ex-trader, interview, February 17, 2017; three miners, second interview, March 13, 2017). The rise in the value of the resource, as per PR theory, also has an impact on conflict. When the price of copper or cobalt rises, artisanal miner demand for minerals rises as well. A Légion nationale d'intervention representative deployed to site B linked the fact that large numbers of miners were coming to the site to a rise in the cobalt price (LNI representative and Mine Police representative, interview, March 20, 2017; miner and his wife, interview, March 31, 2017). In 2015, data was gathered on 31 attacks; in 2016, 123 attacks were reported, a nearly $400 \%$ increase that a company B security officer linked to the copper price rise after it plunged in 2015 (interview, January 27, 2017). Therefore, the global nature of the market also means that artisanal miners, like LSM companies, are affected by, and respond to, fluctuations in cobalt and copper prices, which has implications for conflict (Congolese National Police official 1, interview, November 8, 2016).

Yet the converse of tolerance of miners' presence is, I argue, the non-recognition of their property claims. Despite their reportedly relatively lax attitude towards artisanal miners in certain areas of the concession, company C's official stance on the miners, like companies $\mathrm{A}$ and $\mathrm{B}$, is that they are illegal. The company does not recognise their presence or status as miners; the same goes for the traders in its concession (journalist, second interview, February 8, 2017; trader/miner, interview, May 19, 2017). In reporting to the Voluntary Principles on Security and Human Rights, the company refers to the miners as "illegal artisanal miners". 
Unlike company B, which "demobilised" the miners by paying them off, company C representatives didn't want to negotiate directly with the miners (journalist, second interview, February 8, 2017; company C questionnaire, April 17, 2017). Therefore, while miners are at times tolerated, this is not a pathway to real recognition of, or response to, their claims.

\subsubsection{When the Covert becomes Overt: Conflict between Corporate Enforcement and Authorised Clandestine Mining}

This section focuses primarily on the causes of conflict between the corporate enforcement and authorised clandestine mining facets of the property rights regime. A range of actors, including agents of the state, is always present and involved in different ways and different capacities with corporate enforcement and authorised clandestine extraction. These actors are entangled with, and mediate, processes of uneasy coexistence and/or confrontation between companies and artisanal miners. While the corporate enforcement and authorised clandestine facets of the property rights regime at times reinforce one another, they also at different times clash, resulting in conflict.

Equating police involvement at LSM sites with private interests alone does not capture the whole picture. While structures and mechanisms for authorised clandestine extraction are highly exploitative of artisanal miners, they rest to some extent on reciprocity practices and ensure access to mineral resources for miners with few options. Despite its harshness and often seemingly arbitrary nature, a certain amount of flexibility and understanding is built in. If the company tightens up security, the miners plead the Mine Police for access because they lack money, including for school fees (LNI police unit representative and Mine Police representative, interview, March 20, 2017). If a miner is stopped "inside", if the people who stopped him are de bonne foi, the miner may be freed (group of miners, March 4, 2017). As a Mine Police representative described, the police are caught between the company and local community residents. If the police push too hard on the creuseurs, the creuseurs may go into the community, break into houses, and take goods, so the community starts complaining. Therefore, the police have to loosen security to allow the miners to earn some money. Yet if the police loosen security too much, he said, it "punishes" the company. The police have to balance those interests and find a middle ground (interview, April 12, 2017). Another Mine Police officer similarly argued that the Mine Police helps the community in many ways, because there are no jobs in the area. People don't pay a lot, he said, but they gain a lot 
(interview, April 14, 2017). In this way the police do engage in a measure of public state action, through their deployment to mining sites.

Clandestine mining is a market in which security and other services are bought and sold. These processes are at times and in certain areas overt and at other times and locations, of necessity more covert (Daudelin \& Ratton, 2018). These activities are at times overt in large concessions like site $\mathrm{C}$ especially, where many miners gather; a company $\mathrm{C}$ security guard who is the head of a patrol team sees about 500 miners a day (interview, May 27, 2017). Large numbers of artisanal miners live in towns and villages within the company's concession, albeit not in locations where the company is extracting minerals and has deployed security officers. At other times, participants attempt to keep these activities covert, especially when there is a risk of discovery by security. At sites where minerals are present, however especially high-value minerals - PSC guards and police officers take steps to ensure these practices remain covert, to avoid discovery by a supervisor or patrol not in on the deal. At site C2, for example, I met a Mine Police officer who was there to make sure the minibuses transporting minerals paid before loading. He wasn't in uniform, and said he was undercover (interview, April 14, 2017). Yet keeping this market covert is difficult because of artisanal miners' numbers and the fact that they are found in many places throughout company C's concession including open-pit mines, extraction zones, and processing plants (company $\mathrm{C}$ security employee, interview, May 27, 2017). Whenever there's an éboulement (pit collapse) in company C's concession, and miners die - thus rendering clandestine mining visible and overt - the company typically cracks down on artisanal mining given the reputational damage associated with such incidents. The overtness of a given market contributes to an intrinsically insecure environment, particularly in the case of illicit markets, because of these markets' vulnerability to intervention by the police (Daudelin \& Ratton, 2018). In the case of clandestine mining, there is a risk of interruption and intervention by other security teams, by patrols, and/or by higher echelons of security seeking to prevent clandestine transactions and mine site access. Sometimes, as I present below, the closing of barriers and the interruption of clandestine mining can last for days, even weeks.

As noted, while security guards and police officers at times act in line with company priorities and directives, different security forces are instrumental in enacting the structures and processes of clandestine extraction, allowing artisanal miners into the mine site and allowing the transport of raw minerals in exchange for payment (doctoral candidate, interview, February 1, 2017). While corporate enforcement and clandestine extraction coexist peacefully at different times and different sites, at certain moments one facet of the regime is 
better enforced than others or enforced in a way incompatible with the enforcement of the claims associated with a different component of the regime.

Given that powerful mining companies are part of the PR regime, Susan Strange's concept of structural power (May, 1996) provides insight into why conflict erupts at certain times. When it comes to conflict between corporate enforcement and authorised clandestine extraction, the situation at the case-study sites echoes broader dynamics around corporate investment in the DRC generally: mining MNCs wield significant power and other actors can impose their will only partially or for a limited period (Szablowski \& Campbell, 2019). Given that these companies are granted not only legal access but also have significant access to technology, capital, markets, labour, knowledge, authority, and more (Ribot and Peluso, 2003), they wield significant power in ensuring the enforcement of their property rights. Additionally, since LSM companies have contracts with, and therefore provide essential financial support for, the Congolese national police as well as PSCs, these bodies put considerable effort into ensuring that it looks as though they are enforcing corporate PR even when they are doing the opposite. A security guard or police officer that fails to perform his duties vis-à-vis the mining company runs the risk of being sent elsewhere and losing the lucrative opportunities associated with deployment at the concession. A police officer or Industrial Guard representative may in theory be fired if found to be involved with miners (Mine Police representative, interview, February 7, 2017; civil society representative, interview, February 9, 2017). However, police officers face different incentives than PSC employees. If caught collaborating with miners they are, as state agents, not fired, but transferred to earn money in a similar way elsewhere (Mine Police representative 1, interview, February 16, 2017). Company security and other company employees, but also PSC guards and sub-contractors, are more at risk. A company A exploration staffer argued that artisanal miners make arrangements with the opérateurs des engins, who are sub-contractors. Miners collaborate with those who operate the "engins" [the extraction machinery] to steal fuel, electrical wires, and spare parts. In response, he said, the company broke a contract with a subcontractor (interview, October 19, 2016). A member of company C security argued that while PSC guards may be removed from site $\mathrm{C}$ for theft, they may not be fired from the PSC altogether. Someone like him, who is employed by the company, will not want to lose his job. He added that many members of the Industrial Guard had been fired for involvement in clandestine extraction, not only those involved in taking minerals but also guards who organise to take copper cathodes [sheets] from the processing facility, or electric cables (interview, April 13, 2017). 
The arrival of unanticipated security patrols or a company supervisor may lead to artisanal miners' expulsion from LSM sites even if the security forces on duty initially accepted money from miners to enter the site. A number of respondents described these interruptions or interventions as a key factor underpinning conflict at mine sites.

Arrangements between police officers and artisanal miners frequently turn conflictual when supervisors arrive on patrol (journalist, interview, February 7, 2017; a miner and two exminers, interview, February 17, 2017; miner and his wife, interview, March 31, 2017; two miners and their mother, interview, March 31, 2017; miners, group interview, April 3, 2017; miner and his wife, interview, April 9, 2017). A company $\mathrm{C}$ security employee provided the clearest statement of these dynamics: if company security is there, the Mine Police pretend [to try to keep miners out]. If the Mine Police is alone, they collaborate (interview, April 13, 2017). At site C, machinery operators frequently allow miners who enter at night to operate undisturbed, unless the operators are surprised by the arrival of security. If the supervisor is present, one respondent explained, the miner is arrested. If no supervisor is there, the miner can give the operator money (a miner and two ex-miners, interview, February 17, 2017). At site $\mathrm{C}$, patrols take place on the hills where miners mine. If the patrol arrives and a miner is taking bags of minerals out, according to one miner, he has to run away or hide because those on patrol are not involved in the arrangements (miner, conversation, March 3, 2017). A respondent who used to work at site $\mathrm{C}$ remarked that the head of the Mine Police and of the Industrial Guard are present on Monday and Friday. When the person in charge of the Mine Police visits the site with the head of company security, the miners flee; other days, they can work without problems (ex-trader, interview, February 17, 2017; two miners and their mother, interview, March 31, 2017). When the head of office does a site visit, the guard may arrest the miner to save his job, even after taking money (two miners, interview, March 16, 2017). ${ }^{26}$

At sites A and B in the Lubumbashi region, miners can negotiate with the security services, but that does not represent a guarantee of working freely, if a supervisor arrives. Those who cooperate are the security guards at the guard posts. If the head comes, even if the miner has cooperated, he has to flee; if the miner resists, he may be arrested. This takes place at both companies, A and B (miner and his wife, interview, April 9, 2017). If the security manager arrives, the guards' priority is to ensure the manager doesn't see the miners, so the miners lose the money they paid (a miner and two ex-miners, interview, February 17, 2017).

\footnotetext{
${ }^{26}$ According to a local judicial official who operates at site $\mathrm{C} 1$, however, artisanal miners who were arrested sometimes say that they were asked for money, and that they paid; alternatively, they sometimes say that they paid the morning security team but that another team arrived and they were arrested (interview, April 12, 2017).
} 
If the patrol passes by while the miner is collecting minerals, the guard denies involvement, saying that the miners entered without him seeing them. When the miners try to run away, some may be arrested (doctoral candidate, interview, February 1, 2017). If the head of security arrives and discovers that there are miners at the site, and the miners aren't willing to leave, it can lead to disorder (miners, group interview, April 3, 2017). When security or a supervisor arrives, miners who refuse to leave the site may be chased out using coercive methods such as tear gas; the security forces may take their minerals, and miners may be subjected to arrest or physical violence, particularly if they resist expulsion (Mine Police representative, interview, February 7, 2017). One miner was an eyewitness at site A when two teams of miners were brought into the site by facilitators, who were then informed of a surprise visit by their boss. The facilitators chased the miners away without reimbursing them and seized their products. The miners threw stones, shots were fired, and tear gas was deployed (trader and her miner son, interview, February 27, 2017). At times, after taking the money, the guard arrests the miner anyway, because supervisors are present. The security agents or Industrial Guard empty his pockets, take his money, and hand him to the Mine Police. The detained miner is asked for the name and number of the head of his team. The Mine Police call the head of the group to say they have one of the members in custody and ask for 15,000 or 25,000 francs for his release. The head of the Industrial Guard believes the miner is in prison, but he has been released (two miners, interview, March 16, 2017), which further demonstrates the clash between corporate and authorised clandestine extraction. Members of the security forces, like the Mine Police, are therefore often able to benefit from both corporate enforcement and authorised clandestine mining, regardless of which one is predominant in a given scenario.

The discussion above should not be taken to mean that high-level officials, whether in company security (the Industrial Guard), the PSCs, or the police, are unaware or not involved in clandestine mining, though one miner argued that some supervisors are aware that miners enter the LSM sites and that some, such as the head or director of security, are not (two miners, interview, March 16, 2017; also two traders, interview, February 9, 2017). The evidence suggests that companies are well informed on what goes on in their concessions. A security official at site B referred to the process of dealing with those who engage in clandestine mining, or who take other items besides minerals, as a "game". He was proud that only 24 thefts had been committed out of 31 violent attacks, a number that includes internal theft of items like tools, which he estimated to be around 30\% (interview, January 27, 2017). Company $\mathrm{C}$ hired several researchers to infiltrate artisanal miners and document how 
clandestine mining occurs (mining consultant, interview, February 28, 2017; March 1, 2017). According to a civil society representative at $\mathrm{C} 3$, company $\mathrm{C}$ is well informed about clandestine mining (interview, February 9, 2017). A Mine Police official said that company C knows there are people at $\mathrm{C} 2$ doing clandestine mining and that he doesn't know why the company doesn't get them out (interview, April 14, 2017). The evidence suggests that highlevel officials within LSM companies and the different security forces are indeed aware of clandestine mining.

It is more difficult to prove, and perhaps less likely, that high-level officials are engaged in such practices, particularly within the companies themselves (Mine Police representative 2, interview, February 16, 2017). The evidence suggests that heads of the police and other services in the mine site area are indeed implicated in these practices. A member of the miners' committee at site C3 argued that even high-level members of company $\mathrm{C}$ security cooperate with the traders, as does the Mine Police major responsible for securing the company's concession (interview, April 12, 2017; businessperson, discussion, March 3, 2017). Within companies, however, these dynamics often involve those at the middle and lower levels. According to a consultant who has done extensive research at site $\mathrm{C}$, in interdiction zones where the company is doing extraction, there is more security. To facilitate clandestine mining, he said, the person in charge of deploying the security forces avoids sending agents to areas where that person knows miners to be. This individual argued that the security guards at the lowest level are involved, but so, too, are those at a "medium" level, i.e. between management and the ordinary guards (mining consultant, interview, February 28, 2017). Respondents described typical clandestine processes as between the miners and ordinary security guards or police officers at their posts: the subordinates, not the heads of security (group of miners, interview, April 3, 2017; landowner, interview, May 15, 2017).

Given institutional dynamics, higher-placed individuals, much like their subordinates, at times have to play their roles in line with the requirements of corporate enforcement (doctoral candidate, interview, February 1, 2017). Not only do they have to live up to a contract, but they may do so for work ethic reasons, or simply because they support LSM companies' property rights. The heads of the security forces, such as the local Mine Police commander, defend companies' PR even as they benefit from authorised clandestine extraction through the rapport. As one respondent described, many rungs of command are involved when it comes to police involvement in clandestine extraction. The police officer, he said, engages in these activities under cover. Some higher-ups are involved, but they allow their lower-level employees to take the punishment if something goes wrong (Mine Police 
representative 2, interview, February 16, 2017). One trader at site $\mathrm{C} 2$, however, explained that the traders give money to the high-placed officials of the Congolese National Police, not the subordinates. The miners, he said, give money to the subordinates at the actual mine site (interview, May 18, 2017).

The property rights protection provided to artisanal miners as part of clandestine extraction is therefore only ever partial and contingent and can be withdrawn on a moment's notice when there is risk of exposure of a market that is often at best only semi-covert. The security forces offer a service - enforcement of ASM miners' claims to property within LSM sites - but cannot fully enforce the associated claims. At certain moments, I argue, members of the security forces are faced with more pressing incentives, like the need to preserve their employment or high-status post by upholding corporate enforcement, and/or to protect corporate interests in a centralised political environment in which they are subject to significant pressure from above to support companies' PR. The fact that members of the security forces so quickly turn on miners at such moments demonstrates the compelling nature of the incentives associated with corporate enforcement vis-à-vis the need to comply with clandestine extraction and deliver the rapport, though local security priorities linked to miners' large numbers and at times aggressive behaviour play a role.

The different incentives faced by members of in-house company security compared with the Mine Police reflect the importance of institutional dynamics. Some respondents argued that certain services accept to cooperate more than others and that the Industrial Guard refuses to cooperate because they are officially hired and are company "allies" (miner, interview, April 3, 2017; miner and his wife, interview, April 9, 2017), while sub-contractors are less likely to be willing to leave the site empty-handed (miner and his wife, interview, April 9, 2017).

Artisanal miners therefore face risks even when they pay off the security services (a miner and two ex-miners, interview, February 17, 2017; three miners, second interview, March 13, 2017). If trouble arises, they have to protect the security guards who gave them access, even if it means putting themselves at greater risk. A miner active in the Lubumbashi region noted that when a miner pays a PSC guard for entry, if the guard sees that company security is on its way, the miner has to hide to avoid causing difficulties for the guard who received the money. If arrested, the miner has to say he entered without the security guard seeing him, so the guard gives the miner access next time. When a miner is asked if he paid someone for entry, he can't reveal the information, even if he is beaten. Otherwise, the guard may lose his job and the miner will no longer be able to collaborate with him (three miners, 
second interview, March 13, 2017). A miner can pay the guards at the post, but agents also patrol for intervention purposes. If the agents doing intervention spot the miners, the miner can't say that he gave money to the guard, so he loses his money. One miner in the Lubumbashi region was arrested in 2016 and brought to the local police detachment. He had paid to mine at night but was caught by police (trader and her miner son, interview, February 27, 2017). In the Lubumbashi area, guards who take money reportedly beat the miners who get caught, so those who come to do the intervention don't notice that the guards are the ones who let miners enter. One miner was arrested and beaten three times: twice after entering without paying, and once when he had paid. If guards with the same service that took money in the first place see their supervisors, they themselves may detain the miner $^{27}$ (three miners, second interview, March 13, 2017). The teammate of a miner at site $\mathrm{C}$ was beaten about two months prior to interview. After giving the security services money, the miner's friend pointed his flashlight to enter the pit in the darkness. Yet security doesn't allow the miners to use flashlights before entering because of the risk that they will be seen. This miner's friend was beaten and then allowed to continue to work (conversation, March 3, 2017).

At times, a security service representative opportunistically breaks the informal contract to get more money, or simply fails to live up to its terms, so the miners don't get anything in return for the money they paid. The "illegality" of clandestine mining means that contract enforcement is not available (Daudelin \& Ratton, 2018). At site B, according to one respondent, the "soldiers" (the LNI) may ask for 15,000 or 20,000 francs from the miners so they can buy alcohol. They then tell the miners to work at a certain area where there are no minerals. At other areas where there are rich minerals, there are surveillance cameras, so the police officers risk getting in trouble if it is discovered that miners were at the site (occasional miner, interview, March 21, 2017). As one respondent mentioned, even if the Mine Police receive money from the miners, they may ask for more money if a miner gets caught and is handed over to them ${ }^{28}$ (two miners, interview, March 16, 2017). Cases of outright theft even occur: security guards may accept money and after taking the money, arrest a miner anyway and bring him to the parquet (two miners, interview, March 16, 2017). However, a local judicial official who works at $\mathrm{C} 1$ said that sometimes artisanal miners who get arrested do say

\footnotetext{
${ }^{27}$ The respondent added, however, that the supervisors don't come too often: they enter briefly to ensure the security agents haven't abandoned their posts (three miners, second interview, March 13, 2017).

${ }^{28}$ Miners are handed to the Mine Police because the Industrial Guard can't take miners to prison or to the parquet; only the Mine Police can do so (two miners, interview, March 16, 2017). However, a police official deployed at site A explained that the Industrial Guard can arrest miners and take note of their identities; these miners are then brought to him (interview, February 18, 2017).
} 
that they gave money to police officers and are acquitted on grounds of police involvement (interview, April 12, 2017).

Broken agreements are therefore common and a significant cause of conflict. Breaches of informal contract can be linked, as mentioned, to the specific incentives that face both security forces as institutions, and individual guards and police officers, in a given situation. Not all security services were said to consistently participate in clandestine extraction or exhibit the same willingness to allow miners to access LSM sites as the Mine Police. According to two miners, the maittres-chien (dog handlers - part of the PSC) at site B do not allow miners to enter (two miners, interview, March 16, 2017). A civil society representative argued that while the Mine Police is systematically involved with clandestine extraction at site C, it is not proven in the case of the Industrial Guard (interview, February 9, 2017). According to a trader, after buying products from the miners at site $\mathrm{C} 3$, he pays the Mine Police to evacuate the minerals. If caught somewhere along the way out by the company security (Industrial Guard) patrol, he has to call the Mine Police at C3. The Mine Police discusses with the company security that stopped the trader and arrange for him to be let go. The Mine Police, this trader said, can tell the Industrial Guard what to do. If the people the trader encountered "are of good faith", he pays some money and is freed. If he encounters "mean" people, on the other hand, he loses his minerals. If a PSC guard catches you, the trader added, there can be no intervention by the Mine Police. However, even with the PSC, there can always be proposals and the payment of some money to avoid losing one's minerals (two traders, interview, February 9, 2017). This scenario demonstrates not only the Mine Police's authority but also other agencies' frequent willingness to go along with clandestine extraction. The example highlights the often-smooth functioning of clandestine extraction, but shows that these processes have boundaries and limits.

Competing incentives therefore affect whether an officer or guard acts in accordance with the dictates and priorities of clandestine mining or of the company. To some extent, employees of different security forces (company security, the PSCs, and the different units of the police) face different incentives and payoffs - including different salary levels depending on the institution they belong to. Security forces' deployment at LSM concession offers them lucrative opportunities both in terms of salaries and other benefits including company bonuses, in addition to the opportunity for rents from clandestine extraction. Therefore, multiple factors play into police officers' and security guards' decision-making, including the size of rents from clandestine mining; the fear of losing their jobs and associated financial and other benefits; a political economy that favours corporate PR; the need to exhibit 
a certain amount of flexibility towards artisanal miners; and more. Despite the pervasiveness of clandestine mining, the Industrial Guard and PSCs may be more likely to refuse to allow miners to access LSM sites, or to allow this access only under pressure by an armed police officer or a miner or group of miners. A company $\mathrm{C}$ security employee said that he could "close his eyes" to the Mine Police giving access to miners, since the police officers do it just to get enough money for airtime to contact their families (interview, April 13, 2017). Company policies also play a role. According to a company A security guard deployed at a different site (not site A), a company guard may allow a miner to enter the site but then inform the intervention team (interview, May 21, 2017).

At times, individual security guards or police officers enforce the rules and regulations of corporate extraction (doctoral candidate, interview, February 1, 2017) rather than of clandestine mining, even when there isn't the risk of a patrol or supervisor passing. The individual characteristics of security guards and police officers can play a role (company A security guard who operates at a different site, not site A, interview, May 21, 2017). Security guards and police officers do not always act according to the dictates of the system. In some cases, the police officer respects his orders to chase away a miner when he sees him, refusing to negotiate. According to a Congolese doctoral candidate, a security guard's response depends partly on his mood but particularly his personality. Individual miners can't afford to give the guards a lot of money, like 300,000 or even 150,000 Congolese francs, given the high probability that they won't find anything, and since miners don't have much to begin with. The decision to allow a miner to access the site, a respondent argued, therefore depends on a guard's mood but more importantly, on his identity or personality (doctoral candidate, interview, February 1, 2017; also two traders, interview, February 9, 2017; civil society representative, interview, February 9, 2017). One miner who enters sites A and B cooperates with the guards that he knows are willing, agreeing that it depends on the person and not on the particular service (miner, interview, April 3, 2017). Similarly, two traders I interviewed at site C3 said that some people refuse to make arrangements and that it often depends on the will of the person. Everyone may be paid the same, but people's hearts are different (two traders, February 9, 2017), which points to different guards' differing attitudes to risk.

These competing incentives help explain why the security forces at times reinforce security without miners understanding why. Company A, for example, used to pay a 20 USD bonus per miner caught, but due to budget cuts, this practice was halted (company A security officer, interview, December 6, 2017). The table shown in the research puzzle chapter that tracks the capture of individual miners mentions that the granting of bonuses was halted as of 
22 July 2015. The number of miners caught each month dropped once the bonus was no longer being given to the different security forces (there may also be a link with the significant drop in the copper price, shown in the table below, which occurred in the same year, 2015, and at around the same time).

Fig. 4

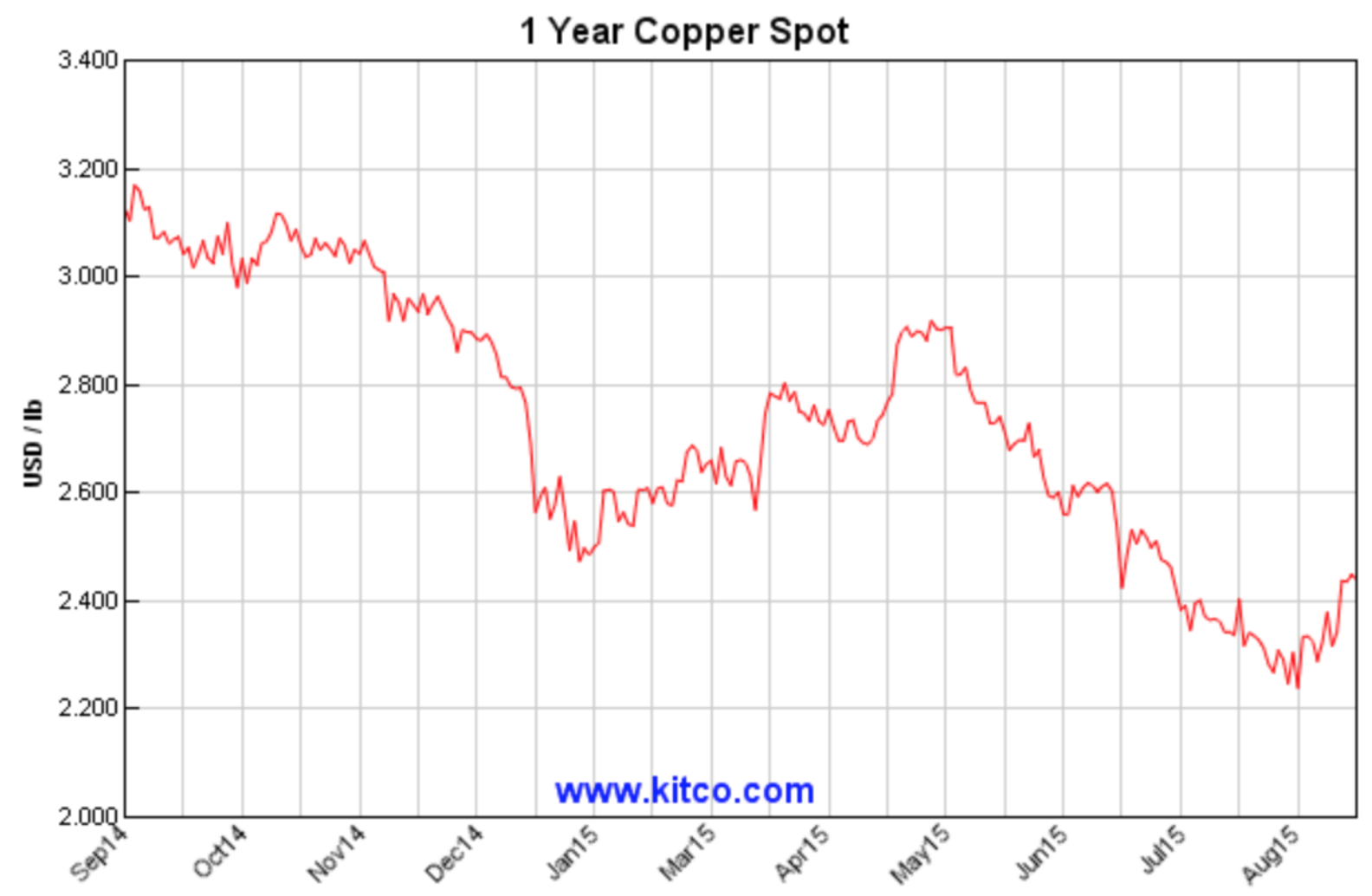

Source: Kitco.com

In interview a LNI representative indeed mentioned that company A used to provide a 20 USD bonus per miner arrested, but this motivation - frais de motivation is a common term used in the DRC for bonuses/incentive payments, e.g. for public officials (e.g. "Gratuité de l'enseignement", 2019) - was discontinued about a year prior to interview. The elimination of the bonus, he said, "demotivated" the security forces for catching miners. At company B, if members of the LNI arrest miners, they aren't given anything. The LNI is also deployed at another mine site (not part of my study) in Haut-Katanga and is given \$25 per miner. The LNI representative pointed out, apparently without irony, that with this motivation, a police officer will make an effort to arrest 10 miners (LNI representative and Mine Police representative, interview, March 20, 2017; three parquet representatives, interview, December 1, 2016). The drop in miners caught after the cancellation of the bonus suggests that it was no longer profitable for security guards to stop miners, compared to the payments for allowing them in. 
This data lends weight to the importance of competing incentives in determining how members of the security forces behave when they have the opportunity to allow miners to pay for access, i.e. to supply them with PR.

Crucially, the security forces benefit whatever the outcome: by taking miners' money or seizing their minerals for personal gain. When security guards or police officers stop miners, they may not, as they say they do, return the minerals to the company (Mine Police representative, interview, February 7, 2017), but sell the products instead (three traders and an ex-miner, interview, February 4, 2017; two miners, interview, March 16, 2017; trader and two associates, interview, March 3, 2017; village chief and multiple village residents, interview, April 11, 2017; trader and two associates, interview, March 4, 2017). A businessperson based at site $\mathrm{C} 1$ expressed the view that the Mine Police use the miners as a work force. The Mine Police, he said, kick them out and when the miners flee, the police take the minerals: it's an easy way to make money (discussion, March 3, 2017). The fact that company C doesn't use recaptured minerals provides further support for the idea that the security services sell at least some of the minerals they capture. A Mine Police officer explained that company C didn't used to get rid of the minerals seized from artisanal miners, but that after a while the "Human Rights" got worried about blood minerals, and about being accused of using minerals mined by underage miners. Therefore, he explained, they bury the minerals they recapture (interview, April 12, 2017; two miners, interview, February 9, 2017; Mine Police representative, interview, February 7, 2017). A miner contended that if security tells the company they seized minerals, they are questioned about how the miners got access. Security prefers to sell the minerals and share the money, which can yield from $100,000 \mathrm{Fc}$ to 500,000 Fc each (two miners, interview, March 16, 2017). While the Industrial Guard and police officers all take money, someone may refuse to do so, chase the miner away, and then take the product where it was dumped on the ground. If the product is of good quality, the security services sell it (trader and two associates, March 4, 2017). In November 2015, the police at site $\mathrm{C} 1$, the main town in company $\mathrm{C}$ 's concession, seized traders' minerals from depots in a neighbourhood near the mine site entrance. The security guards and the police reportedly sold half the products seized (three traders and an ex-miner, interview, February 4, 2017). Therefore, the security services even find ways to profit from a crackdown on clandestine mining.

Trust relationships and repeated exposure allow both miners and guards to reduce their exposure to conflict by reducing the transaction costs that could prevent agreement. One miner who digs for minerals in the Lubumbashi region said that to cooperate, the security 
guard has to be sure that he is, in fact, a miner. If he sees a miner on a regular basis, he takes the money. Otherwise, he won't, out of fear that the company paid someone to test the guard, in which case the guard will have a reputation of being corruptible and may be fired (three miners, second interview, March 13, 2017). According to a miner, guards are also concerned that when a miner's arrested and beaten, he will say that he gave the guard money. To prevent this outcome, one respondent reported, security guards work with a group of miners. The head of the group is the only one authorised to give money to the guards (three miners, second interview, March 13, 2017). During an interview with a LNI representative deployed to site B, I saw firsthand how miners cultivate connections with security guards. The LNI representative started talking to the miners, who told him that they knew him. They bought him a beer and he thanked them; later, he introduced himself to them (interview, March 20, 2017).

When it comes to conflict between the corporate enforcement and authorised clandestine facets, connections - and money, i.e. the payment of rents to the security forces therefore play a significant role. A miner active at site $\mathrm{C}$ told me that in case of arrest, if you have a lot of connections, they bring you to the police, you make some phone calls and are released. Without connections, he added, you may need from $\$ 1000$ to as much as $\$ 2000$ to pay off the judicial authorities. He said that for miners to get out of prison, their families have to intervene. He personally could get out of a bad situation easily, but he estimated that not many miners - perhaps only 20\% - have his luck (conversation, March 3, 2017). One respondent said, by way of example, that there are miners with a brother ${ }^{29}$ who is a magistrate, colonel, or head of security. The miner's brother won't allow him to go to prison: if a group of five miners is arrested, that one person is freed due to his connections (a miner and two ex-miners, interview, February 17, 2017). Therefore, there are elements of the functioning of clandestine mining that are not strictly financial. One miner operating in the Lubumbashi region said that if a miner doesn't have money, he waits in prison for several months to be judged. He added that a lot of miners are at the prison in Lubumbashi; some are away for so long that miners consider them disappeared. If the miner's family provides money, or if he has connections, he may be freed more quickly (a miner and two ex-miners, interview, February 17, 2017). In Lubumbashi I interviewed a miner recently released from prison, after two and a half months, when his mother paid (miner and his mother, March 29, 2017). One miner was arrested three times, twice at site A and once at site B, in 2013, and spent time in prison. Previously, people didn't know that he was a miner, which made it

\footnotetext{
${ }^{29}$ This does not necessarily refer to a biological brother: "brother" is a commonly used Congolese term for a friend or family member, or someone from your home area or village.
} 
difficult to even speak with the security guards to make an arrangement with them. However, now the security guards know him, so if there are guards present, he can pay them if he has money. Otherwise, they trust him to pay them after he's gotten minerals. They change the guards, but he knows everyone (miner, interview, April 3, 2017). Repeated interactions therefore help to deal with the conflict potential of a relatively "open" market (Daudelin \& Ratton, 2018), but are typically not a substitute for payments to security forces.

Other types of trust relationships, like artisanal miners' alliances with traders, can also help reduce transaction costs, therefore lowering miners' exposure to conflict and the risk to their physical safety (four miners, interview, February 8, 201; three miners, second interview, March 13, 2017; miner, interview, April 3, 2017). Going to an LSM site without a relationship with a trader may represent a greater risk. At site A, some miners feel safer working with traders because if the security guards pass by and see miners, they ask which trader's team they're part of [which trader arranged and paid for his or her miners to work]. When the miners tell the guards which team they're on, the guards leave them be (two miners, interview, March 16, 2017). Some miners in the Lubumbashi area don't enter a mine site without association with a trader: they don't want to take the risk of entering without paying and couldn't afford the entry fee themselves. Because a trader covers them, they have not had problems at the mine site (multiple miners, group interview, April 3, 2017). Traders may intervene if there are complications, like if miners are asked for money (three traders and an ex-miner, interview, February 4, 2017). When a miner is detained, if he entered the site under the responsibility of a trader, that trader may ensure the miner is released. If the miner is independent, he has to fend for himself (two miners, interview, March 16, 2017).

Yet the picture is mixed across the three sites on the impact on transaction costs and therefore conflict when miners work with a trader. One miner argued that unlike at site $\mathrm{C}$, in the Lubumbashi area miners don't call traders when they have problems. Traders don't fund miners because sometimes things go wrong and the money is lost. The trader can't complain to the security guards and recover the money given the lack of contract enforcement in this context of "illegality", so it isn't worthwhile to lend in the first place (three miners, second interview, March 13, 2017). Several miners at site C don't receive help from traders in case of trouble, even though each group has their trader. The traders "abandon" the miners (four miners, interview, February 8, 2017; two miners and their mother, interview, March 31, 2017); the same is said to be true of the Lubumbashi area, where traders' money is the only protection they provide (miners, group interview, April 3, 2017). The lack of assistance can be at least partly attributed to some miners' behaviour. In some cases, a trader gives a miner 
money, but the miner does not return to the trader who lent him the money, instead selling his minerals to another trader (two miners and their mother, interview, March 31, 2017).

\subsubsection{Ethnic Relationships and Conflict}

In the former Katanga membership in an "ethnic community" typically centres on "kinship, a common native language and/or region of origin" (Gobbers, 2016, p. 219). Lands tend to belong to a particular clan (three international NGO representatives, interview, August $31,2016)$. It is plausible that ethnic community membership is a channel through which connections are formed and maintained, reducing transaction costs and making miners, traders, and other actors from certain groups less vulnerable to conflict. Yet the picture is mixed on the importance of a key type of connection - ethnic differences - when it comes to clandestine mining at the three sites. This limitation highlights, as discussed above, the central importance of payments in the smooth functioning of the system, and therefore the potential for conflict when such payments are resisted.

Those who do clandestine mining, including miners and traders, are often not from the milieu (former EMAK representative, interview, February 1, 2017; civil society representative, interview, March 4, 2017; village chief and multiple village residents, interview, April 11, 2017). At site C, many young, unemployed people have travelled from different parts of the DRC (doctoral candidate, interview, February 1, 2017; Mine Police representative, interview, February 7, 2017; community relocation consultant, interview, March 25, 2017). From 2000 and especially 2006-2007, there was significant movement in the former province of Katanga of people searching for work, including people not born in the area, many from the two Kasaï provinces. Because of the mining boom, many came to build homes around site $\mathrm{C}$ or settled on the outskirts of Lubumbashi (doctoral candidate, February 1, 2017; LNI representative and Mine Police representative, interview, March 20, 2017). ${ }^{30} \mathrm{~A}$ Mine Police representative at site $\mathrm{C}$ estimated that $60 \%$ of miners are from the local area while 40\% arrived from elsewhere (interview, February 7, 2017).

Yet multiple respondents argued that ethnic conflict is not present in artisanal mining, despite the diverse backgrounds of miners and traders, and that there have been no conflicts between "autochtonous" miners and artisanal miners from elsewhere (doctoral candidate, interview, February 1, 2017; four miners, interview, February 8, 2017; miner, interview,

\footnotetext{
${ }^{30} \mathrm{~A}$ miner in the Lubumbashi region did note that miners in the area tend to come from Lubumbashi and the province of Haut-Katanga; some come from far away, but most are from the area (interview, February 17, 2017).
} 
February 13, 2017; miner, interview, February 17, 2017; miner, conversation, March 3, 2017; two miners and their mother, interview, March 31, 2017; miner and his wife, interview, March 31, 2017; former EMAK representative, interview, February 1, 2017). One respondent noted that anyone could pay and do clandestine mining and that there wasn't an ethnic character to it (Mine Police officer, interview, April 14, 2017). Another added that LSM site access and the ability to transport one's minerals successfully through checkpoints are contingent on money, not tribal links (mining consultant, email, September 26, 2017). Finally, a civil society representative with expertise on artisanal mining said that in business it's interests, not ethnicity, that matter. He argued that the real tribalism is social class: the rich are in solidarity with the rich and the poor with the poor; the privileged seek to "close" their class to entry by outsiders. He expressed the view that the networks involved are secret and maintained on the basis of trust, and it's not easy to enter into them (civil society representative, interview, January 24, 2017). There's often no ethnic homogeneity in teams of artisanal miners: miners are in solidarity with each other (civil society representative, interview, January 24, 2017). A doctoral candidate argued that the police officer stationed at an LSM site doesn't takes ethnicity into account (interview, February 1, 2017). According to a miner, while it helps to have connections with people from the same province, a miner and a guard might be from the same region but not know each other. The miner still needs a connection with that person, like a friendship or family relationship (trader and her miner son, interview, February 27, 2017). A miner and two ex-miners also said that release after detention or arrest depends on money or the miner's family rather than connections based on clan or tribe (interview, February 17, 2017). Finally, a miner active at site A noted that people from the security services are often from Kasai, and that the security guards from the region are more understanding than those from Kasai. Yet while a security guard from Kasai may refuse access to Katangese miners, he said, if the miners pay the guards generously, there are no problems (interview, February 13, 2017). Geenen and Verweijen (2017), too, point to the importance of class at and around gold-mining sites in eastern DRC.

There does, however, appear to be salience to the Kasaian-Katangese divide when it comes to miner origin. A trader active at site $\mathrm{C}$ said that in October 2016, miners from the neighbouring Kasai region were arrested after beating and chasing the "autochtonous" miners away to intimidate them and confiscate their mining pits. A second trader added that this happens often at site $\mathrm{C} 3$, while my interpreter, a local journalist, expressed the view that the Kasaians are the strongest, so they win out (three traders and an ex-miner, interview, February $4,2017)$. These comments suggest, however, that conflict must be contained to a large extent 
if Kasaian miners successfully use first-party measures to secure and enforce their claims over the desired pits. A miner who works at site $\mathrm{C}$ in a group of Katangese miners reported that a Kasaian wouldn’t work with a non-Kasaian. Kasaian and Katangese miners will enter a pit, but work separately, taking turns. The miner expressed concern that when he goes to the pit alone, the Kasaian group might engage in physical violence against him. Physical conflicts have occurred, but not to him (two miners and their mother, interview, March 31, 2017). On the other hand, a trader/miner recounting an incident at site $\mathrm{A}$ in which a miner threw stones at a police officer and tried to grab his firearm emphasized that the miner's place of origin was not a relevant factor. He said that miners are the same, whether Katangese or Kasaian, and emphasized the behavioural dynamics that characterise groups of miners (interview, February 14, 2017).

Other ethnic dimensions of conflict involve the community more broadly, beyond just artisanal miners. A representative of the local ethnic community's socio-cultural association spoke of an incident, corroborated by other interviewees, in which youth from the area burned a company $\mathrm{C}$ building two years ago, which he linked to the company having forbidden artisanal mining without providing alternative employment. In response to the incident, there was a meeting at which the local chief raised awareness that such acts were not good. The respondent argued that this ethnic community are victims of the "incomers" (two sociocultural association representatives, interview, April 12, 2017). Local authorities may therefore be reluctant to defend the miners, since many are from elsewhere. As highlighted in the August 12, 2016 workshop in Lubumbashi, "autochthonous" groups view themselves as losing out on benefits from the mining sector, though some benefit from miners' presence. At a group discussion in a village - which I call C4 - on the national road within company C's concession, I spoke to the village chief and multiple inhabitants, including artisanal miners. The chief kept asking the miners for 5000 francs, and saying things including that they were "thieves" stealing from the company. He complained that when miners began loading their minerals for transport, he was not aware of it [and therefore unable to tax them] (April 11, 2017). In comparison, a prominent land chief has placed his people at site $C 2$ to levy money for him when the transport vehicles depart with minerals (Mine Police officer, interview, April 14, 2017; miner, conversation, March 3, 2017). One respondent based at site C1 said that the customary chief is "like a king" in the area (discussion, March 1, 2017). Overall these dynamics suggest that the village chief - who has a much smaller jurisdiction and, like other village chiefs, doesn't have lands (land chief, interview, September 2, 2016) - has less power and authority, including in the eyes of the artisanal miners. The land chief, on the other hand, 
is a relatively young, educated man, and much of company C's concession is on his lands - as he explained it, the "juiciest" part of the concession (interview, September 2, 2016). In sum, while the picture is mixed on the impact of ethnic identity in terms of conflict, there are times at which it plays a role and is often resolved in favour of "outsiders" rather than autochtonous groups, though certain autochtonous actors are better able to avoid such negative impacts.

\subsection{Summary and Interactions between Facets}

In summary, clandestine extraction provides a certain degree of property rights enforcement for, and protection to, artisanal miners who enter LSM sites. This enforcement of artisanal miners' claims falls into an ambiguous category: it doesn't qualify as a public service and is highly contingent on state and other security actors' private interests and incentives. Nonetheless, this protection does have some degree of public-ness, as when the police recognise that miners have few other employment options. In outcome, as Raeymaekers (2007) showed for the case of the Nande trading community in Butembo, "the solution to an apparently private problem (i.e. the quest for private property protection) can potentially lead to the generation of public outcomes - in casu the governance of collective security" (p. 3). Across the three case-study sites, the private interests of members of the security forces result in some benefits for artisanal miners. A Mine Police officer who collects payments in exchange for allowing the safe passage of minerals mined clandestinely in company C's concession pointed out that the Mine Police allows the creuseurs to go to the mountains though they aren't supposed to, and told me that "we are protecting them" [the community]. He said that the Mine Police protects the community from the mining company, and from the artisanal miners (interview, April 14, 2017).

At regularly occurring intervals, however, corporate enforcement mechanisms like patrols and supervisory visits create interruptions for clandestine extraction processes. These interventions are a strategy designed to surprise artisanal miners at work. These dynamics result, on a regular basis, in conflict and disruption for the miners. The functioning of trust relationships is easily disrupted when it comes to the corporate enforcement facet implemented by powerful companies and their allies. In certain cases, agreement is too costly to achieve because the interests are too diverse, the parties too different, and the solution too difficult to agree on through bargaining. When these facets clash, conflict results, and may become aggravated if miners continue to press their claims. Despite the predictability and relative institutionalisation of clandestine extraction, therefore, the implementation and performance of corporate enforcement is to some extent successful at disrupting clandestine 
mining arrangements, with a range of negative consequences for miners. The persistence of clandestine mining given these dynamics and the frequency of conflict can be linked to factors including the broad legitimacy of clandestine extraction and the presence of locally legitimate governance mechanisms that help resolve conflict at the local level. I examine one such mechanism, the "miners" committee" at site C3, below.

The discussion about clashes between the two facets should not be taken to mean automatically that corporate enforcement is more "impersonal" (Gallien, 2019) than local, "corrupt" clandestine mining systems and processes. Many of the same actors are involved in both. Across the three case-study sites, the security forces ensure that they benefit both from clandestine mining and from efforts to curb these practices. The role they play cannot be easily reduced to police officers for hire, resource users, or state officials acting impartially. At different times and for different purposes, they play on all three elements, which further complicates investigations into what Gallien (2019) describes as third-party enforcement in informal institutions - or, in this case, contexts of illegality. Hönke $(2013 ; 2018)$ argues that the hybrid security practices that transnational corporations engage in often differ from transnational standards and corporate policies. Mining companies across the three case-study sites, too, deviate from their stated principles both when it comes to corporate extraction (site C3 miners' committee member, interview, April 13, 2017) and clandestine mining, which frequently involves LSM company employees. Perhaps more importantly, LSM companies co-constitute a PR regime in which many actors view clandestine extraction as their only viable livelihood option.

In principle corporate interests and the authorised clandestine system are in opposition, such as when the parquet allows for a miner's release in exchange for money, instead of passing the case on to the tribunal, while the company may prefer that the miner go to the tribunal to be punished for taking minerals (company C security employee, interview, April 13, 2017). The two components' objectives conflict when there's a surprise inspection or visit by company management that, albeit only temporarily, disrupts the functioning of the authorised clandestine arrangement. Yet these interests often align: corporate measures at times contribute to the enforcement of the rules and regulations of authorised clandestine mining, and vice-versa. Since the authorised clandestine facet operates to restrict the volume of miner entry - miners need money to enter LSM sites by paying off security, and even then are not always granted access - the two components to some extent function in sync. Security forces' management of clandestine entry contributes to the achievement of company goals, albeit (from companies' perspective) in a suboptimal way compared to an "ideal" - and 
unachievable in the Congolese context except at a high human and material cost - scenario in which all miners are successfully excluded from the concession. Companies' first-party enforcement strategies and fortress protection present the security forces and other actors with a golden opportunity to extract rents as well as the means to do so. At site C, an interviewee reported, it's difficult for miners to work on the hills without paying. The security forces are always at the principal locations where miners operate: they know all the miners' spots and go up on the hills to observe (two miners and their mother, interview, March 31, 2017). One miner argued that at site B, the security forces control access and entry: it is difficult for miners to access the site without approval and authorisation from the security forces. Security surrounds the miners from all sides. Even at the larger site A, he noted, the company installed a fence and placed security guards all around (miner and his mother, interview, March 29, 2017).

The "miners" committee" at site C3 is an example of how authorised clandestine extraction contributes to the achievement of corporate goals though informal conflict resolution mechanisms. This committee is "informal" because the committee's activities within the concession are not legal according to Congolese law, nor permitted by company $\mathrm{C}$ (miner, interview, February 17, 2017; civil society representative, interview, March 4, 2017; company $\mathrm{C}$ security employee, interview, April 13, 2017). At the time of the research the committee had been in existence for over a year, since approximately December 2015 (local journalist, interview, May 19, 2015). The committee (perhaps more appropriately referred to as a "traders' committee", though that is not how respondents referred to it) organizes the transport and exit of minerals mined clandestinely at site $\mathrm{C}$ and purchased by traders from artisanal miners (two socio-cultural association representatives, interview, April 12, 2017; company C security employee, interview, April 13, 2017). The committee's role is to make sure there is no "fraud" or "leakage" of minerals, e.g. traders who do not want to pay fees for taking their minerals out (company $\mathrm{C}$ security employee, interview, April 13, 2017). On one visit to site C3 I spoke to "Pascal", a committee member. The traders, he said, support their representative "André", the president. Pascal is the president of a local business association (an association of Congolese drivers) as well as of the unemployed youth. Pascal described himself as a senior figure at $\mathrm{C} 3$ given his role in the business association. He helps to negotiate the price of vehicles to transport minerals, and his buses also transport minerals. The traders first go to maisons in Kisanfu, where they are given 2000 or 3000 USD. They give money to the miners, who enter the concession. Each trader, he explained, has his 10 or 20 miners. The traders buy the minerals and transport them out by motorcycle or vehicle, making 
deals with and paying company $\mathrm{C}$ security, the Bureau 2, and the Mine Police. If there are problems, he said, the traders provide 10,000 or 15,000 Congolese francs of support to the miners (interview, April 13, 2017). The committee cooperates with the representatives of different state services like the ANR (Congolese intelligence), the Bureau 2 [of the police], and the Congolese police, the PNC. At the barriers on the main road, all the services are present, including company employees and Bureau 2 agents. The committee has also organised its allies on the road to Kolwezi where company security is not present but state security - the Congolese National Police (PNC) and the Mine Police - are jointly present. About 150 or 200 Noah minibuses pass the barriers each day; according to one respondent, agents of the police, the ANR, the Bureau 2, and the FARDC (the army) all have Noah vehicles. Traders organise the whole process, and $\$ 120$ is paid at each barrier for a vehicle to pass (two socio-cultural association representatives, interview, April 12, 2017; company C security employee, interview, April 13, 2017). One respondent said it would be possible for me to meet with committee representatives, but that they would be worried about arrest (two socio-cultural association representatives, interview, April 12, 2017).

There is evidence that there is an ethnic dimension to the functioning of this committee and therefore, further evidence of an ethnic element of the "deals" that are a key part of authorised clandestine mining. According to a member of company $\mathrm{C}$ security, the local head of the ANR collaborates with many authorities, including the governor of the province; he and the provincial governor are from the same ethnic community. If there is a problem the head of the ANR calls the governor. The committee president is not from that ethnic community, but another top member is (interview, April 13, 2017). I also interviewed a former committee member who was also of this ethnic community. A local journalist based at $\mathrm{C} 1$ with whom I discussed the phenomenon of local "presidents of the artisanal miners" also argued that there is an ethnic element to clandestine mining. He said that the national Member of Parliament (MP) for the territory, and the governor, are "brothers" in ethnic terms, and that they put forward their "brother" to become the so-called "president of the creuseurs" (interview, February 7, 2017). ${ }^{31}$ I met this "president of the creuseurs" at site C1, who said that he had advocated for hills for the miners to work at. He mentioned that the [provincial] government had promised him four motorcycles to supervise the artisanal miners, but that he had not received a response ("president" of the artisanal miners, interview, February 11, 2017; interview, February 11, 2017). His comments highlight another way in which involvement

\footnotetext{
31 "Presidents of the creuseurs" in this setting are an "informal" phenomenon, given that the miners are
} technically "illegal" and could not be "officially" represented within company C's concession. 
with clandestine mining - in a position that is ostensibly designed to represent and benefit the artisanal miners - is a source of potential rents instead.

The miners' committee at site $\mathrm{C} 3$ is a governance mechanism that helps lower transaction costs and to alleviate the potential for conflict. In doing so, this committee is somewhat redistributive at the local level: the committee helps ensure that local traders, artisanal miners, and others continue to benefit from LSM. According to several interviewees, this committee encadre [a French term that means to provide support for or supervise] the creuseurs (two socio-cultural association representatives, interview, April 12, 2017; two trotteurs, interview, April 13, 2017; site C3 miners' committee member, interview, April 13, 2017; company C security employee, interview, April 13, 2017). One respondent said that the committee supports the miners so there isn't any trouble because creuseurs drink alcohol and take drugs. In his view, they need a leader to guide them (two trotteurs, interview, April 13, 2017). The committee calms the miners down, telling them not to create disorder because otherwise the company will shut down miners' access. A member of company $\mathrm{C}$ security similarly argued that the committee is a "necessary evil", telling the miners not to create disorder or get angry with company security - for example, if miners are injured or killed in a pit collapse - or the company will close off miners' access. The committee warns that if there is trouble, the company will call for police intervention from Kakanda, Kolwezi, and Lubumbashi, and even the "Kuluna" from Kinshasa [the LNI]. There will no longer be "free" access for the miners because the intervention teams don't collaborate with miners, since the company houses, feeds, and transports them. The respondent, revealingly, argued that "calm is necessary for evacuating stolen things" (interview, April 13, 2017). A Congolese National Police representative, too, echoed that those who call themselves traders try to support the miners, and named as the president of the traders the same individual that others named as the committee president. ${ }^{32}$ If a miner dies, he said, the committee helps with burial (interview, May 25, 2017). However, company C reportedly doesn't just leave miners to their fate in case of an accident: on May 18, 2017, a trader told me that two miners had died in a pit collapse on one of the hills the previous week, but that the situation remained calm and the company paid to transport the bodies to the morgue. It should be noted that company $\mathrm{C}$ has an incentive to

\footnotetext{
${ }^{32}$ I tried to interview the president, but he said he would only accept with permission from the local ANR representative, who I had met and who seemed suspicious of my activities (we had only a brief conversation during which he asked to see my passport). On this basis I decided that it would be more prudent not to try to interview the president.
} 
pay burial fees given the risk of disorder if it does not. Through their engagement with miners, therefore, the traders ensure their own continued access to resources.

Pascal, too, explained that the president of the miners' committee and the traders calm the miners down when they get too aggressive vis-à-vis the company and its facilities, so the miners don't jeopardise clandestine extraction and everyone's benefits. At other times, he said, powerful local authorities instrumentalise miners' ability to create disorder. According to Pascal, the people in charge gather the miners together and push them to enter site $\mathrm{C}$ to create disorder. If a miner dies, he pointed out, people blame the company, but they themselves encouraged the miners to enter. He pointed the finger in particular at the head of the ANR; a company $\mathrm{C}$ employee from one of the services other than security; and a FARDC official, specifying that when they encourage disorder by the creuseurs, they "eat" at company $\mathrm{C}$, when they go secure the concession. If the miners are quiet, these same actors benefit at the barriers. He referred to these dynamics as a double-edged sword (interview, April 13, 2017).

Despite the committee's contribution to conflict mitigation, a former member spoke less positively about the committee. He said that the committee organised itself to protect the community, but that when others, like the current president, came, he (the interviewee) refused to work with them. He contended that the committee only wanted to enrich themselves at the expense of the miners, and, having no capital of their own, started to collect money from the traders. In his view, the committee is in place simply for its own interests. He added that creuseurs and trotteurs, most of whom are not educated and don't know their rights, were intimidated into buying cards. He noted that the cards are for EMAK (l'Association des exploitants artisanaux miniers, mentioned above), a mining cooperative headquartered in Kolwezi. According to him these cards constitute a "covert operation" and even the Mine Police doesn't agree with the practice, because it's a private cooperative. He did add that when a miner dies, the committee pays for the burial because otherwise, the miners get annoyed (interview, May 19, 2017). Proper burial for their creuseurs friends, therefore, is another of the claims that miners use different strategies to enforce. A civil society respondent made similar comments about mining cooperatives in general, arguing that wealthy men rather than artisanal miners set up cooperatives. These are not real cooperatives/mutual associations, he said, but made up of rich people with capital to which one pays fees to join. The cooperatives can help a miner with a coffin in case of need, but they don't really have a purpose, he argued, and do not help miners save money (civil society representative 2, interview, August 23, 2016). 
Despite the imperfect nature of the miners' committee, it does seem to have had some impact on moderating artisanal miners' behaviour. A company $\mathrm{C}$ security employee confirmed the more positive side of Pascal's account, saying that the traders easily calm the miners down, and that this negotiation had been going on for as long as three years, even before the current president of the miners' committee (interview, May 27, 2017). A journalist based at site $\mathrm{C} 3$ said that the president of the committee speaks to the miners a lot, including making them understand that they are in a private mining concession. The president reportedly tells the miners that they are all "thieves" and that if the miners make trouble, the governor will send police officers to the area and everyone will suffer. The journalist said that there had indeed been a change in miners' behaviour (interview, May 19, 2017). Yet Pascal's comments about the double-edged sword proved prescient: in August 2019 major disorder broke out at site $\mathrm{C} 1$, reportedly encouraged by Kabikwa Mastaki, a national-level MP for the territory (“Au moins un mort", 2019). In light of these recent events at C1, more research is needed on the role of local committees and mechanisms, and of interactions between local elites and artisanal miners, at sites $\mathrm{C} 1$ and $\mathrm{C} 3$, and on their impact on conflict.

At other times, the interests of local authorities, elites, and other actors, and of the companies, are clearly in opposition. The November 2016 death of at least 13 miners in a shaft collapse at site $\mathrm{C}$ - a high-publicity event that compromised the "strategic covertness" of clandestine mining - led the company to complain to the governor that the company is not kept secure from miners (three traders and an ex-miner, interview, February 4, 2017; journalist, interview, February 7, 2017; "Près de 10000 creuseurs clandestins", 2016). The governor reportedly asked how these people could have died despite the fact that company $\mathrm{C}$ has guards. The company allegedly responded that the governor himself sends people into the concession, having said to leave the miners a little freedom to operate as they are originaires $d u$ pays and don't have work (journalist, interview, February 7, 2017). This response points to the extent to which authorised clandestine extraction is embedded in the region's formal political structure at high levels. These dynamics demonstrate the high-level support for authorised clandestine mining and its frequently, and to a significant extent, overt nature. As one respondent argued, within company C's concessions firearms are used to discourage those who have not paid for entry. If it were to protect the minerals, company C would not "suffer" [from miners' presence] (site C3 miners' committee member, interview, April 13, 2017).

In response to the above-mentioned miners' deaths, the company decided to close the barriers on the main road so products could not leave. The clandestine removal of minerals from the concession through the barriers was prevented for around three weeks. The 
interdiction was lifted due to complaints from those who depend on the clandestine mineral trade, including miners, who became desperate for money. People were reportedly heard on the radio pleading for the interdiction to be lifted. In December 2016, during the closure, the police stopped the minerals a trader had loaded into a minibus. Despite giving the police 400,000 Congolese francs, the driver was arrested and paid $\$ 1,300$ to get out of prison; the trader managed to hide (three traders and an ex-miner, interview, February 4, 2017). As this case shows, transporters are another group at-risk group when conflict arises, particularly given that they are in the vehicle carrying minerals and can therefore be easily detained. A case in November 2015 also affected traders' interests. The police in the main town in company C's concession were reportedly ordered to go to the mineral depots in a neighbourhood near the mine site entrance, and seize the traders' minerals, because the miners had "overflowed" and were entering the site even during the day. There was no violence, but the police fired in the air and people ran away (three traders and an ex-miner, interview, February 4, 2017). According to one respondent, these types of occurrences are common. He spoke of products that leave sites $\mathrm{C} 1$ and $\mathrm{C} 2$, in taxi-buses, which are then stopped. When the mining company gets wind of a large quantity of minerals that leave the site, he said, they block the transport. If miners die in the company's concession, the company asks how it happened and requests for these products to be blocked, which can last from 2-3 weeks to a month. People start to go hungry, so there are many complaints. He added that this happens nearly every month: there are 2 to 3 months of peaceful work, until troubles arise in the form of injuries or deaths (trader and two associates, interview, March 4, 2017.

Finally, at times, there is a rent-seeking dimension to closures of the barriers. A member of the miners' committee at site C3 explained that if the mayor of Kolwezi or of town C3 says that the traders are fraudeurs and asks for 2 million Congolese francs, and the situation gets "blocked" [minerals can't pass through the barriers], the traders give money to the president, who goes to Kolwezi, or to the major of the Mine Police, to pay (interview, April 13, 2017).

\subsection{Conflict between Authorised and Unauthorised Clandestine Extraction}

Clashes between the corporate and authorised clandestine facets of the regime are not always the cause of what, on the surface at least, looks like conflict between artisanal miners and the security forces trying to defend companies' concessions. An additional layer that is relatively unexamined in the literature, and that represents one of my contributions, is conflict between the authorised clandestine and unauthorised clandestine components of the property 
rights regime. At the three sites, conflict erupts on a regular basis between those who are instrumental in implementing the authorised clandestine component, and miners who attempt to get around its rules and restrictions. Miners do so in several ways: avoiding this facet entirely by hiding or running away or attempting to change the "rules of the game" through persuasion, intimidation, and/or violent behaviour. Much conflict at LSM sites is linked to security forces' efforts to disrupt and penalise efforts to circumvent the unauthorised component of the regime - or, in other words, to "close" the security market to those who do not pay for services. Companies' presence grants the security forces the mandate and authority with which to uphold these informal rules and regulations. When it comes to explaining conflict incidence, it is necessary to take into consideration miners' attempts to avoid confrontation with security forces and their efforts to aggressively define and enforce their claims. These dynamics again showcase the disparity between artisanal miners' demand for property rights, and the supply of PR.

As mentioned, some miners only seek access to LSM sites when security guards or policy officers call them, and they pay for entry. When a miner sees the security guards, he can be protected, if he has "spoken" with - i.e. paid - the guards (miner, interview, April 3, 2017). Yet some miners at times enter LSM sites without paying (three miners, second interview, March 13, 2017; miner, interview, April 3, 2017). Due to the socio-economic context of the region and their difficult financial circumstances, artisanal miners have an incentive to get around the rules of authorised clandestine extraction (four miners, interview, February 8, 2017). Miners often don't have any money for entry (trader, interview, May 10, 2017), so they have to go around security (three traders and an ex-miner, interview, February 4, 2017; miner and his wife, interview, April 9, 2017; two traders, interview, February 25, 2017): more evidence that many miners do not or cannot rely on a trader for money. Some miners lack the capacity to save in a context and culture that rewards a certain kind of consumption and lifestyle (Cuvelier, 2011). According to one trader, miners who are very smart have a lot of possessions. Others spend their money less wisely, on alcohol or women, and are left empty-handed. Miners who fit the latter profile, he contended, take more risks (three traders and an ex-miner, interview, February 4, 2017; community relocation consultant, interview, March 25, 2017). Miners also choose to go around security because of the risk that even if they pay one guard, another guard will not accept the money out of fear of being caught by his supervisor (miner and his mother, interview, March 31, 2017). A miner who enters site B without paying argued that it's very expensive to go to the site, because all the security services have to be paid. Even then, once a representative from another service 
emerges, that representative refuses access and betrays the miner (two miners and their mother, interview, March 31, 2017; four miners, interview, February 8, 2017). In working with a particular trader, a miner might get access to the site only once or twice a week, so might decide to enter without going through the security forces (two miners, interview, March 16, 2017). Even at site A, with its reputation for being easier to enter than site B, it can take five or six days to find the guards scheduled to work. When a trader arranges for a group of miners to enter the site, it may be several days before the miners can go back in collaboration with that trader; they may choose to enter the site independently as a result. Entry is reportedly even more tightly controlled at site B (miner and two former miners, interview, February 17, 2017; trader and her miner son, interview, February 27, 2017). For these reasons, many miners try to enter, clandestinely and without authorisation, by avoiding the police and security guards rather than paying them (three miners, second interview, March 13, 2017).

Finally, miners' attitude to different kinds of risk influences why some miners and not others pay for entry (trader and her miner son, interview, February 27, 2017; miner, interview, February 27, 2017). Unauthorised access can actually be a risk-reduction strategy. One miner goes around security at site B because cooperating with the four services (the PSC, company security, the police, and undercover officers) is difficult. His brother, a site $\mathrm{C}$ miner, prefers areas where the company is still extracting minerals (the open-pit mine), and where it's necessary to pay for entry, because he simply takes the minerals and leaves. Where the company is finished extracting minerals and entry is free, he said, it's dangerous due to high temperatures and the difficulty to breathe in the pits (two miners and their mother, interview, March 31, 2017).

Entering a mine site without paying involves significant risks for miners. The miner who is invited and pays for entry is more likely to be able to work without problems - though, as I have shown, there are no guarantees, and miners often lose their money even if they have paid for entry. Miners who don't pay take more risks than those who do (two miners, interview, March 16, 2017) and if seen by the security guards, may be arrested (miner, interview, April 3, 2017). One interviewee decides when he will try to enter the site, but miners who work with the security services are called to enter. If the services have work, they call the miners, and he goes too. If he wants to work by himself, he can go to the site when he wants. If a miner enters without being called, he may be chased out or sent away. If he is called by the PSC or security services, it's difficult for him to be sent away (interview, April 3 , 2017). A community activist living near site B explained that police officers have 
arrangements with some miners. Without money a miner can't make an arrangement with the police, who have to be paid before giving miners access. If a miner just goes into the concession and someone comes across the miner, they see that he doesn't have an arrangement with anyone. The miner runs away and may be beaten (interview, October 15, 2016). A group of miners in the Lubumbashi area reported that they don't want to take the risk of entering the site without cooperation: if a miner enters and is arrested, he is brought to the parquet, where, they said, he has to spend no less than 500 or 600 dollars. These miners had not been arrested before, because they always work "under cover" of traders. If they were to enter without cooperating with security, the outcome would depend on chance (interview, April 3, 2017). The lack of flexibility at sites in the Lubumbashi region and particularly site B is another factor. A miner who goes to site B explained that it's necessary to go around security because if security sees a miner, they call for reinforcements and the miner gets caught. When I mentioned that multiple people told me that miners cooperate with the security guards, he asked how a miner could cooperate given that there is lots of security. At site B there are four different security services, which makes collaborating complicated: if a security service is on site with which a miner has not cooperated, the miner is arrested. It is difficult to cooperate with multiple services: the private security company, company security, and the LNI unit of the police, the "Kuluna", as well as what the miner described as agents who wear civilian clothing to pass themselves off as miners (two miners and their mother, interview, March 31, 2017).

Significantly, more than one respondent referred to the practice of circumventing the authorised system for clandestine extraction, by not paying the security services, as "fraud" ("president" of the artisanal miners, interview, February 11, 2017; miner and his wife, interview, April 9, 2017; company C security employee, interview, April 13, 2017). As a respondent explained, security may discover that a miner has committed "fraud" and there's a "foreign body" at the site: someone who has entered without paying. Miners who try to enter "fraudulently" tend to get discovered because miners who pay work as a group and will not allow a miner who hasn't paid to work with them. They tell him that he was able to enter the site because of them, and that he should work elsewhere because they don't want problems. Therefore, artisanal miners themselves, as resource users, also enforce the rules and regulations associated with clandestine mining - which, again, demonstrates the broad acceptance of this facet of the regime. The security guards count heads: if seven people pay to enter and an eighth has joined, they detain everyone. The security agents secure those in the group who have paid and tell them when to leave. Miners who enter LSM sites without 
paying are responsible for their own security: they don't have guards' assistance to protect them from arrest. When a miner has paid, if the police officer on patrol at the site sees danger, he signals that miner. If an officer sees miners who haven't paid, he signals other security to catch those miners (trader and her miner son, interview, February 27, 2017; three miners, second interview, March 13, 2017; two miners, interview, March 16, 2017; miner and his wife, interview, April 9, 2017). One miner was arrested at site B several times, always when he did not "cooperate" (miner and his wife, interview, April 9, 2017).

Therefore, the use of force to deal with miners falls most heavily on the people who don't give money in exchange for entry to the mine site (journalist at site $\mathrm{C}$, interview, February 7, 2017). When a miner is stopped, his options are to pay, hand over the minerals, or be "attacked" (journalist at site C, second interview, February 8, 2017). It's possible, a respondent reported, for a miner to enter sites A or B without being caught, arrested, or beaten if he's very vigilant (three miners, second interview, March 13, 2017). Yet miners' attempts to enter the site without paying increase their physical risk, since the security guards whip the miners when the latter don't make arrangements (four miners, interview, February 8, 2017), which contravenes company C's supposed human rights policy. According to a journalist based in company C's concession, shots tend to be fired when miners are spotted having entered the site without going through the arrangements (interview, February 7, 2017). A group of four miners at site $\mathrm{C}$ reported in February 2017 that two days ago, a miner who had not paid for entry took some minerals and a police officer wanted to chase after him to get the bag; the officer fired and the miner died (interview, February 8, 2017). ${ }^{33}$ Those artisanal miners who are "stubborn" are either arrested, or they succeed (miners' committee member, interview, April 13, 2017). Therefore, aggressive behaviour and risk-taking does sometimes pay off, whereas miners who are more cautious have to accept that they will not make any money on that occasion.

The security forces have two main incentives to ensure miners comply with and pay into the system in place. First, there is the financial incentive: police officers and PSC guards receive money or minerals in exchange for permitting entry. Secondly - and related to the motive of obtaining rents - the security forces have an incentive to keep "unauthorised" traffic to as low a level as possible. The more miners enter a site - the more open the market

\footnotetext{
${ }^{33}$ The previous day, a Mine Police representative told me that miners go into the galeries in the open-pit mine. He described these as dangerous zones and noted that there had been a death the previous day, which fits with the miners' report of a death on February $6^{\text {th }}$. Yet the Mine Police representative attributed the death to a mine collapse, saying that the clandestine miners take the body and run away (interview, February 7, 2017).
} 
becomes - the greater the risk that the security forces will run into trouble with the mining firm. There is therefore a link with the (c)overtness dimension, for if the security services open the market to too many participants, they run the risk of turning a semi-covert market into an overt one. This represents not only a risk to an individual guard or police officer's employment but has the potential to result in a crackdown on miners' activities both authorised and unauthorised.

One respondent's story demonstrates that in some circumstances - when it's in the security forces' interest - miners who have paid and miners who have not are dealt with equally harshly. In 2014 "Jacques" (a pseudonym) was injured by a bullet at mine site B, fired by the "soldiers" (the police) when they were chasing miners out of the site. He was hospitalised for three or four months and then released at which point, he says, they arrested, hit, and sent him to prison. He showed me extensive scar tissue on his arm from the bullet wound. When the security forces were chasing the miners and the miners were running and fleeing, he was surprised to find that a bullet had hit him. Jacques reported that the "soldiers" were face to face with the miners and the bullets could not have been stray bullets. Those chased away included those who entered without paying and those with whom the security forces collaborate. However, when asked, Jacques agreed that the police protect the people with whom they work. At times the security forces transport miners with whom they collaborate in their vehicle and drop them where they can work (miner and his mother, interview, March 29, 2017).

Despite all the tactics miners employ to increase their security, as shown, miners regularly experience detention, incarceration, and physical violence. Yet there may be some flexibility in terms of paying off security when surprised by them. Some miners enter without paying, but if caught, are obliged to pay. If a miner caught at site $\mathrm{C}$ does not have money, he is beaten, and his products are taken away. If he has money, the guards leave him alone (three traders and an ex-miner, interview, February 4, 2017). One respondent reported that when a PSC agent at site B comes upon a miner suddenly, the miner can pay him (miner and two exminers, interview, February 17, 2017). To some extent, connections can mitigate the punishment if a miner is caught having entered without paying. Whether a miner is beaten or just chased away can depend on his connections. If the miner knows the guard, if the miner is lucky the guard just tells him to leave. Otherwise, the guard may take the minerals and even hit him. The miner is likely to be brought directly to the parquet (three miners, second interview, March 13, 2017). 
Conflict between the authorised and unauthorised facets also includes large-scale confrontations (company A security officer, interview, October 11, 2016; occasional miner, interview, March 21, 2017; two miners, interview, March 16, 2017; LNI representative and Mine Police representative, interview, March 20, 2017). At times, miners who don't have money to give the guards may enter the site not by stealth, but by using aggressive behaviour. When miners do not want to pay the entry fee demanded by security forces, or don't have the money, many use aggressive or even violent behaviour, like throwing stones, particularly when in a large group. This strategy is another example of how miners ally, however temporarily, with each other. Miners who don't work with traders and therefore don't have money to enter the site are more likely to use these types of strategies. One miner explained that « qui ne risque rien n'a rien »: someone who risks nothing gains nothing. A miner might wake up in the morning without money and decide to enter the mine site by force, just for enough to survive: a few kilos, 50 kilos (miners, group interview, April 3, 2017). At site C, when miners operate at night, company employees driving machinery sometimes see them, but tend not to do much because miners are determined, and some are prepared to fight. The employee driving the vehicle often leaves the miners be, to not be attacked (doctoral candidate, interview, February 1, 2017). Miners are willing to get into a confrontation with some security guards, since only the police are armed. Even an armed police officer may be injured if caught by surprise (journalist, interview, February 7, 2017). A large-scale confrontation took place at site A in December 2012, when miners were seeking money for the holidays. At site A, company security cooperates with the Mine Police to give miners access to the site. That year, multiple security agencies and forces were deployed (two miners, interview, March 16, 2017). In 2012-2013 there were reportedly over 1000 miners at site A; even the armed forces were present. According to the miners, the governor had said they could enter the site and take minerals (LNI representative and Mine Police representative, interview, March 20, 2017). There were several deaths (two miners, interview, March 16, 2017). At site B, 2013 was a turbulent year with a lot of disorder. There were many miners, day and night, and physical attacks on security guards. Miners, a LNI representative claimed, attack the guards with barres de mine and bêches (spades) if they don't find or get access to minerals (LNI representative and Mine Police representative, interview, March 20, 2017; Mine Police official 1, interview, November 8, 2016). Some respondents drew a link between artisanal miners' behavioural patterns and the decision to enter a mine site by drawing on forceful behaviour. According to several respondents, some miners take drugs, particularly chanvre (marijuana) for courage to access the site and do the difficult work in the mine or pit. 
This habit can reportedly affect their behaviour by making them unwilling to pay for entry and more likely to confront the security forces (journalist, second interview, February 8 , 2017). One respondent described miners as "stubborn" (C3 miners' committee member, interview, April 14, 2017). Miners are young and often united; they smoke marijuana and drink alcohol together and develop a common way of thinking (doctoral candidate, interview, February 1, 2017; company B officer, interview, February 6, 2017; trader/miner with knowledge of site C, interview, February 14, 2017; artisanal miner, interview, February 27 , 2017). One miner doesn't like to work in a group because, he said, some miners are désordonnés (disorderly). Sometimes, when the miners in a group share the money between them, if one of the miners drinks too much alcohol, the miner may say that he's been given too little money, and threaten or be aggressive (miner, interview, April 3, 2017). Members of the security forces tended to emphasize that miners drink too much and then act out (Congolese National Police representative, interview, May 25, 2017; company C security employee, interview, May 27, 2017). Of course, mining companies have incentive to blame artisanal miners, rather than the security forces, for clashes and human rights abuses.

In addition to cases in which miners try to circumvent the authorised system of extraction, tensions result when there is disagreement on the rules and modalities for entry. As noted, miners can try to negotiate a lower entry price with security (miner, interview, April 3, 2017; doctoral candidate, interview, February 1, 2017). If there is no agreement on the amount of money, miners and security agents may get into a dispute. The Mine Police may demand an amount, like 50,000 Congolese francs, that the miner can't or isn't willing to pay (civil society representative, interview, March 4, 2017). In one case at site A, the police wanted more money and the miners didn't want to pay, which led to an argument (miner, interview, February 13, 2017). Miners and the security forces also do not always see eye to eye on the amount of time miners can spend at the site. At site $\mathrm{C}$ in 2015, the company stopped working at two hills after extracting minerals but placed the Industrial Guard so people don't take panels or the generator. When the heads of security are there, the miners are told to leave for an hour (ex-trader, interview, February 17, 2017). When miners are given permission to enter, they may refuse to leave, which can lead to conflict. Miners are made to leave the site with the group they entered with. No one is allowed to stay behind because miners who are unwilling to comply tend to throw stones at the police. If there are injuries or killings of miners, these tend to affect those who do not comply with orders (company B officer, interview, February 6, 2017; trader/miner with knowledge of site C, interview, February 14, 2017; artisanal miner, interview, February 27, 2017). In December 2016, one 
miner reported, miners gained access to site A during the night. When it came time for them to leave, security started to throw tear gas to get the miners out. Several miners went up to the level of the battés, which is what artisanal miners call the five-metre-tall steps (marches in French) known as benches and "cut into the side of an open-pit mine" (Wikipedia, n.d.; company A exploration staffer, October 19, 2016; company A manager, interview and site visit, September 24, 2016). One miner stayed behind and a police officer went down to where he was. When the miner saw the officer he threw a stone at him, and reportedly tried to take the officer's weapon. In response, the officer reportedly fired on the miner, killing him. The conflict arose because, once the security forces start throwing tear gas, a miner has to load the minerals on his shoulders and leave immediately (trader/miner, interview, February 14, 2017).

Miners are typically at the mercy of security guards and police. If they want to enter the site to get money for the day, they often need to check ahead. At times, they are simply denied access without information on why, which contributes to the seemingly arbitrary nature of their dealings with mine security. Confrontations often occur if miners are unable to gain access for too long. From a policy perspective the question arises of whether there is a middle ground between no access, and access with relatively frequent conflict. At sites A and B, where in 2017 security recently was not accepting money from miners for entry, miners had to enter by being stubborn and having la tête dure (a hard head). They had to impose themselves, for example, if a week had gone by and they were out of money (a miner and his wife, interview, March 31, 2017). In summary, much of the conflict at and around LSM sites is linked to the security forces" efforts to "close" clandestine extraction by discovering and repressing miners' attempts to avoid complying with its various provisions.

Other actors, not just traders and miners, are also affected by punitive measures designed to ensure that people in the ASM supply chain do not circumvent the system for authorised clandestine extraction. A woman who owns a plot of land near company A where traders buy, pack, and transport minerals explained that her husband was arrested twice in 2013. The first time, he paid 30,000 Congolese francs. The second time, they paid 50,000 francs and he was released. Her husband and the security services then came to an agreement that the security services could set up shop in the area to receive money, so that it wouldn't be necessary to bother the owners each time. The artisanal miners, the landowners, and the traders all pay into this system. Since the arrests in 2013, she explained, there has been no conflict in that regard (interview, May 15, 2017). Implementing regularity of payments is another way to lower transaction costs, come to agreement, and reduce the potential for conflict. 
Finally, a key example demonstrates the intersection between the three facets: an attempt to get around authorised clandestine extraction can result in a company crackdown. A miner mentioned that at one point "voyous" ("thugs") were going to two key barriers on the main road in company C's concession and threatening the Industrial Guard in order to get their minerals through. He confirmed that to get minerals out people have to negotiate with security by calling them on the phone, and pay them. They give the authorisation to go, with the vehicle, to a main selling point on the national road. Yet the "voyous", he said, take money to pay security and keep it. They had refused to pay and tried to use force to remove the barriers. They reportedly succeeded in getting five minibuses through; the company, he said, reinforced the security as a result, and at site $\mathrm{C} 2$ people could not get money. The situation only lasted one or two days (conversation, March 3, 2017).

\subsubsection{Institutional Dynamics and Conflict}

There remains a further dimension or layer of analysis in this highly pluralist property rights regime. Some of the conflict between the unauthorised and "authorised" facets of clandestine extraction relates to the dynamics between different security forces at LSM sites: specifically, the conflict between these forces, and their efforts to ensure that they are not cut out of potential rents.

Given that the police, unlike PSCs, are armed, they can use their coercive power against agents working for private security companies (Mine Police representative, interview, February 16, 2017), which leaves little room for resistance by unarmed agents who, out of concern for their jobs, might wish to prevent miners from entering the concession. The police, who unlike PSCs and the Industrial Guard are armed (Mine Police representative, interview, February 16, 2017, three PSC managers, interview, March 20, 2017), have a tendency to use the fact that they have firearms (trader, interview, February 14, 2017). A trader/miner provided insight into the dynamics underpinning conflict between services at a different site in the province of Lualaba - not one of the sites in this study - arguing that the police dominate and are always the ones who wish to be paid. They impose their will on other security services, saying that the others are civilians and that the police have weapons. When police officers receive money from miners, he said, they keep most of it for themselves and give little money to the other services (interview, February 14, 2017). A PSC manager similarly reported that at site $\mathrm{C}$, the police are under direct control of the company and follow the orders of the company's Security Manager, which he said creates difficulties for the PSC 
and for the other sub-contractors: the police don't listen to the PSC. At site B, on the other hand, the PSC pays and feeds the police (three PSC managers, interview, March 20, 2017). Since the LNI supports the PSC at site B, if a police officer creates a problem, the PSC gets rid of him (three PSC managers, interview, May 12, 2017). A miner who operates at site C gives money to the Mine Police, which then shares with the other services, the Industrial Guard and PSC (two miners and their mother, interview, March 31, 2017).

There is also evidence from the three case-study sites that conflicts between different security services negatively impacts miners. One artisanal miner reported that, whether at site $\mathrm{A}, \mathrm{B}$, or $\mathrm{C}$, when a miner goes to an open-pit mine, all the security forces must be aware. The nature and mix of specific services - which can include the PSCs, Industrial Guard, and/or police - isn't important, but the miner has to pay off all the services (interview, February 27, 2017). Coupled with miners' need to spend as little money on security as possible, this fact may lead to conflict between services when one service receives money from a miner and not another. According to a miner active in the Lubumbashi region, the different security services may betray one another. Miners can lose their money if they've paid a service at part of the mine, and the other force discovers that the miners gave money to the first service, at a different level of the open-pit mine. The latter service creates problems for the one that received the money (three miners, second interview, March 13, 2017). As one trader explained, the different security services collaborate but if they can't agree on how the money received is shared out between services - if there isn't an equitable distribution - betrayal can occur (trader, interview, February 10, 2017). The conflict discussed above, between SAESSCAM and EMAK, during the period in which the company was preparing to clear miners from the site, is another example of how institutional dynamics and rent seeking can lead to conflict. In that case, some miners reportedly beat SAESSCAM agents when SAESSCAM tried to delay the process through which miners were to be paid, in order to ensure that SAESSCAM would benefit from the clearing of miners (former EMAK representative, interview, February 1, 2017). The fact that, as noted, rules aren't fixed and amounts are to be negotiated, coupled with limited contract enforcement, leads to a situation of uncertainty and inconsistency that may ultimately negatively impact the artisanal miners as well as one or more of the security forces involved.

The case of the LNI at site B is a good example of how conflict sometimes results when miners give money to one security representative or group, but not to another, because the security representative or group that did not receive the money won't let the miners enter (miners, group interview, April 3, 2017). Given that the LNI is not typically deployed at 
security posts in the concession, if a LNI officer takes a miner's money, the miner may be caught if another security service shows up (three miners, interview, February 17, 2017). The police at site B don't have specific posts, so they may take money from a miner and leave. When the other services [the PSC and the Industrial Guard] find the miner in their sector, they arrest him (miner and two former miners, interview, February 17, 2017). Since police (LNI) intervention is often required at site $\mathrm{B}$, at a minimum every few days and sometimes as frequently as every 1-2 days (LNI representative and Mine Police representative, interview, March 20, 2017), police are frequently within the site. Two miners reported that at site B, different groups of miners work with three different security services. There are miners who enter the site through connections with the PSC; those who do so through the maitres-chiens (the security guards who work with dogs) ${ }^{34}$; and those who enter in collaboration with the LNI. The three services, they said, don't get along. If the LNI see a group of miners whose entry was facilitated by the PSC, they may arrest them. The same goes for the PSC when it comes to groups facilitated by the LNI or maitres-chiens (two miners, interview, March 16, 2017). Another miner reported that at site B, there are those who cooperate with the PSC and the police. Some miners cooperate with the police but not the PSC, and some with the PSC but not the police (interview, April 3, 2017).

The case of Jacques, the creuseur mentioned above, provides support for the impact on conflict of different institutions not working well together. A LNI representative deployed at site B alleged that Jacques was creating panic at the mine site and nearby neighbourhood. During eight months of struggle against the miner, he said, Jacques beat two security guards and took two radios. According to the representative, Jacques also threatened to sabotage or set fire to the company's transformer. If he wasn't able to access the mine site or didn't have time, he would take other miners' minerals. On December $31^{\text {st }}, 2016$, the parquet issued a warrant and Jacques was arrested. At the time of interview a LNI representative had learned four days ago that Jacques was released after less than three months in prison; he emphasized that they had nonetheless done their job (LNI representative and Mine Police representative, interview, March 20, 2017). A company B security officer, who described Jacques as part of a purely criminal element rather than really linked to the creuseurs, also said that Jacques attacks not just the company but also the population, and engages in extortion (interview, January 27, 2017).

\footnotetext{
${ }^{34}$ The canine unit is part of the PSC contracted to operate at site B (three PSC managers, interview, May 12, 2017). The fact that there is reportedly rivalry between different services within a single PSC is an interesting dynamic that suggests that just like LSM firms, private security companies are not unitary, either.
} 
After Jacques' release, I interviewed him and his mother, who witnessed his arrest; Jacques confirmed that he had been released a week ago. The site B "soldiers" (how miners in the area often refer to the LNI police unit) arrested him at home after he left the site with minerals. During an interview in which his mother did most of the talking, I was told that the police surrounded his home and started pulling him outside, and stabbed him in several places, including the head, with a baïonnette (bayonet) ${ }^{35}$. A neighbour ran to Jacques' mother's house and shouted that her son was being arrested and taken away. His mother went and found Jacques covered in blood. The police started firing bullets to scare her, telling her not to advance. She responded that she wanted to see why they had arrested her son. Surrounded by police, Jacques told his mother to hold on to him; she held his trouser leg. His father came running, so the police started shooting bullet and tear gas in his direction. As Jacques was affected by the tear gas, they began to pull him into the vehicle. He continued to resist, and the police let go when people started throwing stones. At that point, Jacques' family brought him into his mother's house. As the area was full of police officers, his family couldn't take him to the hospital. When the police saw that the family had brought the miner into the house, they took his mother's 10-year-old daughter and put her in the vehicle. The police parked close by and started knocking on the windows; one broke and another fell off. Finally, the soldiers entered the house and pulled Jacques into their vehicle. During the incident, one of his friends was shot in the leg. Before leaving, the police destroyed tables, windows, and a freezer. They took ten and a half cases of beer Jacques had to sell, the speaker, and all the goods including radios. They fired in the air as they left. Jacques spent two months and 25 days in prison; after paying 500,000 Congolese francs, he was released three days later. Jacques' mother asked if this is how the police can accomplish its mission, even when tasked to make an arrest (miner and his mother, interview, March 29, 2017).

Jacques' account of the reasons for his arrest differs from the version of events given by the company B security officer and the LNI representative. Jacques said that the police officers suggested that he work with them, and he collaborates with PSC agents instead, so the police turned against him. He prefers to work with the PSC not because the police don't take money from miners, but because the "soldiers" are mean; the PSC guards are more understanding that the miners don't have jobs. But if the police arrest a miner, especially one who doesn't work with them, he said, the LNI officer holds a grudge and wants revenge. The police officers also ask for more money for entry than the PSC. Even when the police arrest

\footnotetext{
${ }^{35}$ A large knife attached to a firearm and used by police (university professor, email, October 9, 2018).
} 
Jacques or put him in prison, he refuses to work with them (miner and his mother, interview, March 29, 2017).

I do not claim that any of the above accounts of these events constitutes the "truth": each of the parties involved has an incentive to portray themselves in a positive light. The key point is that institutional dynamics, specifically if different services don't get along or collaborate, have an impact on conflict. Jacques argued that the services do not fight each other physically but if they catch a miner, they beat him even if he has already paid: for example, if three members of different security forces are present, and one was not informed and did not get his share (miner and his mother, interview, March 29, 2017). Ultimately, the miner suffers the most due to conflict between the services. Jacques's story also provides further evidence on how the corporate and authorised clandestine facets of the property rights regime at times support the attainment of each other's goals - in this case, forceful punitive action against a noted "troublemaker".

One miner could not confirm whether each security service at site A works with its own group of miners, as at site B, but noted that while miners often speak with members of the Industrial Guard on the phone, the Mine Police doesn't have a problem with it. The Mine Police and the company's own security, he said, cooperate to avoid any animosity between the two and better facilitate the miners' work (two miners, interview, March 16, 2017). At site A, where there are only two security services, he said, many miners are able to pay for entry, while at site B it's very difficult because there are four services (two miners and their mother, interview, March 31, 2017). A miner active in the Lubumbashi area argued that at site A, the security services - the Mine Police, the Industrial Guard, and a different PSC than at site B get along well, compared to site B. He argued that the factor making these services more cooperative is their salaires de misère (very low salaries). At site A, he said, everyone is poorly paid, so everyone is cooperative (miner and his wife, interview, April 9, 2017). A company A security employee deployed at a different site than site A provided confirmation of this view, saying that before, employees at site A would escort copper "cathodes" (finished copper) out clandestinely in exchange for some money. After this source of money was blocked, he said, employees find another way to make ends meet each month: leaving an open breach for the miners, who pay something at the exit (interview, May 21, 2017). Entry is therefore said to be better coordinated - in terms of cooperation between services - and less strictly regulated at site A than at site B, which helps to explain miners' easier access to site A (miner, interview, March 21, 2017). At site A, the Mine Police and other services reportedly see eye-to-eye on collaboration with miners, ensuring smoother entry, while at site B the 
police and the other services are often in conflict (two miners, interview, March 16, 2017), which can mean more frequent disruption of miners' attempts to enter the site. These dynamics also show that actors' relative homogeneity can reduce transaction costs and ensure a less conflictual outcome.

\subsubsection{Discussion}

Though miners who enter without paying take more risks, clandestine extraction at LSM sites is always highly exploitative and risky. Whether the miner has paid or not paid for entry, as soon as a security guard catches a miner, he may hit the miner to scare him into not accessing the site. One miner concluded that whether a miner pays for entry or not, he always runs the risk of losing his money, and of being arrested and beaten (three miners, second interview, March 13, 2017).

Yet if miners decide not to engage in these types of strategies and choose to leave the mine site instead, they do not receive any money until they can enter the site again. Not resisting has the advantage of being, at least in theory, less risky from the perspective of physical risk or the risk of arrest. Miners willing to accept higher levels of risk are more likely to be involved in conflictual encounters with security forces. While this point seems rather simple and expected, it has two important implications. First, of all the people in the supply chain, miners bear the greatest physical risk. Second, there is a significant trade-off between physical and financial risk: no matter what strategy they pursue, miners are always at some form of risk, whether conflict occurs or not. I now deal with these points in turn.

First, miners deal with the most physical risk of all the participants in the supply chain. It's rare for traders to be detained or go to prison, but it happens frequently to miners (three traders and an ex-miner, interview, February 4, 2017). Unlike traders, miners physically enter the extraction site (interview, February 14, 2017). Traders are more physically removed: at site $\mathrm{C}$ they are in several villages and towns - not at the extraction site itself - where minerals are brought to the buyers. According to a Mine Police representative, the police don't know the traders, who work in the shadows, whereas they see the miners and arrest them (interview, February 7, 2017). Yet I saw a number of mineral depots openly operating at site C2 and met traders there, including a trader known to a representative of the armed forces. This reality suggests that traders are protected by their financial means and status, and their relationships with the security forces, rather than just physical distance from the mine site. According to a journalist active at site $\mathrm{C}$, the police do not have the mandate to shut down the mineral depots around the concession. The police at times have mandats de perquisition (warrants), but 
according to the journalist, these warrants are for people like miners, who stock minerals in their houses (journalist, interview, February 7, 2017). A miner in the Lubumbashi region reported that it's common for miners to be arrested by the police in the neighbourhoods around the mine sites (miner and his wife, interview, March 31, 2017). Traders don't typically stock minerals at home, other than samples. They put the minerals at clandestine depots around the site. The police don't typically raid these local depots because the traders pay off the different state services (the police, the Bureau 2, and the local judicial authorities) and are able to transport their minerals without problems for sale at bigger depots further away. While traders are not arrested often (trader and her miner son, interview, February 27, 2017), I did speak to several traders who had lost money and/or minerals (trader/miner, interview, February 14, 2017; trader, interview, May 10, 2017; trader and two associates, March 4, 2017). As a trader explained, if the security services need money, they create complications so they can take the minerals. He personally lost 50 sacks to the security services (trader, interview, May 18, 2017). At times the police notice vehicles carrying minerals, with low tires because of the weight. If they try to give chase, the trader - through the driver - pays to be left alone. Once the driver passes the barrier leaving the site, it's no longer possible for the police to arrest him (trader and her miner son, interview, February 27, 2017).

Second, the significant trade-off between physical and financial risk means that if miners seek to ensure their physical safety, they compromise their financial interests, and vice-versa. Though the justice system in the DRC has a reputation for being dysfunctional, miners are afraid of being arrested. The same people are often arrested again and again, and spend time in prison (Mine Police representative, interview, February 7, 2017). Miners then have to pay to get out of prison (three traders and an ex-miner, interview, February 4, 2017). Avoiding LSM sites means they can avoid imprisonment, but also requires them to sacrifice income.

These additional elements help to explain the persistence, and often highly conflictual nature of, encounters between artisanal miners and the different forces that secure mining concessions. Members of different security forces systematically work to keep this market "closed" to those who do not pay, rather than "open" to those who have basic tools and the ability to sneak into a mine site and dig for and collect minerals. As noted, the security forces also attempt to keep this market covert (Daudelin \& Ratton, 2018), not always an easy task due to the need for artisanal miners' physical presence at the mine site and the risk of them being seen at the open-pit mine or on the hills. Miners' sometimes-unpredictable behaviour complicates efforts by security guards and police officers to keep clandestine mining closed 
and covert. In keeping with their corporate enforcement duties, police officers and security guards must be seen to be preventing miners from entering the concession. It is now possible to nuance that argument by arguing that this is typically done by taking on miners who enter the concession without passing by the arrangements in place, so the security forces can appear to be doing their jobs (journalist, interview, February 7, 2017) without compromising their financial interests in clandestine mining. Yet the sheer volume of miners means there is a mismatch between artisanal miners' demand for property rights, and the supply of PR by the security forces who give miners access. Miners not only seek more frequent access to mine sites but also resent attempts to curb the amount of time they can spend at LSM sites. In turn, miners sometimes use aggressive behaviour to obtain an increase in the supply of PR. This mismatch, which sits at the intersection of the three facets of the property rights regime, is therefore at the heart of much of the conflict that erupts at and around LSM sites. This application of PR theory suggests that the solution lies not in fewer PR for artisanal miners within LSM sites [i.e. greater enforcement] but in more, informal and negotiated, PR. The data on rising numbers of "attacks" at site B in the last couple of years highlights the limits of a more effective exclusion strategy of the kind company B prides itself on implementing. In times of need, artisanal miners and other people who have few other ways to earn a living are prepared to fight to gain resource access, and without more appropriate policy approaches this trend is likely to continue.

\subsection{Conflict Across Sites: Mine Site Interdependence}

Despite company efforts to fence and wall off their mine sites, these sites are, in some ways, interdependent. Specifically, conflict and exclusion dynamics at one site impact other sites. A Mine Police representative deployed at site A said that if a new company opens where people are being hired, the number of miners at site A drops. He linked the "criminality" problem to the closure of previously artisanal sites - like Kawama and Whisky - after the sale of these sites (interview, March 24, 2017), an issue raised by other interviewees as well. One artisanal miner explained that he used to work as an opérateur d'engin for two constructionmaterial companies, but that with the fall in the copper price, many mining companies or companies linked to the mining industry cut down their workforce (several traders and miners, interview, March 9, 2017).

The availability of minerals at LSM sites is affected by the process of extraction, which can have an impact on conflict, even at neighbouring sites. A company A exploration staffer explained that at site A, with the gradual exhaustion of the richest and more sought- 
after types of minerals, there has been a little less "theft" (interview, October 19, 2016). At site A, a certain type of mineral known as oxydé has been increasingly mined out. At the company's open-pit mine, they are now at the zone of mixed minerals. At the beginning, there were more oxydés; going downwards, there is more sulfur (company A exploration staffer, interview, October 19, 2016; three PSC managers, interview, March 20, 2017). As a longtime company A manager explained, the top part is 0-40 metres. Water and the sun transformed the mineral so that it became oxydé (oxydised). The minerals found at depth, on the other hand, are sulfurés. The treatment of the two types of minerals is different. For the oxydés, they lixide with sulphuric acid in solution form. But the sulfurés don't pass easily into solution. They have to be converted into oxydés, in order to be treated with sulphuric acid. At site A, this employee explained, the oxydés are coming to an end, raising the question of how to treat the sulfurés. Company A was in the process of building a processing plant at site A to treat the tailings from previous operations, which would last for ten years, perhaps even a bit longer. Between the oxydés and the sulfurés, he added, there is something that miners can take - a few kilograms (interview, September 22, 2016).

One PSC manager argued that the number of miners at site B had been declining as miners moved elsewhere, and that miners run away if there is a lot of security present at site B (three PSC managers, interview, March 20, 2017; company B officer, interview, February 6, 2017). In contrast, the PSC manager said, at site A it was more permeable, and miners were easily able to negotiate for entry (three PSC managers, interview, March 20, 2017). Indeed, a company B officer noted that at site B the minerals are located deeper in the earth (interview, February 6, 2017). At site B, he argued, they were more at ease before because the miners were always at site A. Recently, though, he explained, the disappearance of oxydés minerals at site A had led to an increase in the number of "attacks" at site B (three PSC managers, interview, March 20, 2017). Indeed, according to one miner, at site A there isn't a lot of work available for miners now and security is at times reinforced, so miners tend to head to site B instead (two miners, interview, March 16, 2017), an account corroborated by a PSC manager (three PSC managers, interview, March 20, 2017). This factor demonstrates a link with the particular stage in the life of the project, a factor highlighted by a civil society representative as explaining company behaviour (interview, August 11,2016).

Some miners move from site to site (company B officer, interview, February 6, 2017; two miners, interview, March 16, 2017; two miners and their mother, interview, March 31, 2017; miner and his wife, interview, March 31, 2017), though not all are willing or able to do so (miners, group interview, April 3, 2017). As a company A manager explained, when a 
mine is installed somewhere, there is electricity and people come to live in the area, which is what happened at site A (interview, September 22, 2016). A company B officer described how, in the early days when the company was removing artisanal miners from its site, there were 2500 or 3000 miners at the beginning of the process, but by the end of the clearing process he had to organise the departure of 4000 or 5000 miners, some of whom came from site A when that site was cleared (interview, February 6,2017). If there is a site with a bit of "freedom", miners travel there from many areas (three traders and a former miner, interview, February 4, 2017). One interviewee concurred that at site C, a very large concession, many miners come from elsewhere to work. The respondent said that in Lubumbashi there are people from the community, but also from Maniema, Kolwezi, Likasi, and elsewhere who have settled there. Two brothers I interviewed on the outskirts of Lubumbashi were born in that part of the city, as was their mother. Their family's origin, however, is Bukavu, South Kivu, in eastern DRC (two miners and their mother, interview, March 31, 2017). The number of miners at site $\mathrm{C}$ reportedly mushroomed from between 5,600-6,300 in 2016 to 12,000 or 13,000 in 2017 (university researcher, interview, March 29, 2017). As a police official explained, if other ASM sites open up in the surroundings of Lubumbashi, the number of people mining clandestinely may decline. Otherwise, he said, they go in large numbers to the LSM site near where they live, and call friends (interview, February 18, 2017). A miner who goes to sites $\mathrm{A}$ and $\mathrm{C}$ reported that the team with which he works in concession $\mathrm{C}$ lives in Lubumbashi, but has pits at site $\mathrm{C}$, and goes back and forth. Many miners have left the Lubumbashi area for site $\mathrm{C}$, where there are lots of visible minerals (miner and his wife, interview, March 31, 2017). One miner used to work at site B but stopped in 2016 and went to site $\mathrm{C}$ after one of his friends was bitten and killed by a dog at site $\mathrm{B}$ (two miners and their mother, interview, March 31, 2017).

Yet not all miners have the same mobility if they can't get access to a mine site in the area where they live. If a miner moves elsewhere for a significant length of time, he may not be able to get money to his family. Some leave Lubumbashi to go work at site C, but reportedly not many. Many of the miners who operate at sites A and B live in the area, even if not from there originally (miners, group interview, April 3, 2017). A police official deployed at site A distinguished between artisanal miners who do not go far from their families, and those willing to travel $300 \mathrm{~km}$ away from the Lubumbashi area and send money to their families. Most of the miners arrested, he said, are always the same ones (interview, February 18, 2017). 


\subsection{Conclusion}

In this chapter I sketched out and examined the implications of mine site governance for conflict incidence. I argued that conflict incidence at and around LSM sites falls along two key fault lines linked to the functioning of the property rights regime: first, at the intersection of the corporate extraction and (un)authorised clandestine facets, and second, of the authorised and unauthorised clandestine components. Understanding the complex structures and realities in which miners are embedded and that regulate how artisanal extraction occurs within LSM sites can help inform policy in this challenging area. The involvement of the security forces in clandestine extraction is not incidental but co-constitutive. They aim to profit as much as possible from clandestine extraction - a fact that influences conflict dynamics at and around LSM sites. I have also made the case that LSM companies fundamentally co-create the property rights regime, which includes the clandestine extraction facet. To a significant extent, the interests of the security forces and of companies align even if we would expect them to be in opposition.

The frequent occurrence of conflict, including arrest or physical clashes, reflects factors including the large number of miners, which at times makes them difficult for security to control and complicates the security forces' efforts to keep the market at an acceptable level of (c)overtness, as well as closed to those who do not pay for access. Conflict dynamics also reflect miners' anger and the persistence of their claims in the face of efforts to control and exploit them, and to strictly regulate when and how they enter LSM sites, again with the aim of keeping clandestine mining covert. Multiple respondents in southeastern DRC emphasized artisanal miners' aggressive behaviour and responsibility for conflict. This focus is no coincidence given that companies rely on state goodwill, cooperation, and legitimisation to operate undisturbed. It's easier for companies and other actors to point the finger at artisanal miners rather than the authorities and guards that facilitate their access, though the security forces' involvement is well known. Emphasizing the role of ASM miners in spurring LSM-ASM conflict downplays the fundamentally political, state-sanctioned nature of clandestine mining. The way the property rights regime operates contributes to the enforcement of companies' property rights - which also serves the interests of the central government and its local/regional representatives - and provides access to rents from the clandestine sale of minerals from LSM concessions. These rents benefit local elites but are also passed up the chain in keeping with the system of rapports in a centralised system. Companies, I argued, benefit from the governance of authorised clandestine mining by the 
different security forces. At times, however, the security forces crack down on miners' presence, at the cost of miners' physical safety and/or financial well-being.

While some of the evidence suggests that companies don't benefit from disproportionate acts of violence, particularly killings, and seek to cut down on such acts (some more than others), these firms are aware of, instrumental to, and complicit in how the public and private security forces engage at LSM sites: a combination of collaboration and repression. Companies benefit from this engagement: they are able to continue their profitmaking activities on a day-to-day basis, with few serious disruptions to their activities. Arguably, more than any CSR activity undertaken in the area, (un)authorised clandestine mining allows for LSM in the region to remain socially and economically viable. Artisanal miners and unarmed security guards are the most vulnerable in terms of physical injury and loss of life, as well as financial costs and the lost time and livelihoods linked to time in prison. Yet the price of putting a stop to these dynamics would be even greater, and most miners are not prepared to cease entering LSM sites. The trade-off between physical and financial risk is one that they understand all too well and miners makes their - highly constrained - decisions in light of these risks.

Despite the frequent conflict at and around LSM sites, the situation is unlikely to change anytime soon. The large-scale repression that would be necessary to permanently clear miners from LSM sites is impossible given the human rights implications, including for miners' social and economic rights. There are too many miners, with many dependents, and too few viable or desired economic alternatives. Until the minerals are gone, which, in the case of site $\mathrm{C}$, may not happen for 100 years or more (community relocation consultant, interview, March 25, 2017), the lure of large profits will keep companies investing. If one LSM buyer leaves, there will always be another as long as there are profits to be made, as recent changes of ownership at sites $\mathrm{C}$ and $\mathrm{B}$ demonstrate. Unless a force majeure political event takes place, such as renewed civil war, the daily pressure linked to the presence of large numbers of miners is not sufficient for companies to down tools. Yet conflict is likely to intensify as the minerals at smaller sites like A and B are exhausted in the next 10 years or so, and miners are forced to move to LSM sites that are still producing.

These realities also have an effect on the distribution of resource access at the local level. As I show in the following chapter on distributional outcomes, the dynamics I have presented above also impact the distribution of (access to) economic resources as well; once again, artisanal miners benefit the least. It is vital for policymakers to understand and take into 
account the distributional consequences of the property rights regime at and around LSM sites in the region. 


\section{Chapter 8: Distributional Impacts of Property Rights Regime Dynamics at and Around LSM Sites}

\subsection{Introduction}

When it comes to the broad category of mining governance at and around large-scale mining sites in southeastern DRC, the previous chapters described the existence of a plural property rights regime at the case study sites. As shown, the functioning and interactions of the PR regime's multiple components give rise to a range of conflict dynamics resulting from overlapping claims to resource access, and their incomplete or selective enforcement in different situations coupled with, at times, highly repressive enforcement. Yet conflict outcomes are not the only consequences of the interactions of the different facets of the property rights regime at and around the selected sites.

Large-scale mining's characteristics complicate local people's ability to benefit. These include the non-renewable character of mineral resources; the fact that this type of extraction is capital- rather than labour-intensive (Gilberthorpe \& Banks, 2012; Banchirigah, 2006); its short production chain, which limits the associated economic and social linkages (Gilberthorpe \& Banks, 2012); and the fact that only a limited share of the revenues from large-scale mining tends to reach communities in rural areas (Banchirigah, 2006; Frederiksen, 2019). The selective enforcement of LSM companies' and other actors' property rights and claims also has consequences in terms of the distribution of (access to) resources for those involved in or reliant on artisanal and small-scale mining for income. This chapter highlights the consequences, in terms of the distribution of resource access and resources at the local level, of overlapping claims and their incomplete enforcement. While much of the literature on LSM-ASM relationships focuses on conflict, examining conflict alone is not sufficient to shed light on equity and fairness considerations. The distributional impact at the local level of the interaction between the different components of the PR regime - corporate enforcement and authorised and unauthorised mechanisms for clandestine extraction - is particularly important given high poverty rates and extreme inequality in this region renowned for its mineral riches.

This chapter considers several questions: First, which actors are able to successfully assert their claims to resource access, how, and to what extent? Second, what are the distributional impacts of the PR regime associated with LSM investment, specifically the enforcement of companies' property rights as well as of other actors' PR and claims including those of weaker parties like artisanal miners - at the local level? LSM has much 
broader distributional consequences for local communities, but the focus in this chapter remains those who rely, directly or indirectly, on ASM at sites now occupied by companies.

In keeping with the bundle of rights discussed earlier in the presentation of property rights theory and how it has been applied in parts of the Global South, when I talk about the distribution of resources I cast a wide net, focusing principally on mine-site access but also on resources like minerals and money. As discussed in the theory chapter, Ribot and Peluso (2003) engage with property rights theory but move in a different direction, though there is significant overlap with the PR theory literature. The authors talk about access to natural resources; Geenen and Claessens (2016) apply Ribot and Peluso's theory of access, specifically with respect to access control, to gold mining in eastern DRC. Therefore, access to mine sites and resources is an appropriate lens through which to examine distributional outcomes at and around the case-study sites in southeastern DRC. Here, resources encompass not only copper and cobalt in their raw, unprocessed form, but also the different rents that actors derive from these resources.

In this chapter I argue that the extent to which miners are excluded from different mine sites is an outcome of the shifting and dynamic interactions between the different facets of the property rights regime. In turn, the extent of this exclusion is a major factor when it comes to distributional impacts for artisanal miners and their communities. I first consider the distributional dynamics aligned with each facet of the property rights regime in turn, including by assessing the impact of different companies' security practices. I examine the impact of these property rights regime dynamics in terms of artisanal miners' and other actors' exclusion from mine sites and resource access more broadly, and the associated resource distribution. As noted in the literature review, the dispossession associated with LSM - i.e. the corporate enforcement facet - has been well documented (e.g. Geenen, 2014), as have the distributional impacts of clientelist practices in resource extraction. A key aim of this chapter is to assess the distributional outcomes associated particularly with the latter two facets of the PR regime - authorised and unauthorised clandestine extraction - as each one interacts with the other components of the regime.

Exclusion is not the only factor that impacts on the distribution of resources. Even when artisanal miners do gain access to LSM sites, the financial payments built into systems and processes of clandestine extraction drain resources from miners and other actors including traders, drivers/transporters, landowners, miners' family members, and others. These payments include rents in cash or in kind for the security forces and other actors who give miners access, and for actors outside LSM sites who demand payment in exchange for 
allowing the transport of minerals to points of sale. Yet a key argument in this chapter is that arrangements and processes for clandestine extraction, whether authorised or unauthorised, should not be reduced to negative dynamics like corruption, clientelism, or neopatrimonalism (Olivier de Sardan, 2008). These dynamics, while unquestionably exploitative, have some positive implications in terms of local resource distribution.

The functioning of the property rights regime at and around the selected LSM sites means that overall, certain groups of people tend to be the "winners" in terms of resource access, while others do comparatively worse and even lose out on resource access they previously had. Companies benefit the most, given not only the fast pace of industrial extraction and processing at their sites but also the generous taxation provisions granted to them under the 2002 Mining Code. Members of the different security forces, especially the Mine Police, benefit from corporate enforcement, not only through company payments, benefits, and bonuses, particularly at higher levels, but also by confiscating minerals from artisanal miners and traders. The security forces also gain access to resources through their involvement in authorised clandestine extraction, specifically rents they receive for granting access to LSM sites. Some local chiefs benefit both from corporate enforcement and authorised clandestine extraction, while some struggle to obtain rents from the large numbers of miners from elsewhere who do not necessarily recognise their authority. Actors in relatively prominent roles, like representatives from the artisanal miners' cooperative EMAK, have also lost out along with the disappearance of the basis for their authority, having been cleared from sites for which artisanal miners used to pay the cooperative for access. Other winners include the mainly Chinese but also Lebanese and Indian buyers who purchase raw ore, which highlights the salience of ethnicity when it comes to the distributional impacts of ASM. Lower-level traders, including female traders, have also struggled.

I first describe the processes through which local communities in general, and artisanal miners and traders specifically, were stripped of their resource access - which in some cases has been further eroded over time - after the arrival of LSM companies. I then move to a comparison of different sites' security practices, specifically neighbouring companies A and $\mathrm{B}$, and the distributional impact of these differences. Next, I discuss reported changes when it comes to exclusion in the Lubumbashi region especially, and the impact of these changes on the distribution of access to resources. The next major section deals with the distributional impact of authorised clandestine extraction, particularly when it comes to payments for entry, exit, transport, and protection. I devote a section to a discussion of barriers to entry and how, even with its multiple obstacles, challenges, and risk, authorised clandestine mining still 
represents a relatively accessible means, for artisanal miners, of earning a living. In the second-to-last section of the chapter I consider the distributional impact of unauthorised clandestine extraction. I conclude with some implications for policy and future research.

\subsection{Distributional Impact of Corporate Enforcement}

I first turn to an assessment of the distributional impact of the property rights regime associated with LSM investment at the case-study sites in southeastern DRC, specifically the enforcement of LSM companies' property rights in addition to other actors' PR and claims.

\subsubsection{Dispossession of Communities by Companies: Initial Clearing by Mining Companies and}

\section{Ongoing Impacts}

As the DRC emerged from war, private mining companies began to invest in the southeastern part of the country in the early- to mid-2000s, occupying concessions and dispossessing communities, artisanal miners, and traders (Geenen, 2014). Yet to understand the distributional impact of the property rights regime co-constituted by LSM, it is necessary to go further back in time. Lubumbashi was founded in 1906 (Dibwe dia Mwembu, n.d.). Mining has shaped Lubumbashi for a long time: one respondent argued that Gécamines created Lubumbashi (community relocation consultant, interview, August 9, 2016). Mine sites $\mathrm{A}$ and $\mathrm{B}$ were then one site. The Belgians brought labour in from the Kasai region, as well as Tutsis from Rwanda, to work in the industrial mines (civil society representative, interview, August 9, 2016; community activist, interview, October 21, 2016). In the 1970s Zaïrianisation took place in the sector. What was known as the phénomène Bulongo (Bulongo phenomenon - Bulongo means «terre ») arose later, after the decline of state-owned mining entreprise Gécamines, when artisanal mining appeared as people began to dig for minerals (civil society representative, interview, August 9, 2016). Gécamines workers themselves began sending people into Gécamines concessions and mine sites to collect minerals (civil society representative, interview, August 22, 2016). Several respondents cited 1998 or thereabouts as the year in which ASM began in earnest, after Congolese President Laurent-Désiré Kabila urged people to make a living in this manner (miner, interview, March 21, 2017; two sociocultural association representatives, interview, April 12, 2017; community activist, interview, October 15, 2016; EMAK representative, interview, February 1, 2017). After the fall of the diamond industry in the Kasai region, more Kasaians came to the Katanga region. In 2002, following liberalisation and privatisation of the mining sector, it was no longer just stateowned Gécamines that was involved. The industrial-mining sector and large mining 
companies - to which several interviewees referred to as "miningi" in Swahili or "mining" in French - materialised at this point (civil society representative, interview, August 9, 2016; community relocation consultant, interview, August 25, 2016; land chief, interview, September 2, 2016; two company C officers, interview, September 27, 2016; group of miners, interview, April 3, 2017). A company A manager used "mining" to refer to the whole mining process, from the mine to transformation into commercial products, namely copper/cobalt "cathodes" to cobalt hydroxide. He compared artisanal mining to a gold rush, explaining that Gécamines had trouble preventing miners from entering these sites, and that the miners had to be “demobilised" (interview, September 22, 2016).

Gécamines and other state-owned enterprises did a great deal for the community in terms of social initiatives and taking care of their workers (civil society representative, interview, September 2, 2016; civil society representative, interview, August 22, 2016; company A manager, interview, September 22, 2016). If a customary chief got sick, he was treated at the Gécamines hospital; he also received a monthly stipend and a travel ticket. Gécamines, too, sponsored traditional ceremonies. In one respondent's view, the population of the village sees a little Gécamines where they live (civil society representative, interview, September 2, 2016). A company A manager who had a parent who worked for Congolese national rail was able to attend the company school and hospital for free (interview, September 22, 2016). There is a common perception that the way things used to be done was much better: Gécamines looked after its employees and the wider community very well, whereas multinational corporations don't look after people, especially communities around their mine site, nearly as well (civil society representative, interview, September 2, 2016). Corruption in the signing of mining contracts is also a problem, as demonstrated by cases like Glencore's ${ }^{36}$ investment in the DRC and the controversy over the involvement of businessman Dan Gertler, who used his links with the government to makes money from state assets (civil society representative, interview, September 2, 2016; Tokar, 2019). Government bodies and the justice system in the DRC tend to have limited capacity to monitor and enforce Congolese laws including environmental legislation. Additionally, the centralisation of politics and economics in the DRC, coupled with the LSM sector's importance for the central government's budget, means that mining revenues tend to benefit the centre rather than the copper- and cobalt-mining regions. The redevances - what mining companies pay to the state and that are supposed to be redistributed among different levels of government - are not paid

\footnotetext{
${ }^{36}$ Glencore is not one of the companies chosen as a case study for this project.
} 
at the local level where the minerals come from, but rétrocédées (transferred later) (civil society representative, interview, September 2,2016$) .60 \%$ is paid to the public treasury for social administration, while $40 \%$ is supposed to come back to the province: $25 \%$ for provincial administration and $15 \%$ for the territory, to support infrastructure and more (government official responsible for mining, interview, August 29, 2016; company C representative, interview, August 11, 2016). Several respondents raised the issue of irregularities in how much-needed funds are transferred to the local level (civil society representative, interview, August 22, 2016; civil society representative 1, interview, August 23, 2016; civil society representative, interview, August 27, 2016; civil society representative, interview, September 2, 2016; doctoral candidate, interview, February 1, 2017).

When the state signs LSM concessions over to companies, there is a major impact on local communities' land. Congolese legislation - la loi Bakajika - emphasizes the sovereign's ownership of the sol et le sous-sol (ground and underground) (doctoral candidate, interview, February 1, 2017). The dispossession of land has occurred despite the existence of empires and the fact that the land belongs to villagers for whom it is the land of their ancestors. When granting mining rights the state takes little notice of the claims communities have to these lands. Most of the mine sites in the provinces of Haut-Katanga and Lualaba have been sold, and communities may continue to be moved (civil society representative, interview, September 2, 2016). Pollution from LSM companies also affects local people's livelihoods, while blasting for minerals causes damage to homes. A respondent from a local socio-cultural association for what Gobbers (2016) refers to as a local "ethnic community" linked the population's deprivation to pollution by company $\mathrm{C}$ without financial compensation, as well as to the destruction of the mountains. He also mentioned delocalisation (displacement) as a big problem, with people being moved towards lands that are not rich (two socio-cultural association representatives, interview, April 12, 2017). A number of respondents also expressed expectations vis-à-vis LSM companies in terms of employment (village chief, company-sponsored workshop, August 12, 2016; land chief, interview, September 2, 2016; two socio-cultural association representatives, interview, April 12, 2017; former EMAK official, interview, February 1, 2017). One of the socio-cultural association representatives argued that company $\mathrm{C}$ hired people who have studied and gave them indeterminate contracts, while those from his ethnic community only got short-term contracts. The claims the sociocultural association makes vis-à-vis company $\mathrm{C}$ include hiring people from that community. There is a widely held belief in the area that the company unfairly favours people from other areas when it comes to hiring, particularly those living in cities (two socio-cultural association 
representatives, interview, April 12, 2017; university researcher, interview, August 13, 2016). Company $\mathrm{C}$ employs about 3000 people, of whom 95\% are Congolese (land chief, interview, September 2, 2016; civil society representative, interview, February 9, 2017; company C promotional materials). Company A employs about 2000 (company A manager, interview, September 22, 2019). While significant numbers on the face of it, many more people are employed in, or provide complementary services to, ASM.

At a workshop sponsored by a different company (not one of the case-study firms), a representative of a school the company built in the village mentioned that the school covers primary education only: there is no secondary school. The children, the representative noted, don't have any other occupation, so they enter the mine site, or are sent by adults, for something to live on. He noted that the company educates a small number of children, but the vast majority are left behind. He urged the firm to build a secondary school so children don't enter to mine any more (company-sponsored workshop, August 12, 2016). One of the representatives from the socio-cultural association active in company C's concession also spoke about children not in school. The representative argued for good schools, universities, and centres for women's empowerment. The association also has the objective of ensuring the fulfillment of the company's stated objective to spend a certain percentage on local social initiatives, as well as advocating for the rights of customary chiefs, including material support for their families. According to him, company $\mathrm{C}$ produces more than Gécamines did but does less for the population. He added that the company is responsible for the fact that there are creuseurs, given the lack of training and education, though the company did create a training school (two socio-cultural association representatives, interview, April 12, 2017).

Expectations at the local level in the post-Gécamines period are very high.

Communities therefore see themselves as having claims on LSM companies' resources, which firms argue are limited. Communities have significant expectations vis-à-vis LSM companies in terms of children's education and other areas, while companies view many of these claims, precisely because they are so high and because the Congolese government does so little, as impossible to meet.

It is not, however, the case that no one from local communities benefits from LSM investment. As noted, LSM companies draw on local chiefs to achieve their objectives and ensure smooth operations. Chefs coutumiers (customary chiefs) are important authorities in contact with much of the population in rural areas - though the situation is evolving including in company $\mathrm{C}$ 's concession, where there are several chiefs including chefs de groupement, chefs de terre, and chefs de village (doctoral candidate, interview, February 1, 
2017). A civil society representative argued that certain chiefs put their own needs above those of the community, such as in wanting a $4 \times 4$ vehicle or a house (interview, September 2, 2016). Companies also tend to approach chiefs if they are seeking to hire a number of people, for example 100, to do manual work (doctoral candidate, interview, February 1, 2017). A prominent land chief whose lands are in company C's concession used to work for company $\mathrm{C}$ before his grandfather died and he became a chief, though it was perceived to be a conflict of interest between the company and traditional authority (community relocation consultant, interview, March 25, 2017; land chief, interview, September 2, 2016; two socio-cultural association representatives, interview, April 12, 2017). When I interviewed him, he was no longer working for the company. The company also built the land chief a house, though he was not satisfied with the windows they put in (land chief, interview, September 2, 2016; land chief, interview, February 28, 2017).

Interviewees had a favourable opinion of company $\mathrm{C}$ compared to other companies; one person described the firm as a "better model" of how a company should behave, particularly with respect to CSR (civil society representative 2, interview, August 23, 2016). My interviews and site visits to company C's concession, during which I saw different community initiatives and structures implemented by the company, provided support for this positive view. Several respondents mentioned that unlike other firms, the company sets aside " 0.3 percent of net revenue from the production sales $[\ldots]$ to create an investment fund for agriculture and social development in the area" (Kumwamba \& Simpere, 2008, p. 14), as per its convention with the government (civil society representative, interview, August 11, 2016; civil society representative 2, interview, August 23, 2016; civil society representative, interview, February 9, 2017). To this end, the company has a community social fund (civil society representative, interview, August 11, 2016), with its funds kept in the U.S, reportedly 14 million to date (civil society representative 2, interview, August 23, 2016). Company $C$ has implemented a number of CSR initiatives in the community around the mine site and within the concession, including building a hospital at $\mathrm{C} 1$ (two company $\mathrm{C}$ officers, interview, September 27, 2016) and a health centre at site C3 (journalist, discussion, March 9, 2017), both of which I was able to visit. The company has donated Jeeps (through their Fonds Social) for hospital use as part of the site $\mathrm{C} 1$ health zone (site visit, September 27, 2016). The hospital is for company employees but according to two company $\mathrm{C}$ officers, people from the cité go there too (interview, September 27, 2016). At C4, a village on the main road in company C's concession, the company had installed a water well/pump (village chief and multiple village residents, interview, April 11, 2017). As discussed in the research puzzle chapter, companies 
A and B are much less favourably viewed on the CSR front and have poor reputations (particularly company A) when it comes to minimising the negative effects of industrial mining.

\subsubsection{Dispossession $\underline{37}$ of Actors in the Artisanal-Mining Supply Chain}

I now turn to the situation of actors in the artisanal-mining supply chain. Artisanal miners and traders were two of the groups dispossessed when LSM companies occupied concessions in southeastern DRC. With the arrival of the late president Laurent-Désiré Kabila, miners were able to enter mine sites, including in the Lubumbashi region, relatively freely, until as late as 2006-2007 (miner, interview, March 21, 2017). In 1998 Laurent-Désiré Kabila's government asked Gécamines to put some quarries at the disposal of artisanal miners. Tens of thousands of miners piled into these sites; different actors put into place a supply chain for marketing heterogenite (ore rich in cobalt); and the construction of smelters and hydrometallurgical plants took place. At first, businessmen of Greek and Indian origin already operating in the country set up these factories. In the mid-2000s, Chinese entrepreneurs who had migrated to the country began building small facilities for processing in different parts of the Copperbelt. Some of these businesses still buy heterogenite from traders, artisanal miners, and dealers, while Indian and Chinese-owned entreprises of medium size do semi-industrial or industrial mining (Rubbers, 2019). A Chinese mining company in the Lubumbashi region (not one of those in the study), for example, also buys minerals from traders (representative of a Chinese mining company, interview, August 22, 2016; three international NGO representatives, interview, August 31, 2016). As a former EMAK representative explained, he was there at the beginning when EMAK was created, in 1999. He and 18 others were extracting copper, including malachite, as well as heterogenite, in the Lubumbashi region (EMAK representative, interview, February 1, 2017). Malachite is a "green copper carbonate hydroxide mineral" (King, n.d.) commonly used by local artisans/sculpters to make objects for sale, particularly to tourists: there is a malachite market not far from site B. The EMAK representative and his associates would enter the Gécamines mine site at night and extract minerals, which they then sold in an (as he called it) "illicit, unofficial, and clandestine" manner. They decided that it would be better to become officialised, particularly after being arrested in 2000 or 2001. The EMAK officer and his colleagues wrote to the president of the republic, who told the former Minister of Mines to ask

\footnotetext{
${ }^{37}$ I came across this term in the context of LSM-ASM conflict in Geenen (2014).
} 
them to conduct a census. He said that they came to a total of 34,000 artisans and creuseurs and put in a request: that's how EMAK was born and started selling products to expatriates (interview, February 1, 2017). Since Joseph Kabila took power and sold concessions here and there, miners do not work freely, but enter by "fraud" (miner, interview, March 21, 2017; former EMAK representative, interview, February 1, 2017).

As noted, the clearing of miners from company A's site was violent, with multiple injuries and deaths (miner and his wife, interview, May 31, 2017; miner, interview, April 3, 2017; journalist, interview, April 12, 2017; community activist, interview, October 15, 2016; former EMAK representative, interview, February 1, 2017). Some respondents alleged that company A did not provide compensation (community activist, interview, October 15, 2016; journalist, interview, February 7, 2017; journalist, interview, April 12, 2017; miner and his wife, interview, May 31, 2017; miner, interview, April 3, 2017). According to a former EMAK representative, however, the company did provide $\$ 25$ and two sacks of flour for each miner. He said that it was supposed to be more, but that SAESSCAM misappropriated some of the intended compensation (interview, February 1, 2017). It should be noted that as a competing agency during the miner removal process, an EMAK representative has an incentive to portray SAESSCAM in a negative light.

Company B reportedly learned its lesson from the violent eviction of miners at site A, so it paid each miner 200 USD to leave (local government official, interview, October 26, 2016; trader/miner, interview, February 14, 2017). The removal of miners from site B was reportedly more peaceful than at site $\mathrm{A}$ as a result of this decision (miner and his wife, interview, May 31, 2017). The $\$ 200$ the company provided to artisanal miners and traders in exchange for them leaving was very limited compared to the potential future income stream from mining. Nonetheless, miners' departure from site B was relatively peaceful after a transitional period of over a year, in which regular meetings were held to explain the situation to the miners, and after the financial compensation was paid to each miner. This compensation was, however, less than the $\$ 500$ per miner that the miners originally wanted (former EMAK representative, interview, February 1, 2017). Even $\$ 500$ per miner is a very low amount for leaving such a highly mineralised site and shows miners' relative lack of information about the richness of the deposit (compared to the company) as well as their limited bargaining power. As a company B official reported, on the agreed date, they prepared a file to identify the miners. Each miner got a badge with a photo. People displaced at company A and from a third site, he said, had also come to "invade" their site, so the company identified 2500 miners who were there from the beginning (interview, February 6 , 
2017). ${ }^{38}$ The company therefore divided the population of miners into those eligible for compensation and those not - "legitimate" miners and "illegitimate" miners - based on where they happened to be working. Yet all miners were being displaced and in need of compensation and support. The company official added that SAESSCAM (the government body responsible for artisanal and small-scale mining) and EMAK (a prominent artisanal miners" cooperative) wanted payment for the "success" of the operation. There was a ceremony at a restaurant and the members of the displacement committee were given thankyou bonuses (interview, February 6, 2017). A former EMAK representative involved with the operation mentioned that those who helped organise the miners' departure received $\$ 2000$ compared to the $\$ 200$ the miners got (interview, February 1, 2017). However, he presented a convincing argument for the company to pay him more than \$2000: he and the others, he pointed out, made it possible for the company to make much more money (former EMAK representative, interview, February 1, 2017).

After site B was cleared, according to a company official, some traders created small businesses selling sand or doing construction, which were still working with the company at the time of interview. Yet he mentioned only two or three such cases. Some artisanal miners were hired as day workers and were with the company for three or four years (interview, February 6, 2017). According to a former EMAK representative, 400 miners were taken on as day workers but not hired: not a permanent solution. Company B also reportedly asked EMAK for a list of artisanal miners who could be hired as security and hired at least 20. These employees, he explained, no longer work at company B, which hired people from other areas instead, typically on the basis of "recommendations" that he and the others on the committee did not have. He added that for all intents and purposes EMAK no longer exists (interview, February 1, 2017). His story demonstrates that some individuals may be able to use their prominent role to benefit from LSM investment, at least initially. Yet when the basis for their authority and income - including access to rich mining sites and the presence of many dues-paying artisanal miners - is taken away, their resource access may drop off, particularly for individuals who lack connections or are unable to play on their position.

Company $\mathrm{C}$ did not provide any compensation to artisanal miners, but just cleared them from the concession and told them not to return. As the company described in their questionnaire responses, "Artisanal mining activity within the [redacted] concession is considered illegal under the applicable DRC law, no compensation can be paid nor considered

\footnotetext{
${ }^{38}$ A former EMAK representative cited 5000 as the number of miners registered with EMAK who were to receive compensation (interview, February 1, 2017).
} 
strictly on this basis." (Company C questionnaire, April 17, 2017) Even at the mine acquired by company $\mathrm{C}$, which has a reputation for respecting human rights - but where no compensation was provided to the displaced miners - there were major clashes between artisanal miners and the company (Global Witness, 2006; journalist, interview, April 12, 2017; community relocation consultant, interview, March 25, 2017). A community relocation consultant contended that many of the miners displaced from site $\mathrm{C}$ started doing agriculture but noted that many more miners came to the site after that (interview, March 25, 2017).

The distributional impact in terms of loss of livelihoods and impoverishment of mineadjacent/mining communities, alongside corporate enrichment, is also linked to a shift away from LSM companies buying minerals from artisanal miners (civil society representative, interview, August 22, 2016). Company A purchased minerals from miners and traders for some time but stopped when the company started doing the extraction itself (company A employee, interview, March 30, 2017; trader/miner, interview, February 14, 2017, company A manager, interview, September 22, 2016). One trader/miner showed me his old trader card issued by company A and said that now «tous nous sommes par terre » [we are all on the ground] (interview, February 14, 2017). There were thousands of miners in company A's concession when the company occupied the site; the same was true of other sites, including $\mathrm{C}$. At site A, a company A employee explained, the artisanal miners worked for the Lebanese, and washed minerals for them. The minerals were sold in Zambia. For a time, starting in 2003, company $\mathrm{C}$ used these same miners for semi-artisanal extraction. The miners sold the minerals to the company as the priority buyer. In 2006, company A embarked on full mechanisation (company A manager, interview, September 22, 2016).

The problem is not so much the loss of markets as the loss of supply: Chinese buyers and other nationalities buy minerals at points near barriers in company C's concession as well as at maisons d'achat in places like Kolwezi (journalist, interview, February 7, 2017; EMAK representative, interview, February 1, 2017) and Lubumbashi. Some companies only buy and process minerals extracted artisanally (civil society representative, interview, August 22, 2016). There are Chinese and Lebanese comptoirs that do not have associated mine sites, which means the minerals they purchase are often from LSM sites (mining consultant, interview, February 28, 2017; three PSC managers, interview, March 20, 2017; company A manager, interview, September 22, 2019). Overall - when copper and cobalt prices are high demand outstrips supply. Lubumbashi, one trader reported, is the "capital of the traders". There are not enough products available for those who purchase minerals clandestinely (three traders and an ex-miner, interview, February 4, 2017). More serious for miners and traders 
than the issue of buyers, then, is the removal of artisanal miners from LSM sites. Another factor is the decline of rich, easily accessible minerals, particularly at site A, which can be easily collected or mined in a clandestine fashion.

The clearing of the LSM sites also had a negative impact on women traders. Some women trade because according to local custom they are not allowed to go into the mines to dig for minerals (doctoral candidate, interview, February 1, 2017; two traders, interview, February 25, 2017); there is a common belief in the region that women can't go where miners extract minerals or the ancestors will get angry and the filon (mineral vein) will be lost (doctoral candidate, interview, February 1, 2017; civil society representative, interview, August 22, 2016). Buying and selling minerals is one of the ways women are able to profit from the mining sector (two traders, interview, February 25, 2017). The clearing of these sites presented serious difficulties for miners and traders seeking sites where they can (safely) work, and many have exhibited exceptional perseverance in doing so. A woman trader stopped buying at site A when the company chased away the traders and miners. From 2006 onwards, she left for a site called Kawama. From 2010 she stopped buying minerals for a time, since a company had occupied Kawama too and sent the miners away. In 2016, she tried to go to a site in the region of Kolwezi, the capital of Lualaba province. When that attempt did not work out, she returned home. She also went to Whisky (a mine site along the road to Zambia that was artisanal for a time) in 2016 to buy cobalt. At the Lupoto site she went to once, the Mine Police said a company had occupied the previously artisanal site and took all her minerals. At the time of interview, she was not buying due to lack of money. She added that some traders keep samples at home to remember the "good times". The woman's son had been a miner since 2005, at sites A and B. After the miners were excluded from site A, he went to Lupoto for a few months. When that did not work out, he returned to Whisky. He started to return to site A in 2015 because there are no other sites to go to (miner and his mother, interview, February 27, 2017). When an LSM company takes over a mining site, female traders are not the only women who lose out. Wherever there is artisanal mining, women - some of whom are miners' wives or girlfriends - are there too selling food and drinks or running restaurants. Even though women can't access the actual mine site, they crush, sort, and wash minerals in exchange for payment (Mine Police official 1, interview, November 8, 2016; doctoral candidate, February 1, 2017). Sexual services to artisanal miners are another means through which women can make money.

When miners are arrested, they or their families - often their mothers - often have to pay to get them out of detention or prison. As noted, miners may have to pay an informal 
(non-official) 50,000 Fc fee to the police and/or Industrial Guard if caught at site C, or face time in jail (ex-trader, interview, February 17, 2017). One mother of two young miners, as noted, had to pay $\$ 150$ to the head of the children's tribunal in 2014 for the release of her miner sons, one of whom was arrested at site A. None of the traders with whom the miners work intervened. If a miner cannot pay and spends time in prison (two miners and their mother, interview, March 31, 2017), he is not earning anything from mining during that time, in addition to any amounts he or his family have to pay for support in, and/or release from, prison. The workshop discussion mentioned above suggests that many miners only serve a few weeks or months, but as noted, this comes at a cost. The mother whose two sons were arrested said that the tribunal fixed the price to pay, like a fine. They started with the amount of $\$ 250$ and, after negotiating, arrived at $\$ 150$. Leaving aside the question of whether these fees reach the Congolese treasury, the fact that miners have to pay them when the legitimacy of companies' property rights is in question highlights the distributional consequences and high costs, for miners, of the enforcement of these rights. If a miner and his family don't have the money to pay for his release, they have to borrow it, pushing them into debt. If the miner doesn't pay, he may be brought to the prison in Lubumbashi for three months (two miners and their mother, interview, March 31, 2017). One miner, arrested several times in 2013, raised the money to get out of prison through his side business of rearing livestock (miner, interview, April 3, 2017). As noted, miners with money and/or connections tend to be released more quickly: anyone lacking one or the other (or both) will spend longer in detention and not be able to resume work as quickly.

Despite the link between high unemployment and artisanal mining in their concessions (two socio-cultural association representatives, interview, April 12, 2017), LSM companies typically reject the legitimacy of miners' claims. At the August 12, 2016 workshop in Lubumbashi, a company $\mathrm{C}$ representative argued that the security issues companies face are often linked to the presence of artisanal miners who should not be at LSM sites, but should instead be in zones d'extraction artisanale (artisanal extraction zones, the ZÉA). The representative argued that the state services responsible for artisanal mining have to find a solution to get the miners out of LSM sites, so they can be directed towards the ZÉA. However, as noted, these ZÉAs largely do not exist yet while the few that the state has granted are not rich. Mineral extraction at those ZÉA is very difficult for artisanal miners given that the rich seam is sometimes at 60 metres in depth (participant, company-sponsored workshop, August 12, 2016; civil society representative 2, interview, August 23, 2016). Therefore, distributional outcomes are linked to deficiencies in the availability of artisanal- 
mining zones and to the lack of other livelihood options for miners, in a context in which the vast majority of concessions have been turned over for LSM companies' sole use.

Several respondents asserted that the governor of the province of Lualaba, as recently as November 2016, has promised artisanal miners in company C's concession that they will be given their own hill(s) to mine (journalist, February 7, 2017; village chief and multiple village residents, interview, April 11, 2017; two socio-cultural association representatives, interview, April 12, 2017; site C3 traders' committee member, interview, April 13, 2017). A trader even said that the governor delivered mines to the artisanal miners at site $\mathrm{C} 1$ and that the miners work freely (interview, February 14, 2017). The governor's comments suggest that artisanal miners do benefit from some support from authorities, even if it is just verbal support, and that central government interests do not always overlap with those of provincial authorities. Yet I found no evidence that these hills would be granted, or are actually in the governor's power to grant, particularly when it comes to hills in the company's concession. One respondent said that the governor wants to find the miners hills elsewhere, but argued that even then, the miners would remain in company C's concession (site C3 traders' committee member, interview, April 13, 2017).

A land chief in concession $\mathrm{C}$ contended that company $\mathrm{C}$ could manage the miners differently, and that these miners are the state's responsibility. He added that many of the more than 200,000 inhabitants of the main town within concession C came for work (interview, September 2, 2016). Previously, there were only 40,000 people living at site C1 (two company C officers, interview, September 27, 2016). Yet the company only employs 3000 people (land chief, interview, September 2, 2016). These dynamics highlight political figures' at times competing incentives. Political leaders like the governor need to appease artisanal miners through offering concessions that may not even be theirs to offer or that may be poorly mineralised, while they work in other ways to support companies' interests and the enforcement of their property rights. Pacifying the miners through such promises is a way to safeguard companies' PR.

The "autochthonous" / "non-autochthonous" divide is salient when it comes to distributional consequences of the PR regime. According to a land chief whose lands are in company C's concession, there were people digging within the concession before the company's arrival. However, while the miners did not arrive because of company $\mathrm{C}$, this tendency increased with the company’s presence. Many people came from Kasai, where nearly all the mine sites have been sold, the minerals are of poor quality, and soldiers guard the mines (interview, September 2, 2016). The local ethnic community, as discussed, views 
itself as losing out in terms of earning money from the mining sector. This grouping has indeed borne some of the costs of the presence of many miners from elsewhere within company C's concession, including destruction of company and community property, while many of the economic benefits like employment accrue to people from elsewhere. Yet members also benefit from the presence of large numbers of miners, including by renting homes or selling goods to them. A socio-cultural association representative said in an interview at site $\mathrm{C} 1$ that artisanal mining, not company $\mathrm{C}$, makes up the economy of the town (two socio-cultural association representatives, interview, April 12, 2017).

In terms of distributional outcomes, no matter where artisanal miners are from, in the wake of private, corporate takeovers of the state-owned mining concessions, these miners are at the mercy of company decisions and extraction processes. One miner reported that production at company A was good when a sub-contractor was actively extracting minerals there. Since that sub-contractor left, production isn't good anymore. He added that there aren't sufficient minerals, but that whatever the miners leave with is enough to feed themselves and for household needs (miner and his wife, interview, April 9, 2017). Given their limited authority and power - and the "taxes" they have to pay - the benefits miners receive from mineral extraction, both authorised and unauthorised clandestine, often only add up to subsistence rather than allowing them to invest for the long term (miner and his mother, interview, February 27, 2017; EMAK representative, interview, February 1, 2017), though some individual miners do better than others. One miner enters site A at night just to get what he needs to pay for his studies. He sells the minerals in the morning and goes to pay his school fees (trader and her miner son, interview, February 27, 2017).

A complete distributional picture includes not only the "losers" from the enforcement of corporate property rights, but also an assessment of who wins. Companies are the biggest winners overall from the current property rights arrangement, even in a context of significant clandestine mining and of recent commodity price fluctuations that have led some firms to temporarily cut back or suspend activities in the past several years. As described, each of the three companies - particularly company $\mathrm{C}$, given its concession size - extracts and processes a vast amount of copper and cobalt on a yearly basis. These firms gain a far bigger share than other actors at the local or national level (community relocation consultant, interview, March 25, 2017; Campbell, 2013). The distributional outcome at the local level and beyond also reflects the speed at which LSM companies empty concessions of valuable minerals. At the 
August 12, 2016 workshop, a participant pointed out that the mining company ${ }^{39}$ that organised the workshop could exhaust the mineral reserves at their site by 2024. Company A has a reserve of the type of minerals known as sulfurés that could last until 2034, though falls in mineral prices limit production and thus extend the life of the mine (company A exploration staffer, interview, October 19, 2016). Some of these companies' minerals will therefore disappear in the medium, rather than long, term. The land chief whose lands are in company C's concession pointed out that the company digs fast, and mountains are disappearing. Who wins? He asked. What are people losing? (Interview, September 2, 2016). After about 100 years - perhaps sooner, as the company sets a fast pace - the minerals at site C will all have been mined out (community relocation consultant, interview, March 25, 2017). Companies, with their machinery, are able to extract more minerals at a much faster pace than artisanal miners doing manual extraction (journalist, interview, February 7, 2017; company A manager, interview, September 22, 2016; community relocation consultant, interview, March $25,2017)$. Artisanal miners do not dig deep, or would do so with difficulty, because they would have to pump out water (company A exploration staffer, interview, October 19, 2016). Companies dig into the earth far deeper than artisanal miners can go - legally and in terms of technology - with multiple gradins (SAESSCAM representative, interview, August 19, 2016). Company $C$, with its enormous concession, does not face serious financial risk from clandestine mining, though they do complain because they see products leaving clandestinely (journalist, interview, February 7, 2017; company B security officer, interview, January 27 , 2017). As argued by Siegel in the discussion of the missing ethics of mining, the distribution of resources between artisanal miners and companies inevitably causes artisanal miners, whose access to LSM sites is heavily policed and controlled, to "lose" overall. While the DRC's mineral wealth is typically described in terms of abundance, the reality within the next century will shift to a situation of scarcity, with implications for the distributions of resources (and conflict).

As discussed, mine sites are interdependent in that miners move from site to site. This interdependence may help alleviate the negative distributional consequences of better enforcement and/or decreased availability of minerals at a given site. Thousands of artisanal miners are active within company C's concession, some of whom travelled from other sites given the site's relatively easy access (two miners and their mother, interview, March 31, 2017). If a miner sees that there's more money to be made elsewhere, he may move to a

\footnotetext{
${ }^{39}$ Not one of the case-study sites.
} 
different site (miner and his wife, interview, April 9, 2017). Miners are not just structurally disadvantaged and actively exploited, but also take advantage of the opportunities available to them. In line with the theme of solidarity between miners, some miners talk to each other and give each other tips. Artisanal miners therefore have the option of "exit" (Hirschman, 1970) if their tactics to gain entry to mine sites - paying for access or trying to circumvent the security forces - fail. Some miners travel among sites, like the many miners who have travelled to company C's concession, though as discussed, not all can or wish to do so. However, artisanal-mining sites have become scarce. Until durable solutions are found many miners will have no other option than clandestine mining at LSM sites despite the risks to their safety and finances.

Finally, different actors hired or contracted by the company to secure their concessions benefit financially from their involvement with the company. In addition to their salaries, Congolese and expatriate staffers working for company $\mathrm{C}$ are housed and fed at a camp at the mine site. Their clothing is washed and everything is provided (land chief, interview, September 2, 2016). Teams of Congolese National Police, particularly the Mine Police, who are deployed to LSM sites gain both through company payments and the opportunity to benefit financially from authorised clandestine extraction. The government pays the Mine Police at sites $\mathrm{A}$ and $\mathrm{C}$, but these companies also give them primes (bonuses) ${ }^{40}$. A Mine Police representative at site $\mathrm{C} 1$, and his second in command, are housed at the company base (though the other police officers are not) (interview, December 3, 2016; interview, February 7, 2017). A Congolese National Police representative explained that when he was at site $A$ as a Mine Police official, the company gave him the money to pay the police officers. However, there are differences between companies in terms of working conditions for the police. Having served both in the Mine Police at site A and for the Congolese National Police at C3, a PNC representative argued that the working conditions for police officers are better at company $\mathrm{C}$ than at $\mathrm{A}$, where at the time of his deployment, the police had to get around on foot. They also had to stay in tents [bâches] rather than in houses like at site C (PNC representative, interview, May 25, 2017). The 20 USD bonus that used to be paid to members of the security forces at site A, for each miner caught, is another example of corporate benefits. Other government actors also gain from company resources. A company A manager expressed the view that Moïse Katumbi, former governor of the province of Lualaba, personally benefited from the LSM sector through sub-contracting. His own personal

\footnotetext{
${ }^{40}$ However, a Congolese National Police representative spoke of these bonuses not as significant amounts, but as just enough for police officers to buy themselves soap (PNC representative, interview, May 25, 2017).
} 
businesses were able to benefit from these opportunities while, in this person's view, the exgovernor should have pushed more for Congolese people generally to get more contracts at the mines (interview, September 22, 2019). One local government official is part of the committee that gets together regularly to deal with the negative impacts of company B's use of explosives on the community's homes. The company used to provide collations (snacks), in addition to coming to collect the members and drop them off again in a company vehicle. However, with the financial crisis [the drop in the copper price], he said, the company stopped these benefits (interview, October 27, 2016). Like the cancelled bonus at company A, this example demonstrates that the incentives for supporting the enforcement of corporate PR are not fixed or static.

Miners have struggled to find other revenue-generating activities in a context of displacement by LSM and high pressure on land (particularly in heavily urbanised areas like Lubumbashi). Some miners have been, or are able to, move to sites that are still artisanal elsewhere in Haut-Katanga province or in the province of Lualaba. Yet the number of open artisanal sites - sites allocated to ASM - in southeastern DRC is becoming increasingly limited. Miners have been pushed from site to site in search of places where they can work (miner, interview, February 13, 2017). The importance of a relatively "open" mine site for miners in the Lubumbashi region (or indeed elsewhere) should not be underestimated and represents a more equitable distribution of resources between the company and the miners than a relatively "closed" site. However, in the Lubumbashi region - where miners often can't show up, without advance notice, to pay off a guard - miners' presence even at site A was being increasingly restricted as of February 2017. Miners were being told there was no work that day: the police would refuse the money and say it was not possible due to a patrol on duty. Previously, there was more freedom at site A, and more opportunities for miners to enter in collaboration with the security forces; it was not clear to miners what had changed (trader and her miner son, interview, February 27, 2017). A miner who works at site B said that since the beginning of March 2017 the police and PSC guards had been saying it wasn't possible to work properly at the site. He didn't know why (miner and his mother, interview, March 29, 2017). According to another miner in the Lubumbashi region, there had been a lot of arrests at site B recently, but again, he did not know why. Nor did he know why access had been restricted at the site lately (miner and his wife, interview, March 31, 2017). Another miner worked at site B in January and February 2017, but not since then because it was becoming difficult (two miners and their mother, interview, March 31, 2017). 
Yet the number of arrests reported cast doubt on the claim made by some mining company representatives that the artisanal-mining phenomenon is going away. At the end of March 2017, a Mine Police representative deployed at site A provided arrest figures for the past two years. In 2016, he said, the overall figure was 66 miners caught. In 2017, in just under three months, they had already caught 75 miners. He linked the rise in numbers to economic factors, including the rise in the price of cornflour imported from Zambia and the rising exchange rate with the dollar (second interview, March 24, 2017). Artisanal miners operating in LSM concessions and living on precarious incomes, as well as their dependents, will feel the impact of rises in the cost of living that much more.

\subsection{Distributional Impact of Authorised Clandestine Extraction}

\subsubsection{The Clandestine Mining Supply Chain and Payments for Entry}

As described, artisanal miners and traders have to pay a range of actors inside and outside the mine site, not only for site access but also in transporting minerals to sale points. Miners and traders incur significant costs and pay for every single privilege/right, including to access high-value minerals. A range of actors gain rents from multiple practices that include charging for entry; confiscating minerals and selling them rather than returning them to the company; and arresting miners in exchanges for company payments or bonuses. Different factors, as noted, affect the amount miners have to pay to gain authorised clandestine entry to LSM sites, including the particular LSM site. The amount I was told of $\$ 500$ for a group of ten miners just for entry in the Lubumbashi region is significant, particularly if miners don't find anything, yet the fact that many continue to return suggests that on balance, if not every single visit, they make enough to live on (doctoral candidate, interview, February 1, 2017). As described, miners typically pay more to access the high-value minerals. Miners can pay lower amounts for entry to sites where less-rich minerals are found, but that limits the value of what they can gather. At site C, the amounts for entry are much lower. Yet since miners often dig pits, it takes a long time before they can extract ore, sometimes months, during which time they have to be sponsored by a trader for food and other costs. According to one respondent, miners at site $\mathrm{C}$ who collect minerals at an extraction site, rather than digging pits, may enter as a team of as many as 15 or 20. Everyone takes on average 100 kilos: 100 kilos times 20 people is 20 tonnes. For two tonnes, they may make $600,800,1000$, or 1500 dollars (doctoral candidate, interview, February 1, 2017). As noted, in the Lubumbashi area it can cost as much 
as $\$ 500$ or $\$ 700$ for a group of ten miners. A kilo of malachite (a form of copper typically used for art and sculpture) sells for between $\$ 5$ and $\$ 10$. If miners leave the site with five sacks, they can earn $\$ 4000$ as a group (miner, interview, February 13, 2017). Yet the miners have to split the amount between them and with any traders who sponsored them, in addition to reimbursing the trader for any costs incurred in paying off security as well as for other expenses like food and boots (civil society representative, interview, August 10, 2016). During an interview with a LNI representative and a Mine Police representative a group of miners who were in the same bar said that a miner could earn as much as $\$ 200$ per day (March 20, 2017), but that figure is high if a miner can only carry about 100 kilos or less; the price of the kilo at the time was around 1300 Congolese francs per kilo and again, miners have to subtract what they paid for security. Nor are miners always able to collect as much as 100 kilos. At sites A and B, as noted, some miners mine simply for subsistence and the rich, easily accessible minerals are becoming exhausted. Miners also frequently have their minerals confiscated. One interviewee who works for company B said that the previous week, the company had stopped at least eight tonnes of minerals (company B employee, interview, January 27, 2017).

The social milieu and life challenges that many miners face also often lead them to spend the money they earn quickly, for example on alcohol or the services of sex workers (civil society representative, interview, August 10, 2016), which hinders their ability to save. Given that the amounts of money demanded by the security forces can be significant and that there are many miners, the sums add up. The security forces at site $C$ ask for 10,000 or 20,000 Congolese francs per miner. There are many miners (journalist, interview, February 7, 2017): estimates are as high as 12,000 or 13,000 (university researcher, interview, March 29, 2017). As a journalist described, in the main town in company C's concession, the "big bosses", the people with a lot of money, are the police, because of their involvement in clandestine mining. The category of "big bosses" also includes the territorial police, the PNC (interview, February 7, 2017) and members of the Congolese army, the FARDC (journalist, interview, February 7, 2017; two traders, conversation, April 6, 2017; two trotteurs, interview, April 13, 2017; site C3 miners' committee member, interview, April 13, 2017). The security forces make significant amounts of money allowing miners to operate at LSM sites, while the miners do the difficult and dangerous work of extracting the minerals. According to a Congolese doctoral candidate, each day, a police officer can leave site C with 100,000 Congolese francs or, for a two-day shift, 150,000 or 200,000 francs. A police officer can earn around 30,000 francs (just over 20 USD at the time of interview) from a single miner (doctoral candidate, 
interview, February 1, 2017). Relationships with traders, as discussed in the chapter on conflict, can be a way for artisanal miners to access more capital than what they already have or can earn through mining, to pay security or buy supplies and equipment. For different reasons, however, not all miners can or do enter into such relationships. In the Lubumbashi region, there are far fewer active traders than before the concessions were privatised. Typically traders wait for miners to come out with products, and pay at that point: a miner would need to use his own money to enter the site. Traders, as noted, also charge high interest (miner, interview, March 21, 2017; miner and his wife, interview, April 9, 2017; Sovacool, 2019).

Dissatisfaction with the price miners receive from the traders or maisons d'achat they sell to is a common theme. Traders are said to impose their sale price (village chief and multiple village residents, interview, April 11, 2017). One respondent argued that the current price offered by the traders was not good. He added, however, that the low price does not discourage artisanal miners. At site C3 (one of the main towns in company C's concession), the price for copper is 1300 per kilo. Cobalt does not get sold by the kilo, but by the pail. For a small pail, the price can be as high as 8000 Congolese francs. However, to fill that small pail in a day is difficult (two miners and their mother, interview, March 31, 2017). One trader at site C3 mentioned that miners are frequently already angry when they come to him, saying that they took risks at the mine site. The miner then wants to "impose" his price, the trader said, and if the trader offers an amount that is too low, the miners chase him away (two traders, interview, February 9, 2017). A miner who goes to site C prefers not to work with money from a trader but to sell the first minerals he and his team obtain. If he and his colleagues bring their own minerals to the maison of Chinese buyers in Kisanfu, they can make a better profit than by working with a trader (interview, February 17, 2017). Multiple interviewees also reported issues with the scales used to weigh the minerals by traders and buying houses alike (mining consultant, interview, February 28, 2017; village chief and multiple village residents, interview, April 11, 2017; journalist, interview, February 7, 2017; civil society representative, interview, August 10, 2016). Several argued that those who buy minerals "steal" both on the weight and on the mineral content of the minerals (former EMAK representative, interview, February 1, 2017). A Radio Okapi article from 2016 mentioned the issue too, noting that artisanal miners in the Lualaba region had been given a superior "Metorex" scale ("Les creuseurs artisanaux reçoivent", 2016). One respondent linked the purchasing of minerals at very low prices to the lack of competition: the owner of a concession where miners operate may demand that the miners sell to the owner (civil society 
representative, interview, August 22, 2016). In terms of distributional outcomes there is a big difference between the price for raw ore, at which artisanal miners sell their products, and even the relatively low price copper and cobalt concentrates fetch on the world market ("DRC bans cobalt, copper concentrate exports", 2019). Finally, the fact that Chinese especially, but also Indian, and Lebanese mineral buyers dominate the market in places like Lubumbashi, Kisanfu, and Kolwezi (SAESSCAM representative, interview, August 19, 2016; former EMAK representative, interview, February 1, 2017; civil society representative, interview, August 10, 2016; trader, interview, March 6, 2017; three PSC managers, interview, March 20, 2017; trader, interview, May 10, 2017) points to another area of salience of membership in an ethnic community when it comes to the distribution of resource access. It is therefore not just LSM companies who make significant profits when compared with "autochtonous" groups or local communities; buyers of different national origins do as well.

Miners' "illegal" status means that in addition to ASM miners' already low bargaining power, they cannot be represented in formal structures like the miners' cooperative EMAK (EMAK representative, interview, February 1, 2017). EMAK and other cooperatives are, as discussed, problematic and imperfect. Yet miners' lack of representation may contribute to their inability to bargain for better prices, increasing their reliance on informal mechanisms like negotiations with traders. Miners are similarly reliant on the discretion of others and on informal means - like the "miners' committee" at site C3, or just their own first-party strategies - to secure mine site access as well as financial support in times of need.

In keeping with the findings of this study about how traders benefit relatively more than artisanal miners, Faber, Krause, and Sánchez De La Sierra (2017) find, in a study of the cobalt supply chain in the region, that "overall miners appear to capture a significantly smaller price for their output than traders are paid further downstream in the supply chain of DRC." The authors conclude that

Artisanal miners living in the mining communities of the copper cobalt belt capture a relatively small share of the price paid for their output downstream. The price that miners receive directly for selling the most commonly traded cobalt purity to intermediaries in the supply chain is less than half, and potentially as low as $6 \%$, of the price-by-weight for the equivalent cobalt purity that traders farther down the supply chain obtain from their sale of the mineral to processors in the DRC" (p. 8). ${ }^{41}$

\footnotetext{
${ }^{41}$ The question of whether artisanal miners capture more or less of the price when working at LSM sites, compared to ASM sites, is important and merits research.
} 
Sovacool (2019) estimates, based on interviews in the region, that typical artisanal miners in the provinces of Haut-Katanga and Lualaba produce 30 to 50 kilogrammes of raw ore per day and earn between $\$ 1$ and $\$ 3$ daily, or $\$ 30$ to $\$ 50$ each month, which is considered to be a good monthly income for the area. Peyer and Maillard (2011) described still low, but higher earnings in the sector for artisanal miners: $\$ 3$ to $\$ 5$ per day, or $\$ 30$ on a very good day. Traders, buyers, security actors, and others in the supply chain therefore have much more significant resource access than artisanal miners, though these earnings are vitally important for many of those involved in ASM.

Despite the highly exploitative nature of the system, miners are at times able to make money and invest, including one miner I interviewed who was in the process of building a house (interview, February 13, 2017) and another who, as mentioned, has used the money from mining to pay school fees (miner and his mother, interview, February 27, 2017). One trader got his start as an artisanal miner going underground but saved up money and became a trader (interview, May 18, 2017). While it is challenging to evaluate the number of miners at each site and in the region more broadly, artisanal miners significantly outnumber those in formal employment at LSM companies. A former EMAK representative living in the community in the vicinity of site B estimated that there might be around 1000 (interview, February 1, 2017). Tsurukawa, Prakash, and Manhart (2011) estimate that there is a permanent presence of around 7000 to 9000 artisanal miners at site $\mathrm{C}$ and that during peak season, this can rise to between 9000 and 11000 miners. In the Lubumbashi-Kipushi deposit group, the authors likewise estimate permanent numbers of 7000-9000 miners and peakseason numbers of 9000-11000. In comparison, even a large project like company $\mathrm{C}$ offers formal employment to only about 3000 .

Yet visits to a number of miners' homes suggested that while clandestine mining can bring in enough money to invest, this is not the case for the majority of artisanal miners. Many miners live in very poor conditions even after, in some cases, a decade or more of clandestine mining (miner and his wife, interview, April 9, 2017). One respondent argued that some artisanal miners can't even afford to build a two-room home (two socio-cultural association representatives, interview, April 12, 2017). There are always exceptions to the trend, however. One miner that I met, with his wife, had a nicer home than those of some of the other miners/traders I interviewed: his floor was covered, and he had a TV and speakers (miner, interview, April 3, 2017). Yet it was clear from their homes that many of them struggle financially and are earning only a subsistence living. Many miners, as discussed, do not have good spending habits (civil society representative, interview, August 10, 2016). 
Overall, in terms of distributional outcomes, clandestine extraction is stacked against artisanal miners, who are least able to financially profit from these processes that their labour sustains.

The arrangements and processes for authorised clandestine extraction are therefore extremely exploitative of artisanal miners from a distributional perspective, though miners retain a certain amount of agency and capacity to earn. An interview with a miner who was shot by security forces and who has been beaten and imprisoned, moreover, was a stark demonstration of just how difficult miners' lives are (miner and his mother, interview, March 29, 2017). The unpredictability and violence of these arrangements and processes also undoubtedly impacts miners' daily ability to earn a livelihood, save, and plan ahead. The police and PSC guards sometimes say miners can't enter and refuse to take money, particularly if a patrol is taking place. To cooperate with a security guard, as discussed in the conflict chapter, a miner may need connections or contacts. Some miners avoid going to the site spontaneously to try to "corrupt" the security guard, but prefer to wait to be called (miner and his mother, interview, February 27, 2017), which means opportunities to enter the site are based on someone else's decisions and may be restricted.

Artisanal miners are therefore at the base of the pyramid when it comes to the distribution of resources (Katz-Lavigne, 2016). Traders do have their minerals confiscated and therefore suffer financial losses but are much less likely to be arrested (miner and his mother, interview, February 27, 2017) and to have to pay to get out of detention. Miners spotted by security forces are often chased away, which means they don't get any minerals that day and lose whatever they had already collected, as well as their entry fee. Even if they do pay, they may not be able to get good minerals to sell on a given day. That said, while, as noted, traders are not arrested often (trader and her miner son, interview, February 27, 2017), traders at times have minerals taken from them, and/or lose money (trader/miner, interview, February 14, 2017; trader and two associates, March 4, 2017; trader, interview, May 10, 2017; trader/miner, interview, May 19, 2017). As noted, some miners take money from a trader and then do not return to sell them minerals and allow them to recover their investment (two traders, interview, February 9, 2017). Miners often get their minerals confiscated, but so do traders, and traders may lose significantly more minerals given that they buy from several people. Lower-level traders or trotteurs, as well as some women who buy a few kilos locally to get by, are vulnerable to losing their capital at the hands of different branches of the security forces. One trader reported that traders do have difficulties, even his boss at the maison de négoce (purchasing house). If a trader loses his minerals when the security forces intercept the bus, he has to explain to the buyer what happened, and reimburse the buyer for 
the lost minerals, in addition to losing a potential bonus for bringing the buyer a lot of minerals. One woman trader had her products taken by the Mine Police when the Lupoto site was sold to a company (trader and her miner son, interview, February 27, 2017). When one trader's minerals were taken, he lost his products and the money he spent (trader and two associates, March 4, 2017). Another trader also lost malachite at the Lupoto site, among several who had their minerals confiscated. Afterwards, he was not able to work for a long time as he had no capital left and the copper price was very low. In 2017, however, he returned to site A with 70,000 francs to try to build up again what he had before (interview, May 10, 2017). One individual who was previously a trader bought minerals at one site for several years, but a Chinese company took his minerals and then closed their depot without paying him. He tried to go to court, but didn't succeed (trader/miner, interview, May 19, 2017).

Some distinguished between grands négociants and petits négociants: a grand négociant is someone who buys a lot of minerals (trader, interview, May 10, 2017). While, as discussed, some traders are vulnerable to having their minerals taken away, others do relatively well, including those with financial support. One trader at site $\mathrm{C} 2$ said that his brother, who owns vehicles, suggested that he go to $\mathrm{C} 2$ to buy minerals, and gave him the money to do so. Their parents, he reported, were grands commerçants (big businesspeople) who brought palm oil from the capital of the current province of Tanganyika to a town in Lualaba province. His brother, he said, has a "parapluie" (someone who covers him) (interview, May 18, 2017). Another trader said that his father was a military official in Kinshasa and had given him capital (three traders, initial contact, May 18, 2017). In site C's concession I also met a trader from South Kivu originally who travels all over - including South Africa - to do business (trader, discussion, March 2, 2017). In comparison with lowerlevel traders, influential actors - which may include some traders (miner, follow-up discussion, May 18, 2017) - unsurprisingly have an easier time of their involvement in clandestine mining. The trader whose father is a military official said that he could call his father if he had a big problem, like being arrested (three traders, initial contact, May 18, 2017). Therefore, while the informal institution that is clandestine mining is indeed to a significant extent impersonal (Gallien, 2019), particularly at the lower echelons, it becomes more personalised and its functioning smoother and less conflict-affected the higher up the hierarchy of connections and material wealth the people involved in it are (interview, March 6, 2017). Yet even marketeurs are not immune to losing their minerals. One day in concession C, I witnessed a haul of confiscated minerals - 53 sacks, I was told - taken from a marketeur. 
A Mine Police official explained that the OPJ would write up a report and the minerals would be returned to the company (site visit, March 2, 2017).

In terms of distributional outcomes, the police benefit from clandestine extraction and from corporate enforcement, whether they treat artisanal miners flexibly or inflexibly. Clandestine extraction is well organised among state security services including the Mine Police. A Mine Police representative working at site $\mathrm{C}$ mentioned his house-building project and how he was writing tenders for roofing and electricity: each job would cost around $\$ 2000$. He added that he wanted to build multiple homes as his pension. Once he was retired, he explained, he could live in one house and rent out another (interview, April 12, 2017). Given low police salaries, he no doubt earned money from clandestine mining. A Mine Police representative deployed at site $\mathrm{C}$ explained that sometimes, he captures artisanal miners but instead of arresting them, he takes their minerals and tells them that if he sees them again, he will fouette (whip) them. They are grateful at being let go but return the next day and try to hide: if they see him, they run away (Mine Police representative, interview, April 12, 2017). When miners are caught at site $\mathrm{C}$, one company staffer reported, their minerals are taken away and they are let go (interview, August 11, 2016). Yet as described, multiple respondents said the police do not return recovered minerals. Even when authorised clandestine mining goes wrong, therefore, the security forces often still benefit in material terms.

Government authorities also benefit from miners' presence in a range of ways, directly and indirectly. On an April 10, 2017 visit to site C3 my research assistant and I encountered a government representative from the provincial Direction des recettes du Lualaba (DRLU) who was there to collect fees from shop owners. He also said that the DRLU tries to sell cartes de creuseurs (miners' cards) to the miners, but that many are not interested in getting them, so they don't know how many miners are in the area (site visit, April 10, 2017; journalist, interview, February 7, 2017; miner, conversation, March 3, 2017). The cards cost $\$ 5$ ("president" of the artisanal miners, interview, February 11, 2017; journalist, interview, February 7, 2017). Given the "illegality” of miners' activities in company C's concession, there is no possibility to formally register them, which demonstrates the "unofficial" nature of such cards and fees - just another tax on top of the many others levied on miners. A journalist based at $\mathrm{C} 1$ said that cartes de creuseurs are also being sold at $\mathrm{C} 1$, and that miners had been asked to go and be identified and to buy the cards. The journalist added that the money goes directly to the DRLU and that they even provide a receipt. He added that the sale of these cards is a source of income for the government: there are many miners, and $\$ 5$ per miner adds up. The territorial administrator also reportedly earns money from clandestine mining at site $\mathrm{C}$ 
(journalist, interview, February 7, 2017; civil society representative, interview, March 4, 2017). Figures who sponsor teams of artisanal miners at site $\mathrm{C}$ were said to include the Mine Police (trader and two associates, interview, March 4, 2017) and ANR and Bureau 2 representatives (site C3 miners' committee member, interview, April 13, 2017). A PSC manager asked me who could remove 40 tonnes of minerals from site $\mathrm{C}$, and said that he points the finger at police, military, and political authorities when it comes to removing significant quantities of minerals from LSM sites. By way of example, he said that there could be miners with, say, 10 kilos. They sell the minerals to a colonel, who stores the minerals. He has the power not to be disturbed and can take the minerals out in broad daylight. The PSC manager asked who could attack this colonel, given that he protects the company. If anyone gets arrested it's the miners, not the colonel. The respondent explained that it takes someone with power to protect those who buy clandestinely mined minerals: typically, Lebanese, Chinese, and Indian buyers pay someone to go purchase minerals, who in turn pay someone else to buy, as the chain gets closer to the mine site itself. An influential individual covers the original buyer (three PSC managers, interview, March 20, 2017).

The distributional picture is also more complex than "security guards vs. artisanal miners". Many ordinary security guards and police officers, as discussed, are financially reliant on clandestine extraction to make up for low salaries. Yet at times, these practices go wrong, and people lose their jobs, a significant loss in a context of high unemployment. As one Mine Police representative explained, everyone at an LSM site is afraid of losing their jobs, except the police (Mine Police representative 2, interview, February 16, 2017).

Finally, as noted, "autochtonous" groups sometimes view themselves as being less favoured by the LSM sector, which tends to hire people from other regions rather than local labour, particularly for higher-level, better-paid jobs. The influx of artisanal miners from elsewhere is another important issue when it comes to understanding how resource access is distributed at the local level. A trader/miner argued that when it comes to dynamics between miners, the autochtones are marginalised by others who come from elsewhere. The group that is autochtonous to the area, he said, is not very involved in artisanal mining in the concession (interview, May 19, 2017). A representative from a socio-cultural association representing the autochtonous group in the site $\mathrm{C}$ area echoed this view, saying that only 1 out of 10 miners might be from that ethnic community and that ASM is "not in their nature" (two sociocultural association representatives, interview, April 12, 2017; company C security employee, interview, April 13, 2017). Yet many local people have benefited from artisanal miners' presence, including higher-placed individuals involved in and able to benefit from clandestine 
mining, as well as those who supply miners with a range of goods and services including housing (village chief and multiple village residents, including miners, interview, April 11, 2017). As noted, a prominent land chief in company C's concession has received benefits from the company and also obtains rents from authorised clandestine extraction. Yet many artisanal miners are not from the area and therefore do not necessarily recognise chiefly authority. In some cases artisanal miners are seen as failing to live up to their financial duties. The group discussion with the village chief and multiple villagers, including artisanal miners, at $\mathrm{C} 4$ is a good example. The village chief had not been able to benefit financially from the miners' presence and wanted them to pay him 5000 francs, which was complicated by the fact that he wasn't aware when miners were loading their minerals for transport (April 11, 2017). In comparison, as discussed, a prominent land chief has people at site $\mathrm{C} 2$ who levy money on his behalf when the transport vehicles leave with minerals. The land chief's power and authority means he can benefit from payments when minerals are transported, compared to the village chief who has not been able to benefit in similar fashion. Yet ethnic "outsiders", too, have the opportunity to capitalise on clandestine extraction. Near mine site A, a woman with a plot of land makes money allowing traders to use her land as a buying, selling, and transporting point. She was born in Lubumbashi, but a different part, and belongs to an ethnic community from elsewhere in the former province of Katanga. Despite not being from the immediate area, she benefits from the fact that traders need a place to store their minerals (landowner, interview, May 15, 2017).

Therefore, authorised clandestine mining is a process from which many actors are able to benefit - some more than others, particularly actors at higher echelons of involvement particularly government actors and members of the security forces. As a category, "traders" tend to do better in terms of resource access than artisanal miners, but as noted, there is differentiation within the broad category of traders. In terms of resource distribution, some members of local ethnic communities are also able to better seize the opportunities presented by clandestine mining than others. Many artisanal miners, however, view the services they receive in exchange for their payments as limited and often arbitrary, the payments excessive. They are therefore at the bottom of the pyramid when it comes to access to resources.

\subsubsection{Barriers to Entry}

Despite its major difficulties, relatively few barriers to entry prevent artisanal miners from entering the system of clandestine extraction. Formal employment in large-scale mining, 
in comparison, depends only on frequently complex skill sets; education (often higher education); and/or a privileged upbringing. Connections and recommendations by others are also a significant factor (EMAK representative, interview, February 1, 2017; company A exploration staffer, interview, October 19, 2016; two socio-cultural association representatives, interview, April 12, 2017) meaning those who lack connections - of an ethnic nature or otherwise - face serious obstacles. Moreover, women tend to be underrepresented in formal employment at LSM firms (civil society representative 1, interview, November 9, 2016) whereas they are involved in a range of activities in the ASM supply chain.

Similarly, as discussed in the literature review, mining companies' CSR initiatives are characterised by significant limitations and shortcomings. As Frederiksen (2019) argues, these can be seen as rent flows aimed at those with significant holding power (i.e. groups and individuals that could inflict costs on the mining company) such as local leaders who are in turn enabled to wield greater patrimonial power over their subjects by deciding who is and is not included in the projects and opportunities the mining company provides (p. 168)

With clandestine mining, on the other hand, capital and/or the ability to form connections and trust relationships enable a miner or group of miners to gain relatively easy access to an LSM site, even if they do not possess much of this holding power. With even relatively limited amounts of capital, both artisanal miners and traders can get involved in the clandestine mining supply chain. If miners do not have capital to pay security, they can often borrow from a trader against the minerals they will collect at an LSM site.

Artisanal miners include a range of people with different educational levels (civil society representative, interview, August 10, 2016; Congolese National Police representative, interview, May 25, 2017). The population of miners at site $C$, for instance, is large and diverse: some miners have not studied, while some have diplomas and graduate-level degrees (four miners, interview, February 8, 2017; Mine Police representative, second interview, March 24, 2017; miners, group interview, April 3, 2017). One member of company C security reported that a doctor was found dead in a pit collapse at one of the hills in company C's concession (interview, March 9, 2017). One miner who is also a trotteur said that the need for survival pushed him to do both at the same time. His parents worked for Gécamines and he himself was licencié (had a degree) in political science. He applied for a job at company C, but was unsuccessful (interview, May 19, 2017). Many miners are young (miners, group interview, April 3, 2017), particularly those who come from far away (village chief and multiple village residents, interview, April 11). A Mine Police official said that miners' ages 
vary between 18 and 34 or even 40 (Mine Police official 1, interview, November 8, 2016). On the visit to the Mine Police office at site $\mathrm{C} 1$ when I saw five detained miners sitting on the floor, the Mine Police representative who was showing me around asked several of them their ages: they were 34,37 , and 19. Another, who did not give his age, also looked young, around 19. The two older miners were married and had two children each (site visit, February 7 , 2017). According to a Mine Police representative, most miners have not studied, which pushes some of them to LSM sites (second interview, March 24, 2017) - though in the DRC even those who have studied often have trouble getting jobs. Some miners have lost their father or both parents, or their parents divorced. A miner living at a grandmother's, having lost both parents, without enough food or a way to go to school, may decide to enter LSM sites for survival (Mine Police representative, second interview, March 24, 2017). One miner started artisanal mining in 2003, when he was 16 or 17 . His father, a soldier, died and he did not know his mother. He found a way to survive by starting to mine at site B, which was not yet occupied by a company the way site A was. He was at both sites A and B when the companies cleared the miners out (miner, interview, April 3, 2017). Another miner said he was born in 1997 and that he was 20, but my research assistant and I both felt he could not be older than 15 (several traders and miners, interview, March 9, 2017). There are older miners as well - including a couple that I met - though older miners also tend to enlist the assistance of their sons. The miner who made this comment indeed works with his son (miners, group interview, April 3, 2017; also miner and his wife, March 31, 2017). Therefore, artisanal miners with a range of characteristics have the opportunity to enter LSM sites even if not well connected, particularly if they have money and/or good social skills and the ability to communicate.

While relationships that facilitate access to LSM sites may form between people from the same province, they can also be family relationships or friendships (miner and his mother, interview, February 27, 2017). One respondent said that the Mine Police are from different regions/provinces, including Kinois [people from Kinshasa] as well as Katangese. All are easy to cooperate with, which suggests that in some scenarios at the mine site, these types of identities are not overly salient when it comes to distributional consequences (miner and his wife, interview, April 9, 2017). Therefore, to make connections a miner must have money, and to be able to build trust with other actors (civil society representative, interview, January 24, 2017). The fact that miners can earn money relatively easily points to an egalitarian element of the system, which "outsiders" from other regions can frequently access. For miners with poor social skills or who are unwilling to behave as demanded by the security forces, the 
picture is more complicated. Miners may choose aggressive and/or violent behaviour, rather than building trust, to gain access to resources - i.e. "unauthorised clandestine" extraction, the distributional impact of which I turn to next.

\subsection{Distributional Impact of Unauthorised Clandestine Extraction}

I have argued that in line with their limited power and authority, the benefits miners receive from clandestine mineral extraction frequently amount only to subsistence, though some miners do better than others. As noted, in the mining business social class is a significant factor. Wealthy individuals are often in solidarity with one another and seek to keep outsiders out of their privileged class (civil society representative, interview, January 24, 2017). In other words, in line with Daudelin and Ratton (2018), the multiple actors who govern the authorised clandestine mining "market" seek to "close" this market to those who are either unwilling to pay to enter or to pay the price that is demanded, or who do not accept to abide by some or all of this type of extraction's rules and regulations.

Miners' attempts to enforce their claims to resource access, which at times include opposition to both company practices and the dictates of authorised clandestine extraction, are an important factor when it comes to distributional outcomes. Circumventing security means miners can save money - at times large sums - they would otherwise have to pay to enter the site. Some miners use aggressive behaviour, particularly as a large group, to intimidate security and gain access to LSM sites. This approach carries significant risks of violent repression, but may also help miners avoid entry fees, or simply to gain access to an LSM site at all so they can make money that day. As I have discussed, companies typically view artisanal miners as illegitimate interlocutors: for reasons including miners' numbers, they pose a significant "threat" to companies' continued operations and bottom line. In the absence of meaningful opportunities to discuss and negotiate, miners are often forced to use aggressive tactics to secure a marginally fairer distributional outcome.

These dynamics support my contention that despite the human cost, some conflict may be associated with a better distributional outcome for miners. That is because when miners successfully use a particular type of strategy to enforce their claims in the face of opposition, conflict is more likely to occur. On the other hand, if miners avoid pressing their claims and just obey the security forces on how much money to pay and when to leave the site - or decide not to enter at all - many of them risk getting nothing for one or more days. Miners I spoke to, who had increasingly given up on entering LSM sites because of the risks, are an example of this. Given miners' need to earn a living and the fact that many of them - 
including people like "Jacques" - are willing to take significant physical risks, flexibility by companies and the security forces is likely to ensure a more equitable distribution. Otherwise, the distributional outcome will weigh in favour of the more aggressive, organised "bands" that the company B security representative mentioned - who take not only minerals but also company property - and the ordinary creuseur will increasingly lose out on resource access (interview, January 27, 2017). A flexible policy would also be associated with a lower human - and, for the companies, reputational - cost than strictly enforcing LSM firms' property rights. Companies are also complicit in the most negative distributional outcome of all: the loss of life. Whether by assigning different security forces to guard their sites with force, or by contributing to the conditions in which multiple miners lose their lives in pit collapses, significant numbers of miners - albeit a small fraction of the total active across the region have paid with their lives. These deaths also affect the distribution of resources for others as well, especially miners' wives, children, and other dependents.

Artisanal miners' unauthorised clandestine mining strategies may therefore have some positive distributional impacts. Yet miners' enforcement of their claims in this manner at times negatively impacts local communities at and around the mines, which includes "autochtonous" groups. The division between autochtonous/non-autochtonous groups is not clear-cut even in more rural areas like the villages and towns in concession C. One civil society representative who lives in $\mathrm{C} 3$, for example, is involved in the community but is not from C3 originally (interview, February 9, 2017). The term "local community" in places like C3 can encompass a broader group of people than simply the group known to be indigenous to the region. Members of the local community, including autochthonous people, have faced costs linked to the presence of many artisanal miners from other regions. These include damage to community property, including company-provided facilities. As described, if a pit collapse occurs miners tend to be left to their own devices and the company may not take charge of burial. If the miners don't get what they want they have a tendency to rise up in protest, which can include attacking company facilities or vehicles, as with the company's community liaison bureau. These actions can have negative consequences for the community. After the incident mentioned above that took place at site A when a miner was reportedly killed after trying to take a police officer's weapon, other miners created disorder as they left the site, going to the nearby market where they knocked over flour and buyers' other goods. After the dead miner was buried, the situation calmed down (trader/miner, interview, February 14, 2017). During a visit to $C 3$ on March $4^{\text {th }}, 2017$, I walked around with a civil society representative. An elderly woman stopped to speak to the representative, who told me 
afterwards that she was a widow and that her house had been damaged by the blasting carried out by the mining company. She wanted to know how she could ask the company to repair the damage. It was Saturday, so the civil society representative told her to go to the community liaison bureau on Monday morning. Yet the company doesn't have a permanent presence at the bureau since it was damaged, but rather operates what the representative referred to as a bureau ambulant (interview, March 4, 2017), meaning members of the local community may have less easy direct access to company representatives.

A local journalist born at site $\mathrm{C} 3$ indeed said that there are many miners living there who damage the population's property (interview, May 19, 2017). A civil society representative based a site $\mathrm{C} 3$ reported that in 2016 angry artisanal miners broke windows at a local school built through company C's social fund, and which is found in a location that the artisanal miners often pass by. He explained that sometimes, when miners emerge from the site and have not found anything, they get angry and damage property that was built by the company's social fund (interview, March 4, 2017). I visited the school and saw the damage (see photos below). Though I did not have time to corroborate his story that miners were responsible, the first photo below shows that the school is on the path of those who come down the hill shown in the background. Therefore, local civil society views the miners as responsible for these acts, which leads to tensions between the local community and the miners.

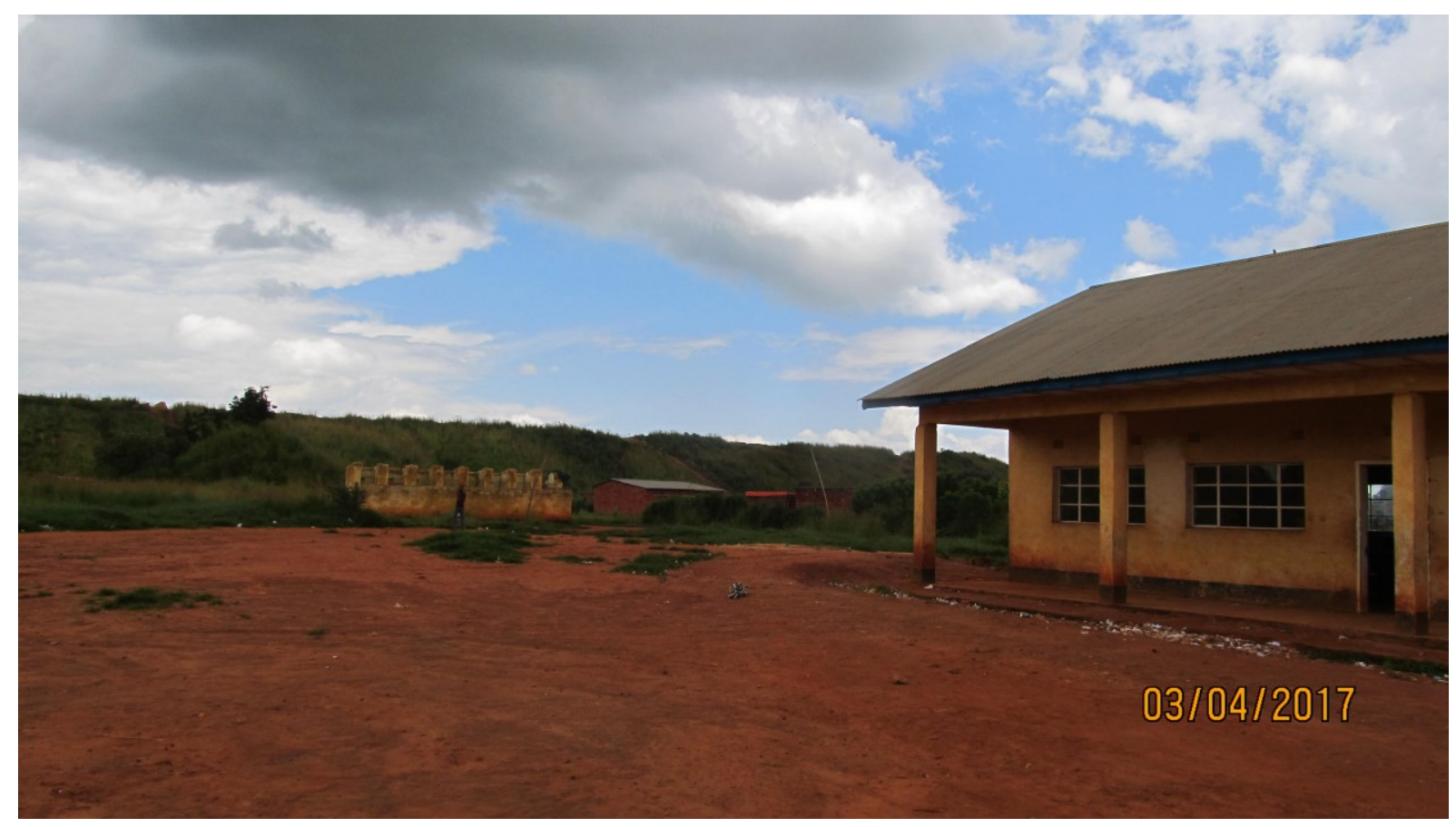

Image 9: Community school near hill, Sarah Katz-Lavigne, March 4, 2017. 


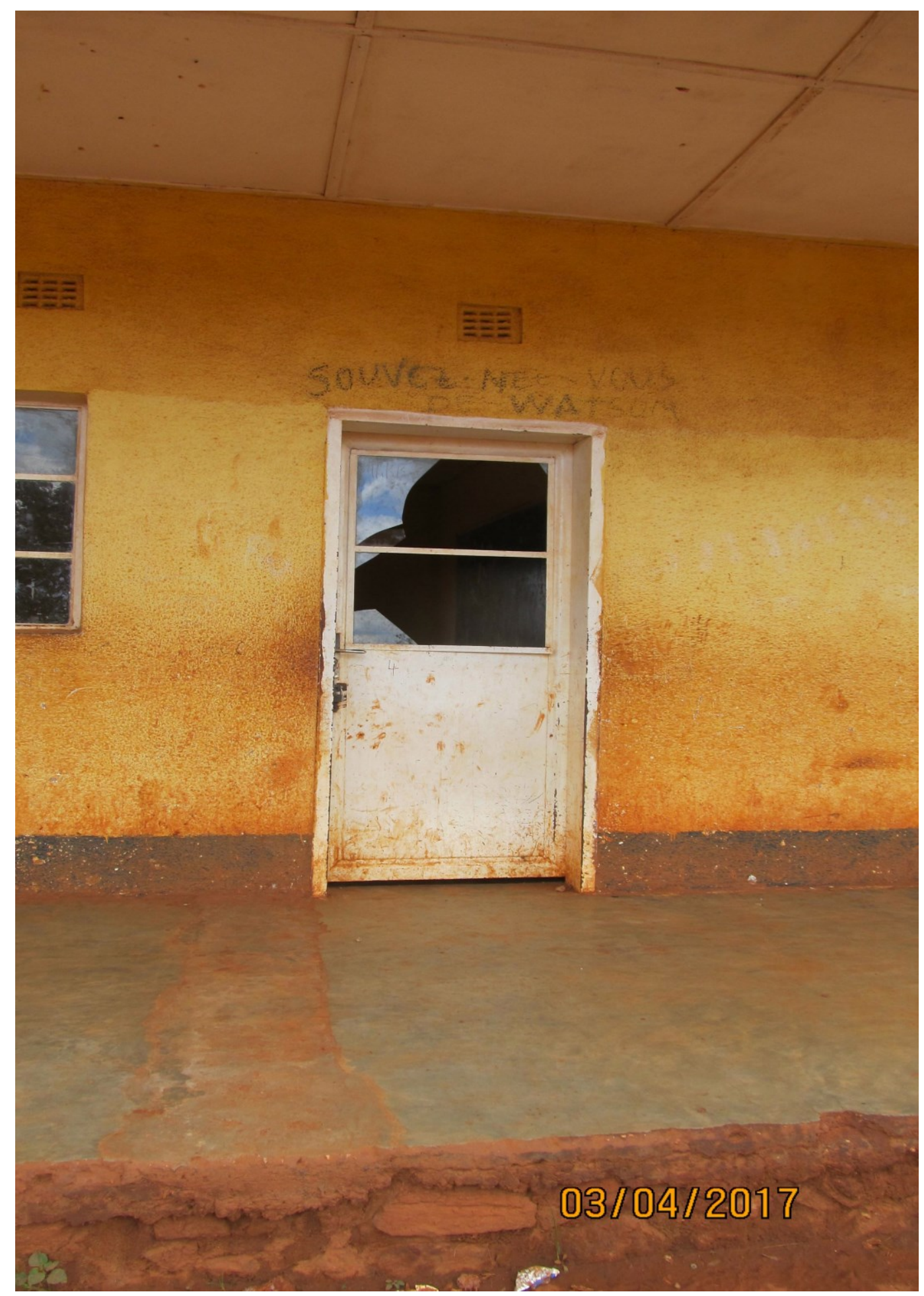

Image 10: Damaged school window, Sarah Katz-Lavigne, March 4, 2017. 


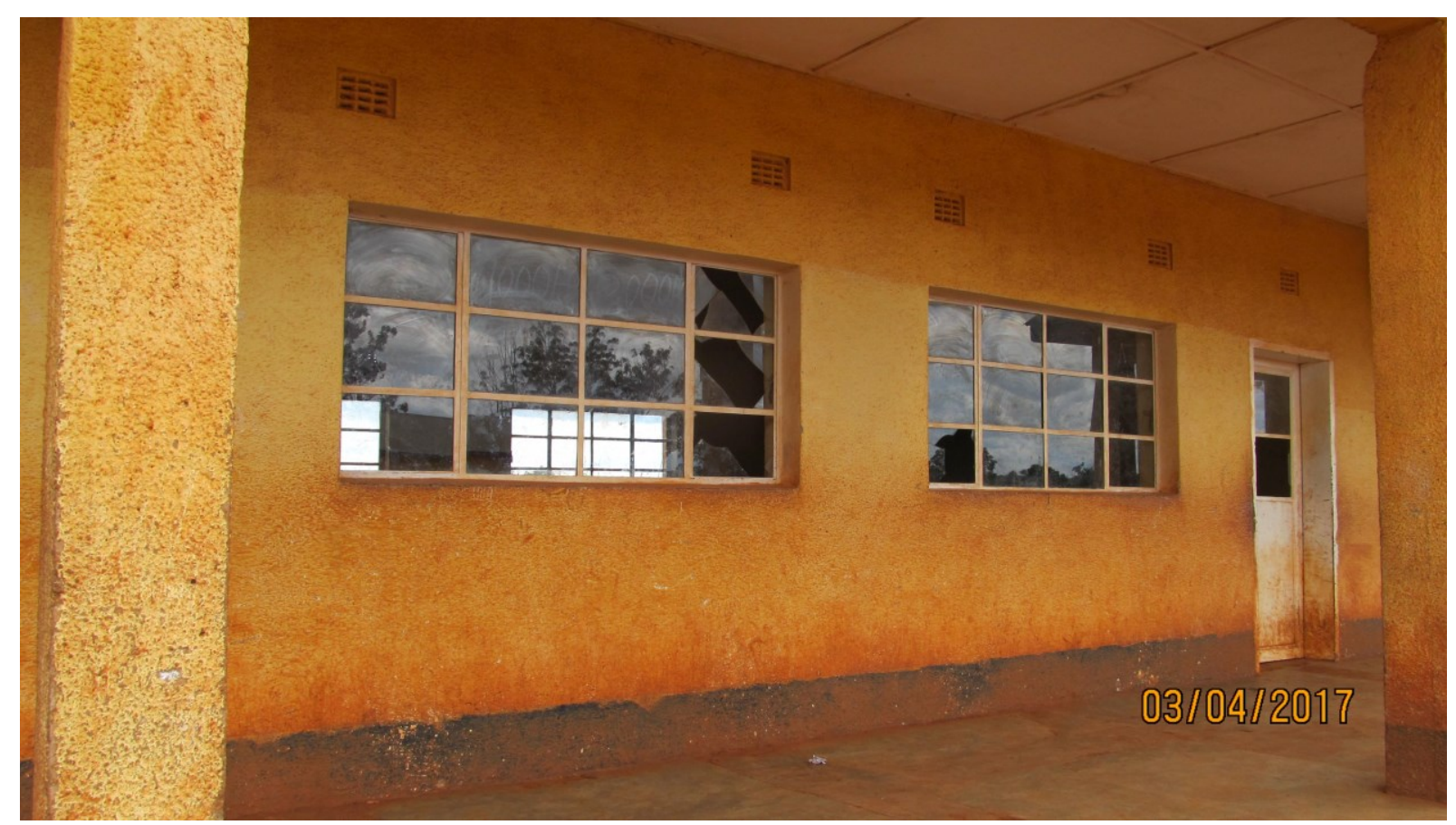

Image 11: Damaged school windows, Sarah Katz-Lavigne, March 4, 2017.

\subsection{Conclusion}

In this chapter I have sketched out and examined the distributional consequences of mining governance at and around LSM sites in southeastern DRC in terms of different resources, including for specific individuals and groups. The way corporate and other actors enforce their property rights and claims in the context of this specific PR configuration, including well-established systems and networks of both authorised and unauthorised clandestine extraction, has a major impact on artisanal miners' access to and exclusion from LSM sites. These realities ultimately impact distributional dynamics with respect to multiple resources: mine site access, minerals, money, and symbolic capital. I examined the distributional consequences associated with the corporate extraction; authorised clandestine; and unauthorised clandestine facets of the property rights regime. First, a number of negative consequences have resulted from corporate investment and PR enforcement, including the dispossession of artisanal miners and traders; a lack of sites where traders and miners can safely work; serious deficiencies in the availability of alternative ASM zones; and the vulnerability of miners' resource access to company decisions and extraction processes. Multiple scholars have examined these dynamics: my contribution, building on their work, is in-depth analysis of the distributional consequences of the interactions between the three major components of the regime, including not just corporate enforcement but also authorised 
clandestine and unauthorised clandestine mining. Authorised clandestine extraction, while a source of revenues for miners, also represents a significant financial burden for them, particularly given its unpredictability and risk. The financial payments built into these systems and processes drain resources from artisanal miners and towards the security forces and other actors. Efforts to avoid these costs and ensure a more favourable distributional outcome increase miners' physical risk. Artisanal miners face many trade-offs as they try to make a living. Overall, artisanal miners receive the fewest benefits from clandestine extraction, despite taking the most risks. Yet certain characteristics of these systems and processes likely ensure a more favourable distributional outcome, for miners, than would be the case in their absence. Miners' efforts to gain unauthorised access to LSM sites, while even riskier, play the same role in the context of a highly unequal distribution of resources at the local level.

The small size of the concessions around Lubumbashi and the fact that even low-value minerals could be treated given the right technology (company B security officer, interview, January 27, 2017), as well as the short projected life cycle for some mines (companysponsored workshop, 11 August 2016), especially sites A and B, means that competition between LSM and artisanal mining is likely to remain zero-sum. If companies continue to resist flexible options, it is in fact likely that conflict will worsen in a context of growing mineral scarcity. The link between exclusion and further conflict is an important area for further research. For miners with few livelihood alternatives, security practices that result in greater exclusion have consequences for the well being of miners and their dependents.

The reported trend of more difficult access at sites A and B has led to increasing exclusion for artisanal miners and their dependents and, given the absence of viable livelihood alternatives, growing economic hardship. A final area of further research that has received attention elsewhere in the DRC relates to the distributional impact of LSM as it displaces the development of ASM locally (Radley, 2019). My findings suggest that given how the property rights regime operates at LSM sites in southeastern DRC, in terms of distributional outcomes the current reality lies somewhere in between two ideal types, i.e. "pure LSM" and "pure ASM", and that this point is not fixed. It is important not to overstate the redistributive nature of either "pure ASM" extraction or of the way the PR regime currently functions. Nonetheless, in a world in which LSM companies would prefer no artisanal miners at their sites, the current reality at least allows for some wealth to be redistributed. An area for further research is the consequences of these distributional dynamics for further peace or conflict, and the associated policy implications. The failure to compensate those losing access to resources and ensure a distributional outcome viewed as legitimate by miners is highly likely to result in 
further conflict. Policy initiatives that focus on ending ASM-LSM conflict alone should also take into consideration the distributional consequences of conflict mitigation (Katz-Lavigne, 2018). My findings about the importance of authorised and unauthorised clandestine mining when it comes to distributional outcomes relative to artisanal miners and others who rely on ASM are likely to hold true elsewhere in Africa. 


\section{Chapter 9: Conclusion}

This dissertation represents an adaptation and application, to the copper- and cobaltmining sector of southeastern DRC, of property rights theory as employed by some scholars, namely Daniel Fitzpatrick (2006) and Esther Mwangi (2007), to acknowledge and analyse the endurance of overlapping claims to resources. The overlap is a result of the fact that although LSM firms and other resource users seek, through a range of means, to enforce their property rights, they are not always able to do so. At certain moments, this overlap results in conflict (Fitzpatrick, 2006). The application of the theoretical approach involved systematically considering the measures on which mining companies and other resource users like local elites, security guards and police officers, and artisanal miners rely to define and enforce their rights to property in the DRC's LSM sector. I applied Fitzpatrick's three (2006) categories of PR enforcement measures: self-enforcement (first party), coalitional (second party), and thirdparty, mainly state-based measures.

My contribution to the large and growing body of literature on LSM-ASM conflict includes the development of a tripartite framework to explain conflict dynamics - which includes frequent moments and periods of peaceful interactions - within the mining "enclave". I have argued that at and around the case-study LSM sites in southeastern DRC, natural resource governance - more specifically, the property rights regime - is characterised by the existence of at least three components of a multidimensional property rights regime. These three building blocks, which are at times in competition and at times mutually reinforcing, are ideal-type categories but are useful for analytical purposes. The first component refers to corporate enforcement practices. The second is the processes and arrangements for extracting minerals from LSM sites without company authorisation: this authorised clandestine extraction is enabled by an array of actors, including members of the security forces and company employees. Finally, artisanal miners endeavour to circumvent the rules and regulations that govern the authorised clandestine removal of minerals; these strategies can be termed unauthorised clandestine extraction. The three mechanisms therefore co-constitute the plural PR regime at and around the case-study sites, in which a number of claims are delineated and enforced to different degrees and at different moments. These dynamics, crucially, impact both conflict incidence and distributional outcomes at and around mine sites. Conflict is not only caused by the interaction of corporate extraction and artisanal mining but occurs at the intersection of the three components mentioned above. A significant element of my contribution lies in the presentation of how the overtness-covertness and 
openness-closure dimensions are crucial for understanding both conflict and distributional outcomes at and around LSM sites. Using these dimensions, I presented a systematic explanation for the points at which conflict erupts and the incentives faced by different actors and institutions, which go a long way towards explaining their actions and choices at these key moments. Conflict therefore tends to follow a certain pattern and to affect certain individuals more than others. The incidence of conflict reflects dissatisfaction with a given distribution of resources, but there is also a dynamic process at work in which further exclusion leads to more conflict, and therefore potentially more exclusion again. It is frequently a vicious, rather than virtuous, cycle.

While the regime's different elements are sometimes opposed to one another, they often reinforce each other even if they seemingly have contradictory goals. The corporate enforcement and clandestine extraction components are frequently mutually reinforcing, to the detriment of ordinary artisanal miners. Though these three components play a key role and have a tendency to persist, I do not claim that they constitute a full, or exhaustive, characterisation of the property rights regime - which is dynamic and fluid - at and around the selected LSM sites. For instance, as noted, there is scope for further research on the largerscale clandestine removal of minerals from LSM sites, including using trucks, by actors including company employees and security. These findings, though preliminary, reinforce the point that while artisanal miners constitute an easy target for law enforcement and (trans)national policymaking, they are - as Geenen and Hönke (2014) point out - embedded within a wider political and economic structure that determines their opportunities and channels their activities.

Corporate enforcement refers to LSM firms' practices - deployed more or less "successfully" - to define and enforce their - if not legitimate, at least legal according to Congolese law - property rights vis-à-vis artisanal miners and other actors. Mining firms' range of practices is adapted to; is partially an outcome of; and co-constitutes the PR regime. Second, authorised clandestine extraction involves a similar range or "assemblage" (Abrahamsen \& Williams, 2017) of actors, including the security forces; company employees; local government officials and customary authorities; and artisanal miners working together to gain access to resources and rents from LSM sites. These networks are plural, interconnecting, and often reconfigured, for the actors involved (for example, police officers and security guards) are often rotated. Such arrangements oversee and enable, among other things, artisanal miners' access to LSM sites. Third, unauthorised clandestine extraction describes the means that some artisanal miners use to get around the rules governing 
authorised clandestine extraction from LSM sites; these approaches include attempting to bypass security altogether or using aggressive or even violent behaviour as a tool. In this manner artisanal miners - despite their structural weakness and lack of material resources are at times able to resist the terms and conditions of both corporate enforcement and authorised clandestine extraction and maintain de facto rights to resources on - at least to some extent - their terms. In attempting to secure resource access in this manner, however, miners put their physical security at greater risk: going around security or employing aggressive behaviour is not only not in line with the dictates of authorised clandestine extraction, but is actively discouraged in different ways, including the use of force.

While I distinguish between different facets of the property rights regime for analytical reasons, there is therefore significant overlap between the different components. The regime operates as a whole, and its is the functioning of the whole regime that affects conflict incidence in addition to having distributional consequences. I made the case for a careful analysis of on-the-ground dynamics: what appears to be corporate flexibility towards miners may not be an outcome of corporate policies at all, but of the property rights regime and constrained conditions within which a company operates coupled with the dynamics of (un)authorised clandestine extraction. Additionally, companies may not possess perfect information, including about the extent of employees' involvement in clandestine extraction. Nor, despite corporate attempts at creating “enclaves" (Ferguson, 2005), do companies operate independently of the property rights regime, which includes the involvement of company employees like members of the Industrial Guard in clandestine extraction. The use of sub-contractors further reinforces the fact that companies in this context are non-unitary actors. Finally, some flexibility vis-à-vis miners is built into the system, and they have some, albeit constrained, negotiating power within it. Attempts to disrupt clandestine extraction whether authorised or unauthorised - on the grounds that it is exploitative, violent, and risky for miners are likely to have negative distributional consequences for artisanal miners.

The "illegality" of artisanal mining in LSM concessions, as noted, is an important feature of the system and one that has multiple effects, including the fact that it gives mining companies and the security forces that they hire the authority to forbid artisanal miners' presence in these concessions - or to tax them for it. Yet the fact of artisanal miners" "illegal" status is a necessary, but not sufficient explanation for conflict given the security forces' inextricable involvement in clandestine extraction practices. Of vital importance is the predominance of corporate objectives and of companies' structural power (May, 1996; Szablowski and Campbell, 2019), which intersects with the other two facets of the PR regime 
in ways that frequently, though not always, produce conflict. Key factors that help explain the incidence of conflict include first, the "overtness / covertness" dimensions and second, the "openness" / "closure" features, on which I draw from Daudelin and Ratton (2018).

With respect to "overtness" and "covertness", the non-unitary nature of MNCs is demonstrated by the fact that some security services or representatives within one mine site/company are regularly involved in catching others out for their involvement in clandestine mining, even when the former are also instrumental in clandestine extraction practices. Some of these dynamics are performative, though individuals and services do incur punishment for involvement in clandestine mining. Key moments at which there is potential for conflict include when a previously relatively covert market can no longer be kept covert such as when a security patrol arrives, or there is a high-publicity mine collapse - meaning that the cost of providing PR to artisanal miners rises and may become prohibitive. Other instances of conflict of this nature arise when miners refuse to obey the rules and regulations of clandestine mining, including orders to stay hidden; to only work at certain parts of the mine or at certain times of the day; and to leave the mine site after a given amount of time. At such times, when the fragile balance that is the strategic (c)overtness of clandestine mining is at risk, miners are frequently chased away or arrested, and longer-lasting conflict may break out. Artisanal miners, once again, tend to suffer physically and financially when conflict erupts in this way.

At site C, with its very large size and significant number of miners from a number of places, the market is relatively "open", though repeated interactions and/or the relatively long time frame of miner activity (especially when digging pits) at these sites help to mitigate some of the potential challenges associated with a large and heterogeneous group (Libecap \& National Bureau of Economic Research, 1999). Indeed, a range of respondents indicated that "foreign" miners do not necessarily fare worse than miners from the region, as long as they pay their dues to the security forces. Yet to protect their rents and keep numbers at an acceptable level - across all sites - members of the security forces use coercion and force to try to "close" the clandestine market to miners who do not pay for entry. Such moments, if miners do not acquiesce, hold the potential for conflict. Some high-profile conflict incidents, including property destruction, have been linked to miners' anger and frustration, including at the deaths of their colleagues at LSM sites. My findings build on existing literature like Geenen and Claessens (2016), who consider the use of violence as an access mechanism. These types of incidents reflect miners' agency as actors in their own right, and the fact that efforts by companies, local government respresentatives and authorities, and members of the 
security forces to govern, punish, and direct miners' conduct are not always successful. The result, at times, is conflict and even violent conflict. Conflict typically disproportionately negatively affects miners, given the imbalance in terms of weaponry between miners armed with slingshots and barres de mine, and a police force equipped with tear gas and firearms. It also takes a heavy toll on unarmed guards. Miners' numbers and the fact that some of them are willing to deploy aggressive behaviour makes them an actor that - despite companies' efforts to portray them as "illegal" and to avoid engaging with them - cannot be ignored. This is particularly the case given that companies' financial incentives means their security costs have to be kept below a certain level.

In this context, therefore, assumptions about LSM-ASM conflict as uniformly "bad" or as having only negative consequences should be critically evaluated with an eye to the distributional implications of these dynamics. Some conflict can be directly linked to artisanal miners aggressively resisting the "closure" of the security market that is clandestine mining. Miners frequently use their coercive power for the purpose of gaining access to LSM sites which ensures a better distributional outcome for them - particularly at key times like the Christmas holidays, when they seek money to prepare for family celebrations. At times like those, however, conflict tends to escalate, and the security forces also systematically mistreat the miners in response. Other actors are also at different times affected by conflict, including traders who have their minerals seized or transporters who get arrested. The husband of a landowner I interviewed had been detained twice as a result of their decision to make their land available for traders wanting to store minerals there. I discussed the impact of local governance mechanisms like the "miners' committee", which serves multiple functions including resolving conflict with miners at the local level and therefore allowing corporate and clandestine extraction to proceed relatively smoothly. These types of mechanisms are another key factor highlighted in the analysis - and have been highlighted by other scholars working on the DRC, such as Raeymaekers (2007) - for they help to reduce transaction costs that prevent coalitional agreements from functioning and from maintaining a relatively peaceful balance within broader systems of clandestine extraction. As noted, however, these types of institutions also have destabilising potential, as when miners' numbers and popular anger is manipulated for political ends.

As discussed in the theory chapter, focusing on visible manifestations of conflict, including violence, while important, does not fully reveal the distributional impacts of the workings of the property rights regime at and around LSM sites. The fact that conflict doesn't tell the whole story is demonstrated by the theoretical reflection that if companies were able to 
successfully exclude all unwanted actors from their concessions, the outcome would be "peaceful", but only in the limited sense that there would be no overt conflict or physical violence - Galtung's “negative peace" (1964). In distributional terms, the arrangement would be extremely exclusionary and inequitable (Katz-Lavigne, 2016). The fact that a given situation is non-violent doesn't mean that the distribution of resources is just: it just means that the systems of governance in place are able to define and crucially, impose a certain resource allocation. Unpacking the distribution of resources is important for explaining conflict, but looking solely at conflict, as much literature and policymaking on ASM-LSM relations tends to do, may not be sufficient for understanding inequality in resource access at the local level. Therefore, the work of scholars like Campbell (2013), Geenen (2014), Radley (2019), and others sheds important light on distributional outcomes at the national and local levels in the DRC. I highlighted some of the "winners" and "losers" from the functioning of the property rights regime. Winners include the companies themselves; the employees and security forces who receive benefits and bonuses from participation in corporate enforcement; some customary chiefs; some traders, particularly higher up the supply chain; Chinese, Indian, and Lebanese traders; some artisanal miners (although typically not the majority), including those from other regions; and more. Those who have lost out from LSM investment and the associated PRR include women in the artisanal-mining supply (including female traders); the majority of miners and traders (particularly lower-level traders), which includes miners who lack connections (or the ability to create them) and/or money; some members of ethnic communities at the local level; customary chiefs who possess less, or declining, authority; and others. Even the "losers" do receive some benefits, including through authorised or unauthorised clandestine mining, but mining companies siphon far more out of this resourcerich area than they return in financial or in-kind contributions at the local or national levels.

When corporate property rights are better enforced, there is a negative impact on the extent to which the local resource distribution is equitable i.e. more inclusive of a larger number of local actors, particularly on the lower end of the socio-economic scale. Less effective enforcement practices, on the other hand, contribute to a more equitable resource distribution, though obviously one that is less fair than a situation with no LSM investment would be - as emphasized by Siegel's (2013) discussion of the "missing ethics of mining". It is not only the initial granting (definition) of corporate property, but crucially, the extent to which these PR are enforced, that affects the distribution of resources at the local level. LSM sites with fewer active artisanal miners, everything else being equal, represent a more exclusionary resource distribution (Katz-Lavigne, 2018). The fact that MNCs' property rights 
to mining concessions, granted by the central government, are widely viewed as illegitimate by Congolese civil society and local people is a crucial part of the picture. Young and old, people mining in industrial-mining concessions view these areas as ancestral land on which they are entitled to work (Hönke, 2010; civil society representative, interview, January 24, 2017).

Members of different branches of the security forces as well as government officials benefit in a variety of ways from authorised clandestine extraction, Yet the trend of increasing restrictions on artisanal miners' economic opportunities in Haut-Katanga and Lualaba has had, and continues to have, highly negative effects on miners' livelihoods, socio-economic status, and overall wellbeing. Women are among those negatively affected by these changes, as traders and other actors in the artisanal-mining supply chain, and as dependents of artisanal miners who rely on these miners' income for household expenses. As per findings by Geenen and Claessens (2016), some community members of the communities at and around LSM sites, including land chiefs and members of autochtonous ethnic communities, do benefit financially from the presence of LSM companies and artisanal miners in these areas while others have been negatively affected or unable to benefit from associated opportunities.

Growing inequality is likely to prompt further conflict. As company B's statistics demonstrate, conflict, including violent conflict, at the site is not diminishing but growing in intensity. While some miners are deterred by increased enforcement at LSM sites, some artisanal miners and other individuals and/or groups - who may not be artisanal miners at all, but a different category of people that take company property for sale - are not deterred. These actors may continue to step up their "access maintenance" actions (Geenen $\&$ Claessens, 2016), including aggressive and even potentially violent actions if necessary, to continue to access these sites and the resources they contain. Distributional outcomes across the region may stay relatively stable or worsen somewhat, but this is likely to come at the cost of further conflict, injuries, and deaths.

A key thread that runs through the whole dissertation is the relationship between conflict and distributional outcomes, which are inextricably linked. As explained in the theory chapter, a distribution of resources viewed as unacceptable by part of the population, and their continued pursuit of their claims to these resources, are necessary conditions under which there is significant potential for conflict to occur. Growing exclusion is likely to result in a corresponding increase in conflict, though it is certainly not the only factor; I highlighted the importance of demand for copper and cobalt - linked to price changes and/or growing demand on the world market - for the extent to which outside parties are prepared to use 
different means, including aggressive behaviour, to gain access to these resources. However, as also highlighted in the theoretical chapter, greater exclusion may also push in the direction of greater negative peace, as artisanal miners are deterred by increased security presence and/or adapted security practices - like the use of guard dogs - at LSM sites. My research highlighted that both trends are at work, with certain miners, particularly in the Lubumbashi region, revealing that they no longer take the risk of entering sites $\mathrm{A}$ and/or $\mathrm{B}$. The net impact on conflict of the two trends is therefore a question for further research. Increased restrictions on site entry at a given site have multiple impacts, including deterring those who cannot afford to pay or don't have the necessary connections with a trader to obtain pre-financing, or are unwilling to use aggressive tactics for entry. More restrictive LSM security practices potentially punish more conciliatory behaviour and incentivise more aggressive or violent behaviour. Some miners travel to more "open" sites, which does not resolve the problem of the lack of sites where artisanal miners can safely operate, but only displaces it elsewhere. Therefore, as long as company C's vast mining concession remains a comparatively "open" LSM site in the region for a large number of miners, the distributional impacts in the region are likely to remain, to some extent, stable. However, if miners' economic opportunities are closed off to an extent to which they can no longer fulfill their basic needs, and as the minerals become exhausted at smaller sites like A and B, the situation may even erupt into a state of open conflict as during the guerre civil sociale in Katanga in the 2000s (Hönke, 2009). Addressing the unequal distribution of resources is important not only for instrumental reasons related to conflict, as highlighted in this paragraph, but also, more fundamentally, for ethical reasons (Siegel, 2013). Debates on gender equality have similarly distinguished bewtween intrinsic and instrumental motivations (Klasen, 2000).

This dissertation has also highlighted the importance for international relations scholarship of understanding and assessing the role of property, which is a crucial element of the political economy of southeastern DRC. ${ }^{42}$ Examining the functioning of the property rights regime has made it possible to highlight the importance of power and authority when it comes to property and the distribution of access to resources, as well as the other way around: the way that property matters when it comes to the exercise of power. I have described a variety of ways in which a range of actors, including companies, state security forces, and PSCs, engage in direct violence against artisanal miners who operate in LSM concessions (Galtung, 1969). The extent to which repression and violence is visited onto artisanal miners

\footnotetext{
${ }^{42}$ I am grateful to Rita Abrahamsen for her comments as my discussant at the International Studies Association (ISA) conference in Toronto, Canada, in March 2019, on which this paragraph draws.
} 
when they stake their claims in ways considered unacceptable to security actors and authorities - including avoiding paying rents, and aggressive or unpredictable behaviour - is a clear demonstration of this violence. Equally, though, it can be argued that the property rights regime described above, and its conflict-related consequences and distributional outcomes, constitute structural violence in that the "violence is built into the structure and shows up as unequal power and consequently as un-equal life chances" (Galtung, 1969, p. 171). The property rights regime that I have described, and its strict enforcement - albeit with variation across sites - represents a clear example of structural violence. ${ }^{43}$

I have argued that corporate practices do not always map neatly onto, or overlap perfectly with, company characteristics. Violent incidents and significant human rights abuses have taken place at site $\mathrm{C}$ just like at the other sites. Yet this study has also drawn attention to the impact of the specific property rights regime dynamics at different sites. For instance, the destruction of property, like company C's community liaison bureau, seems counterintuitive considering that this and other, similar incidents took place at a site owned by a company that gives the miners considerable freedom, and respect for their human rights. Such incidents can be linked to the specific dynamics at site $\mathrm{C} 3$, which include a certain amount of company tolerance for artisanal miners' activities; an enormous concession in which town $\mathrm{C} 3$ is right next to the area where the company is extracting minerals; the presence of a large number of miners; and significant popular anger felt by miners, particularly when their colleagues die. Due to the high costs of enforcement miners have a relative amount of "freedom" at site C, but the at times insufficient supply of PR to miners, or only partial fulfillment of their claims, leads them to engage in aggressive behaviour. Additionally, in a comparison of companies A and $\mathrm{B}$, site $\mathrm{A}$ had a reputation of being much easier to enter than site B despite the two sites' proximity to one another. I linked this outcome to the functioning of the property rights regime at these sites, including the specific security approaches adopted by each company. In accordance with Hönke (2010), however, all companies used "harder" forms of security, like the LNI, at different points over time, and one of the PSCs on contract at company C was trialling the use of dogs (already used at company B) during my second research stay. Therefore, there is a need not to lose sight of the broader property rights regime in place beyond these three sites, with similar dynamics likely to be unfolding at other sites in the region, the country, and the continent.

\footnotetext{
${ }^{43}$ Rita Abrahamsen also provided these important insights.
} 
The absence of a tidy overlap between company characteristics, strategies/policies, and practices demonstrates not only the importance of in-depth empirical analysis but also the impact of the functioning of the property rights regime. This analysis highlights the importance, for a deeper understanding of how LSM investment operates, of assessing the types of practices companies engage in at the local level. As Hönke and Börzel (2013) argue, it is essential to understand how companies actually engage in areas of limited statehood rather than always relying on more normative frameworks, as in some of the vast CSR literature. Company practices that merit careful scrutiny include the specific partnerships they enter into with state security forces and private security companies to enforce their property rights, and the terms and outcomes of those arrangements.

While I have drawn attention to the role played by a range of actors, the aim of this study has not been to absolve companies of responsibility for human rights abuses including injuries and deaths of artisanal miners within their mining concessions. Indeed, as shown above by the interview with a company B security officer, some mining-company employees, including those at management level, have significant knowledge of the political economy and property rights regime. They have to have this knowledge in order to ensure the viability of the firm's activities, and gathering this information is part of their job. Company C, as noted, uses researchers to document clandestine extraction and infiltrate artisanal miners. In line with the discussion of direct and structural violence above, the choice to invest in this socio-economic context is an inherently violent choice, regardless of the fact that the Congolese government signed these contracts in the first place. LSM firms first removed artisanal miners from the sites on which they were reliant for their livelihoods, despite the fact that there are few viable livelihood alternatives in the area. In turn, these companies have placed miners in a position in which, at sites where they previously worked or that they live in the vicinity of, they are in regular contact with frequently unaccountable security forces. One of the different security forces' main goals is to look out for their own interests through coercion and even violence if necessary. In a context where the different security forces charged at different times and different sites with guarding the mines have been implicated in human rights abuses, it is not only how companies engage with these actors that matters but the fact that they do so to begin with. I have analysed very fine-grained, locally embedded processes yet, as shown by Hönke $(2013,2014)$, LSM investment in southeastern DRC is a hybrid phenomenon governed at multiple levels, including the transnational. Efforts like corporate social responsibility and adherence to the Voluntary Principles on Security and Human Rights are a way for companies to ensure that their operations run smoothly as much 
as they are measures to benefit local people and protect them from human rights abuses. Companies co-constitute a highly exploitative property rights regime and therefore bear a significant share of responsibility for a situation in which miners are frequently and repeatedly at the mercy of security forces, with all the human rights abuses, dispossession, and economic exploitation that that situation involves. Hönke's (2010) concept of "indirect discharge" can also be applied in reverse, to the fact that companies rely on state actors and bodies to carry out a significant number of tasks, including securing their mine sites. Consequently, companies can and do "discharge" responsibility when injuries or deaths occur at their sites.

I do not, however, seek to imbue networks and processes for clandestine extraction of minerals with an undeservedly positive or egalitarian character, in the way that, as Kate Meagher (2014) points out, some recent scholarship has done when it comes to African clandestine economies - though I also avoid the term "predatory" that Li (2018) uses. As Geenen and Hönke (2014) and Geenen and Claessens (2016) argue, powerful local and national elites have proven highly skilled at protecting and advancing their interests in a context of LSM investment. Yet, as shown by Raeymaekers (2007), the activities of security forces seeking to fulfill their own interests also happen at times to assist miners in seeking theirs, in a way arguably more supportive of broad local redistribution than any measures that flow through the central government and/or the mining companies - which includes CSR. Further study is needed on the impact on miners's physical and mental wellbeing of these continuous, repeated, everyday encounters at LSM sites, and how these dynamics impacts their ability to save, invest, and pursue meaningful lives. Previous research on artisanal miners in southeastern DRC has indicated that miners are often under social pressure to live a lifestyle not conducive to financial stability (Cuvelier, 2011). The impact on miners of living a life in which many of them are regularly chased away, beaten, arrested, or worse - or in which they are obliged to pay out significant sums in an attempt to avoid that fate - is an important area of further study and should be part of the policy discussion around ASM. There is also a need to compare miners' incomes in "pure ASM" versus in clandestine mining, to ascertain whether the "illegality" associated with the latter means lower incomes, or if miners across the region are equally (poorly) remunerated no matter what their status.

A further area of research lies in the fact of an increasingly inequitable resource distribution and an increasingly squeezed population of artisanal miners and dependents. This dissertation has included compelling evidence that a significant enough share of the population is able to use creative tactics to secure access to LSM sites in a context in which they struggle to provide for their daily needs. Therefore, compensation - such as the 200 USD 
that company B provided to miners when they were cleared from the site - could potentially be an important part of policy measures to address the plight of artisanal miners. Yet in light of the record and of people's experiences in a similar issue area-compensation for displacement from community land - it is highly likely that miners will not view compensation-based solutions as sufficient. Officially at least, actors involved in ASM are not seen as legitimate partners for discussion and cooperation across the case study sites in southeastern DRC (Hönke, 2018). Unofficially, there may be greater flexibility shown in practice, as each of the sites exhibited to greater or lesser degrees. There would likely be a disconnect between what companies are willing to pay and what artisanal miners would consider an acceptable sum to compensate for the loss of their livelihoods; these significant transaction costs would make it difficult, if not impossible, to come to agreement (Libecap, 1986). There was no consistency across the case study sites in terms of compensation when artisanal miners were cleared from the concessions after these sites were occupied. While the miner eviction process at site B (where miners received 200 USD each) was more peaceful than at site A, where no compensation was provided, at the time of research many miners continued to travel to site B to extract minerals (EMAK representative, interview, February 1, 2017). These dynamics highlight the limitations of compensation-based solutions without wider improvements in the availability of viable or desired livelihoods. Additionally, artisanal miners lack bargaining power and the people meant to represent them, including government representatives, may place their own private interests above ensuring that miners' claims are acknowledged and their rights respected. Policy solutions that have been proposed elsewhere in Africa for concession sharing between MNCs and miners are likely to represent a more viable path, though it is unlikely that these sorts of mechanisms can be formalised in the context of southeastern DRC, where companies are unwilling to even recognise artisanal miners as interlocutors. Formalisation-based approaches also have significant potential limitations (Geenen, 2012) that may mean there is a continued advantage to unstructured, negotiated, and contextually specific adaptations like clandestine mining itself. Efforts to push companies to be more flexible towards miners, or to raise broad public awareness of miners' plight, may be counterproductive if these efforts cause unwanted publicity for companies, leading them to crack down on the presence of artisanal miners. If companies espouse inflexible security practices, there is an inevitable impact on miners' livelihoods. The stepping-up of company security at sites in the Lubumbashi area is therefore of concern, as is the fact that security practices that instill fear in miners - specifically, the use of dogs - have been adopted, at least on a trial basis, at site $\mathrm{C}$ as well. Policy initiatives that address LSM- 
ASM conflict in the region and elsewhere in Africa should consider the complexity of the issues involved when it comes to resolving conflict or preventing human rights abuses in the cobalt-mining sector.

Finally, training - like company $\mathrm{C}$ has organised for the Mine Police in the wake of injuries and deaths of artisanal miners - is also an important element of the policy picture. Company $\mathrm{C}$ reporting over time suggests that this training has had a favourable impact on the incidence of conflict and human rights abuses. It is worth pursuing training as a policy solution to the extent possible. Although multiple cases of deaths of miners at the hands of the security forces have been documented at the different sites, the relatively low numbers of such incidents suggest that miners' deaths are, to some extent, taken seriously and addressed by companies and other actors, like MONUSCO. However, my data suggests that other human rights abuses, such as beatings by security guards and police officers, continue across all sites and should also be taken seriously from a policy perspective. The high human and financial toll associated with repeated arrest reflects not only the functioning of the property rights regime, but also the ongoing structural violence that is likely to persist in this region of the $\mathrm{DRC}$ as long as the large-scale mining does. 


\section{Reference List}

Abrahamsen, R., \& Williams, M. C. (2009). Security beyond the state: Global security assemblages in international politics. International Political Sociology, 3(1), 1-17. doi: 10.1111/j.1749-5687.2008.00060.x

Abrahamsen, R., \& Williams, M. C. (2017). Golden assemblages: Security and development in Tanzania's gold mines. In P. Higate and M. Utas (Eds.), Private security in Africa (15-31). London; Uppsala: Zed Books; Nordiska Afrikainstutet.

Abuya, W. O. (2016). Mining conflicts and Corporate Social Responsibility: Titanium mining in Kwale, Kenya. The Extractive Industries and Society, 3(2), 485-493.

doi:10.1016/j.exis.2015.12.008

Acemoglu, D., \& Robinson, J. (2012). Why nations fail: The origins of power, prosperity and poverty. New York: Crown.

ACIDH. (2012). Company responses to ACIDH re: Unheard Voices. https://www.businesshumanrights.org/sites/default/files/media/documents/company_responses/companyresponses-to-acidh-re-unheard-voices-2012.pdf

Akram-Lodhi, A. H. (2007). Land reform, rural social relations and the peasantry. Journal of Agrarian Change, 7(4), 554-562.

doi: 10.1111/j.1471-0366.2007.00156.x

Alston, L. J., Harris, E., \& Mueller, B. (2009). De facto and de jure property rights: Land settlement and land conflict on the Australian, Brazilian and U.S. frontiers. Cambridge, MA: National Bureau of Economic Research.

http://www.nber.org/papers/w15264.pdf

Amnesty International. (2013). Profits and loss: Mining and human rights in Katanga, Democratic Republic of the Congo.

https://www.amnesty.org/en/documents/afr62/001/2013/en/

Anderson, T. L., \& McChesney, F. S. (Eds.). (2003). Property rights: Cooperation, conflict, and law. Princeton and Oxford: Princeton University Press.

Aubynn, A. (2009). Sustainable solution or a marriage of inconvenience? The coexistence of large-scale mining and artisanal and small-scale mining on the Abosso

Goldfields concession in Western Ghana. Resources Policy, 34(1-2), 64-70.

doi:10.1016/j.resourpol.2008.04.002

Bagree, S. (2019). The money drain: Financial outflows from Southern Africa. Review of

African Political Economy (ROAPE). http://roape.net/2019/09/17/the-money-drain-financialoutflows-from-southern-africa/

Banchirigah, S. M. (2006). How have reforms fuelled the expansion of artisanal mining? Evidence from sub-Saharan Africa. Resources Policy, 31(3), 165-171. doi:

10.1016/j.resourpol.2006.12.001 
Banchirigah, S. M. (2008). Challenges with eradicating illegal mining in Ghana: A perspective from the grassroots. Resources Policy, 33(1), 29-38. doi:

10.1016/j.resourpol.2007.11.001

Bayart, J.-F., \& Ellis, S. (2000). Africa in the world: A history of extraversion. African Affairs, 99(395), 217-267. https://www.jstor.org/stable/723809

Berdal, M. (2005). Beyond greed and grievance: And not too soon . . . a review essay. Review of International Studies, 31(4), 687-698. https://www.jstor.org/stable/40072114

Bierschenk, T. (2019). La police, la bureaucratie et l'État. Arbeitspapiere des Instituts für Ethnologie und Afrikastudien der Johannes Gutenberg-Universität Mainz (Working Papers of the Department of Anthropology and African Studies of the Johannes Gutenberg University Mainz). https://www.blogs.uni-mainz.de/fb07-ifeas/files/2019/07/AP_185.pdf

Blundo, G, \& Oliver de Sardan, J-P. (2001). La corruption quotidienne en Afrique de l'Ouest. Politique africaine, 3(83), 8-37. https://www.cairn.info/revue-politique-africaine-2001-3page-8.htm

Bolay, M. (2014). When miners become "foreigners": Competing categorizations within gold mining spaces in Guinea. Resources Policy, 40, 117-127.

doi:10.1016/j.resourpol.2014.02.001

Boone, C. (2018). Legal empowerment of the poor through property rights reform: Tensions and trade-offs of land registration and titling in Sub-Saharan Africa. The Journal of Development Studies, 55(3), 384-400. doi:10.1080/00220388.2018.1451633

Börzel, T. A., \& Hönke, J. (2011). From compliance to practice: mining companies and the voluntary principles on security and human rights in the Democratic Republic of Congo. (SFB Working Paper; No. 25). Berlin: DFG Research Center (SFB) 700. https://www.sfbgovernance.de/en/publikationen/sfb-700-working_papers/wp25/index.html

Börzel, T. A., Hönke, J., \& Thauer, C. (2012). Does it really take the state? Limited statehood, multinational corporations and corporate responsibility in South Africa. Business and Politics 14(3): 1-34. doi:10.1515/bap-2012-0023

Brozus, L. (2011). Applying the governance concept to areas of limited statehood: Implications for international foreign and security policy. In T. Risse, T. (Ed.), Governance without a state? Policies and politics in areas of limited statehood (pp. 262-280). New York: Columbia University Press.

Bruce, J. W., \& Mearns, R. (2002). Natural resource management and land policy in developing countries: Lessons learned and new challenges for the World Bank. https://web.worldbank.org/archive/website00668/WEB/PDF/NATURALR.PDF

Campbell, B. (2010). Revisiting the reform process of African mining regimes. Canadian Journal of Development Studies, 30(1-2), 197-217. doi:10.1080/02255189.2010.9669288

Campbell, B. (2012). Corporate Social Responsibility and development in Africa: 
Redefining the roles and responsibilities of public and private actors in the mining sector. Resources Policy, 37(2), 138-143. doi:10.1016/j.resourpol.2011.05.002

Campbell, B. K. (Ed.). (2013). Modes of governance and revenue flows in African mining. Palgrave Macmillan.

Carstens, J., \& Hilson, G. (2009). Mining, grievance and conflict in rural Tanzania. International Development Planning Review, 31(3) > doi:10.3828/idpr.31.3.5

Carter Center, The. (2007, November 30). Review of DRC Mining Contracts - Update and Recommendations.

https://www.cartercenter.org/documents/drc_mining_contracts_113007.pdf

Carter Center, The. (2012, October). Les investissements miniers en République

Démocratique du Congo : Développement ou appauvrissement des communautés locales? https://www.cartercenter.org/resources/pdfs/news/peace_publications/human-rights/cartercenter-mining-governance-hria-oct2012.pdf

Carter Center, The. (2017). A state affair: Privatizing Congo's copper sector. https://www.cartercenter.org/resources/pdfs/news/peace_publications/democracy/congoreport-carter-center-nov-2017.pdf

Chojnacki, S., \& Branovic, Z. (2011). New modes of security: The violent making and unmaking of governance in war-torn areas of limited statehood. In T. Risse, T. (Ed.), Governance without a state? Policies and politics in areas of limited statehood (pp. 89-114). New York: Columbia University Press.

Collier, P., \& Hoeffler, A. (2004). Greed and grievance in civil war. Oxford Economic Papers 56(4), 563-95. doi:10.1093/oep/gpf064

Congo copper production down 8.2 pct in Q3: chamber of mines. (2015, November 14). Reuters. https://af.reuters.com/article/africaTech/idAFKCN0T30XK20151114

Copper price close to six-and-a-half-year low. (2015, September 29). BBC News. Retrieved from http://www.bbc.com/news/business-34390615

Coumans, C. (2019). Minding the "governance gaps": Re-thinking conceptualizations of host state "weak governance" and re-focussing on home state governance to prevent and remedy harm by multinational mining companies and their subsidiaries. The Extractive Industries and Society, 6(3), 675-687. doi:10.1016/j.exis.2019.06.003

Counter Balance. (2008). EU development money extracting more wealth from Africa, finds new report on Congolese copper mine. https://www.counter-balance.org/eu-developmentmoney-extracting-more-wealth-from-africa-finds-new-report-on-congolese-copper-mine/

Côte, M., \& Korf, B. (2017). Making concessions: Extractive enclaves, entangled capitalism and regulative pluralism at the gold mining frontier in Burkina Faso. World Development, 101, 466-476. doi: 10.1016/j.worlddev.2016.11.002 
Custers, R., \& Nordbrand, S. (2008). Risky business: The Lundin Group's involvement in the Tenke Fungurume Mining project in the Democratic Republic of Congo.

https://www.diakonia.se/globalassets/documents/diakonia/publications/reports/20080219_risk y_business.pdf

Cuvelier, J. (2011). Men, mines and masculinities: the lives and practices of artisanal miners in Lwambo (Katanga province, DR Congo). https://biblio.ugent.be/publication/1863372

Daudelin, J., \& Ratton, J. L. (2018). Illegal markets, violence, and inequality: Evidence from a Brazilian metropolis. Palgrave Macmillan.

Democratic Republic of Congo (DRC) Cadastre Minier (CAMI) and Trimble Land Administration. (2017). DRC Mining Cadastre Portal. http://drclicences.cami.cd/en/

Democratic Republic of Congo: Mineral industry overview. (2011, September 25). Afribiz. https://web.archive.org/web/20120102141004/http://www.afribiz.info/content/democraticrepublic-of-congo-mineral-industry-overview

De Koning, R. (2009). Artisanal mining and post-conflict reconstruction in the Democratic Republic of Congo. SIPRI Background Paper.

https://www.files.ethz.ch/isn/109111/SIPRIBP0910b.pdf

De Soto, H. (2000). The mystery of capital: why capitalism triumphs in the West and fails everywhere else. New York: Basic Books.

Demsetz, H. (1967). Toward a theory of property rights. The American Economic Review, 57(2), pp. 347-359.

https://econ.ucsb.edu/ tedb/Courses/Ec100C/Readings/Demsetz_Property_Rights.pdf

Dibwe dia Mwembu, D. (n.d.). La problématique de l'habitat dans la ville de Lubumbashi (Elisabethville), province du Katanga, 1910-1960. https://opr.degruyter.com/the-politics-ofhousing-in-colonial-and-postcolonial-africa/donatien-dibwe-dia-mwembu-la-problematiquede-lhabitat-dans-la-ville-de-lubumbashi-elisabethville-province-du-katanga-1910-1960/

Diemel, J. A. (2018). Mining reform, governance and the state in the Democratic Republic of the Congo: The traces 'conflict-mineral' policy left behind on natural resource governance in Katanga. https://repub.eur.nl/pub/111768

Diemel, J., \& Cuvelier, J. (2015). Explaining the uneven distribution of conflict mineral policy implementation in the Democratic Republic of the Congo: the role of the Katanga policy network (2009-2011). Resources Policy, 46(2). p.151-160.

10.1016/j.resourpol.2015.09.006

The DRC: Dangerous battle for influence in the former Katanga. (2017, June 19). Zimbabwe Independent. https://www.theindependent.co.zw/2017/06/19/drc-dangerous-battle-influenceformer-katanga/

Drohan, M. (2003). Making a killing: How and why corporations use armed force to do business. Random House Canada. 
Enough Project. (2018, October). Powering down corruption: Tackling transparency and human rights risks from Congo's cobalt mines to global supply chains. Callaway, A. https://enoughproject.org/wp-content/uploads/PoweringDownCorruption_Enough_Oct2018web.pdf

Eriksson Baaz, E., Olsson, O., \& Verweijen, J. (2018). Navigating 'taxation' on the Congo River: the interplay of legitimation and 'officialisation'. Review of African Political Economy, 45(156), 250-266. Doi:10.1080/03056244.2018.1451317

Euro Security Products. (n.d.). Tonfas. https://www.euro-security.info/en/tonfas.html

Extractive Industries Transparency Initiative Democratic Republic of Congo (EITI DRC). (2015a, December). Rapport ITIE RDC 2014. Moore Stephens LLP. https://eiti.org/sites/default/files/documents/2014_drc_eiti_report_fr.pdf

Extractive Industries Transparency Initiative Democratic Republic of Congo (EITI DRC). (2017, December). Rapport ITIE RDC 2015. Moore Stephens LLP.

https://eiti.org/sites/default/files/documents/rapport_de_conciliation_itie_rdc_2015__signe_envoye_st.pdf

Factbox-mining in the Democratic Republic of Congo. (2008, May 14). Reuters.

https://www.reuters.com/article/congo-democratic-mining/factbox-mining-in-the-democraticrepublic-of-congo-idINL1464465520080514? $\mathrm{rpc}=44$

Faber, Krause, and Sánchez De La Sierra. (2017). Artisanal mining, livelihoods, and child labor in the cobalt supply chain of the Democratic Republic of Congo.

http://cega.berkeley.edu/assets/cega_research_projects/179/CEGA_Report_v2.pdf

Farrell, L. A., Hamann, R., \& Mackres, E. (2012). A clash of cultures (and lawyers): Anglo Platinum and mine-affected communities in Limpopo Province, South Africa. Resources Policy, 37(2), 194-204. doi:10.1016/j.resourpol.2011.05.003

Feeny, D., Berkes, F., McCay, B.J., \& Acheson, J.M. (1990). The Tragedy of the Commons: Twenty-two years later. Human Ecology, 18(1), 1-19. https://link.springer.com/article/10.1007/BF00889070

Ferguson, J. (2005). Seeing like an oil company: Space, security, and global capital in neoliberal Africa. American Anthropologist, 107(3), 377-382.

doi:10.1525/aa.2005.107.3.377

Fitzpatrick, D. (2006). Evolution and chaos in property rights systems: The Third World tragedy of contested access. The Yale Law Journal, 115, 996-1048.

http://www.yalelawjournal.org/essay/evolution-and-chaos-in-property-rights-systemsthethird-world-tragedy-of-contested-access

Fleury, A-M., \& Davies, B. (2012). Sustainable supply chains - minerals and sustainable development, going beyond the mine. Resources Policy, 37(2), 175-178.

doi:10.1016/j.resourpol.2012.01.003 
Frederiksen, T. (2019). Political settlements, the mining industry and corporate social responsibility in developing countries. The Extractive Industries and Society, 6(1), 162-170. doi:10.1016/j.exis.2018.07.007

Galiani, S., \& Schargrodsky, E. (2011). Land property rights and resource allocation. Journal of Law and Economics, 54(4), S329-S345. doi:10.1086/661957

Gallien, M. (2019). Informal institutions and the regulation of smuggling in North Africa. Perspectives on Politics, 1-17. doi:10.1017/S1537592719001026

Galtung, J. (1964). An editorial. Journal of Peace Research 1(1), 1-4. Retrieved from https://www.jstor.org/stable/422802

Galtung, J. (1969). Violence, peace, and peace research. Journal of Peace Research, 6(3), 167-191. https://www.jstor.org/stable/422690

Gardner, K., Ahmed, Z., Bashir, F., \& Rana, M. (2012). Elusive partnerships: Gas extraction and CSR in Bangladesh. Resources Policy, 37(2), 168-174.

doi:10.1016/j.resourpol.2012.01.001

Geenen (2012). A dangerous bet: The challenges of formalizing artisanal mining in the Democratic Republic of Congo. Resources Policy, 37(3), 322-330.

doi:10.1016/j.resourpol.2012.02.004

Geenen, S. (2013). 'Who seeks, finds': How artisanal miners and traders benefit from gold in the eastern Democratic Republic of Congo. The European Journal of Development Research, 25(2), 197-212. https://link.springer.com/article/10.1057\%2Fejdr.2012.19

Geenen, S. (2014). Dispossession, displacement and resistance: Artisanal miners in a gold concession in South-Kivu, Democratic Republic of Congo. Resources Policy, 40, 90-99. doi:10.1016/j.resourpol.2013.03.004

Geenen (2016). Hybrid governance in mining concessions in Ghana. IOB working paper. https://www.uantwerpen.be/en/research-groups/iob/publications/working-papers/wp2016/wp-201605/

Geenen, S., \& Claessens, K. (2013). Disputed access to the gold sites in Luhwindja, eastern Democratic Republic of Congo. The Journal of Modern African Studies, 51(1), 85-108. doi:10.1017/S0022278X12000559

Geenen, S., \& Claessens, K. (2016). Different faces of access control in a Congolese gold mine. Third World Thematics, 1(2), 249-266. 10.1080/23802014.2016.1180544

Geenen, S., \& Hönke, J. (2014). Land grabbing by mining companies: Local contentions and state reconfiguration in South Kivu (DRC). In A. Ansoms and T. Hilhorst (Eds.), Losing your land: Dispossession in the Great Lakes (58-81). Oxford: James Currey.

Geenen, S., \& Verweijen, J. (2017). Explaining fragmented and fluid mobilization in gold mining concessions in eastern Democratic Republic of the Congo. The Extractive Industries and Society, 4(4), 758-765. doi:10.1016/j.exis.2017.07.006 
George, A. L., and Bennett, A. (2005). Case studies and theory development in the social sciences. MIT Press.

Gewald, J.-B., \& Soeters, S. (2010). African miners and shape-shifting capital flight: The case of Luanshya/Baluba. In A. Fraser \& M. Larmer (Eds), Zambia, Mining, and Neoliberalism (155-183). New York: Palgrave Macmillan.

Gilberthorpe, E., \& Banks, G. (2012). Development on whose terms?: CSR discourse and social realities in Papua New Guinea's extractive industries sector. Resources Policy, 37(2), 185-193. doi:10.1016/j.resourpol.2011.09.005

Global Witness. (2006, July). Digging in corruption: Fraud, abuse and exploitation in Katanga's copper and cobalt mines. https://www.globalwitness.org/en/archive/diggingcorruption/

Global Witness. (2014, May 13). Congo's secret sales.

https://www.globalwitness.org/en/campaigns/oil-gas-and-mining/congo-secret-sales/

Gobbers, E. (2016). Ethnic associations in Katanga province, the Democratic Republic of Congo: multi-tier system, shifting identities and the relativity of autochthony. Journal of Modern African Studies, 54(2), 211-236.

Gratuité de l'enseignement : les parents des élèves inscrits en $7 \mathrm{e}$ et $8 \mathrm{e}$ ne paieront que les frais de scolarité (ministre). (2019, September 17). Radio Okapi.

https://www.radiookapi.net/2019/09/17/actualite/education/gratuite-de-lenseignement-lesparents-des-eleves-inscrits-en-7e-et-8e?fbclid=IwAR38g9AiKndpIJDn7wcSj64KDsJ6q6Z5prJM-S0IZ1RSZIjTwuN7vX2E_c

Haddock, D. D. (2003). Force, threat, negotiation: The private enforcement of rights. In T. L. Anderson \& F. S. McChesney (Eds.), Property Rights: Cooperation, Conflict, and Law (168194). Princeton: Princeton University Press.

Haglund, D. (2010). From boom to bust: Diversity and regulation in Zambia's privatized copper sector. In A. Fraser \& M. Larmer (Eds), Zambia, Mining, and Neoliberalism (91-126). New York: Palgrave Macmillan.

Hilson, G., \& Potter, C. (2005). Structural adjustment and subsistence industry: artisanal gold mining in Ghana. Development and Change, 36(1), 103-131. doi:10.1111/j.0012155X.2005.00404.X

Hilson, G., \& Yakovleva, N. (2007). Strained relations: A critical analysis of the mining conflict in Prestea, Ghana. Political Geography, 26, 98-119.

doi:10.1016/j.polgeo.2006.09.001

Hirschman, A. O. (1972). Exit, voice, and loyalty: Responses to decline in firms, organizations, and states. Harvard University Press. 
Hofferberth, M. (2017). "And of course our major contribution remains to run a decent business." Making sense of Shell's sense-making in Nigeria during the 1990s. Business and Politics, 19(1), pp. 135-165. doi:10.1017/bap.2016.8

Hoffman, K., \& Kirk, T. (2013). Public authority and the provision of public goods in conflict-affected and transitioning Regions.

https://eprints.lse.ac.uk/56353/1/JSRP_Paper7_Public_authority_and_the_provision_of_publi c_goods_in_conflict-affected_and_transitioning_regions_Hoffman_Kirk_2013.pdf

Hönke, J. (2009). Transnational pockets of territoriality. Governing the security of extraction in Katanga (DRC) (Working Paper Series No. 2).

http://www.unileipzig.

de/ ral/gchuman/fileadmin/media/publikationen/Working_Paper_Series/RAL_W

P_2_Hoenke_web.pdf

Hönke, J. (2010). New political topographies: Mining companies and indirect discharge in southern Katanga (DRC). Politique Africaine, 120(4), 105-127. doi:10.3917/polaf.120.0105

Hönke, J. (2012). Multinationals and security governance in the community:

Participation, discipline and indirect rule. Journal of Intervention and Statebuilding, 6, 57-73. doi:10.1080/17502977.2012.655569

Hönke, J. (2013). Transnational companies and security governance: Hybrid practices in a postcolonial world. Abingdon: Routledge.

Hönke, J. (2014). Business for peace? The ambiguous role of 'ethical' mining companies. Peacebuilding, 2(2), 172-187. doi:10.1080/21647259.2014.910383

Hönke, J. (2018). Transnational clientelism, global (resource) governance, and the disciplining of dissent. International Political Sociology, 12(2), 109-124.

doi:10.1093/ips/oly007

Hönke, J., \& Börzel, T. A. (2013). Restraint of statehood and the quality of governance by multinational companies in sub-Saharan Africa (SFB-Governance Working Paper Series). Berlin: DFG Collaborative Research Center.

http://www.research.ed.ac.uk/portal/files/14801631/Restraint_of_Statehood_and_the_Qu ality_of_Governance_by.pdf

Hönke, J., \& Thauer, C. R. (2014). Multinational corporations and service provision in sub-Saharan Africa: Legitimacy and institutionalization matter. Governance, 27(4), 697716. doi:10.1111/gove. 12072

Hönke, J., \& Thomas, E. (2012). Governance for whom?: Capturing the inclusiveness and unintended effects of governance (SFB-Governance Working Paper Series). Berlin:

DFG Collaborative Research Center.

http://www.research.ed.ac.uk/portal/en/publications/governance-for-whom(a5c395aefdd24d45-bf6b-19f11b5dcbed).html 
Hunter, A., Luk, J., \& Zhou, S. (2019, March 20). DRC bans cobalt, copper concentrate exports. Fastmarkets. https://www.fastmarkets.com/article/3864886/exclusive-drc-banscobalt-copper-concentrate-exports-cutting-off-zambia-trade

Idemudia. (2017). Shell-NGO partnership and peace in Nigeria: Critical insights and implications. Organization \& Environment, 31(4), 384-405. doi:10.1177/1086026617718428

International Council on Mining \& Metals. (2015). In brief: Research on company-community conflict. https://www.icmm.com/document/8515

International Crisis Group. (2016, August 3). Katanga: Tensions in DRC's mineral heartland. Africa Report no. 239. https://www.crisisgroup.org/africa/central-africa/democratic-republiccongo/katanga-tensions-drcs-mineral-heartland

Jamasmie, C. (2019, January 18). China Moly ups stake in giant Tenke copper mine to 80\%. Mining.com. https://www.mining.com/china-moly-ups-stake-giant-tenke-copper-mine-80/

Joint UNEP/OCHA Environment Unit. (2004). Mine uranifère de Shinkolobwe, République démocratique du Congo: Mission d'évaluation de la situation humanitaire. https://www.unocha.org/sites/dms/Documents/Humanitaire_Rap_FINAL_161204.pdf

Kankolongo Mbombo, M. (2017). Les patrouilles de la Police Nationale Congolaise à MbujiMayi et les dessous de "L'Operation Café". Facteurs explicatifs et issues possibles. https://idl-bnc-idrc.dspacedirect.org/bitstream/handle/10625/56483/IDL-56483.pdf

Katz-Lavigne, S. (2016). Property rights and large-scale mining: Overlapping claims at and around mining sites in the Democratic Republic of Congo and Zambia. Third World Thematics, 1(2). doi:10.1080/23802014.2016.1196604

Katz-Lavigne, S. (2018). Artisanal copper mining and conflict at the intersection of property rights and corporate strategies in the Democratic Republic of Congo. The Extractive Industries and Society, 6(2), 399-406. doi:10.1016/j.exis.2018.12.001

Keen, D. (2012). Greed and grievance in civil war. International Affairs, 88(4), 757-777. doi:10.1111/j.1468-2346.2012.01100.x.

Kennes, E. (2002). Footnotes to the mining story. Review of African Political Economy, 29(93), 601-606. doi: 10.1080/03056240208704643

Kiconco, A. (2019, June 26). How do you ethically ask a former female child soldier or wartime sexual violence survivor about their experience? openDemocracy.

https://www.opendemocracy.net/en/beyond-trafficking-and-slavery/speaking-about-violencesierra-leone/?fbclid=IwAR2np7pxHtLQxxu-rAvtuK9pL-

ai9zFHS3CiN3x_Dxfc87n8g7PUzXX8nUo

Kilosho Buraye, J., Stoop, N., \& Verpoorten, M. (2017). Defusing the social minefield of gold sites in Kamituga, South Kivu. From legal pluralism to the re-making of institutions?

Resources Policy, 53, 356-368. doi:10.1016/j.resourpol.2017.07.009

King, H. M. (n.d.). Malachite. Geology.com. https://geology.com/minerals/malachite.shtml 
Kinshasa : pour stopper les arnaques, les agents du Bureau 2 seront désormais missionnés par le chef de la police. (2017, August 17). Radio Okapi.

https://www.radiookapi.net/2017/08/17/actualite/securite/kinshasa-pour-stopper-les-arnaquesles-agents-du-bureau-2-seront

Klasen. (2000). Does gender inequality reduce growth and development? Evidence from cross-country regressions. Discussion Paper No 212. https://epub.ub.unimuenchen.de/1602/1/paper_212.pdf

Knierzinger, J. (2014). The socio-political implications of bauxite mining in Guinea: A commodity chain perspective. The Extractive Industries and Society, 1(1), 20-27. doi:10.1080/23322373.2019.1689004

Lee, C. K. (2010). Raw encounters: Chinese managers, African workers, and the politics of casualization in Africa's Chinese enclaves. In A. Fraser \& M. Larmer (Eds), Zambia, mining and neoliberalism: Boom and bust on the globalized Copperbelt (127-153). New York: Palgrave Macmillan.

Le Billon (2001). The political ecology of war: natural resources and armed conflicts. Political Geography, 20(5), 561-584. doi:10.1016/S0962-6298(01)00015-4

Li, T. M. (2018). After the land grab: Infrastructural violence and the "Mafia System" in Indonesia's oil palm plantation zones. Geoforum, 96, 328-337.

doi:10.1016/j.geoforum.2017.10.012.

Libecap, G. D. (1986). Property rights in economic history: Implications for research. Explorations in Economic History 23, 227-252. http://www.colorado.edu/ibs/es/alston/econ4524/readings/Libecap,\%20 Property\%20Rights\%20in\%20Economic\%20History.pdf.

Libecap, G. D., \& National Bureau for Economic Research. (1999, November 15). Contracting for property rights.

https://citeseerx.ist.psu.edu/viewdoc/download?doi=10.1.1.22.5250\&rep=rep1\&type=pdf

Lualaba: les creuseurs artisanaux reçoivent une balance électronique des minerais. (2016, March 28). Radio Okapi. https://www.radiookapi.net/2016/03/28/actualite/economie/lualabales-creuseurs-artisanaux-recoivent-une-balance-electronique

Lualaba: près de 10000 creuseurs clandestins envahissent le site de Tenke Fungurume. (2016, November 21). Radio Okapi.

https://www.radiookapi.net/2016/11/21/actualite/societe/lualaba-pres-de-10-000-creuseursclandestins-envahissent-le-site-de

Lubumbashi : 5 personnes blessées dans les échauffourées autour de la concession de Ruashi Mining. (2013, November 12). Radio Okapi. https://www.radiookapi.net/actualite/2013/11/12/lubumbashi-5-personnes-blessees-dans-lesechauffourees-autour-de-la-concession-de-ruashi-mining 
Luning, S. (2012). Corporate Social Responsibility (CSR) for exploration: Consultants, companies and communities in processes of engagements. Resources Policy, 37(2), 205-211. doi:10.1016/j.resourpol.2011.02.004

Mathys, G., \& Vlassenroot, K. (2016). 'It's not all about the land': Land disputes and conflict in the eastern Congo. Rift Valley Institute PSRP Briefing Paper 14.

http://riftvalley.net/publication/its-not-all-about-land

Marysse, S., \& Geenen, S. (2009). Win-win or unequal exchange? The case of the Sino-Congolese cooperation agreements. The Journal of Modern African Studies, 47, 371396. doi:10.1017/S0022278X09003978.

May, C. (1996). Strange fruit: Susan Strange's theory of structural power in the international political economy. Global Society, 10(2). doi:10.1080/13600829608443105

Meagher, K. (2014). Smuggling ideologies: From criminalization to hybrid governance in African clandestine economies. African Affairs, 113(453), 497-517. doi:10.1093/afraf/adu057

Meinzen-Dick, R., \& Mwangi, E. (2009). Cutting the web of interests: Pitfalls of formalizing property rights. Land Use Policy 26(1), 36-43. doi:10.1016/j.landusepol.2007.06.003.

MiningWatch Canada. [MiningWatch]. (2019, July 3). "Important context, especially when small scale miners are called "thieves" or "intruders" when what is happening is just imbalance of power, on top of economic \& physical insecurity. And what is "illegal" depends on who writes the laws." [Tweet].

https://twitter.com/MiningWatch/status/1146379872954175488.

Mthembu-Salter, G. (2011, October). Indian mining companies in the Democratic Republic of Congo.

https://www.google.com/url?sa=t\&rct=j\&q=\&esrc=s\&source=web\&cd=1\&ved=0ahUKEwiH z5uE05TbAhVJyoMKHV7oBd4QFggpMAA\&url=https\%3A\%2F\%2Fwww.africaportal.org \%2Fdocuments\%2F7023\%2Fsaia_spb_35_mthembu_salter_20111031.pdf\&usg=AOvVaw1P 6WXSr24JsbhFqP8LcvNR

Müller-Koné, M. (2015). Débrouillardise: certifying 'conflict-free' minerals in a context of regulatory pluralism in South Kivu, DR Congo. The Journal of Modern African Studies, 53(2), 145-168. doi:10.1017/S0022278X15000178

Mutti, D., Yakovleva, N., Vazquez-Brust, D., \& H. Di Marco, M. (2012). Corporate social responsibility in the mining industry: Perspectives from stakeholder groups in Argentina. Resources Policy, 37(2), 212-222. doi:10.1016/j.resourpol.2011.05.001

Mwangi, E. (2007). Subdividing the commons: Distributional conflict in the transition from collective to individual property rights in Kenya's Maasailand. World Development, 35(5), 815-834. doi:10.1016/j.worlddev.2006.09.012

Ndulo, M. (2013). African Development Bank High Level Policy Seminar on Optimizing the Benefits of Coal \& Gas in Mozambique: Legal and regulatory frameworks for resource exploration and extraction-global experience. http://www.afdb.org/fileadmin/uploads/afdb/Documents/Generic- 
Documents/Presentation $\% 20$ -

$\% 20$ Legal $\% 20$ and $\% 20$ Regulatory $\% 20$ Frameworks $\% 20$ for $\% 20$ Resource $\% 20$ Exploration. pdf

Ngoie Mwenze, H. (2009). La co-production de la sécurité à l'épreuve de l'observation. Polices publiques et privées dans les Usines Gécamines de Shituru à Likasi (Katanga / RDC) (Doctoral dissertation). University of Lubumbashi, Lubumbashi.

Nguyen, V. T. [viet thanh nguyen]. (2019, April 24). "If you shouldn't call it the Third World, what should you call it?" I don't know...the majority? [Tweet].

https://twitter.com/viet_t_nguyen/status/1121205442758070272.

Nyame, F. K., \& Grant, J. A. (2014). The political economy of transitory mining in Ghana: Understanding the trajectories, triumphs, and tribulations of artisanal and small-scale operators. The Extractive Industries and Society, 1(1), 75-85. doi:10.1016/j.exis.2014.01.006

Nyamu Musembi, C. (2007). De Soto and land relations in rural Africa: breathing life into dead theories about property rights. Third World Quarterly, 28(8). doi:

$10.1080 / 01436590701637334$

Öko-Institut e.V. (2011). Social impacts of artisanal cobalt mining in Katanga, Democratic Republic of Congo. Freiburg: Tsurukawa, N., Prakash, S., \& Manhart, A. https://www.oeko.de/oekodoc/1294/2011-419-en.pdf

Okoh, G. A. (2014). Grievance and conflict in Ghana's gold mining industry: The case of Obuasi. Futures, 62(A). doi:10.1016/j.futures.2013.09.007

Olivier de Sardan, J-P. (2008). À la recherche des normes pratiques de la gouvernance réelle en Afrique. Discussion Paper No. 5. http://www.institutions-africa.org/filestream/20090109discussion-paper-5-la-recherche-des-norms-pratiques-de-la-gouvernance-r-elle-en-afriquejean-pierre-olivier-de-sardan-d-c-2008

Oskarsson, P., \& Lahiri-Dutt, K. (2018). India's resource (inter)nationalism: Overseas mining investments shaped by domestic conditions. The Extractive Industries and Society, 6(3), 747755. doi:10.1016/j.exis.2018.11.006

Ostrom, E. (2009). Beyond markets and states: Polycentric governance of complex economic systems. Prize lecture, December 8, 2009.

https://www.nobelprize.org/uploads/2018/06/ostrom_lecture.pdf

Otchia, C. S. (2019). Commodity booms will not last forever: Implications and recommendations in the Democratic Republic of Congo. The Extractive Industries and Society, 6(2), 279-292. doi:10.1016/j.exis.2018.12.006

Owusu-Nimo, F., Mantey, J., Nyarko, K. B., Appiah-Effah, E., \& Aubynn, A. (2018). Spatial distribution patterns of illegal artisanal small scale gold mining (Galamsey) operations in Ghana: A focus on the Western Region. Heliyon, 4(2). doi: 10.1016/j.heliyon.2018.e00534

Pegg, S. (2012). Social responsibility and resource extraction: Are Chinese oil companies different? Resources Policy, 37(2), 160-167. doi:10.1016/j.resourpol.2011.01.002 
Peyer, C., Feeney, P., \& Mercier, F. (2014). PR or progress? Glencore's corporate responsibility in the Democratic Republic of the Congo. Bread for All, Fastenopfer, and RAID. www.raid-uk.org/sites/default/files/glencore-report-June2014.pdf

Peyer, C., \& Maillard, Y. (2011). Contrats, droits humains, et fiscalité: comment une entreprise dépouille un pays. Le cas de Glencore en République Démocratique du Congo.

Pia, E., \& Diez, T. (2007). Conflict and human rights: A theoretical framework. SHUR Working Paper Series.

https://pdfs.semanticscholar.org/bd11/ded6bae9efb9feee558b1441f62880b449ae.pdf

Pilling, D. (2019, July 3). It is wrong to demonise Chinese labour practices in Africa. Financial Times. https://www.ft.com/content/6326dc9a-9cb8-11e9-9c06-a4640c9feebb

Premicongo. (2015, October). Les investissements miniers chinois au Katanga et la détresse des communautés locales: Cas de la Minière de Kalumbwe Myunga (MKM) et de HUACHIN. Bwenda, C.

Prno, J. (2013). An analysis of factors leading to the establishment of a social licence to operate in the mining industry. Resources Policy, 38(4), 577-590.

doi:10.1016/j.resourpol.2013.09.010

Radley, B. (2019, February 12). Corporate suppression of artisanal mining in the Congo. Review of African Political Economy (ROAPE) blog. http://roape.net/2019/02/12/corporatesuppression-of-artisanal-mining-in-the-congo/

Raeymaekers, T. (2007). The Power of protection. Governance and transborder trade on the Congo-Ugandan frontier. https://biblio.ugent.be/publication/468655

RAID. (2019, September 16). DR Congo: The forgotten victims of Dan Gertler's corruption. http://www.raid-uk.org/blog/dr-congo-forgotten-victims-dan-gertler $\% \mathrm{E} 2 \% 80 \% 99 \mathrm{~s}$-corruption

RDC: au moins un mort lors d'une manifestation dans la cité minière de Fungurume. (August 19, 2019). Radio France Internationale (RFI) Afrique. http://www.rfi.fr/afrique/20190819rdc-moins-mort-manifestations-cite-miniere-fungurume

RDC : environ 40 morts dans un éboulement à Kolwezi. (2019, June 27). Radio Okapi. https://www.radiookapi.net/2019/06/27/actualite/societe/rdc-environ-40-morts-dans-uneboulement-kolwezi?fbclid=IwAR3pn99DaGYGdplaFGJzlsMsZpydOoceEQZ1xKWQe9Mx5azSTr27eh1Y9U

Ribot, J. C., \& Peluso, N. (2003). A theory of access. Rural Sociology, 68(2), 153-181. doi:10.1111/j.1549-0831.2003.tb00133.X

Risse, T. (Ed.). (2011). Governance without a state? Policies and politics in areas of limited statehood. New York: Columbia University Press.

Risse, T., \& Lehmkuhl, U. (2006). Governance in areas of limited statehood-new modes of 
governance? http://www.sfb-governance.de/publikationen/working_papers/wp1_en/SFBGovernance-Working-

Paper-1_en.pdf.

Rubbers, B. (2019). Mining boom, labour market segmentation and social inequality in the Congolese Copperbelt. Development and Change. doi:10.1111/dech.12531

Schneckener, U. (2011). State building or new modes of governance? The effects of international involvement in areas of limited statehood. In T. Risse, T. (Ed.), Governance without a state? Policies and politics in areas of limited statehood (pp. 232-261). New York: Columbia University Press.

Schouten, P. (2017). Parapluies politiques: The everyday politics of private security in the Democratic Republic of the Congo. In P. Higate and M. Utas (Eds.), Private security in Africa (15-31). London; Uppsala: Zed Books; Nordiska Afrikainstutet.

Schuppert, G. F. (2011). Law without a state? A "new interplay" between state and nonstate actors in governance by rule making. In T. Risse, T. (Ed.), Governance without a state? Policies and politics in areas of limited statehood (pp. 65-86). New York: Columbia University Press.

Schwartz Taylor, M., \& Taylor, K. (2018, March 8). Illegal gold mining boom threatens cocoa farmers (and your chocolate). National Geographic.

https://news.nationalgeographic.com/2018/03/ghana-gold-mining-cocoa-environment/

Seitanidi \& Crane. (2009). Implementing CSR through partnerships: Understanding the selection, design and institutionalisation of nonprofit-business partnerships. Journal of Business Ethics, 85(2), 413-429. https://link.springer.com/article/10.1007/s10551-008-9743-y

Siegel, S. (2013, February 14). The missing ethics of mining [full text]. Ethics \& International Affairs.

http://www.ethicsandinternationalaffairs.org/2013/the-missing-ethics-of-mining-full-text/

Siegel, S. \& Veiga, M. M. (2009). Artisanal and small-scale mining as an extralegal economy: De Soto and the redefinition of "formalization". Resources Policy, 34(1-2), 51-56. doi:10.1016/j.resourpol.2008.02.001

Sikor, T., He, J., \& Lestrelin, G. (2017). Property rights regimes and natural resources: A conceptual analysis revisited. World Development, 93, 337-349.

doi:10.1016/j.worlddev.2016.12.032

Slack, K. (2012). Mission impossible? Adopting a CSR-based business model for extractive industries in developing countries. Resources Policy, 37(2), 179-184. doi:10.1016/j.resourpol.2011.02.003

SOAS University of London (School of Oriental and African Studies). (2019, July 3). SOAS research challenges perceptions of Chinese firms' labour practices in Africa. https://www.soas.ac.uk/news/newsitem141431.html 
SOMO in collaboration with Afrewatch, ACIDH, \& Premicongo. (2016, April). Cobalt blues: Environmental pollution and human rights violations in Katanga's copper and cobalt mines. Amsterdam, Netherlands: Scheele, F., de Haan, E., \& Kiezebrink, V. https://www.somo.nl/wp-content/uploads/2016/04/Cobalt-blues.pdf

Sovacool, B. K. (2019). The precarious political economy of cobalt: Balancing prosperity, poverty, and brutality in artisanal and industrial mining in the Democratic Republic of the Congo. The Extractive Industries and Society, 6(3), 915-939. doi:10.1016/j.exis.2019.05.018

Steinberg, Jessica. (2015). Strategic sovereignty: A model of non-state goods provision and resistance in regions of natural resource extraction. Journal of Conflict Resolution, 126. doi:10.1177/0022002714564429.

Szablowski, D., \& Campbell, B. (2019). Struggles over extractive governance: Power, discourse, violence, and legality. The Extractive Industries and Society. doi:

10.1016/j.exis.2019.06.009.

Teschner, B. (2013). How you start matters: A comparison of Gold Fields' Tarkwa and Damang Mines and their divergent relationships with local small-scale miners in Ghana. Resources Policy, 38(3), 332-340. doi:10.1016/j.resourpol.2013.03.006

Thill, M. (2019, October 10). Recycling as bricolage: Training the Police Nationale Congolaise. Conflict Research Programme. https://blogs.lse.ac.uk/crp/2019/10/10/recyclingas-bricolage-training-the-pnc/

Thomas, E. (2014). Sustainable conflict management by multinational mining companies in areas of limited statehood. Freie Universität Berlin, Berlin. https://refubium.fuberlin.de/handle/fub188/353

Tokar, D. (2019). Restitution battle throws three-year-old Och-Ziff settlement into limbo. The Wall Street Journal. https://www.wsj.com/articles/restitution-battle-throws-three-year-oldoch-ziff-settlement-into-limbo-11567810832

Trefon, T. (2014). Congo's environmental Catch-22. In D. Reed (Ed.), In pursuit of prosperity: U.S foreign policy in an era of natural resource scarcity (191-214). New York: Routledge.

Troubles à l'Unilu : 4 officiers de la police devant la cour militaire du Haut Katanga. (2019, January 30). Radio Okapi. https://www.radiookapi.net/2019/01/30/actualite/societe/troubleslunilu-4-officiers-de-la-police-devant-la-cour-militaire-du

Tyagi, J. (2012). Weak states. The Wiley-Blackwell Encyclopedia of Globalization. doi:10.1002/9780470670590.wbeog809

United Nations Development Programme. (n.d.a). Latest Human Development Index (HDI) ranking. http://hdr.undp.org/en/2018-update

United Nations Development Programme. (n.d.b). Income Gini coefficient. http://hdr.undp.org/en/content/income-gini-coefficient 
Un mort dans des heurts autour de concessions minières. (2019, August 19). VOA Afrique. https://www.voaafrique.com/a/rdc-un-mort-dans-des-heurts-autour-de-concessionsminieres/5047620.html

USAID. (2006). The role of property rights in natural resource management, good governance and empowerment of the rural poor. https://land-links.org/wpcontent/uploads/2016/09/USAID_Land_Tenure_Property_Rights_and_NRM_Report.pdf

U.S. Agency for International Development (USAID). (n.d.; updated April 2013). Property rights and artisanal mining - Clarifying and strengthening rights:

Options for policymakers. Washington, DC: Freudenberger, M.S., Ali, S., Fella, T., \& Pennes, S. http://www.usaidlandtenure.net/sites/default/files/USAID_Land_

Tenure_Artisanal_Mining_Issue_Brief_0.pdf.

U.S. Department of the Interior \& U.S. Geological Survey. (2017, July). 2014 Minerals Yearbook: Congo (Kinshasa) [advance release]. Yager, T.

Verweijen, J., \& Kubuya Batundi, S. (2019, June 18). Parc national des Virunga : mettre fin à la « conservation policière » de la nature. The Conversation. https://theconversation.com/parcnational-des-virunga-mettre-fin-a-la-conservation-policiere-de-la-nature-

118165?utm_term $=$ Autofeed\&utm_medium $=$ Social\&utm_source $=$ Twitter\#Echobox $=156090$ 3778

Wegenast, T., \& Schneider, G. (2017). Ownership matters: Natural resources property rights and social conflict in Sub-Saharan Africa. Political Geography, 61, 110-122.

doi:10.1016/j.polgeo.2017.07.007

Wild, F., Silver, V., \& Clowes, C. (2018, November 16). Trouble in the Congo: The misadventures of Glencore. Bloomberg. https://www.bloomberg.com/news/features/2018-1116/glencore-s-misadventure-in-the-congo-threatens-its-cobalt-dreams

Woman killed in DR Congo illegal mining crackdown. (2019, August 19). AFP. https://finance.yahoo.com/news/woman-killed-dr-congo-illegal-mining-crackdown111034047.html?soc src $=$ socialsh\&soc_trk=tw\&guccounter $=1 \&$ guce_referrer=aHR0cHM6Ly90LmNvL1k4ekVPalVMSTQ YW1wPTE\&guce_referrer_sig=AQAAAMBp1NDLO8hALzpnHuGr95xHqzgw7fS0arvuYNkAuiav13IQVk35rDOufuN7NfuEu9T3AomU4JeJrWo_7DWWDZQzba575fv7YNm66ZYVkxqKtVy fyNiRp1Ir0DwIghrfLMTer7Uw3MStd-a6eDW3QPRnqt32qmoMGkFQsFDLSw

World Bank. (2007). Democratic Republic of the Congo - Poverty and social impact analysis: mine sector reform.

http://documents.worldbank.org/curated/en/750411468019743700/Congo-DemocraticRepublic-of-Poverty-and-social-impact-analysis-mine-sector-reform

World Bank. (2016). Small-scale mining. http://web.worldbank.org/WBSITE/EXTERNAL/TOPICS/ EXTOGMC/0,,contentMDK:20246087 menuPK:509392 pagePK:148956 piPK:216618 theSitePK:336930 isCURL:Y,00.html 
Zhdannikov, D., \& Payne, J. (2018, October 23). Exclusive: Justice Department demands details from Glencore on intermediary firms - sources. Reuters.

https:/www.reuters.com/article/us-glencore-usa-subpoena-exclusive/exclusive-justicedepartment-demands-details-from-glencore-on-intermediary-firms-sourcesidUSKCN1MX1JP 


\section{Interview List}

\begin{tabular}{|c|c|c|c|}
\hline Date & Role & Location & Type \\
\hline 9 August 2016 & Civil society representative & Lubumbashi & \begin{tabular}{|l|} 
Interview \\
\end{tabular} \\
\hline 9 August 2016 & Community relocation consultant & Lubumbashi & Interview \\
\hline 10 August 2016 & Civil society representative & Lubumbashi & Interview \\
\hline 11 August 2016 & Civil society representative & Lubumbashi & Interview \\
\hline 11 August 2016 & Company-sponsored workshop & Lubumbashi & Workshop \\
\hline 11 August 2016 & Company $\mathrm{C}$ representative & Lubumbashi & Interview \\
\hline 12 August 2016 & Company-sponsored workshop & Lubumbashi & Workshop \\
\hline 13 August 2016 & University researcher & Lubumbashi & Interview \\
\hline 16 August 2016 & IDAK - 24e plénière & Lubumbashi & Workshop \\
\hline 18 August 2016 & Mining consultant & Lubumbashi & Meeting \\
\hline 19 August 2016 & SAESSCAM representative & Lubumbashi & Interview \\
\hline 19 August 2016 & Civil society representative & Lubumbashi & Meeting \\
\hline 22 August 2016 & Civil society representative & Lubumbashi & Interview \\
\hline 22 August 2016 & $\begin{array}{l}\text { Representative of a Chinese mining } \\
\text { company }\end{array}$ & Lubumbashi & Interview \\
\hline 23 August 2016 & Civil society representative 1 & Lubumbashi & Interview \\
\hline 23 August 2016 & Civil society representative 2 & Lubumbashi & Interview \\
\hline 24 August 2016 & $\begin{array}{l}\text { Socio-cultural association } \\
\text { representative }\end{array}$ & Lubumbashi & Interview \\
\hline 25 August 2016 & Community relocation consultant & Lubumbashi & Interview \\
\hline 26 August 2016 & $\begin{array}{l}\text { Socio-cultural association } \\
\text { representative }\end{array}$ & Lubumbashi & Interview \\
\hline 27 August 2016 & Civil society representative & Lubumbashi & Interview \\
\hline 27 August 2016 & $\begin{array}{l}\text { Government representative for gender, } \\
\text { women, family, and the child }\end{array}$ & Lubumbashi & Interview \\
\hline 30 August 2016 & Environmental Manager & Lubumbashi & Meeting \\
\hline 31 August 2016 & $\begin{array}{l}\text { Three international NGO } \\
\text { representatives }\end{array}$ & Lubumbashi & Interview \\
\hline $\begin{array}{l}1 \text { September } \\
2016\end{array}$ & Ministry of Mines official & Lubumbashi & Interview \\
\hline $\begin{array}{l}\text { 1 September } \\
2016\end{array}$ & $\begin{array}{l}\text { Two representatives of a humanitarian } \\
\text { organisation }\end{array}$ & Lubumbashi & Interview \\
\hline $\begin{array}{l}\text { 2 September } \\
2016\end{array}$ & Civil society representative & Lubumbashi & Interview \\
\hline
\end{tabular}




\begin{tabular}{|c|c|c|c|}
\hline $\begin{array}{l}\text { 2 September } \\
2016\end{array}$ & Land chief & Lubumbashi & Interview \\
\hline $\begin{array}{l}\text { 6 September } \\
2016\end{array}$ & Doctoral candidate & Lubumbashi & Interview \\
\hline $\begin{array}{l}\text { 7 September } \\
2016\end{array}$ & $\begin{array}{l}\text { Former socio-cultural association } \\
\text { official }\end{array}$ & Lubumbashi & Interview \\
\hline $\begin{array}{l}8 \text { September } \\
2016\end{array}$ & Civil society representative 1 & & Interview 25 \\
\hline $\begin{array}{l}\text { 8 September } \\
2016\end{array}$ & Civil society representative 2 & Lubumbashi & Interview \\
\hline $\begin{array}{l}9 \text { September } \\
2016\end{array}$ & Ministry of Mines official & Lubumbashi & Interview \\
\hline $\begin{array}{l}9 \text { September } \\
2016\end{array}$ & $\begin{array}{l}\text { Copper-processing company } \\
\text { representative }\end{array}$ & Lubumbashi & Interview \\
\hline $\begin{array}{l}\text { 14 September } \\
2016\end{array}$ & Company A legal manager & Lubumbashi & Meeting \\
\hline $\begin{array}{l}\text { 14 September } \\
2016\end{array}$ & Company manager & Lubumbashi & $\begin{array}{l}\text { Preliminary } \\
\text { interview }\end{array}$ \\
\hline $\begin{array}{l}\text { 14 September } \\
2016\end{array}$ & Company manager & Lubumbashi & Interview \\
\hline $\begin{array}{l}16 \text { September } \\
2016\end{array}$ & Company B human resources manager & Lubumbashi & Interview \\
\hline $\begin{array}{l}19 \text { September } \\
2016\end{array}$ & Cadastre minier official & Lubumbashi & Interview \\
\hline $\begin{array}{l}19 \text { September } \\
2016\end{array}$ & $\begin{array}{l}\text { Fédération des entreprises du Congo } \\
\text { (FEC) official }\end{array}$ & Lubumbashi & Interview \\
\hline $\begin{array}{l}20 \text { September } \\
2016\end{array}$ & $\begin{array}{l}\text { Police de protection de l'enfant et de } \\
\text { lutte contre les violences sexuelles } \\
\text { official }\end{array}$ & Lubumbashi & Interview \\
\hline $\begin{array}{l}21 \text { September } \\
2016\end{array}$ & Company A manager & Lubumbashi & Interview \\
\hline $\begin{array}{l}21 \text { September } \\
2016\end{array}$ & Company A social manager & Lubumbashi & Interview \\
\hline $\begin{array}{l}21 \text { September } \\
2016\end{array}$ & Company C employee & Lubumbashi & Interview \\
\hline $\begin{array}{l}22 \text { September } \\
2016\end{array}$ & Company A manager & Lubumbashi & Interview \\
\hline $\begin{array}{l}23 \text { September } \\
2016\end{array}$ & Mining company manager 1 & Lubumbashi & Interview \\
\hline $\begin{array}{l}23 \text { September } \\
2016\end{array}$ & Mining company manager 2 & Lubumbashi & Interview \\
\hline $\begin{array}{l}23 \text { September } \\
2016\end{array}$ & Nurse & & $\begin{array}{l}\text { Guided tour } \\
\text { of the clinic }\end{array}$ \\
\hline $\begin{array}{l}23 \text { September } \\
2016\end{array}$ & $\begin{array}{l}\text { Former company B human resources } \\
\text { manager }\end{array}$ & Lubumbashi & Interview \\
\hline $\begin{array}{l}\text { 24 September } \\
2016\end{array}$ & Company A human resources employee & Lubumbashi & Interview \\
\hline
\end{tabular}




\begin{tabular}{|c|c|c|c|}
\hline $\begin{array}{l}24 \text { September } \\
2016\end{array}$ & Company A manager & Site visit & Mine site visit \\
\hline $\begin{array}{l}\text { 26 September } \\
2016\end{array}$ & $\begin{array}{l}\text { Mining company officer and mining } \\
\text { lawyer }\end{array}$ & Lubumbashi & Interview \\
\hline $\begin{array}{l}27 \text { and } 28 \\
\text { September } 2016\end{array}$ & Two company $\mathrm{C}$ officers & $\mathrm{C} 1$ & Discussions \\
\hline $\begin{array}{l}28 \text { September } \\
2016\end{array}$ & Company $\mathrm{C}$ officer & $\mathrm{C} 1$ & $\begin{array}{l}\text { Informal } \\
\text { discussion }\end{array}$ \\
\hline $\begin{array}{l}28 \text { September } \\
2016\end{array}$ & Two company $\mathrm{C}$ officials & $\mathrm{C} 1$ & $\begin{array}{l}\text { Interview (off } \\
\text { the record) }\end{array}$ \\
\hline 3 October 2016 & $\begin{array}{l}\text { Official at the Tribunal de paix } \\
\text { Lubumbashi / Kamolondo }\end{array}$ & Lubumbashi & Interview \\
\hline 3 October 2016 & $\begin{array}{l}\text { Official at the Tribunal de paix } \\
\text { Lubumbashi / Kamolondo }\end{array}$ & Lubumbashi & Interview \\
\hline 3 October 2016 & Official at the Greffe pénale & Lubumbashi & Interview \\
\hline 3 October 2016 & $\begin{array}{l}\text { Official at the Parquet Général de } \\
\text { Lubumbashi }\end{array}$ & Lubumbashi & Interview \\
\hline 5 October 2016 & $\begin{array}{l}\text { Extractive Industries Transparency } \\
\text { Initiative representative }\end{array}$ & Lubumbashi & Interview \\
\hline 7 October 2016 & Mine Police representative & Lubumbashi & Interview \\
\hline 8 October 2016 & Doctoral candidate & Lubumbashi & Interview \\
\hline $\begin{array}{l}10 \text { October } \\
2016\end{array}$ & Civil society representative & Lubumbashi & $\begin{array}{l}\text { Follow-up } \\
\text { interview }\end{array}$ \\
\hline $\begin{array}{l}11 \text { October } \\
2016\end{array}$ & Company A security officer & Lubumbashi & Interview \\
\hline $\begin{array}{l}12 \text { October } \\
2016\end{array}$ & Company A human resources employee & Lubumbashi & Interview \\
\hline 13 October & Congolese academic & Lubumbashi & Interview \\
\hline $\begin{array}{l}13 \text { October } \\
2016\end{array}$ & Civil society representative & Lubumbashi & $\begin{array}{l}\text { Follow-up } \\
\text { interview }\end{array}$ \\
\hline $\begin{array}{l}14 \text { October } \\
2016\end{array}$ & Congolese university professor & Lubumbashi & Interview \\
\hline $\begin{array}{l}15 \text { October } \\
2016\end{array}$ & Community activist & Lubumbashi & Interview \\
\hline $\begin{array}{l}17 \text { October } \\
2016\end{array}$ & Company A legal manager & Lubumbashi & Interview \\
\hline $\begin{array}{l}19 \text { October } \\
2016\end{array}$ & Company A exploration staffer & Lubumbashi & Interview \\
\hline $\begin{array}{l}20 \text { October } \\
2016\end{array}$ & Local government official & Lubumbashi & Interview \\
\hline $\begin{array}{l}21 \text { October } \\
2016\end{array}$ & Community activist & Lubumbashi & $\begin{array}{l}\text { Follow-up } \\
\text { interview }\end{array}$ \\
\hline $\begin{array}{l}22 \text { October } \\
2016\end{array}$ & Civil society representative & Lubumbashi & $\begin{array}{l}\text { Follow-up } \\
\text { interview }\end{array}$ \\
\hline $\begin{array}{l}25 \text { October } \\
2016\end{array}$ & Civil society representative & Lubumbashi & Interview \\
\hline
\end{tabular}




\begin{tabular}{|c|c|c|c|}
\hline $\begin{array}{l}26 \text { October } \\
2016\end{array}$ & Local government official & Lubumbashi & Interview \\
\hline $\begin{array}{l}27 \text { October } \\
2016\end{array}$ & Local government official & Lubumbashi & Interview \\
\hline $\begin{array}{l}27 \text { October } \\
2016\end{array}$ & Parquet official & Lubumbashi & Interview \\
\hline $\begin{array}{l}31 \text { October } \\
2016\end{array}$ & Civil society workshop & Lubumbashi & Workshop \\
\hline $\begin{array}{l}31 \text { October } \\
2016\end{array}$ & Civil society representative & Lubumbashi & Brief meeting \\
\hline $\begin{array}{l}1 \text { November } \\
2016\end{array}$ & International NGO representative & Lubumbashi & Interview \\
\hline $\begin{array}{l}1 \text { November } \\
2016\end{array}$ & $\begin{array}{l}\text { Socio-cultural association } \\
\text { representative }\end{array}$ & Lubumbashi & Interview \\
\hline $\begin{array}{l}3 \text { November } \\
2016\end{array}$ & Civil society representative & Lubumbashi & Interview \\
\hline $\begin{array}{l}3 \text { November } \\
2016\end{array}$ & Community-based group & Lubumbashi & $\begin{array}{l}\text { Group } \\
\text { discussion }\end{array}$ \\
\hline $\begin{array}{l}3 \text { November } \\
2016\end{array}$ & International NGO representative & Lubumbashi & Brief meeting \\
\hline $\begin{array}{l}3 \text { November } \\
2016\end{array}$ & $\begin{array}{l}\text { Two community-based group } \\
\text { representatives }\end{array}$ & Lubumbashi & Interview \\
\hline $\begin{array}{l}8 \text { November } \\
2016\end{array}$ & Mine Police official 1 & Lubumbashi & Interview \\
\hline $\begin{array}{l}8 \text { November } \\
2016\end{array}$ & Mine Police officials 2, 3 & Lubumbashi & Interview \\
\hline $\begin{array}{l}9 \text { November } \\
2016\end{array}$ & Civil society representative 1 & Lubumbashi & Interview \\
\hline $\begin{array}{l}9 \text { November } \\
2016\end{array}$ & Civil society representative 2 & Lubumbashi & Interview \\
\hline $\begin{array}{l}9 \text { November } \\
2016\end{array}$ & Civil society representative & Lubumbashi & $\begin{array}{l}\text { Brief } \\
\text { discussion }\end{array}$ \\
\hline $\begin{array}{l}10 \text { November } \\
2016\end{array}$ & $\begin{array}{l}\text { United Nations Organization } \\
\text { Stabilization Mission in the Democratic } \\
\text { Republic of Congo (MONUSCO) } \\
\text { human rights representative }\end{array}$ & Lubumbashi & Interview \\
\hline $\begin{array}{l}10 \text { November } \\
2016\end{array}$ & Local government official & Lubumbashi & Interview \\
\hline $\begin{array}{l}11 \text { November } \\
2016\end{array}$ & Two civil society representatives & Lubumbashi & Interview \\
\hline $\begin{array}{l}12 \text { November } \\
2016\end{array}$ & $\begin{array}{l}\text { Civil society representative involved } \\
\text { with community compensation }\end{array}$ & Lubumbashi & Interview \\
\hline $\begin{array}{l}14 \text { November } \\
2016\end{array}$ & $\begin{array}{l}\text { Community member with her husband, } \\
\text { daughter, and neighbour }\end{array}$ & Lubumbashi & Interview \\
\hline $\begin{array}{l}15 \text { November } \\
2016\end{array}$ & $\begin{array}{l}\text { Community members (five men and } \\
\text { two women) }\end{array}$ & Lubumbashi & $\begin{array}{l}\text { Group } \\
\text { discussion }\end{array}$ \\
\hline
\end{tabular}




\begin{tabular}{|c|c|c|c|}
\hline $\begin{array}{l}15 \text { November } \\
2016\end{array}$ & $\begin{array}{l}\text { Civil society representative involved } \\
\text { with community compensation }\end{array}$ & Lubumbashi & $\begin{array}{l}\text { Follow-up } \\
\text { interview }\end{array}$ \\
\hline $\begin{array}{l}16 \text { November } \\
2016\end{array}$ & $\begin{array}{l}\text { Company B social department } \\
\text { employee }\end{array}$ & Lubumbashi & Interview \\
\hline $\begin{array}{l}17 \text { November } \\
2016\end{array}$ & Civil society representative & Lubumbashi & Interview \\
\hline $\begin{array}{l}17 \text { November } \\
2016\end{array}$ & Members of an agricultural association & Lubumbashi & $\begin{array}{l}\text { Group } \\
\text { discussion }\end{array}$ \\
\hline $\begin{array}{l}17 \text { November } \\
2016\end{array}$ & Civil society representative & Lubumbashi & Interview \\
\hline $\begin{array}{l}17 \text { November } \\
2016\end{array}$ & Pastor and community members & Lubumbashi & $\begin{array}{l}\text { Group } \\
\text { discussion }\end{array}$ \\
\hline $\begin{array}{l}18 \text { November } \\
2016\end{array}$ & Local neighbourhood authority & Lubumbashi & Interview \\
\hline $\begin{array}{l}18 \text { November } \\
2016\end{array}$ & PNC officer & Lubumbashi & Interview \\
\hline $\begin{array}{l}19 \text { November } \\
2016\end{array}$ & Customary chief & Lubumbashi & Interview \\
\hline $\begin{array}{l}21 \text { November } \\
2016\end{array}$ & $\begin{array}{l}\text { International Organization for } \\
\text { Migration (IOM) representative }\end{array}$ & Lubumbashi & Interview \\
\hline $\begin{array}{l}21 \text { November } \\
2016\end{array}$ & $\begin{array}{l}\text { International Organization for } \\
\text { Migration (IOM) representative }\end{array}$ & Lubumbashi & Interview \\
\hline $\begin{array}{l}22 \text { November } \\
2016\end{array}$ & Trade union representative 1 & Lubumbashi & Interview \\
\hline $\begin{array}{l}22 \text { November } \\
2016\end{array}$ & Civil society representative & Lubumbashi & Interview \\
\hline $\begin{array}{l}22 \text { November } \\
2016\end{array}$ & Trade union representative 2 & Lubumbashi & Interview \\
\hline $\begin{array}{l}23 \text { November } \\
2016\end{array}$ & Mine Police official & Lubumbashi & Interview \\
\hline $\begin{array}{l}24 \text { November } \\
2016\end{array}$ & Businessperson & Lubumbashi & Interview \\
\hline $\begin{array}{l}24 \text { November } \\
2016\end{array}$ & Displaced community member & Lubumbashi & Interview \\
\hline $\begin{array}{l}25 \text { November } \\
2016\end{array}$ & Former miner & Lubumbashi & Interview \\
\hline $\begin{array}{l}26 \text { November } \\
2016\end{array}$ & Mining sector consultant & Lubumbashi & Interview \\
\hline $\begin{array}{l}26 \text { November } \\
2016\end{array}$ & Local government official & Lubumbashi & Interview \\
\hline $\begin{array}{l}28 \text { November } \\
2016\end{array}$ & Mine Police official & Lubumbashi & $\begin{array}{l}\text { Follow-up } \\
\text { interview }\end{array}$ \\
\hline $\begin{array}{l}29 \text { November } \\
2016\end{array}$ & Mine Police official & Lubumbashi & $\begin{array}{l}\text { Follow-up } \\
\text { interview }\end{array}$ \\
\hline $\begin{array}{l}29 \text { November } \\
2016\end{array}$ & $\begin{array}{l}\text { Customary chief, pastor, and his } \\
\text { nephew }\end{array}$ & Lubumbashi & $\begin{array}{l}\text { Group } \\
\text { interview }\end{array}$ \\
\hline
\end{tabular}




\begin{tabular}{|c|c|c|c|}
\hline $\begin{array}{l}\text { 1 December } \\
2016\end{array}$ & Three parquet representatives & Lubumbashi & Interview \\
\hline $\begin{array}{l}\text { 1 December } \\
2016\end{array}$ & Mine Police representative & Lubumbashi & Interview \\
\hline $\begin{array}{l}2 \text { December } \\
2016\end{array}$ & Local government official & Lubumbashi & Interview \\
\hline $\begin{array}{l}3 \text { December } \\
2016\end{array}$ & Mine Police representative 1 & Lubumbashi & $\begin{array}{l}\text { Preliminary } \\
\text { interview }\end{array}$ \\
\hline $\begin{array}{l}\text { 6 December } \\
2016\end{array}$ & Mine Police representative 2 & Lubumbashi & Interview \\
\hline $\begin{array}{l}6 \text { December } \\
2016\end{array}$ & Company A security officer & Lubumbashi & $\begin{array}{l}\text { Follow-up } \\
\text { interview }\end{array}$ \\
\hline $\begin{array}{l}7 \text { December } \\
2016\end{array}$ & Congolese National Police official & Lubumbashi & Interview \\
\hline $\begin{array}{l}7 \text { December } \\
2016\end{array}$ & Doctoral candidate & Lubumbashi & $\begin{array}{l}\text { Follow-up } \\
\text { interview }\end{array}$ \\
\hline 17 January 2017 & International NGO representative & Skype call & Skype call \\
\hline 24 January 2017 & Civil society representative & Lubumbashi & $\begin{array}{l}\text { Follow-up } \\
\text { interview }\end{array}$ \\
\hline 25 January 2017 & University researcher & Lubumbashi & Interview \\
\hline 27 January 2017 & Company B security officer & Lubumbashi & Interview \\
\hline 27 January 2017 & Company B employee & Lubumbashi & Interview \\
\hline 31 January 2017 & Professor & Lubumbashi & Interview \\
\hline 31 January 2017 & Company B employee & Lubumbashi & $\begin{array}{l}\text { Follow-up } \\
\text { interview }\end{array}$ \\
\hline 1 February 2017 & Former EMAK representative & Lubumbashi & Interview \\
\hline 1 February 2017 & Doctoral candidate & Lubumbashi & Interview \\
\hline 3 February 2017 & Site B observation & Lubumbashi & Site visit \\
\hline 3 February 2017 & $\begin{array}{l}\text { Company B community department } \\
\text { representative }\end{array}$ & Lubumbashi & Interview \\
\hline 4 February 2017 & Three traders and a former miner & Lubumbashi & Interview \\
\hline 6 February 2017 & Company B official & Lubumbashi & Interview \\
\hline 6 February 2017 & Company B manager & Lubumbashi & Interview \\
\hline 6 February 2017 & Local judicial official & Lubumbashi & Meeting \\
\hline 7 February 2017 & Mine Police representative & $\mathrm{C} 1$ & Interview \\
\hline 7 February 2017 & Journalist & $\mathrm{C} 1$ & Interview \\
\hline 8 February 2017 & $\begin{array}{l}\text { Site } \mathrm{C} \text { visit and interview with four } \\
\text { miners }\end{array}$ & $\mathrm{C} 2$ & Interview \\
\hline 8 February 2017 & Territorial administration representative & $\begin{array}{l}\text { His office@ } \\
\text { Fungurume } \\
\text { (cité) }\end{array}$ & $\begin{array}{l}\text { Introduction } \\
\text { only }\end{array}$ \\
\hline
\end{tabular}




\begin{tabular}{|c|c|c|c|}
\hline 8 February 2017 & Local NGO representative & $\mathrm{C} 1$ & \\
\hline 9 February 2017 & Civil society representative & $\mathrm{C} 3$ & Interview \\
\hline 9 February 2017 & Two traders & $\mathrm{C} 3$ & Interview \\
\hline $\begin{array}{l}10 \text { February } \\
2017\end{array}$ & Local government official & $\mathrm{C} 1$ & Interview \\
\hline $\begin{array}{l}10 \text { February } \\
2017\end{array}$ & Trader & & $\begin{array}{l}\text { Introduction, } \\
\text { a few } \\
\text { questions I } \\
\text { think }\end{array}$ \\
\hline $\begin{array}{l}10 \text { February } \\
2017\end{array}$ & Journalist & $\mathrm{C} 1$ & $\begin{array}{l}\text { Follow-up } \\
\text { interview }\end{array}$ \\
\hline $\begin{array}{l}10 \text { February } \\
2017\end{array}$ & Division des Mines representative & $\mathrm{C} 1$ & Interview \\
\hline $\begin{array}{l}\text { 11 February } \\
2017\end{array}$ & National MP & $\mathrm{C} 1$ & Interview \\
\hline $\begin{array}{l}11 \text { February } \\
2017\end{array}$ & Youth representative & $\mathrm{C} 1$ & Interview \\
\hline $\begin{array}{l}13 \text { February } \\
2017\end{array}$ & Miner & Lubumbashi & Interview \\
\hline $\begin{array}{l}\text { 14 February } \\
2017\end{array}$ & Trader/miner & Lubumbashi & Interview \\
\hline $\begin{array}{l}16 \text { February } \\
2017\end{array}$ & Mine Police representative 1 & Lubumbashi & $\begin{array}{l}\text { Preliminary } \\
\text { meeting }\end{array}$ \\
\hline $\begin{array}{l}16 \text { February } \\
2017\end{array}$ & Mine Police representative & Lubumbashi & $\begin{array}{l}\text { Follow-up } \\
\text { interview }\end{array}$ \\
\hline $\begin{array}{l}17 \text { February } \\
2017\end{array}$ & Miner & Lubumbashi & Interview \\
\hline $\begin{array}{l}17 \text { February } \\
2017\end{array}$ & Miner and two former miners & Lubumbashi & Interview \\
\hline $\begin{array}{l}17 \text { February } \\
2017\end{array}$ & Trader/marketeur & Lubumbashi & Interview \\
\hline $\begin{array}{l}18 \text { February } \\
2017\end{array}$ & Mine Police officer & Lubumbashi & Interview \\
\hline $\begin{array}{l}25 \text { February } \\
2017\end{array}$ & Community member & Lubumbashi & Interview \\
\hline $\begin{array}{l}25 \text { February } \\
2017\end{array}$ & Two traders & Lubumbashi & Interview \\
\hline $\begin{array}{l}27 \text { February } \\
2017\end{array}$ & Trader and her son & Lubumbashi & Interview \\
\hline $\begin{array}{l}27 \text { February } \\
2017\end{array}$ & "Liberal" artisanal miner & Lubumbashi & Interview \\
\hline $\begin{array}{l}28 \text { February } \\
2017\end{array}$ & Land chief & Lubumbashi & $\begin{array}{l}\text { Follow-up } \\
\text { interview }\end{array}$ \\
\hline $\begin{array}{l}28 \text { February } \\
2017\end{array}$ & Mining consultant & $\mathrm{C} 1$ & Interview \\
\hline
\end{tabular}




\begin{tabular}{|c|c|c|c|}
\hline 1 March 2017 & Youth representative & $\mathrm{C} 1$ & $\begin{array}{l}\text { Follow-up } \\
\text { interview }\end{array}$ \\
\hline 1 March 2017 & Mining consultant and colleague & $\mathrm{C} 1$ & $\begin{array}{l}\text { Follow-up } \\
\text { interview }\end{array}$ \\
\hline 1 March 2017 & Businessperson & $\mathrm{C} 1$ & Conversation \\
\hline 2 March 2017 & Land chief & $\mathrm{C} 1, \mathrm{C} 2$ & $\begin{array}{l}\text { Follow-up } \\
\text { interview }\end{array}$ \\
\hline 2 March 2017 & Trader & $\mathrm{C} 2$ & Interview \\
\hline 3 March 2017 & Journalist & $\mathrm{C} 2$ & $\begin{array}{l}\text { Follow-up } \\
\text { conversation }\end{array}$ \\
\hline 3 March 2017 & Miner & $\mathrm{C} 2$ & $\begin{array}{l}\text { Follow-up } \\
\text { conversation }\end{array}$ \\
\hline 3 March 2017 & Businessperson & $\mathrm{C} 1$ & $\begin{array}{l}\text { Follow-up } \\
\text { conversation }\end{array}$ \\
\hline 4 March 2017 & Trader and two associates & $\mathrm{C} 3$ & Interview \\
\hline 4 March 2017 & Group of miners & C3 & Interview \\
\hline 4 March 2017 & Civil society representative & $\mathrm{C} 3$ & Interview \\
\hline 4 March 2017 & Company C security guard & $\mathrm{C} 3$ & Interview \\
\hline 6 March 2017 & $\begin{array}{l}\text { Group of traders, miners, and a } \\
\text { transporter }\end{array}$ & $\mathrm{C} 2$ & Interview \\
\hline 6 March 2017 & Trader & $\mathrm{C} 2$ & $\begin{array}{l}\text { Follow-up } \\
\text { interview }\end{array}$ \\
\hline 7 March 2017 & Journalist & $\mathrm{C} 1$ & Interview \\
\hline 7 March 2017 & Local NGO representative and a trader & $\mathrm{C} 1$ & Interview \\
\hline 8 March 2017 & Trader & $\mathrm{C} 1$ & Interview \\
\hline 8 March 2017 & Women who wash minerals & $\mathrm{C} 2$ & Interview \\
\hline 8 March 2017 & Miners who wash minerals & $\mathrm{C} 2$ & Interview \\
\hline 8 March 2017 & Miner & $\mathrm{C} 2$ & Interview \\
\hline 9 March 2017 & Several traders and miners & $\mathrm{C} 3$ & Interview \\
\hline 9 March 2017 & Bicycle transporter & $\mathrm{C} 3$ & Interview \\
\hline 9 March 2017 & Journalist & $\mathrm{C} 3$ & Interview \\
\hline 9 March 2017 & Student & $\mathrm{C} 3$ & \\
\hline 9 March 2017 & Nurse & $\mathrm{C} 3$ & Discussion \\
\hline 9 March 2017 & Member of company $\mathrm{C}$ security & $\mathrm{C} 3$ & Interview \\
\hline 9 March 2017 & Civil society representative & $\mathrm{C} 3$ & Interview \\
\hline 10 March 2017 & Mine Police officer & $\mathrm{C} 1$ & $\begin{array}{l}\text { Follow-up } \\
\text { conversation }\end{array}$ \\
\hline 10 March 2017 & Local government official & $\mathrm{C} 1$ & $\begin{array}{l}\text { Follow-up } \\
\text { interview }\end{array}$ \\
\hline 10 March 2017 & Company C security guard & $\mathrm{C} 3$ & Interview \\
\hline 10 March 2017 & Mine Police officer & $\mathrm{C} 1$ & $\begin{array}{l}\text { Follow-up } \\
\text { interview }\end{array}$ \\
\hline 11 March 2017 & Civil society representative & $\mathrm{C} 1$ & Interview \\
\hline 11 March 2017 & Trader & $\mathrm{C} 1$ & Interview \\
\hline
\end{tabular}




\begin{tabular}{|c|c|c|c|}
\hline 11 March 2017 & PSC manager & Road & Conversation \\
\hline 13 March 2017 & Former EMAK representative & Lubumbashi & Interview \\
\hline 13 March 2017 & Miner and two friends & Lubumbashi & $\begin{array}{l}\text { Follow-up } \\
\text { interview }\end{array}$ \\
\hline 14 March 2017 & Company A manager & Lubumbashi & Interview \\
\hline 15 March 2017 & PSC manager & Lubumbashi & Interview \\
\hline 16 March 2017 & Two miners & Lubumbashi & Interview \\
\hline 19 March 2017 & Former miner & Lubumbashi & $\begin{array}{l}\text { Follow-up } \\
\text { discussion }\end{array}$ \\
\hline 20 March 2017 & $\begin{array}{l}\text { LNI representative and Mine Police } \\
\text { representative }\end{array}$ & Lubumbashi & Interview \\
\hline 20 March 2017 & Three PSC managers & Lubumbashi & Interview \\
\hline 20 March 2017 & PSC manager & Lubumbashi & Interview \\
\hline 21 March 2017 & Occasional miner & Lubumbashi & Interview \\
\hline 22 March 2017 & Company B human resources manager & Lubumbashi & Interview \\
\hline 23 March 2017 & $\begin{array}{l}\text { Two Congolese National Police } \\
\text { representatives }\end{array}$ & Lubumbashi & $\begin{array}{l}\text { Follow-up } \\
\text { discussion }\end{array}$ \\
\hline 24 March 2017 & Mine Police officer & Lubumbashi & $\begin{array}{l}\text { Follow-up } \\
\text { interview }\end{array}$ \\
\hline 24 March 2017 & Parquet intern & Lubumbashi & Discussion \\
\hline 24 March 2017 & Parquet official & Lubumbashi & Discussion \\
\hline 24 March 2017 & Gécamines representative & Lubumbashi & Discussion \\
\hline 25 March 2017 & Three miners & Lubumbashi & Interview \\
\hline 25 March 2017 & Motorcycle driver & Lubumbashi & Interview \\
\hline 25 March 2017 & Community relocation consultant & Lubumbashi & $\begin{array}{l}\text { Follow-up } \\
\text { interview }\end{array}$ \\
\hline 29 March 2017 & University researcher & Lubumbashi & Interview \\
\hline 29 March 2017 & Miner and his mother & Lubumbashi & Interview \\
\hline 30 March 2017 & Company A legal manager & Lubumbashi & $\begin{array}{l}\text { Follow-up } \\
\text { interview }\end{array}$ \\
\hline $\begin{array}{l}\text { Friday, } 31 \\
\text { March } 2017\end{array}$ & Two miners and their mother & Lubumbashi & Interview \\
\hline $\begin{array}{l}\text { Friday, } 31 \\
\text { March } 2017\end{array}$ & Miner and his wife & Lubumbashi & Interview \\
\hline 3 April 2017 & Miners & Lubumbashi & $\begin{array}{l}\text { Group } \\
\text { interview }\end{array}$ \\
\hline 3 April 2017 & Miner & Lubumbashi & Interview \\
\hline 6 April 2017 & Trader & Lubumbashi & Interview \\
\hline 6 April 2017 & Former miner & Lubumbashi & Conversation \\
\hline 6 April 2017 & Two traders & Lubumbashi & Conversation \\
\hline 9 April 2017 & Miner & Lubumbashi & Interview \\
\hline
\end{tabular}




\begin{tabular}{|c|c|c|c|}
\hline 10 April 2017 & Government official & $\mathrm{C} 2$ & Discussion \\
\hline 10 April 2017 & $\begin{array}{l}\text { Two miners, a trader's wife, and a } \\
\text { woman who sells firewood }\end{array}$ & $\mathrm{C} 2$ & Interview \\
\hline 10 April 2017 & Transporter & $\mathrm{C} 2$ & Conversation \\
\hline 11 April 2017 & $\begin{array}{l}\text { Village chief and multiple village } \\
\text { residents }\end{array}$ & $\mathrm{C} 4$ & $\begin{array}{l}\text { Group } \\
\text { discussion }\end{array}$ \\
\hline 11 April 2017 & Trader & $\mathrm{C} 2$ & Interview \\
\hline 12 April 2017 & $\begin{array}{l}\text { Two socio-cultural association } \\
\text { representatives }\end{array}$ & $\mathrm{C} 1$ & Interview \\
\hline 12 April 2017 & Mine Police officer & $\mathrm{C} 1$ & $\begin{array}{l}\text { Follow-up } \\
\text { discussion }\end{array}$ \\
\hline 12 April 2017 & Local judicial official & $\mathrm{C} 1$ & Interview \\
\hline 12 April 2017 & Journalist & $\mathrm{C} 1$ & Interview \\
\hline 13 April 2017 & Company C security employee & $\mathrm{C} 3$ & Interview \\
\hline 13 April 2017 & Two trotteurs & C3 & Interview \\
\hline 13 April 2017 & Site C3 miners' committee member & $\mathrm{C} 3$ & Interview \\
\hline 13 April 2017 & Company C security guard & $\mathrm{C} 3$ & Interview \\
\hline 14 avril 2017 & Mine Police officer & $\mathrm{C} 2$ & Interview \\
\hline 14 avril 2017 & Two miners & $\mathrm{C} 2$ & Interview \\
\hline 9 May 2017 & PSC manager & Lubumbashi & $\begin{array}{l}\text { Preliminary } \\
\text { meeting }\end{array}$ \\
\hline 9 May 2017 & Miner and two friends & Lubumbashi & Interview \\
\hline 10 May 2017 & Trader & Lubumbashi & Interview \\
\hline 11 May 2017 & SAESSCAM representative & Lubumbashi & Interview \\
\hline 12 May 2017 & Three PSC managers & Lubumbashi & $\begin{array}{l}\text { Follow-up } \\
\text { interview }\end{array}$ \\
\hline 13 May 2017 & $\begin{array}{l}\text { Mine Police representative and } \\
\text { professor }\end{array}$ & Lubumbashi & Interview \\
\hline 15 May 2017 & Trader & Lubumbashi & Interview \\
\hline 15 May 2017 & Land owner & Lubumbashi & Interview \\
\hline 15 May 2017 & SAESSCAM representative & Lubumbashi & $\begin{array}{l}\text { Follow-up } \\
\text { interview }\end{array}$ \\
\hline 16 May 2017 & LNI representative & Lubumbashi & Interview \\
\hline 16 May 2017 & Professor & Lubumbashi & Interview \\
\hline 18 May 2017 & Miner & $\mathrm{C} 2$ & $\begin{array}{l}\text { Follow-up } \\
\text { discussion }\end{array}$ \\
\hline 18 May 2017 & Trader & $\mathrm{C} 2$ & Interview \\
\hline 18 May 2017 & Trader & $\mathrm{C} 2$ & Interview \\
\hline 19 May 2017 & Trader/miner & $\mathrm{C} 3$ & Interview \\
\hline 19 May 2017 & Journalist & C3 & Interview \\
\hline
\end{tabular}




\begin{tabular}{|l|l|l|l|}
\hline 20 May 2017 & Miner & C3 & Interview \\
\hline 20 May 2017 & Trader & C2 & Interview \\
\hline 21 May 2017 & $\begin{array}{l}\text { Company A security guard deployed at } \\
\text { a different site, not site A }\end{array}$ & Lubumbashi & Interview \\
\hline 21 May 2017 & Local government official & Lubumbashi & Interview \\
\hline 22 May 2017 & PSC manager & Lubumbashi & Interview \\
\hline 22 May 2017 & Student & Lubumbashi & Interview \\
\hline 24 May 2017 & $\begin{array}{l}\text { Division provinciale des mines } \\
\text { representative }\end{array}$ & Lubumbashi & Interview \\
\hline 24 May 2017 & Miner & Lubumbashi & Interview \\
\hline 25 May 2017 & Congolese National Police official & C3 & Interview \\
\hline 25 May 2017 & Company C geology employee & C1 & Interview \\
\hline 27 May 2017 & Local government official (mining) & Lubumbashi & Meeting \\
\hline 27 May 2017 & Company C security employee & $\begin{array}{l}\text { Phone } \\
\text { interview }\end{array}$ & $\begin{array}{l}\text { Phone } \\
\text { interview }\end{array}$ \\
\hline
\end{tabular}

\section{A Short Biography of the Author}

Sarah Katz-Lavigne is a lecturer and researcher at the University of Bayreuth. She is about to defend her PhD dissertation in International Affairs at the Norman Paterson School of International Affairs at Carleton University and International Relations at the University of Groningen in the Netherlands. Her research focuses on conflict at and around large-scale mining (LSM) sites in southeastern Democratic Republic of Congo (DRC). She examines how a range of actors govern the "clandestine" extraction of minerals from LSM sites, and the impact of the functioning of a multifaceted property rights regime on conflict and distributional dynamics at and around mine sites. Sarah has published in The Extractive Industries and Society, Resources Policy, and Third World Thematics, and has a forthcoming piece in the Canadian Journal of African Studies (with Doris Buss, Aluoka Otieno, and Eileen Alma). She has published policy-focused articles in The Washington Post's Monkey Cage and in Africa is a Country. 